Tesis para optar al título de Dr. en Ciencias Naturales

\title{
USO DE HÁBITAT Y ECOLOGIAA POBLACIONAL DE PEQUEÑOS MAMÍFEROS DEL DESIERTO DEL MONTE CENTRAL, MENDOZA, ARGENTINA
}

Facultad de Ciencias Naturales y Museo, Universidad Nacional de La Plata (U.N.L.P.)

\section{Autora: Lic. Valeria E. Corbalán}

Director: Dr. Ricardo A. Ojeda

Co-director: Dr. Juan A. Schnack

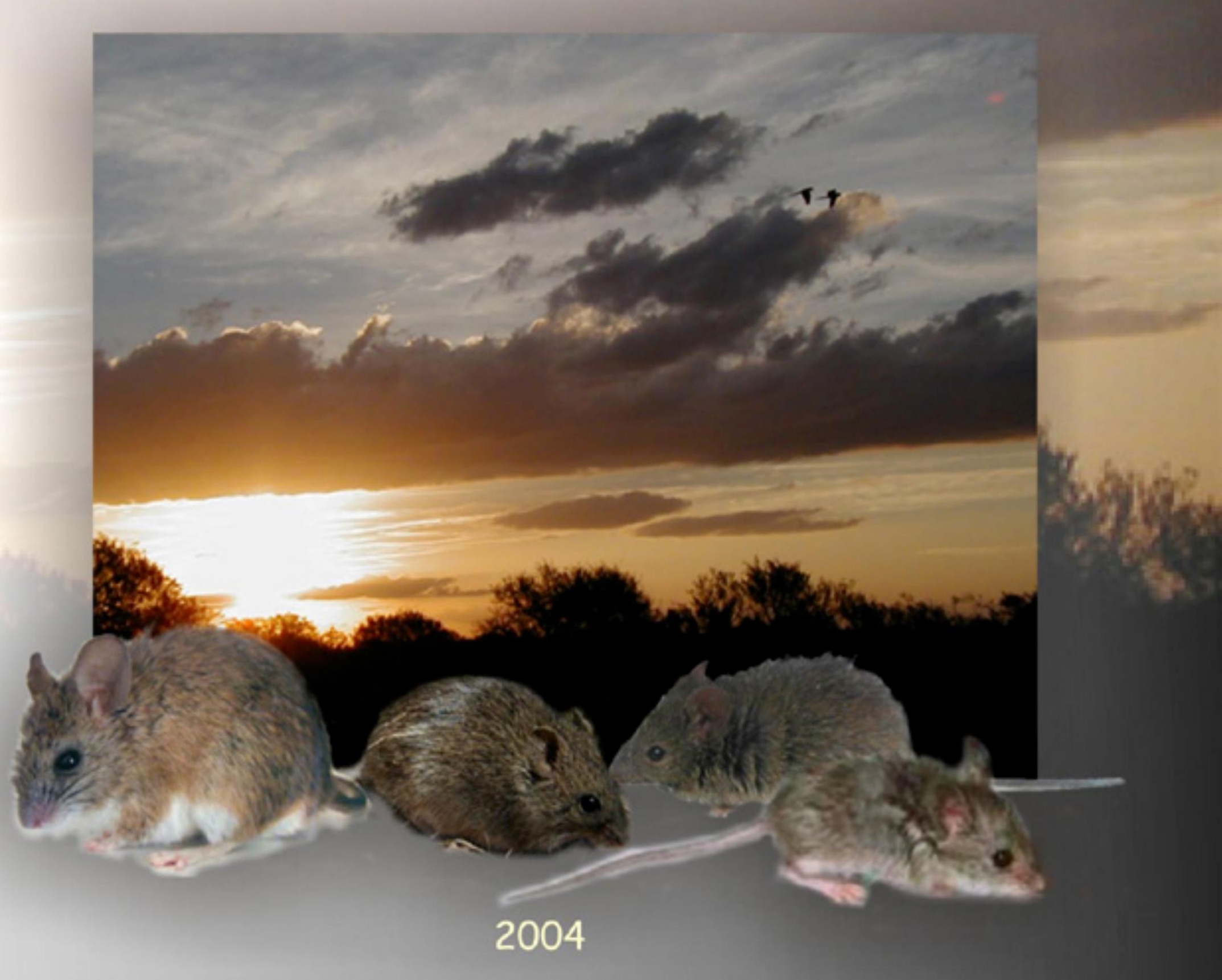


Índice

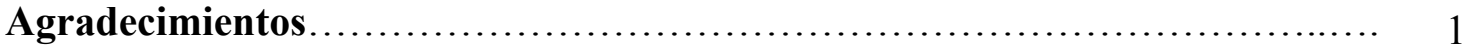

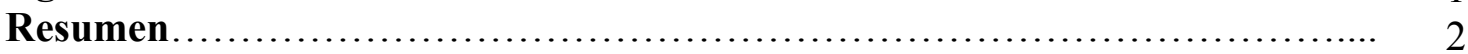

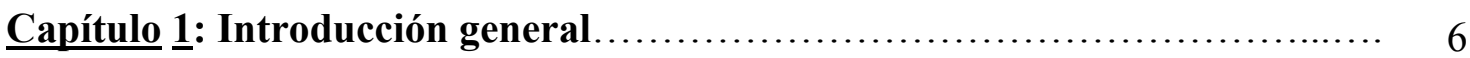

1.1. Introducción general.......................................... 7

Uso de hábitat: antecedentes................................................................ 10

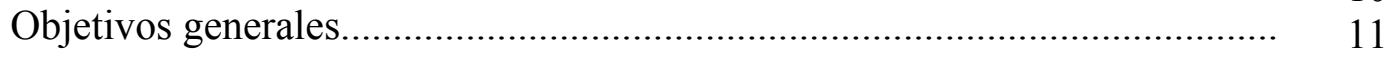

Organización de la tesis............................................................................ 12

$\underline{\text { Capítulo 2: }}$ Materiales y Métodos.................................... 14

2.1. Área de estudio................................................... 15

2.2. Descripción de las especies estudiadas y antecedentes sobre su biología.. 18

Graomys griseoflavus............................................ 18

Akodon molinae .................................................... 19

Calomys musculinus............................................... 19

Eligmodontia typus ............................................... 20

Thylamys pusillus................................................. 21

2.3. Otras especies de vertebrados presentes en la Reserva de la Biósfera de

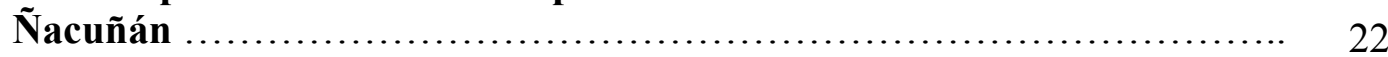

2.4. Metodología general............................................ 23

Captura de pequeños mamíferos.................................... 23

Caracterización de microhábitat..................................... 24

Utilización de polvos luminosos.................................... 25

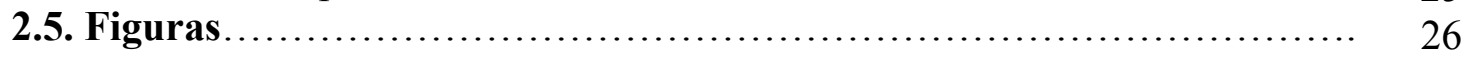

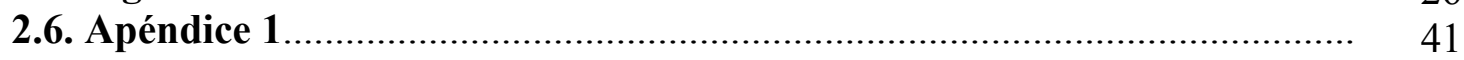

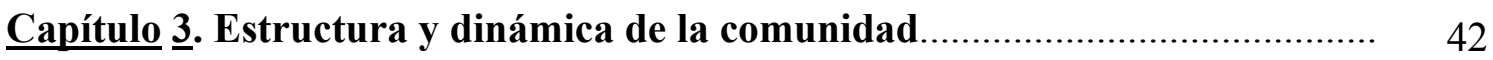

3.1. Introducción.................................................. 43

3.2. Materiales y Métodos........................................... 46

Diversidad.................................................... 46

Densidad y biomasa............................................. 48

Amplitud de nicho............................................. 48

Variación espacial en abundancia.................................... 48

3.3. Resultados.................................................. 50

Diversidad de pequeños mamíferos y heterogeneidad del hábitat............ 50

Variación temporal en densidad y biomasa.............................. 51

Amplitud de nicho............................................... 52

Variación espacial............................................... 53

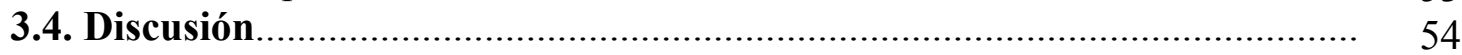




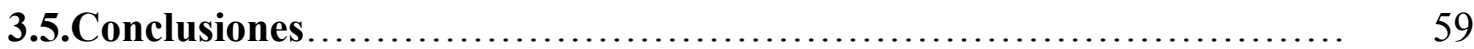

3.6. Tablas y Figuras.................................................... 60

Capítulo 4 . Estructura y dinámica de las poblaciones de múridos:

estimación de calidad de hábitat..................................... $\quad 70$

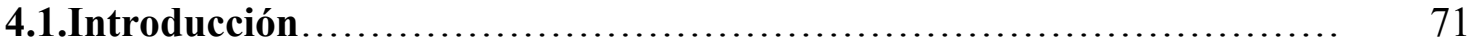

4.2. Materiales y métodos............................................ 73

Metodología general................................................. 73

Estructura de edades................................................. 73

Reproducción...................................................... 74

Relación de sexos................................................... 74

Medidas de persistencia............................................ 74

4.3. Resultados..................................................... 76

Estructura de edades............................................ 76

Reproducción....................................................... 76

Relación de sexos.............................................. 77

Persistencia........................................................... 77

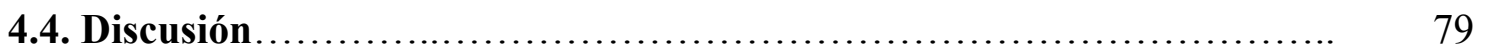

4.5. Conclusiones.................................................. 82

4.6. Tablas y Figuras............................................... 83

Capítulo 5: Selección de hábitat a distintas escalas

espaciales.............................................................. 94

5.1. Introducción...................................................... 95

5.2. Materiales y métodos.............................................. 98

Caracterización del hábitat............................................ 98

Asociación de las especies de roedores con las variables ambientales........ 99

Índices de selectividad.................................................. 100

5.3. Resultados....................................................... 102

Caracterización de cada hábitat........................................ 102

Selección de macrohábitat.............................................. 102

Selección de microhábitat.............................................. 103

Grado de Selectividad.................................................. 104

5.4. Discusión ......................................................... 106

5.5. Conclusiones ..................................................... 110

5.6. Tablas y Figuras.................................................. 111 
Capítulo 6: Estimación de uso y selección de microhábitat mediante la técnica de polvos luminosos

6.1. Introducción......................................................... 124

6.2. Materiales y métodos.......................................... 126

Uso de microhábitat ............................................. 126

Disponibilidad................................................... 127

Análisis estadísticos.................................................. 127

6.3. Resultados......................................................... 129

Uso de microhábitat por Eligmodontia typus............................... 129

Uso de microhábitat por Akodon molinae................................. 130

Segregación de microhábitat.......................................... 130

Selección de microhábitat por Calomys musculinus........................ 131

Selección de microhábitat por Thylamys pusillus.......................... 132

6.4. Discusión........................................................ 133

Implicancias metodológicas......................................... 137

6.5. Conclusiones..................................................... 139

6.6. Tablas y Figuras............................................... $\quad 140$

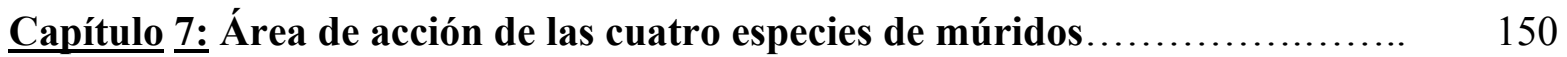

7.1. Introducción........................................................ 151

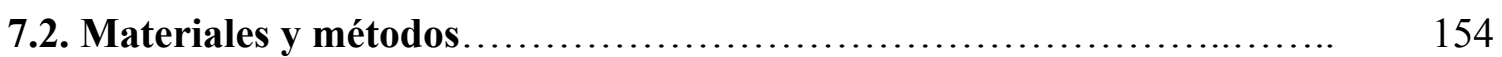

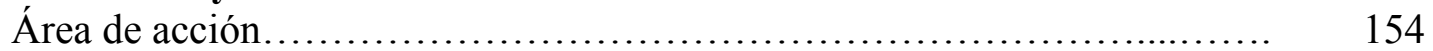

7.3. Resultados........................................................ 157

Diferencias entre sexos......................................... 157

Diferencias entre especies........................................... 157

Diferencias entre hábitats.......................................... 157

Relación entre peso y área de acción...................................... 158

Superposición espacial interespecífica................................... 158

Superposición espacial intraespecífica................................ 159

7.4. Discusión.............................................................. 160

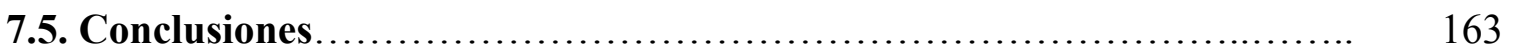

7.6. Tablas y Figuras................................................... 164

Capítulo 8: Conclusiones y discusión general.............................. 172

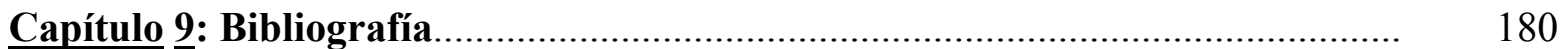




\section{AGRADECIMIENTOS}

A mis padres y hermana por haberme apoyado en todo momento $\mathrm{y}$ darme fuerzas para este nuevo emprendimiento.

Al Dr. Ricardo Ojeda por haber confiado en mí y haberme dado la posibilidad de crecer profesionalmente, pertenecer a un grupo de trabajo y realizar esta tesis, así como al Dr. Juan Schnack por la codirección de la misma.

Al Consejo Nacional de Investigaciones Científicas y Tecnológicas (CONICET) por haber financiado este trabajo.

A Mariana Dacar, Ana María Scollo, Néstor Viñals, Carlos Vázquez, Emilce Rombola, Paula Taraborelli y Guillermo Debandi, por haberme ayudado en el trabajo de campo y haber hecho más fácil y liviana esta tarea. A Eduardo Méndez y Bertilde Rossi por haber determinado las especies vegetales. A Benjamín Bender por las fotos y el diseño de la portada.

A mis compañeras (Solana Tabeni, Claudia Campos, Gabriela Díaz, Stella Giannoni, Paula Taraborelli, Paola Sassi, y Andrea Orofino), a mi director y especialmente a mi codirector de beca (Dr. Carlos Borghi) que con sus sugerencias, críticas, comentarios y discusiones ayudaron a mi crecimiento y a la realización de esta tesis.

Al jurado (Dr. Diego Verzi, Dr. Jaime Polop y Dra. María Busch) por sus valiosas sugerencias en el manuscrito preliminar.

Y por sobre todos a mi esposo, Guillermo Debandi, que sin su amor, su paciencia, su ayuda profesional y su apoyo en todos los momentos difíciles, este trabajo no hubiera terminado. A él se la dedico 


\section{RESUMEN}

Muchos autores han propuesto que la coexistencia de las especies filogenéticamente emparentadas dentro de un hábitat particular es posible gracias a mecanismos de partición de recursos. Esta partición de recursos puede ser mediada por competencia interespecífica o preferencia diferencial de hábitat. El riesgo de depredación puede ser de gran importancia en la dinámica de las poblaciones animales, en el comportamiento y en la evolución. La morfología, el tipo de locomoción, el tamaño corporal y el comportamiento de forrajeo contribuyen a las habilidades de cada especie para evadir depredadores $\mathrm{y}$, en última instancia, determinan la selección del hábitat y microhábitat.

La selección de hábitat es un proceso por medio del cual el animal elige el recurso entre distintas alternativas disponibles. Es un proceso jerárquico que involucra una serie de decisiones comportamentales innatas y aprendidas realizadas por el animal a diferentes escalas del ambiente, desde un nivel de macrohábitat a microhábitat.

En la porción central del desierto del Monte (Argentina) coexisten cinco especies de pequeños mamíferos que pesan menos de 100 gramos, de las cuales cuatro son roedores múridos (Graomys griseoflavus, Eligmodontia typus, Calomys musculinus y Akodon molinae) y una es un marsupial (Thylamys pusillus). Se estudió la estructura de la comunidad y la selección de hábitat de cada especie en tres comunidades vegetales de diferente complejidad estructural: 1) el algarrobal, la comunidad más heterogénea, compuesto por un estrato arbóreo, uno arbustivo, uno herbáceo y suelo desnudo; 2) el jarillal, compuesto por un estrato arbustivo y uno herbáceo-graminoso; 3 ) el medanal, que conforma el hábitat más simple, posee un alto porcentaje de suelo desnudo con algunos árboles y arbustos dispersos. 
Se realizaron capturas vivas en grillas de $7 \times 7$ estaciones de trampeo con trampas tipo Sherman. Los animales capturados fueron identificados, sexados, pesados, marcados y liberados en el sitio de captura. En cada estación de trampeo se midieron variables de cobertura y altura de la vegetación en parcelas de $4 \mathrm{~m}^{2}$.

El período de muestreo abarcó desde junio de 1999 hasta abril de 2001. El esfuerzo total de captura fue de 9386 noches-trampa (3703 en el jarillal, 2716 en el algarrobal y 2967 en el medanal). Se capturaron un total de 280 individuos de Eligmodontia typus, 200 de Graomys griseoflavus, 213 de Akodon molinae, 159 de Calomys musculinus y 12 de Thylamys pusillus. Debido al bajo número de individuos de esta última especie, la mayoría de los análisis de datos fueron realizados solamente con las especies de múridos.

Las cinco especies de micromamíferos estuvieron presentes en los tres hábitats, aunque no todas fueron capturadas en todos los períodos de muestreo. La mayor riqueza de especies se registró en el otoño y la más baja en el invierno. El hábitat de mayor diversidad de micromamíferos fue el jarillal, en tanto que el medanal fue el de menor diversidad, exhibiendo el algarrobal condiciones intermedias.

En el medanal E. typus fue la especie dominante, ya que su abundancia fue significativamente mayor que las abundancias de las restantes especies. En el jarillal y en el algarrobal, en cambio, no se encontraron especies dominantes. Sin embargo, la abundancia de cada especie fue diferente en los tres hábitats. Akodon molinae y Calomys musculinus fueron más abundantes en el jarillal y en el algarrobal, mientras que Graomys griseoflavus lo fue en el algarrobal. Eligmodontia typus fue más abundante en el medanal, pero las diferencias en las abundancias entre este hábitat y el jarillal fueron poco significativas. Sobre la base de las características reproductivas se pudo inferir que el medanal es el hábitat de mejor calidad (hábitat fuente) para E. typus y el jarillal para A. molinae. Probablemente el algarrobal sea el hábitat de mejor calidad para G. griseoflavus y tanto el jarillal como el algarrobal lo sean para C. musculinus. 
La selección a nivel de microhábitat no opera de un modo tan evidente como la selección a nivel de macrohábitat. Los resultados obtenidos a partir de los trampeos indican que las variables seleccionadas por cada especie son diferentes a distintas escalas y aún entre los distintos hábitats. No obstante, en general se mantiene la preferencia de E. typus por microhábitats más abiertos y la selección de las demás especies por microhábitats con mayor cobertura vegetal. Con una técnica alternativa para este estudio, que consiste en la utilización de polvos luminosos, algunos resultados no fueron similares a los encontrados con la metodología de trampeos. Los polvos luminosos permitieron determinar que E. typus utiliza en mayor proporción los microhábitats con cobertura arbustiva. En el medanal se encontró que los individuos de esta especie recorren mayores distancias bajo la cobertura de arbustos que en ausencia de cobertura. Esta metodología permitió detectar que $T$. pusillus y $C$. musculinus además de utilizar el suelo para sus desplazamientos, también hacen uso del estrato vertical (ramas de arbustos y árboles). Estos hallazgos aportan evidencias de que es posible que en esta comunidad estén actuando mecanismos de segregación de recursos que favorecen la coexistencia de las especies.

Con referencia al área de acción, se encontró que no hay diferencia entre las distintas especies, estando los promedios comprendidos entre los $812.9 \mathrm{~m}^{2}$ y los $1201 \mathrm{~m}^{2}$. No hubo diferencias entre las áreas de ambos sexos, excepto para $A$. molinae, donde se encontró que las áreas de los machos fueron mayores a las áreas de las hembras. Tampoco se encontraron diferencias al comparar las áreas recorridas por cada especie en los diferentes hábitats. En los meses de mayor densidad poblacional (abril, mayo), la superposición espacial interespecífica es mayor que en los meses de menor densidad poblacional.

En conclusión, se puede decir que la comunidad de pequeños mamíferos del desierto del Monte central fluctúa espacial y temporalmente. El hábitat es un factor importante que actúa en la distribución de los organismos y en la estructura de la comunidad. La cobertura vegetal proporciona refugio y diminuye el riesgo de depredación. Esto conlleva a una mayor diversidad y riqueza de especies de 
micromamíferos en el algarrobal y en el jarillal respecto al medanal. La selección por microhábitats cerrados parece ser una característica compartida por las especies cuadrúpedas y nocturnas tanto en todos los desiertos de Norteamérica como en los de Asia y África, y relacionado principalmente al riesgo de depredación. Eligmodontia typus es una especie que se distingue del resto ya que es capaz de ocupar el medanal durante todo el año y reproducirse en este hábitat. Sus características morfológicas, que recuerdan a las especies norteamericanas que habitan áreas abiertas, le otorgan ventajas frente a las demás especies para ocupar este ambiente de baja cobertura vegetal y suelo arenoso. 
Capítulo 1

INTRODUCCIÓN GENERAL 


\section{Capítulo 1. INTRODUCCIÓN GENERAL}

Los sistemas desérticos están definidos como aquellos donde las precipitaciones son bajas, variables e impredecibles (Noy-Meir, 1979/80). Su heterogeneidad en términos de clima, suelo e historia tiene marcados efectos sobre el ecosistema, particularmente sobre la energía total, el agua, el flujo de nutrientes y la supervivencia de muchas especies (Noy-Meir, 1974, 1979/80). Uno de los componentes más conspicuos de los desiertos son los roedores. Sus poblaciones generalmente son grandes y proveen alimento para las especies de carnívoros, además de crear hábitats para muchas especies de vertebrados e invertebrados debido a la construcción de sus cuevas (Shenbrot et al., 1999). Como consecuencia, los roedores han servido de modelo para estudios ecológicos y etológicos, especialmente los referentes a la organización espacial de la comunidad y la competencia, los que han contribuido a identificar aquellos recursos que son limitantes para las especies (Kotler y Brown, 1988; Shenbrot et al., 1999).

El nicho ecológico describe el rol de una especie en la comunidad (Pianka, 1982). El número de ejes de recursos para cada nicho ecológico es infinito, pero pueden sintetizarse en un eje trófico, un eje espacial y un eje temporal (Schoener, 1974). En especies de mamíferos coexistentes (excepto carnívoros), los recursos se dividen principalmente a lo largo del eje espacial, mientras que el eje trófico es de menor importancia, siendo el temporal relativamente raro (Kalcounis-Rüppell y Millar, 2002; Shenbrot et al., 1999; Schoener, 1974).

La coexistencia de especies filogenéticamente emparentadas dentro de un hábitat particular es posible gracias a mecanismos de partición de recursos. Ésta puede ser mediada por competencia interespecífica o preferencia diferencial de hábitat (Kalcounis-Ruppell y Millar, 2002). El riesgo de depredación puede determinar el comportamiento de forrajeo de los roedores desérticos e influir en la organización de la comunidad, así como afectar la evolución de morfologías y comportamiento anti-depredador (Kotler et al., 1994). La morfología, el tipo de locomoción, el tamaño corporal y el comportamiento de forrajeo contribuyen a las 
habilidades de cada especie para evadir depredadores y, en última instancia, determinan la selección del hábitat y microhábitat (Kotler, 1989; Kotler et al., 1994).

La selección de hábitat se define como la elección de un tipo de lugar donde vivir (Partridge, 1978). En general, suelen confundirse los términos uso, selección y preferencia, por lo que es conveniente aclarar las diferencias entre ellos:

El uso de un recurso es la cantidad de recurso utilizado por un animal o población en un período de tiempo (Manly et al., 1993). El uso de un hábitat solamente indica una asociación con dicho recurso (Litvaitis et al., 1994). La selección, en cambio, es un proceso en el cual el animal elige el recurso entre distintas alternativas disponibles. Aquí los recursos usados no son proporcionales a su disponibilidad (la cantidad de recurso accesible para el animal). La selección de hábitat es un proceso jerárquico que involucra una serie de decisiones comportamentales innatas y aprendidas que realiza el animal a diferentes escalas del ambiente (Hutto, 1985); es decir, que la selección de hábitat opera desde un nivel de macrohábitat a microhábitat (Kotler y Brown, 1988). El término preferencia hace referencia a la probabilidad de que un recurso sea elegido cuando al animal se le ofrecen varios recursos de igual manera, y es independiente de la disponibilidad. Esta información es obtenida a partir de estudios experimentales (Litvaitis et al., 1994; Manly et al., 1993).

La mayoría de los estudios sobre la estructura de comunidades y selección de hábitat de especies de roedores de desiertos provienen de América del Norte. Se ha generalizado el concepto de que las especies que utilizan áreas abiertas poseen morfologías antipredatorias más desarrolladas que aquellas que ocupan microhábitats cerrados. Estos atributos ecomorfológicos, como los encontrados en las ratas canguro de Norteamérica (gén. Dipodomys), incluyen bullas timpánicas infladas (con las que perciben sonidos de baja frecuencia como, por ejemplo, los generados por las lechuzas y serpientes en el momento del ataque), largas patas traseras que les permiten la locomoción bipedal (lo que facilita el escape) y localización dorsal de los ojos (que les permite detectar a los depredadores más 
rápidamente) (Kotler y Brown, 1988; Thompson, 1982). Las pequeñas especies como Perognathus y Peromyscus, cuadrúpedas y carentes de estas morfologías, deben restringirse a áreas cubiertas donde el riesgo de depredación es menor (Kotler y Brown, 1988). La ventaja de estas especies reside en sus bajas tasas metabólicas debido a su menor tamaño corporal, disminuyendo los costos energéticos de forrajeo y ganando más energía neta por semilla consumida (Kotler et al., 1994). La mayoría de estas especies son granívoras y muchas poseen abazones o bolsas en las mejillas con los cuales pueden acumular alimento para transportarlo luego a sus madrigueras.

La dieta de los pequeños mamíferos sudamericanos, en cambio, es principalmente omnívora; dichos mamíferos carecen de abazones. En la porción central del desierto del Monte, las especies de roedores menores de $100 \mathrm{~g}$ son omnívoras con tendencias hacia la insectivoría (Akodon molinae y el marsupial Thylamys pusillus), a la herbivoría (Graomys griseoflavus) o a la granivoría (Calomys musculinus) (Campos et al., 2001). La omnivoría puede resultar una forma de adaptación a la impredecibilidad que caracteriza a los sistemas desérticos. Los animales de desierto tienden a ser consumidores generalistas y oportunísticos, variando su dieta de acuerdo a la disponibilidad local y estacional (Noy-Meir, 1979/80), aprovechando los recursos alimenticios durante el tiempo en que se encuentran disponibles.

Por otro lado, ninguna de las especies de desierto del Monte posee las características morfológicas que han sido consideradas "adaptativas" para la vida en el desierto (Mares, 1975a). La única especie que ha desarrollado largas patas traseras es Eligmodontia typus. Sin embargo, esta característica no le permite el tipo de locomoción bipedal, aunque puede realizar escapes a saltos ante potenciales depredadores, al igual que Graomys griseoflavus (Taraborelli et al., 2003).

La carencia de este tipo de morfologías ha llevado a sostener que los pequeños roedores sudamericanos no se han adaptado completamente a la vida en el desierto. Según Mares (1975a) el ingreso de los mismos en el Plioceno medio, probablemente debido a la conexión de las masas continentales a través del istmo de 
Panamá y el consecuente Gran Intercambio Biótico Americano, ha impedido esta adaptación debido al poco tiempo de evolución que han experimentado desde su llegada. Sin embargo, se ha encontrado que los pequeños mamíferos sudamericanos poseen características ecológicas, morfológicas, fisiológicas y etológicas que les permiten la vida en zonas áridas (Ojeda 1989; Giannoni et al. 1996, 2000; Campos 1997; Mares et al. 1997; Borruel et al. 1998; Gonnet 1998; Gonnet y Ojeda 1998; Díaz y Ojeda 1999; Ojeda et al., 1999). Estudios recientes han demostrado que las especies del desierto del Monte poseen riñones anatómica y fisiológicamente capaces de aprovechar el agua disponible a partir de mecanismos de concentración de la orina (Díaz, 2001; Díaz y Ojeda, 1999), llegando los filotinos a tener índices renales elevados, incluso mayores que los de los heterómidos (Díaz, 2001). Además, actualmente se considera que el ingreso de los pequeños mamíferos a Sudamérica es anterior al Plioceno medio, siendo los registros más antiguos del Plioceno inferior (Verzi, com. pers.)

\section{Uso de hábitat: antecedentes}

La mayoría de los estudios de uso de hábitat en Argentina no provienen de zonas áridas, sino de agroecosistemas pampeanos. Se ha encontrado que Calomys musculinus usa campos cultivados, sus bordes y pastizales naturales, pero muestra diferencias en abundancia de acuerdo al hábitat (Busch et al., 1984; Busch et al., 1997; Ellis et al., 1997; Kravetz y Polop, 1983; Mills et al., 1991), siendo más abundante en bordes que en campos (Busch et al., 1997; Busch et al., 2000; Mills et al., 1992). Similarmente, Polop et al. (1985) encontraron que C. musculinus estuvo distribuida en distintos hábitats, utilizando repetidamente espacios abiertos, y fue la especie dominante (junto con Akodon dolores) en los pastizales. Los datos que se tienen del desierto provienen de estudios descriptivos, donde se la ha asociado a sectores de vegetación densa con hojas tiernas (Contreras y Rosi, 1980a).

Eligmodontia typus es una especie asociada a áreas abiertas. Ojeda (1989) encontró que tras perturbaciones por fuego en el desierto del Monte, esta es la única 
especie que coloniza los parches quemados al cabo de un año, relacionándose con la disminución en la complejidad vegetal. Gonnet y Ojeda (1998) han reportado que en el piedemonte andino, E. typus y C. musculinus son las especies dominantes en un pastizal disturbado por fuego y ganadería.

Graomys griseoflavus es considerada una especie capaz de ocupar una gran diversidad de hábitats (Gonnet y Ojeda, 1998), desde áreas arenosas semiáridas hasta ríos con selvas en galería (Redford y Eisenberg, 1992). Es hábil trepadora y posee hábitos arborícolas para forrajear y nidificar (Mares et al., 1977). Akodon molinae se encuentra en ambientes con alta cobertura vegetal, principalmente de pastos (Contreras, 1968; Contreras y Rosi, 1980b; Gonnet, 1998) y es la primera especie en desaparecer en sitios incendiados (Ojeda, 1989).

\section{Objetivos generales}

Sobre la base de la hipótesis de que los pequeños mamíferos de desierto coexisten gracias a la selección diferencial de los recursos, en esta tesis se aborda uno de los ejes más importantes del nicho ecológico, el espacial. Estudios previos (Campos, 1997) han abordado la selección de recursos desde el punto de vista trófico pero hasta el momento no se tiene conocimiento de la distribución y organización espacial de pequeños mamíferos coexistentes del desierto del Monte. Para el análisis de estos últimos aspectos, se plantearon los siguientes objetivos generales:

1) Conocer el ensamble de micromamíferos y la diversidad en tres hábitats de diferente complejidad estructural de la porción central del desierto del Monte

2) Conocer la estructura y dinámica de cada una de las poblaciones de roedores múridos

3) Cuantificar la selección de hábitat de cada especie a nivel de macro y de microhábitat y encontrar las variables que determinan la selección.

4) Conocer el área de acción y el grado de superposición espacial de los individuos. 


\section{Organización de la tesis}

La mayoría de los temas abordados en esta tesis fueron estudiados a partir de una misma metodología. Esta metodología general, así como la descripción del área de estudio y de las especies presentes, se desarrolla en el capítulo 2.

La complejidad y la heterogeneidad del hábitat han sido propuestas como las responsables del incremento de la diversidad de especies, al proveer más nichos por unidad de espacio (Holbrook, 1978; Levins, 1968; Mac Arthur et al., 1962). Es decir, que los hábitats más complejos (o heterogéneos) por lo general poseen mayor diversidad de especies, ya que contienen mayor variedad de microhábitats ocupados por especies con requerimientos diferentes (Holbrook, 1978; Price, 1986; Rosenzweig y Winakur, 1969). En el capítulo 3 se abordará la forma en que se estructura una comunidad de pequeños mamíferos del desierto del Monte central y la relación con la heterogeneidad del hábitat, mientras que en el capítulo 4 se estudiarán los atributos de cada población (estructura de edades, características reproductivas, proporción de sexos, supervivencia) en cada hábitat.

Como fue mencionado anteriormente, la selección de hábitat opera a distintas escalas espaciales, desde un nivel de macrohábitat a microhábitat (Kotler y Brown, 1988). Un hábitat adecuado debe contener distintos parches que provean oportunidades para todas las actividades requeridas para el éxito reproductivo de la especie (Orians y Wittenberger, 1991). Debido a que la selección de hábitat es un proceso jerárquico donde la selección de un nivel depende de la selección realizada a un nivel superior, las respuestas de los animales pueden cambiar de acuerdo a la escala que aborde la investigación. La selección a distintas escalas espaciales es considerada en los Capítulos 5 y 6.

Dentro del hábitat, los organismos se mueven en busca de alimento, de pareja y cuidan a sus crías. El área donde el animal realiza sus actividades diarias es la denominada área de acción. Ésta puede cambiar con el tamaño corporal, el sexo, las estrategias reproductivas (monogamia, poligamia) y la edad. Sobre la base de la 
diferencia entre las áreas de acción de machos y hembras, el dimorfismo sexual y la territorialidad, puede deducirse el modo de apareamiento de una especie (Heinemann et al., 1995). El área de acción de las especies de roedores de la porción central del desierto del Monte es tratada en el capítulo 7.

En el capítulo 8 se resumen las principales conclusiones y se incluye una discusión general de la investigación realizada.

El capítulo 9 detalla la bibliografía citada a lo largo de la tesis. 
Capítulo 2

\section{MATERIALES Y MÉTODOS}




\section{Capítulo 2. MATERIALES Y MÉTODOS}

\section{1. ÁREA DE ESTUDIO}

El estudio se llevó a cabo en la Reserva del Hombre y la Biósfera de Ñacunán ( $\left.34^{\circ} 02^{\prime} \mathrm{S}, 67^{\circ} 58^{\prime} \mathrm{O}\right)$ durante el período junio de 1999 - abril de 2001. Esta reserva está ubicada $200 \mathrm{~km}$ al SE de la ciudad de Mendoza, en el Departamento de Santa Rosa, Mendoza, Argentina. Biogeográficamente, el área pertenece a la porción central del Desierto del Monte (Cabrera y Willink, 1980; Fig. 1).

La reserva cubre un área de 12.800 ha y fue creada por Ley provincial en 1961 para proteger el bosque de algarrobo Prosopis flexuosa, uno de los tipos de hábitat más conspicuos en el área. Como ocurre en el Chaco y la Patagonia, el desierto del Monte, y especialmente el área de estudio antes de la creación de la Reserva, sufrió presiones de deforestación y sobrepastoreo (Ojeda et al., 1998; Fig 2).

El clima es semiárido con estacionalidad marcada, presentando veranos cálidos y húmedos e inviernos fríos y secos. La elevada variación anual e interanual en las precipitaciones, especialmente al final de la primavera y el verano (noviembre-marzo), es una característica del área (Ojeda et al., 1998). La precipitación media anual (período 1972-2001) es de 343,68 mm y la temperatura media anual es de $15,02{ }^{\circ} \mathrm{C}$ (Fig 3). La temperatura media en verano está por encima de $\operatorname{los} 20^{\circ} \mathrm{C}$ y en invierno por debajo de $\operatorname{los} 10^{\circ} \mathrm{C}$. La máxima temperatura registrada durante el período de estudio fue de $45,8{ }^{\circ} \mathrm{C}$ en febrero de 2001 , mientras que la mínima fue de $-12,8^{\circ} \mathrm{C}$ en agosto de 1999 .

La Reserva se encuentra ubicada en el centro de la llanura oriental mendocina (540 msnm), en la unidad de las Travesías y Bolsones (Abraham, 2001), que ha sido originada por acumulación de materiales de grano fino provenientes de la Cordillera de los Andes (Tanquilevich, 1971). Los suelos, debido a su corto tiempo de formación, no poseen perfiles diferenciados y la capacidad de 
almacenamiento de agua es muy baja (Tanquilevich, 1971). Por ello, muchas especies vegetales poseen la capacidad de aprovechar al máximo el agua proveniente de las lluvias gracias a sus sistemas radiculares superficiales (Dalmasso, 1994). De acuerdo a la vegetación y fisonomía, la provincia del Monte es definida como un bioma xérico (Morello, 1958), donde domina la estepa arbustiva con flora endémica, principalmente de la Familia Zygophyllacea (Larrea, Bulnesia, Plectocarpa). Dentro de la Reserva pueden diferenciarse varias comunidades vegetales (Roig, 1971; Roig y Rossi, 2001), como el algarrobal, el jarillal, el medanal, el retamal, el zampal, el chañaral y el peladal. Las tres primeras (algarrobal, jarillal y medanal) son las más representativas en cuanto a su extensión (Fig 4) y las elegidas para desarrollar el presente trabajo de investigación. A continuación se dará una caracterización de cada uno de estos tipos de hábitat:

Algarrobal: es la comunidad más representativa y con mayor cantidad de estratos (Fig. 5). El estrato arbóreo está caracterizado por Prosopis flexuosa D.C. (algarrobo dulce) hasta $6 \mathrm{~m}$ de altura y ejemplares aislados de chañar Geoffroea decorticans (Gillies ex Hook. et Arn.) Burkart. A veces los chañares forman facies de alta densidad conformando la comunidad vegetal del chañaral. Otras veces puede encontrarse un bosque mixto de algarrobo con retamo (Bulnesia retama Hooker et Arnott) conformando la comunidad del retamal (Roig y Rossi, 2001). El estrato arbustivo del algarrobal está constituido por Larrea divaricata Cav. (jarilla), Capparis atamisquea Kuntze (atamisque), Atriplex lampa Gillies ex Moq. (zampa), acompañados por Lycium chilensis Mers ex Bertero y Verbena aspera Gill. et Hook. Los arbustos de este estrato son heliófilos y se ven favorecidos con la eliminación del estrato arbóreo (Roig y Rossi, 2001). En el estrato herbáceo se pueden encontrar especies de pastos perennes como Pappophorum caespitosum R. Fries, Digitaria californica (Benth.), Sporobolus cryptandrus (Torr.) y Setaria leucopila (Scribner et Merrill), así como gramíneas anuales entre las que se destacan Aristida mendocina Philippi, A. adscencionis L., Tragus berteronianus Schult. y Bouteloua barbata Lag. (Roig y Rossi, 2001). También están presentes en este estrato plantas 
leñosas como el tomillo Acantholippia seriphioides (A. Gray) y cactáceas como Echinopsis intricatissima Speg. y Cereus aethiops Haworth.

Jarillal: constituido principalmente por Larrea cuneifolia Cav. (jarilla) y caracterizado por una elevada densidad y cobertura de esta especie (Fig. 6). El estrato arbóreo esta representado sólo por árboles aislados y posee herbáceas muy características como Trichloris crinita (Lag.) Parodi, Scleropogon brevifolius Phil. y Bacharis pringraea D.C. Los suelos de esta comunidad son ricos en fracciones finas de limos y arcillas (Roig y Rossi, 2001).

Medanal: en este hábitat donde los suelos son arenosos gruesos y sueltos, pueden distinguirse dos estratos, uno arbustivo y otro herbáceo (Fig. 7). En el primero predominan la jarilla Larrea divaricata y el albaricoque Ximenia americana L., acompañados por Bouganvillea spinosa (Cav.) y Junellia seriphioides (Gillies \& Hook.) Moldenke. El estrato herbáceo está constituido por Solanum euacanthum Phil., Gomphrena martiana Gillies ex Moq., Hyalis argentea Don ex H. et A., Panicum urvilleanum Kunth y Portulaca grandiflora Hook entre otras especies. Las plantas herbáceas desaparecen en el invierno, cuando los médanos quedan casi desnudos de vegetación, y reaparecen en el verano cubriéndolos por completo (Roig y Rossi, 2001). Ocasionalmente, pueden observarse ejemplares dispersos de $P$. flexuosa y G. decorticans conformando un tercer estrato (Roig, 1971). 


\subsection{DESCRIPCIÓN DE LAS ESPECIES ESTUDIADAS Y ANTECEDENTES SOBRE SU BIOLOGÍA}

Los pequeños mamíferos (menores de 100 gs.) de la Reserva de la Biósfera de Ñacuñán que han sido estudiados en el presente trabajo son las cuatro especies de múridos [(Graomys griseoflavus, (Waterhouse 1837), Akodon molinae Contreras, 1968, Eligmodontia typus F. Cuvier, 1837 y Calomys musculinus (Thomas 1913)], y el didelfiomorfo Thylamys pusillus (Desmarest, 1804).

A continuación se dará una breve descripción de las características de las especies y los hábitats utilizados por ellas.

Graomys griseoflavus (pericote común; Fig 8):

De las especies estudiadas, es la de mayor tamaño (longitud media: $262 \mathrm{~mm}$, peso: 62,4 g, Rosi, 1983) y posee cola y orejas largas. El pelo, largo y suave, es marrón o grisáceo en el dorso, más pálido en los lados y blanco en el vientre. Se distribuye en Argentina (Tucumán, Chaco, Salta, La Pampa, Chubut, Buenos Aires y Mendoza), Bolivia, Paraguay y tal vez en el suroeste de Brasil (Redford y Eisenberg, 1992) (Fig. 13). Se encuentra en localidades típicamente xéricas, pero también en campos cultivados, áreas arenosas semiáridas con rocas, laderas rocosas, ríos con selvas en galería y huertos. Esta especie es la que utiliza mayor variedad de hábitats, pero muestra preferencia por microhábitats con vegetación densa donde dominan los arbustos y no se encuentra en lugares disturbados (Gonnet y Ojeda, 1998). Su densidad aumenta conforme lo hace la complejidad vegetal. Sus nidos de pasto se encuentran en cactus, arbustos espinosos o cuevas de Microcavia australis. Algunos autores mencionan que esta especie posee hábitos arborícolas para forrajear y nidificar y que posee habilidad para sobrevivir sin agua libre (Mares, 1977a). Su alimentación es estrictamente herbívora, alimentándose principalmente 
de hojas de Prosopis sp. y Lycium sp. (Campos, 1997; Campos et al., 2001). Son fuertes, agresivos y muerden frecuentemente (Mares, 1973; Mares et al., 1981).

Akodon molinae (ratón pajizo; Fig. 9):

Longitud media: 100,8 mm. Peso promedio de adultos: $31.8 \mathrm{~g}$ (Contreras y Rosi, 1980b).

Posee largas vibrisas y pelo denso y largo, con el dorso pajizo y el vientre grisáceo. Se encuentra sólo en el centro de Argentina (Mendoza, Buenos Aires, Río Negro y La Pampa; Redford y Eisenberg, 1992; Fig 14). Estudios realizados en el área de estudio revelaron que el período reproductivo de esta especie se extiende de agosto a marzo y las máximas densidades se registran en otoño en el jarillal, alcanzando los 14 ind./ha (Navarro, 1991). Ha sido capturada cerca de cursos de agua en la provincia de Buenos Aires (Contreras, 1968), mientras que en el Desierto del Monte se encuentra en ambientes con alta cobertura vegetal, principalmente de pastos (Gonnet, 1998) y es la primera especie en desaparecer en sitios incendiados (Ojeda, 1989). Su alimentación es omnívora, con una clara tendencia hacia la insectivoría (Campos, 1997; Campos et al., 2001).

Calomys musculinus (laucha bimaculada; Fig. 10):

Longitud Media: $127 \mathrm{~mm}$. Peso promedio de adultos: $17.5 \mathrm{~g}$ (Crespo et al., 1970).

Junto con Eligmodontia typus es la especie de menor tamaño corporal dentro de la Reserva. Posee dorso de color marrón agutí, más anaranjado hacia los lados y mejillas, contrastando con un blanco grisáceo en el vientre. Posee una banda blanca detrás de cada oreja. Su cola tiene una longitud de alrededor del 50\% de la longitud total del cuerpo (Massoia et al, 1968). Se distribuye en el centro y noroeste de Argentina (Fig 15). En la Pampa, la reproducción ocurre de noviembre a abril y el 
número promedio de crías es siete. En Córdoba, la expectativa máxima de vida en el campo es de 6 a 8 meses (Crespo et al., 1970).

En el piedemonte mendocino utiliza sitios con elevada cobertura vegetal, donde hay arbustos, cactus y particularmente pastos, ya que es una especie proveniente de la Pampa central. Junto con Eligmodontia domina en pastizales disturbados (Gonnet y Ojeda, 1998). En áreas naturales caracterizadas por la presencia de especies del género Atriplex en Mendoza, alcanza densidades de 37,6 ind./ha, siendo su área de acción de alrededor de $366 \mathrm{~m}^{2}$ (Contreras y Rosi, 1980a). En Córdoba se encuentra en campos de sorgo y alfalfa y es el reservorio de la fiebre hemorrágica argentina.

Eligmodontia typus (laucha colilarga baya; Fig. 11):

Longitud media 168,4 mm. Peso promedio de adultos: 20,6 g (Mares 1977b)

Pequeño, pálido, de pelaje suave. Posee largas patas traseras y pies espadiformes con el carácter distintivo de poseer almohadillas plantares con pelo. El vientre es total o parcialmente blanco. Los animales de poblaciones de tierras altas son más largos que los de tierras más bajas y tienen colas más cortas y pelaje más largo y suelto. Las hembras tienen mayor longitud que los machos. Hay mucha variación geográfica en la coloración, en la longitud de la cola y en el cariotipo (Gyldenstolpe, 1932; Mares,1973, 1977b). Se distribuye en el oeste de Bolivia, sur de Perú, norte de Chile y Argentina (a lo largo de los Andes, desde Salta hasta Magallanes y también en las provincias de La Pampa y Buenos Aires; Fig. 16). Cerca de Bariloche, la reproducción ocurre desde octubre hasta abril. La edad de la primera reproducción es de 6 a 8 semanas, el número promedio de crías es de 5,9 y la longevidad de un año. Son nocturnos y su alimentación es principalmente granívora, consumiendo semillas de Berberis y Prosopis (Daciuk, 1974; Mares, 1973, 1977b; Mares et al., 1981). Prefieren hábitats abiertos, aunque ha sido la especie dominante en el jarillal de Larrea cuneifolia en el piedemonte mendocino (Gonnet y Ojeda, 1998). En sitios incendiados suelen ser las especies dominantes o 
las únicas encontradas luego de un año de ocurrido el incendio (Ojeda, 1989). Se refugian y nidifican bajo tierra, cavando sus propias cuevas o utilizando las de Ctenomys (Redford y Eisenberg, 1992). Poseen determinadas adaptaciones consideradas "típicas" del desierto, como cierto grado de locomoción bipedal y balance de agua (Díaz y Ojeda, 1999). Por este motivo y por encontrarse en suelos arenosos y abiertos, se los compara con los heterómidos de Norteamérica (Redford y Eisenberg, 1992).

\section{Thylamys pusillus (Fig 12)}

Longitud total 197,9 mm. Peso promedio adultos: 18,3 g (Daciuk, 1974).

Dorsalmente $T$. pusillus es gris amarronada y ventralmente blanco amarillenta. El color ventral se extiende hasta las piernas y mejillas. Esta ampliamente distribuida en Argentina, sur de Bolivia y Paraguay (Fig 17). El límite sur de su distribución es la provincia de Chubut. En Jujuy ha sido capturada a 3.500 m de altura (Daciuk, 1974).

Se encuentra en áreas muy secas. También ha sido capturada en pendientes rocosas y a lo largo de cuerpos de agua en la vegetación densa.

Todos los representantes del género Thylamys necesitan una profunda revisión taxonómica (Galliari et al., 1996). Algunos autores consideran que los especímenes de este género provenientes del desierto del Monte corresponden a $T$. pallidior (Flores et al.; 2000). 


\subsection{OTRAS ESPECIES DE VERTEBRADOS PRESENTES EN LA RESERVA DE LA BIÓSFERA DE ÑACUÑÁN}

En la Reserva se encuentra representado el $44 \%$ de la fauna de vertebrados de la provincia de Mendoza. Hay 4 especies de anfibios anuros, 20 especies de reptiles (quelonios y escamados), 103 especies de aves (pertenecientes a 16 Ordenes) y 32 especies de mamíferos (pertenecientes a 5 Ordenes) (Ojeda et al., 1998; Tognelli et al., 2001). Algunas de las especies de tetrápodos presentes son endémicas o se encuentran en peligro de extinción, tal es el caso de la tortuga de tierra Chelonoidis chilensis, el águila coronada Harpyhaliaetus coronatus, el pichiciego Chlamyphorus truncatus, el gato del pajonal Lynchailurus pajeros, la mara Dolichotis patagona y la rata de los salares Tympanoctomys barrerae (Díaz y Ojeda, 2000). El apéndice 1 contiene una lista detallada de los mamíferos de pequeño y mediano tamaño (roedores y marsupiales) presentes en la Reserva.

Entre los carnívoros, posibles depredadores de los roedores múridos, se encuentran el zorro gris (Lycalopex gymnocercus), el puma (Puma concolor), el gato eyra (Herpailurus yaguaroundi) y el gato montés (Oncifelis geoffroyi). También están presentes el zorrino (Conepatus chinga), el huroncito (Lyncodon patagonicus) y el hurón (Galictis cuja). Otros animales que podrían depredar sobre estos pequeños mamíferos son ofidios (Fam. Colubridae y Fam. Viperidae), aves falconiformes como gavilanes, águilas (Fam. Accipitridae) o halcones (Fam. Falconidae), como así también la lechucita de las vizcacheras (Athene cunicularia) $\mathrm{u}$ otros Strigiformes.

Entre las especies exóticas presentes en la Reserva se pueden mencionar a la liebre europea (Lepus europaeus) y el jabalí (Sus scrofa ${ }^{(1)}$.

\footnotetext{
(1) La sistemática de mamíferos seguida en este capítulo corresponde a Galliari et al. (1996)
} 


\subsection{METODOLOGÍA GENERAL}

\section{Captura de pequeños mamíferos}

La principal metodología de muestreo empleada en este trabajo corresponde a la captura viva de los animales y a la utilización de técnicas de marcado y recaptura.

Para ello, en cada uno de los tres hábitats más característicos de la Reserva (algarrobal, jarillal y medanal) anteriormente descriptos, se colocaron dos grillas fijas de muestreo. Las mismas, de forma cuadrangular ( 7 x 7 estaciones), abarcaron 0,81 ha cada una. Las estaciones de muestreo dentro de cada grilla fueron separadas entre sí cada $15 \mathrm{~m}$ y se marcaron con una estaca de madera con la correspondiente rotulación. Las dos grillas del algarrobal fueron separadas entre sí por $500 \mathrm{~m}$, mientras que las del jarillal por $80 \mathrm{~m}$ y las del medanal por $110 \mathrm{~m}$ aproximadamente.

El período de muestreo abarcó desde junio de 1999 hasta abril de 2001, llevándose a cabo un total de 7 campañas en el algarrobal (julio, agosto, octubre y diciembre de 1999, mayo y noviembre de 2000 y abril de 2001), 8 en el jarillal (junio, julio, agosto, octubre y diciembre de 1999, mayo y noviembre de 2000 y abril de 2001), y 6 en el medanal (agosto y octubre de 1999, febrero, mayo y noviembre de 2000 y abril de 2001). Durante cada campaña, una trampa tipo Sherman o Moller (de 23 × 8 × $9 \mathrm{~cm}$. y de $27,5 \times 8 \times 9 \mathrm{~cm}$.) fue colocada en cada estación de las grillas. Las mismas fueron cebadas con avena al atardecer y revisadas temprano a la mañana siguiente, durante 3 a 7 noches consecutivas en cada período. En los meses de bajas temperaturas se colocó papel de diario cortado en tiras para evitar la muerte de los animales por frío. Los animales capturados fueron marcados con ectomización de falanges de acuerdo a un sistema estandarizado de marcado y liberados en el sitio de captura. Para cada individuo se 
registró la especie, el sexo, la edad, el peso y la localización de la trampa dentro de la grilla.

Los datos obtenidos se utilizaron para analizar la estructura de la comunidad (capítulo 3), los parámetros poblacionales (capítulo 4), la selección de hábitat (capítulo 5) y el tamaño del área de acción (capítulo 7) de las especies.

\section{Caracterización del micráhabitat}

En dos épocas del año (estación húmeda y estación seca), se tomaron los datos para la caracterización de los microhábitats. Este procedimiento consistió en marcar alrededor de cada estaca de las grillas una parcela de $2 \mathrm{~m}$ x $2 \mathrm{~m}$ donde se registraron las siguientes variables:

1) especies vegetales presentes

2) cobertura de arbustos (incluye L. cuneifolia, L. divaricata, A. lampa, Condalia microphylla, C. atamisquea, y pequeños individuos de G. decorticans, de hasta 1,5 m. de altura)

3) cobertura de subarbustos (incluye L. chilensis, L. tenuispinosum, Acantholippia seriphioides y Verbena seriphioides)

4) cobertura total de arbustos (incluye los dos tipos anteriores)

5) cobertura de herbáceas (incluye especies de Graminae, Compositae, Malvaceae, Solanaceae, Plantaginaceae e Hydrophilaceae)

6) cobertura de árboles (Prosopis sp. e individuos de más de $1,5 \mathrm{~m}$ de $G$. decorticans)

7) cobertura de mantillo

8) porcentaje de suelo desnudo

9) altura de herbáceas

10) altura del estrato más bajo

11) altura del estrato más alto 
12) distancia desde la estaca al arbusto más próximo fuera de la parcela

13) densidad del follaje (en valores ordinales).

La cobertura vegetal fue estimada en porcentajes de modo subjetivo, mientras que la altura de los estratos arbustivos fue medida hasta $1,5 \mathrm{~m}$. de altura, a partir de la cual el registro fue "más de 1,5 m.". Esta metodología permitió determinar las variables ambientales seleccionadas por los individuos de las cuatro especies de múridos a nivel de macro y microhábitat (capítulo 5).

\section{Utilización de polvos luminosos}

La utilización de polvos fluorescentes es una metodología desarrollada en pequeños mamíferos por Duplantier et al. (1984) y muy utilizada en los últimos años para estudiar el uso o selección de hábitat de las especies (principalmente de roedores). Consiste en capturar animales con trampas de captura viva y colocarles polvos fluorescentes en todo el cuerpo antes de liberarlos. Luego de unas horas, durante la noche (o a la noche siguiente) se sigue el rastro dejado por el animal con luz ultravioleta. En el presente trabajo el método fue modificado ya que se utilizaron polvos fluorescentes durante el día. Una vez descubierto el camino realizado por el animal, se registra la cobertura u otras variables de microhábitat.

Si bien el uso del microhábitat con esta metodología es evaluado en forma más precisa, este procedimiento fue utilizado como complemento de la técnica de marcado y recaptura (capítulo 6), ya que tiene la desventaja de tener corta duración y sólo permite seguir el rastro del animal hasta un poco más de 100 m no siendo posible registrar el movimiento de los animales en días sucesivos. 


\subsection{FIGURAS}

Fig. 1. Ubicación geográfica de la Reserva de Biósfera de Ñacuñán

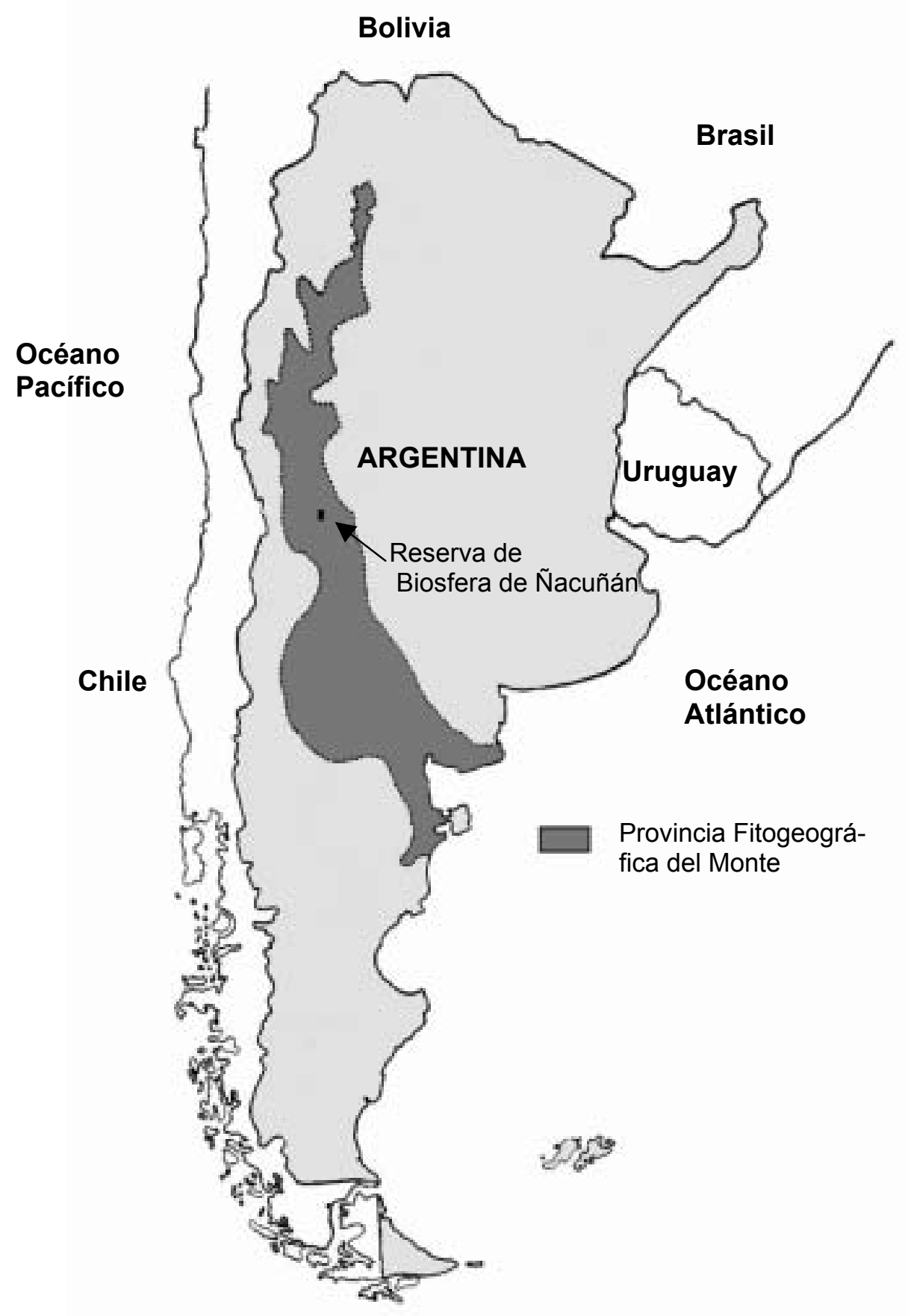


Fig. 2. Foto aérea de la Reserva de la Biósfera de Ñacuñán.

Las zonas claras indican áreas degradadas por sobrepastoreo

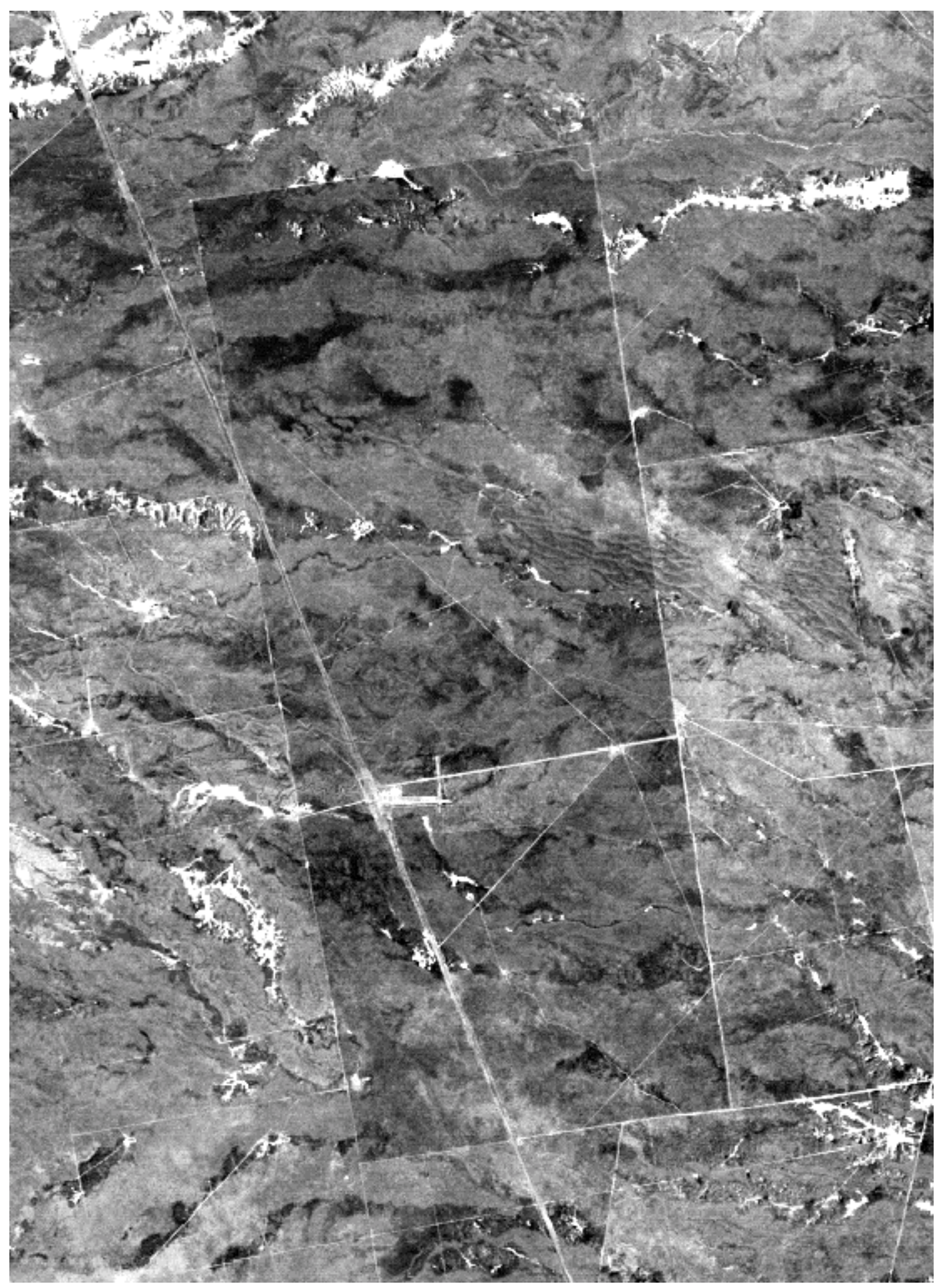


Fig. 3. Datos climáticos de la Reserva de la Biósfera de Ñacuñán desde 1972 hasta 2001.

a) Variabilidad interanual en las precipitaciones

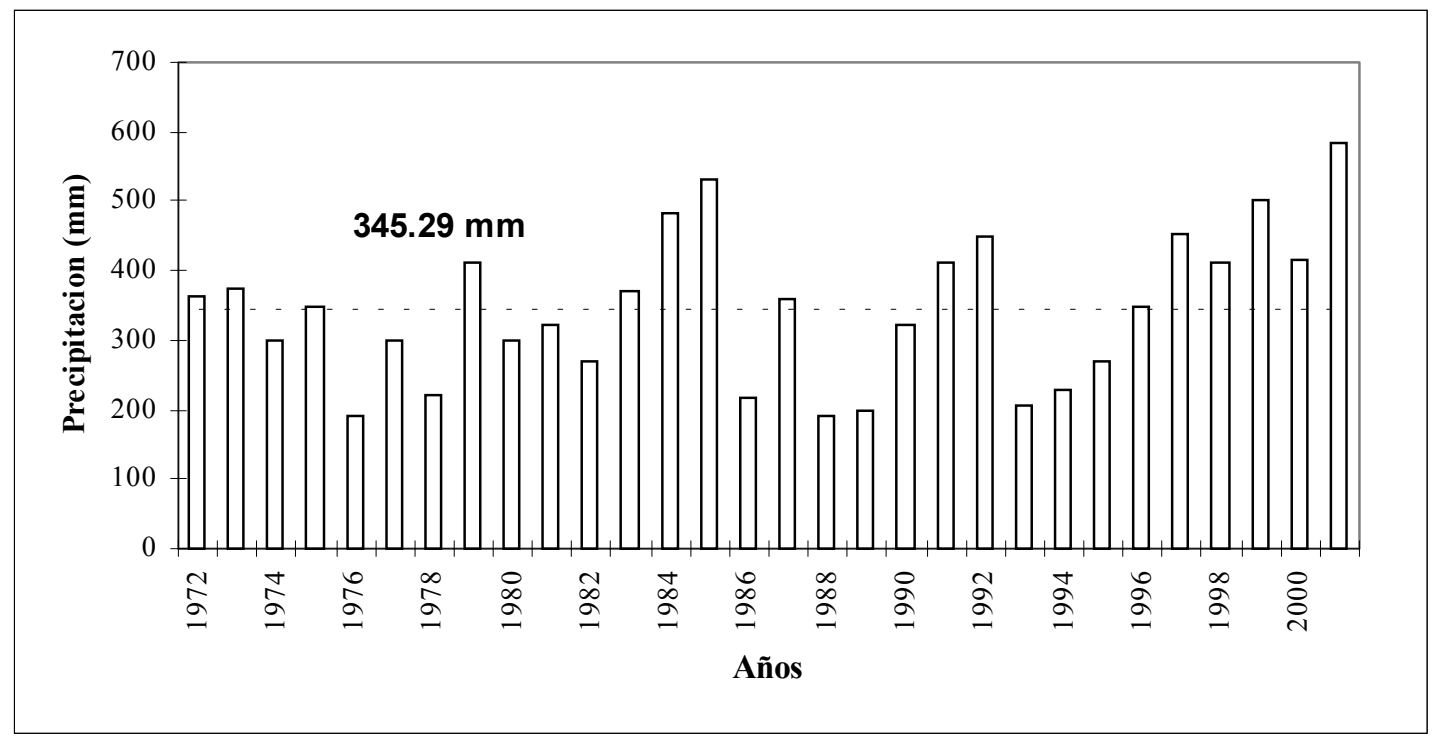

b) Variaciones mensuales en la temperatura

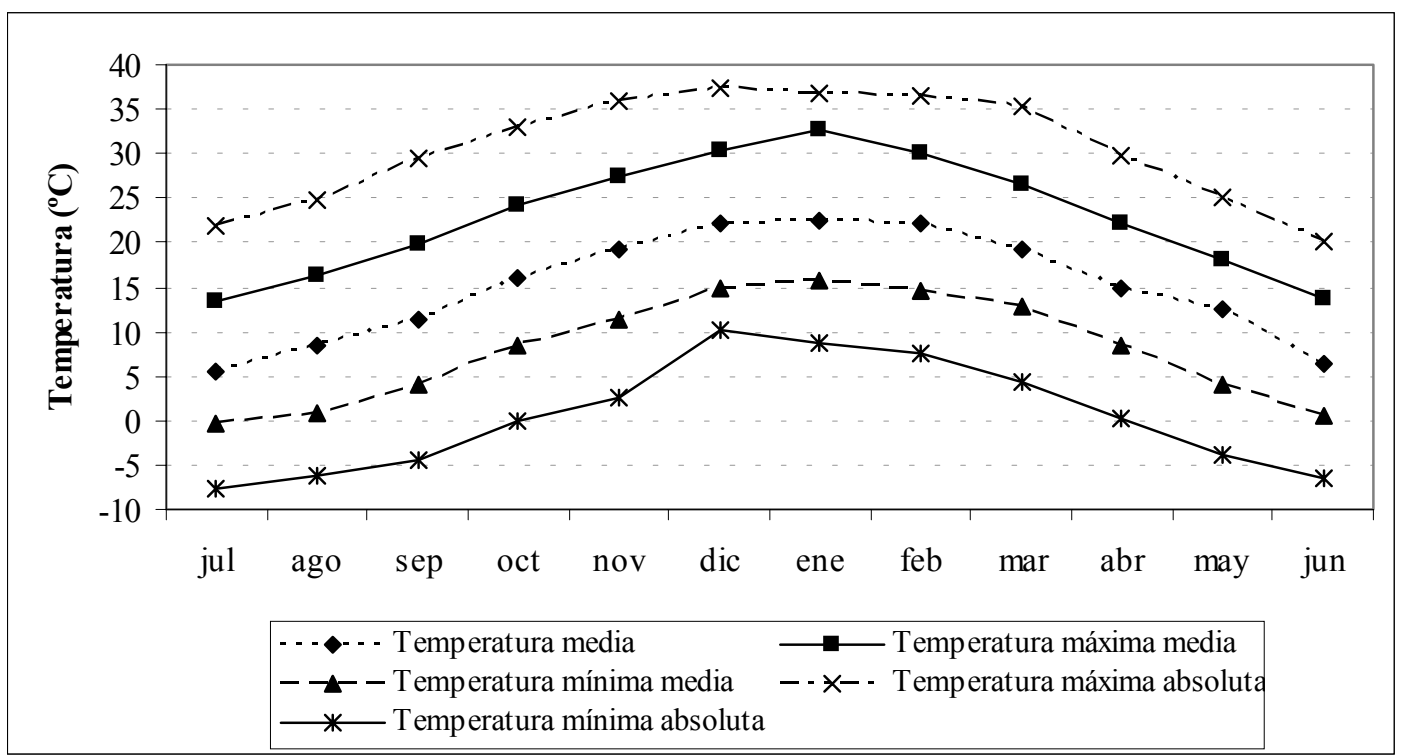


Fig. 4. Carta de vegetación de la Reserva de la Biósfera de Ñacuñán
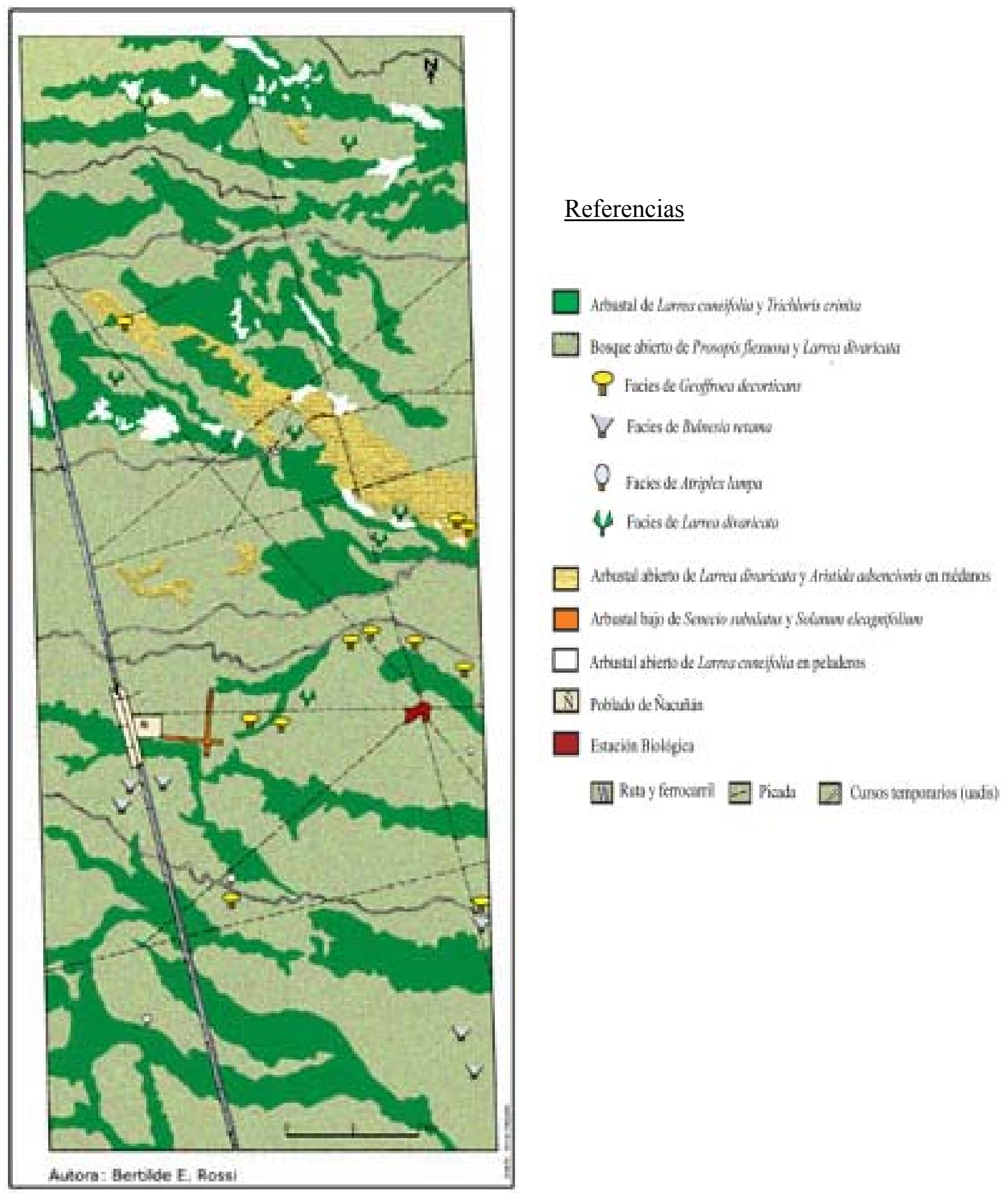
Fig. 5. Algarrobal de la Reserva de la Biosfera de Ñacuñán (en primavera)

a) vista interior

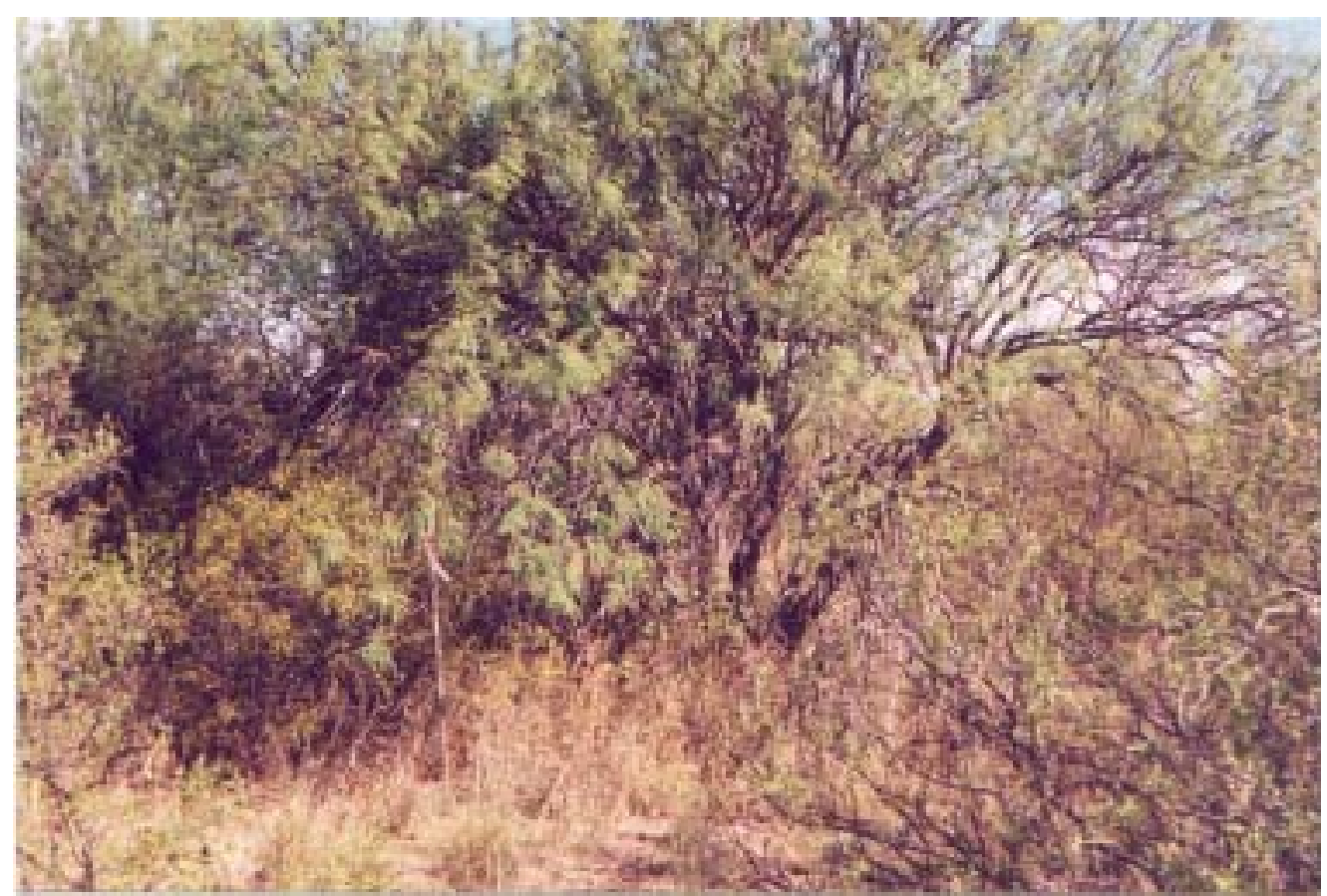

b) vista desde la Ruta Provincial $N^{\circ} 153$. El verde más oscuro (frente) corresponde al jarillal y el verde más claro (atrás) corresponde al algarrobal

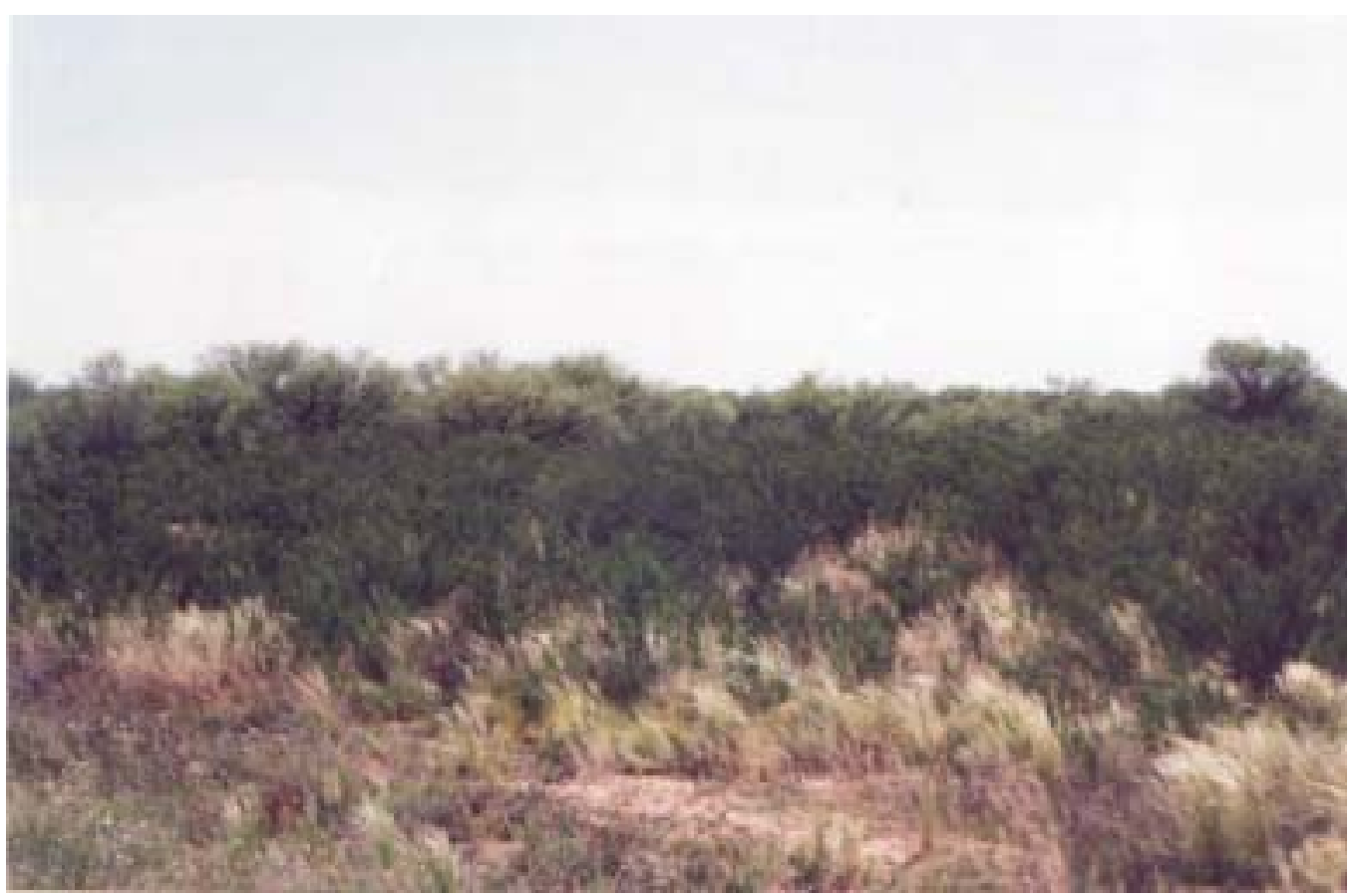


Fig. 6. Jarillal de la Reserva de la Biosfera de Ñacuñán (en primavera)

a) Picada "La Torre"

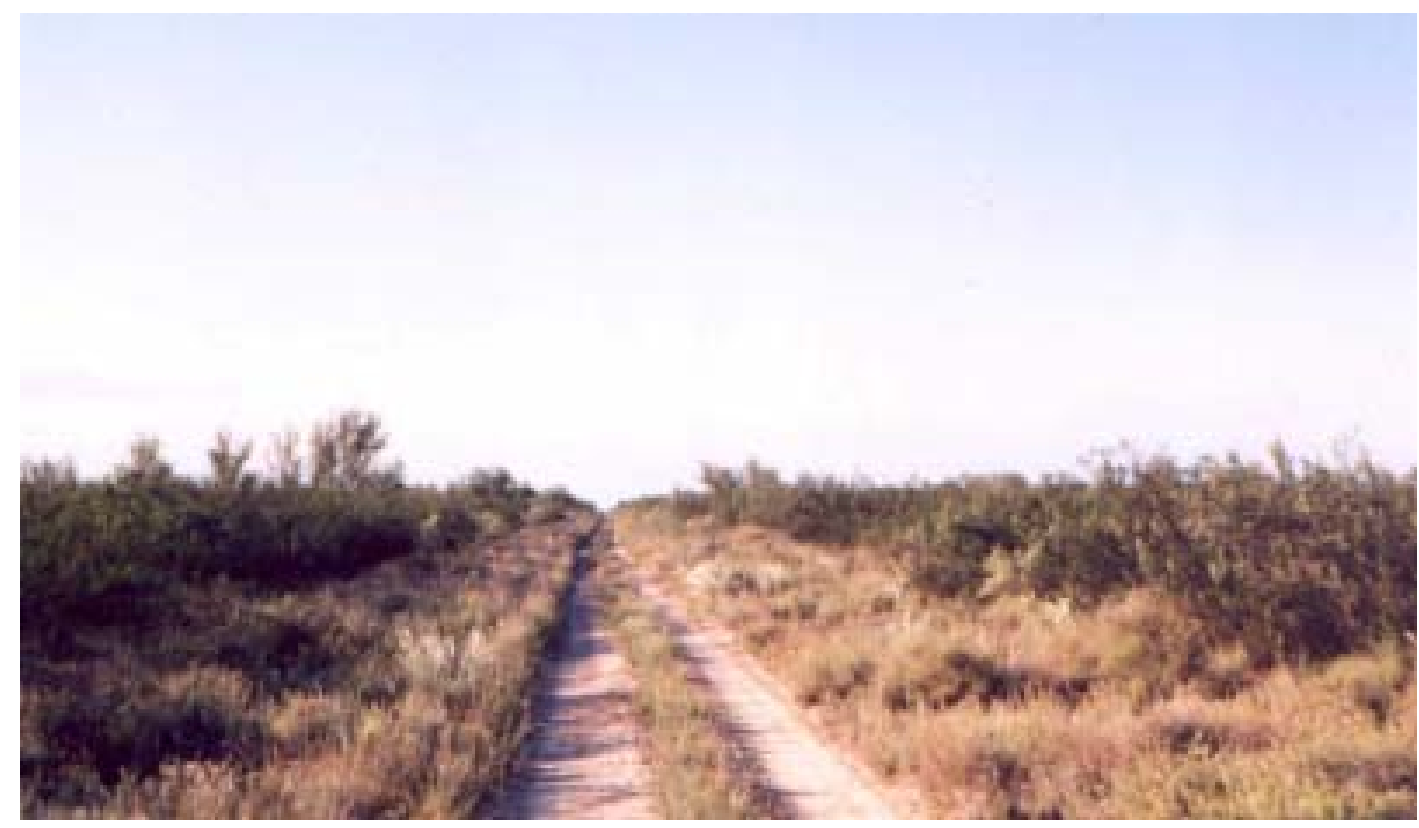

b) vista del interior

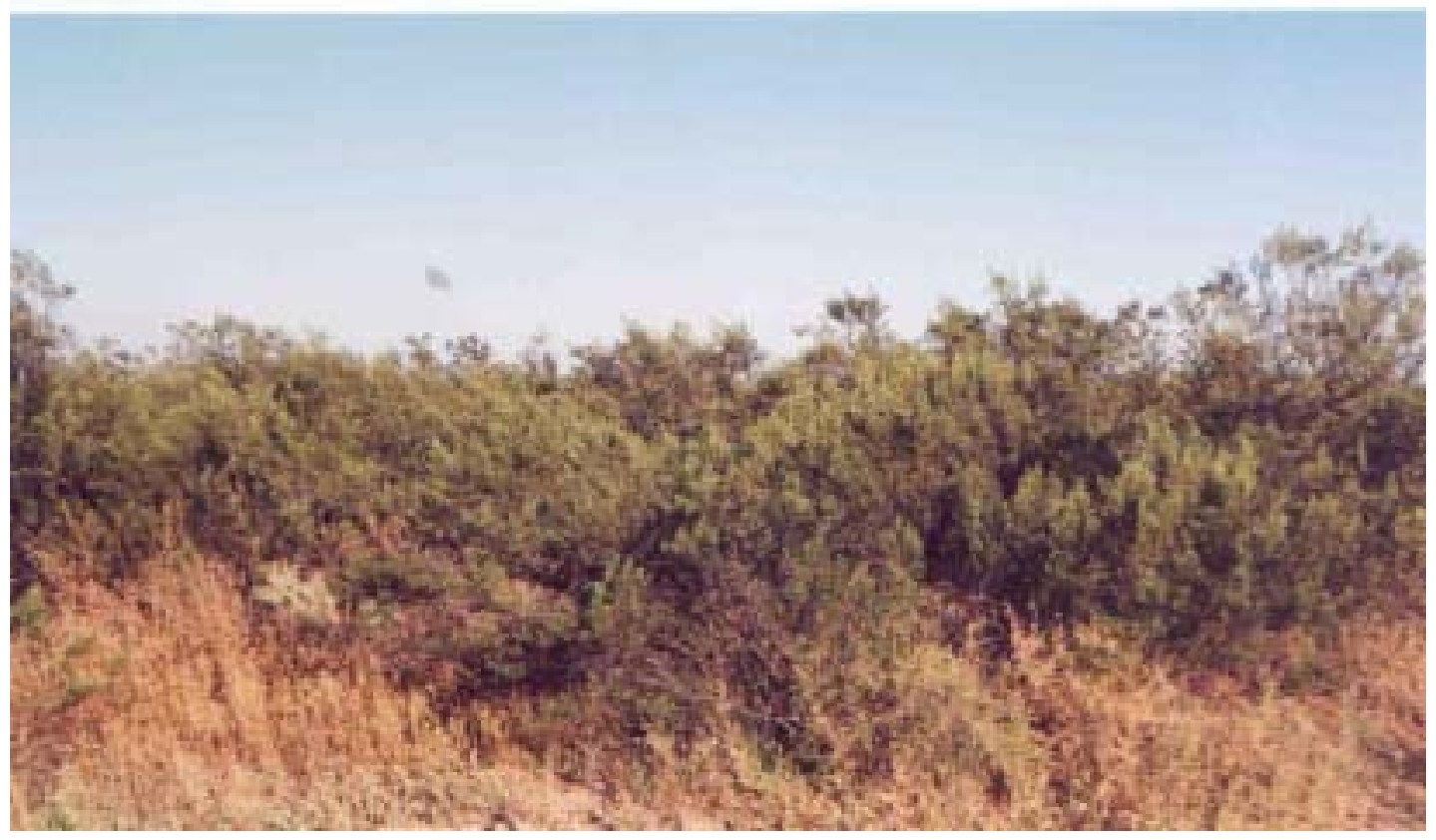


Fig. 7. Medanal de la Reserva de la Biosfera de Ñacuñán (en primavera)

a) vista general

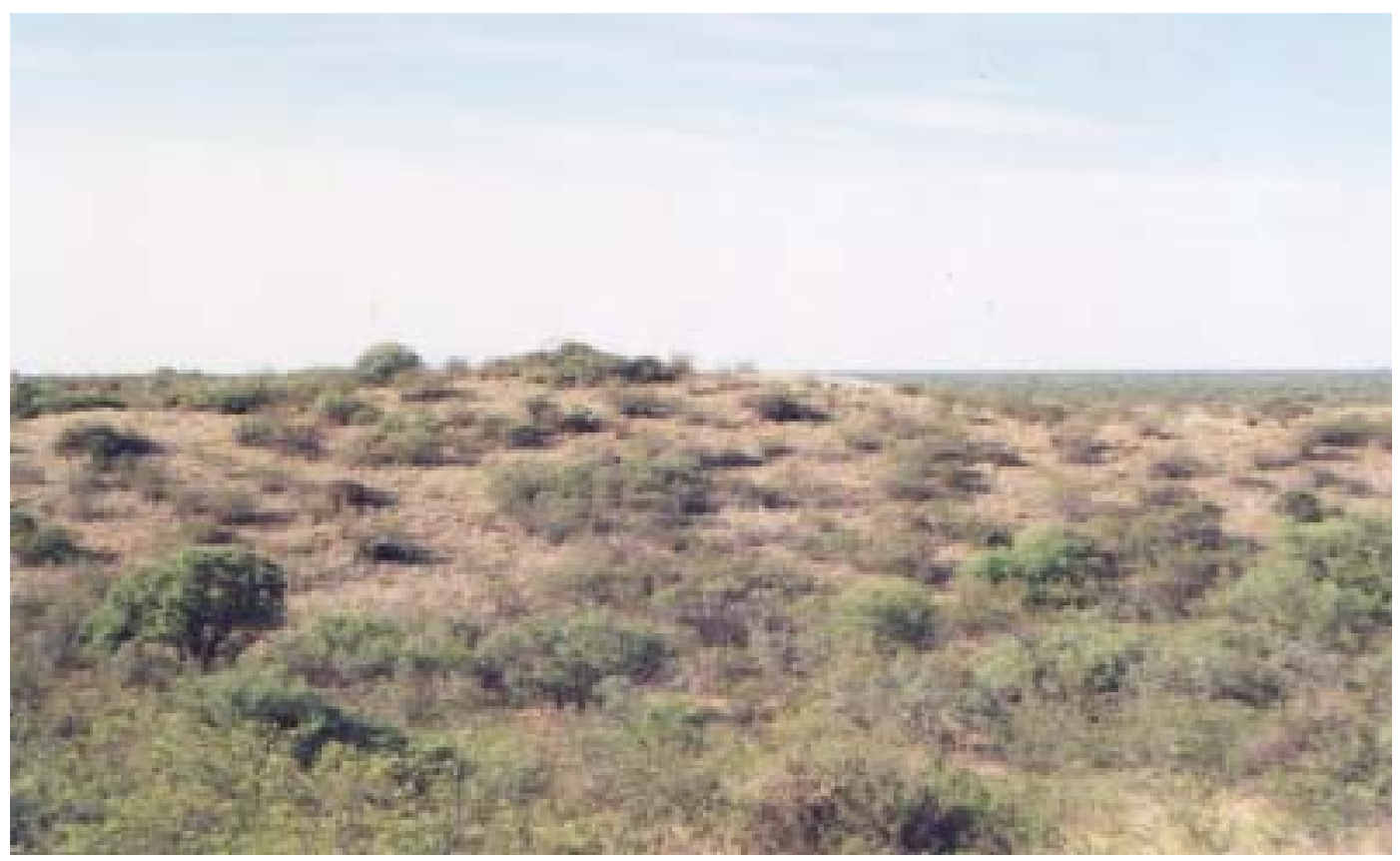

b) vista de una estación de muestreo

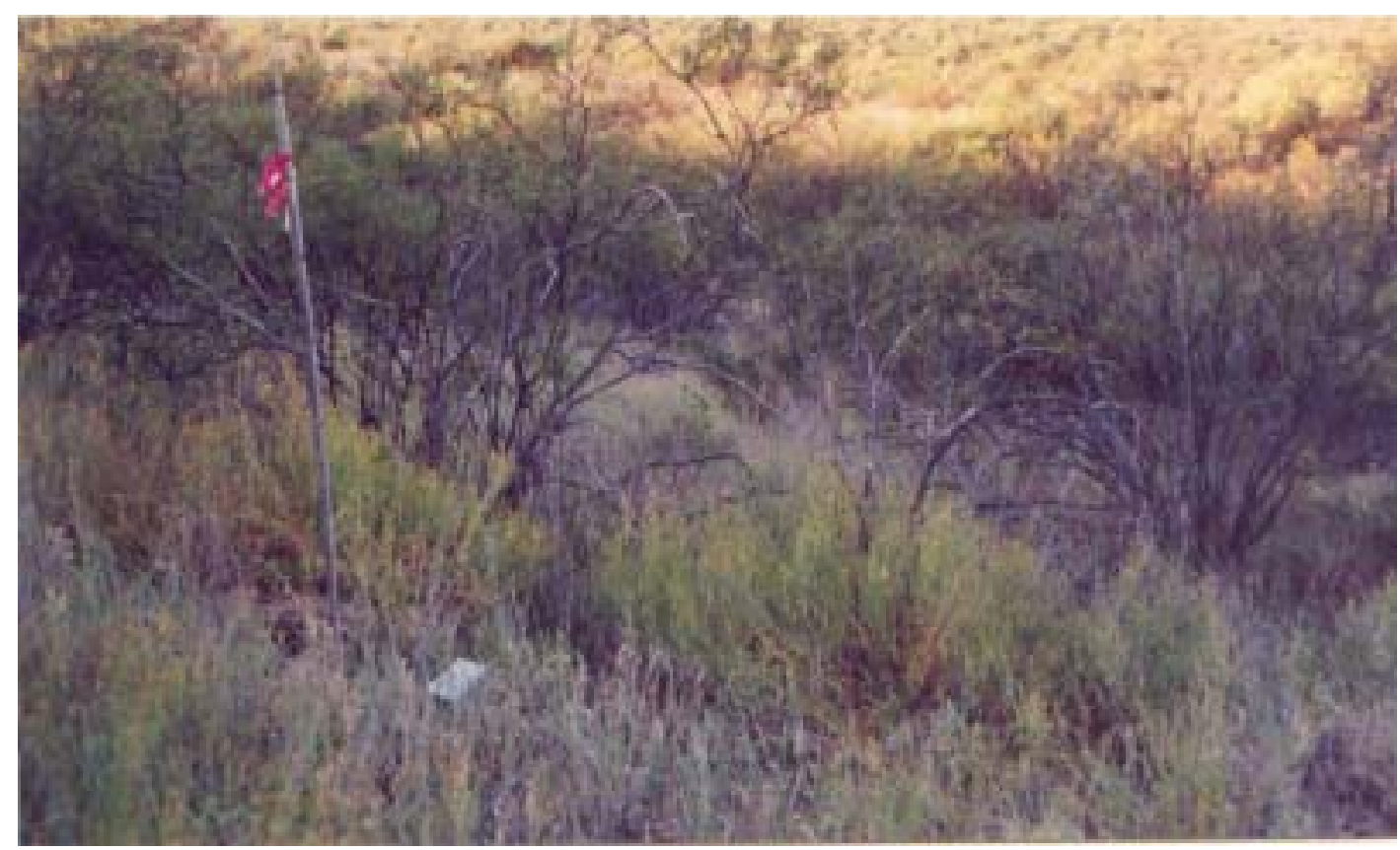


Fig. 8. Graomys griseoflavus (Orden Rodentia, Fam. Muridae)

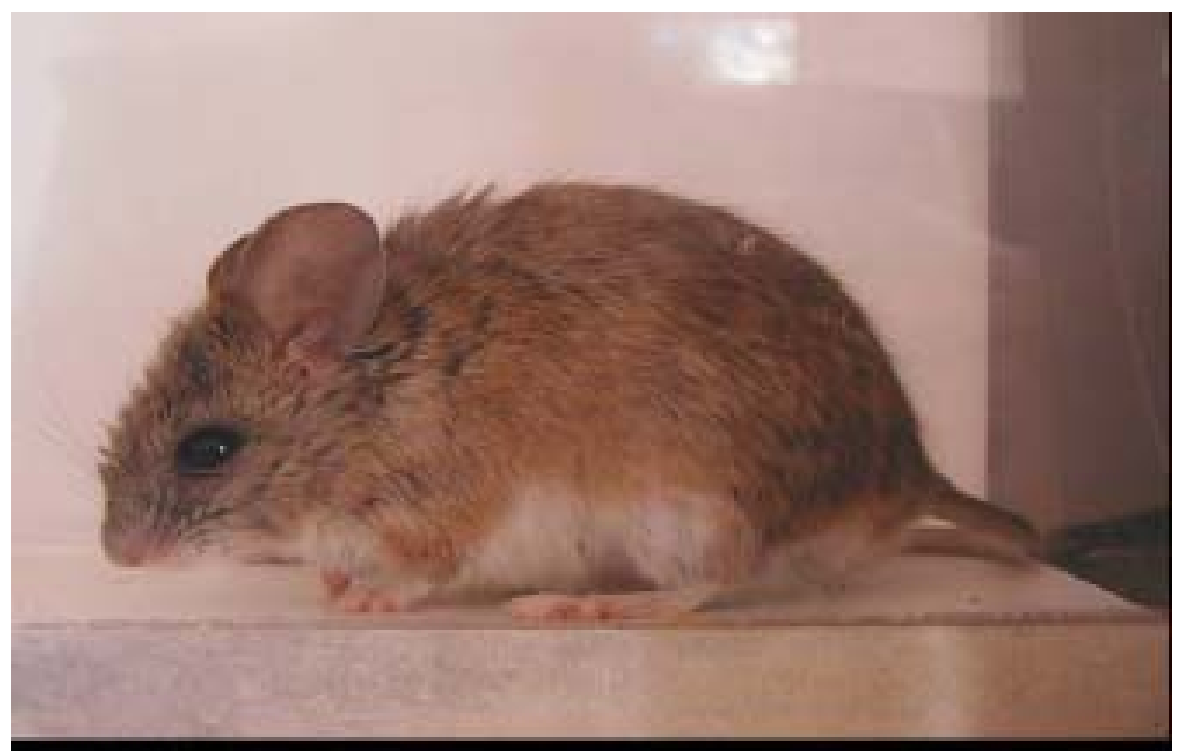

Fig. 9. Akodon molinae (Orden Rodentia, Fam. Muridae)

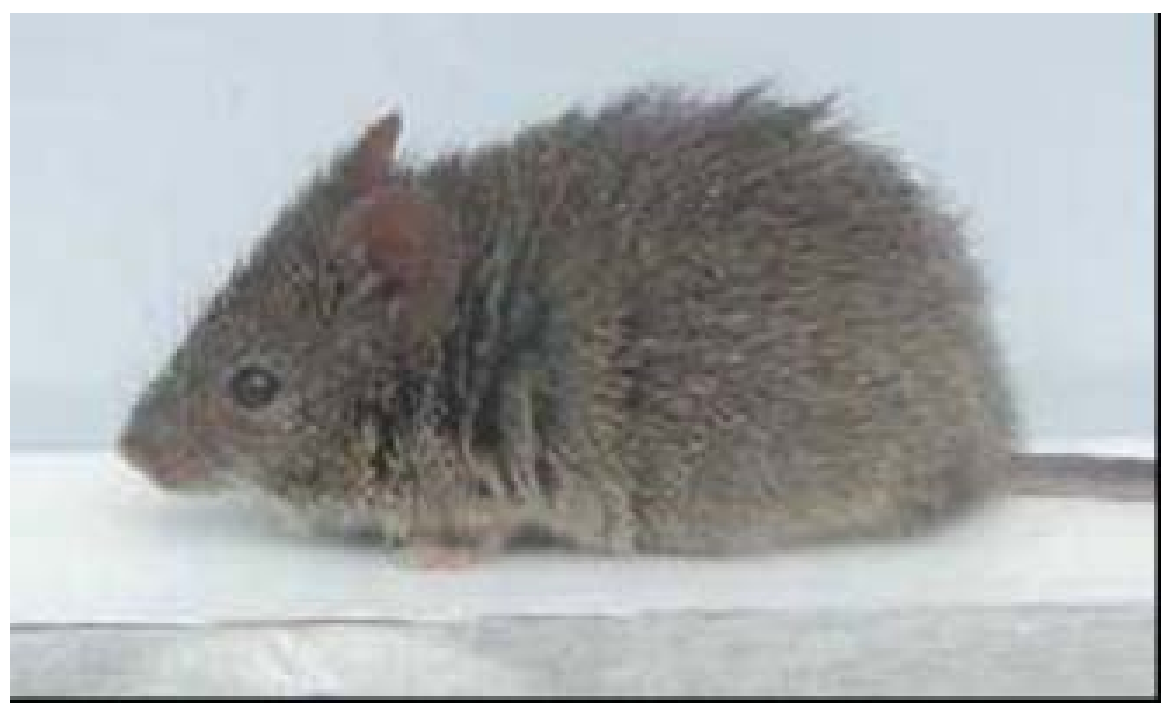


Fig. 10. Calomys musculinus (Orden Rodentia, Fam. Muridae)

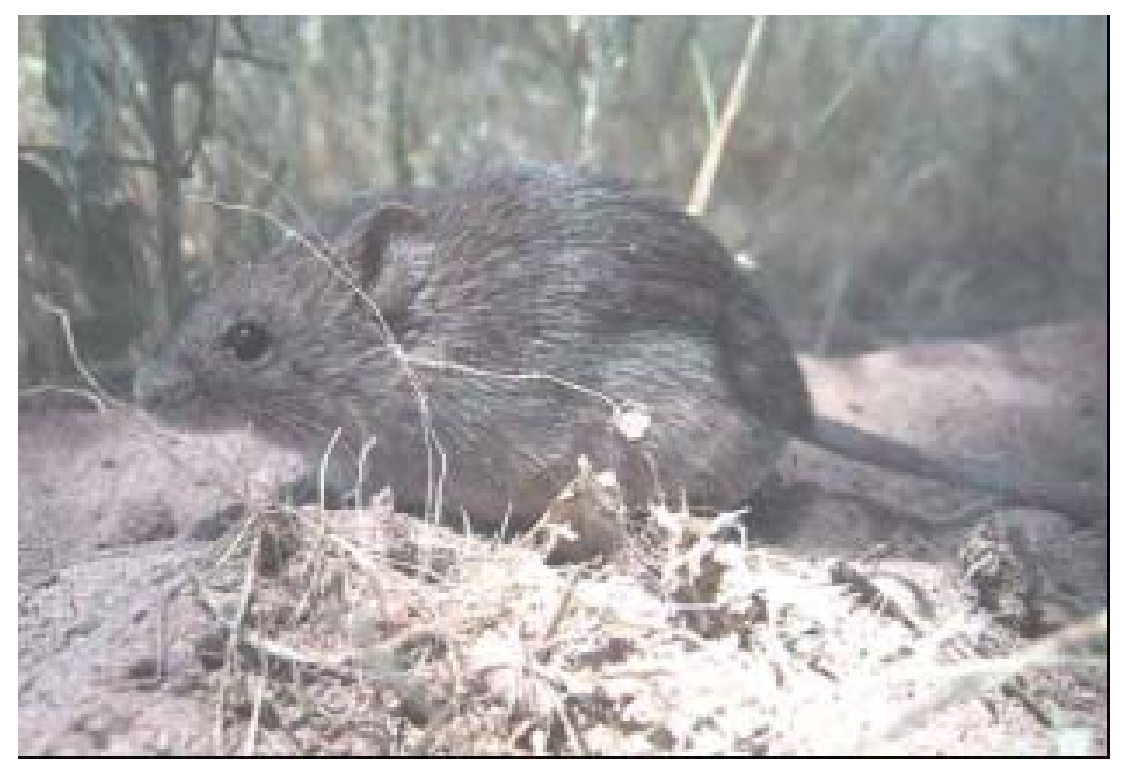

Fig. 11. Eligmodontia typus (Orden Rodentia, Fam. Muridae)

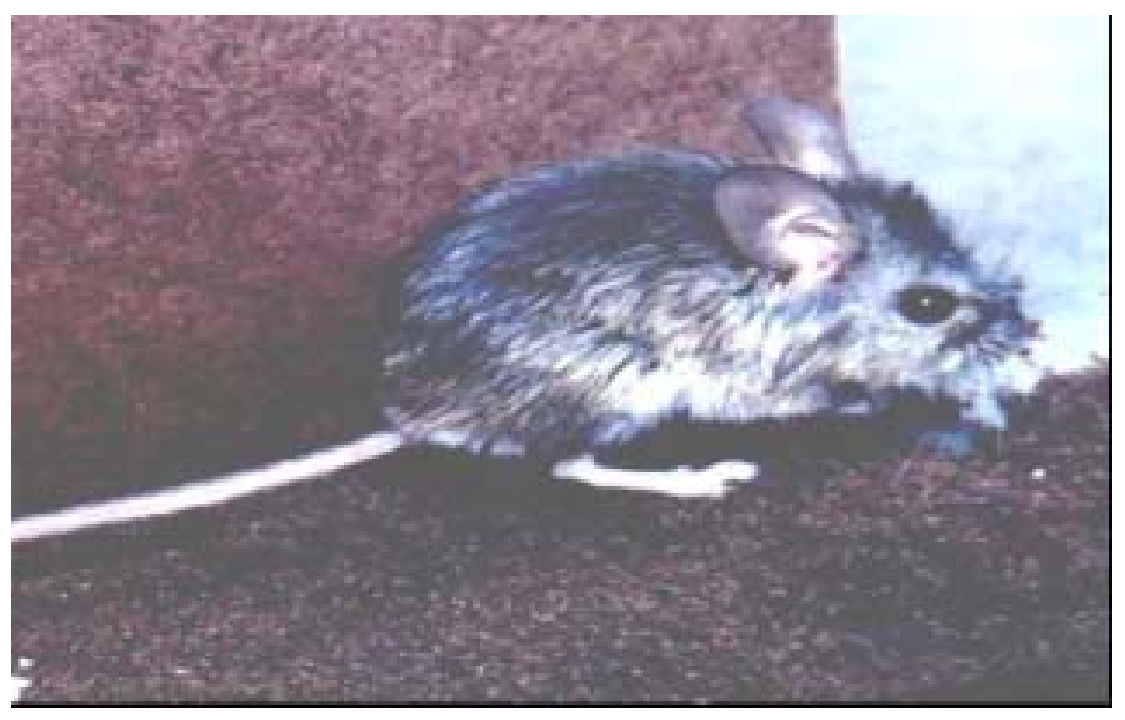


Fig. 12. Thylamys pusillus (Orden Didelphimorphia, Fam. Didelphidae)

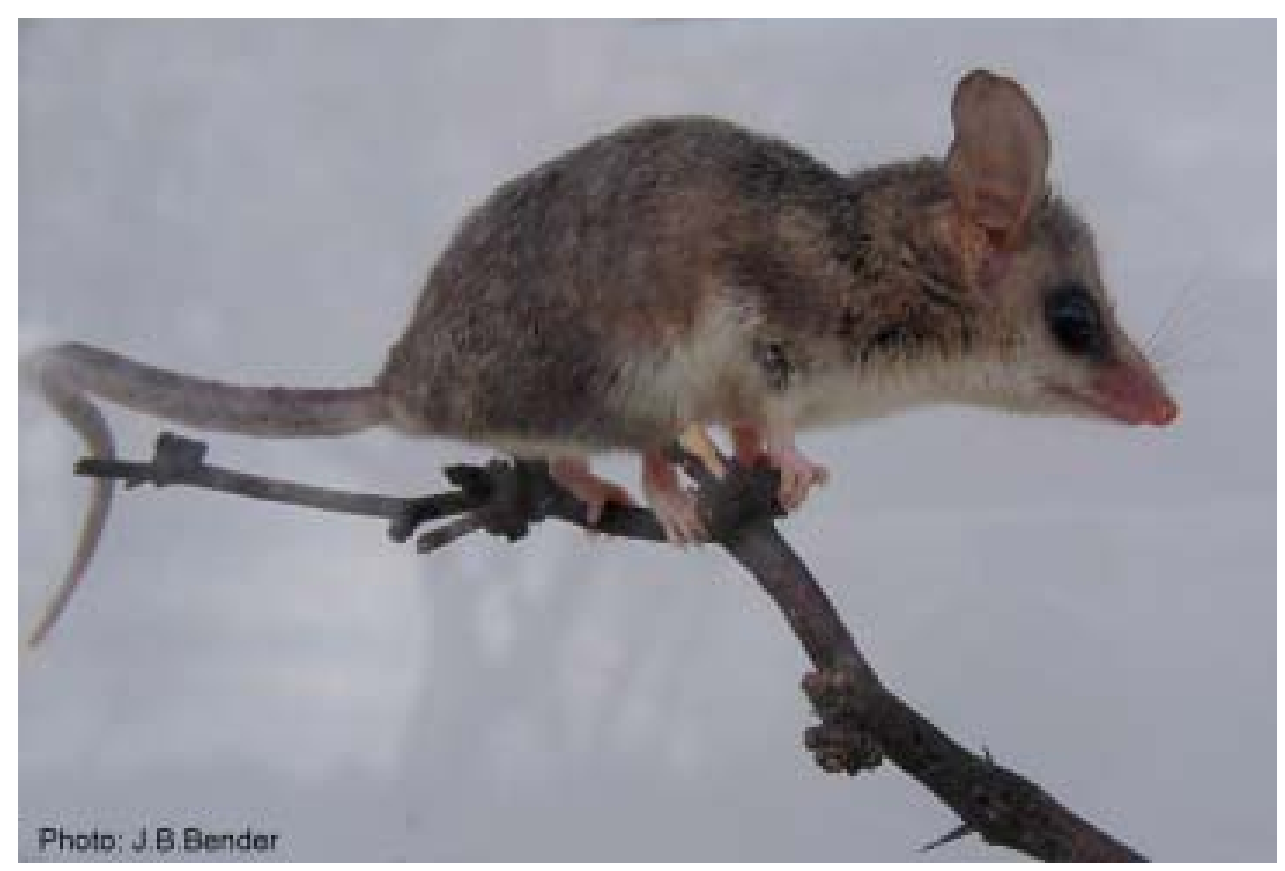


Fig. 13. Mapa de distribución de Graomys griseoflavus

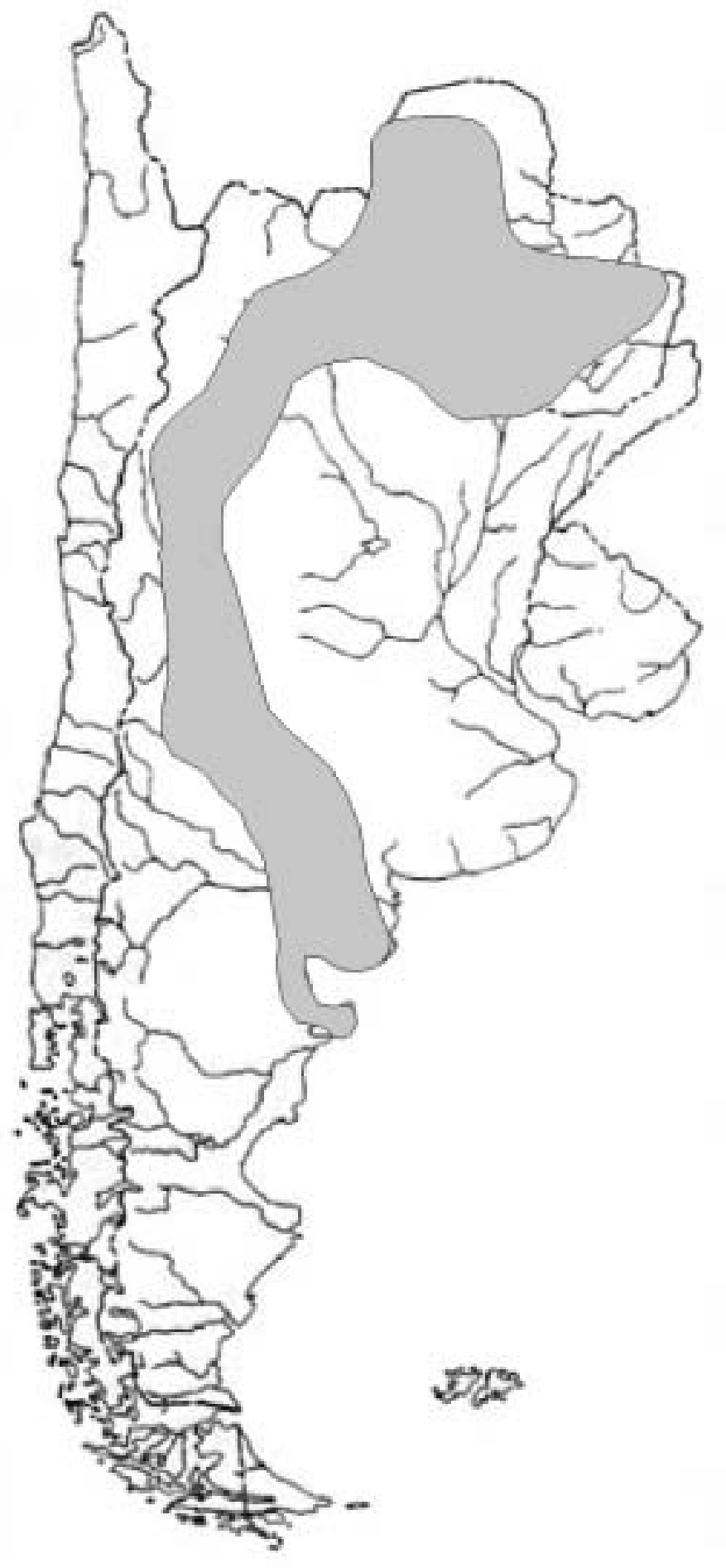

Adaptado de: Redford y Eisenberg (1992) 
Fig 14. Mapa de distribución de Akodon molinae

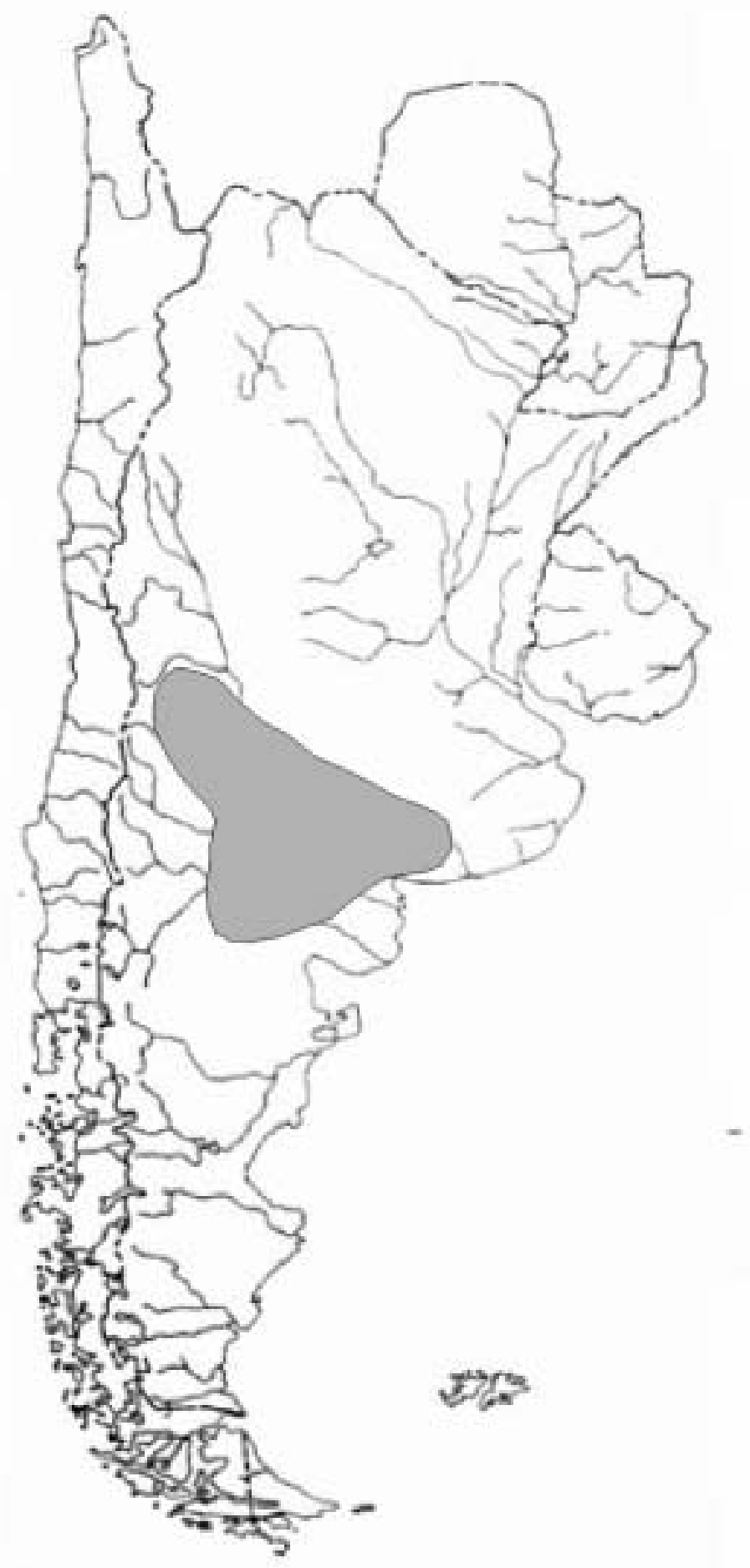

Adaptado de: Redford y Eisenberg (1992) 
Fig. 15. Mapa de distribución de Calomys musculinus

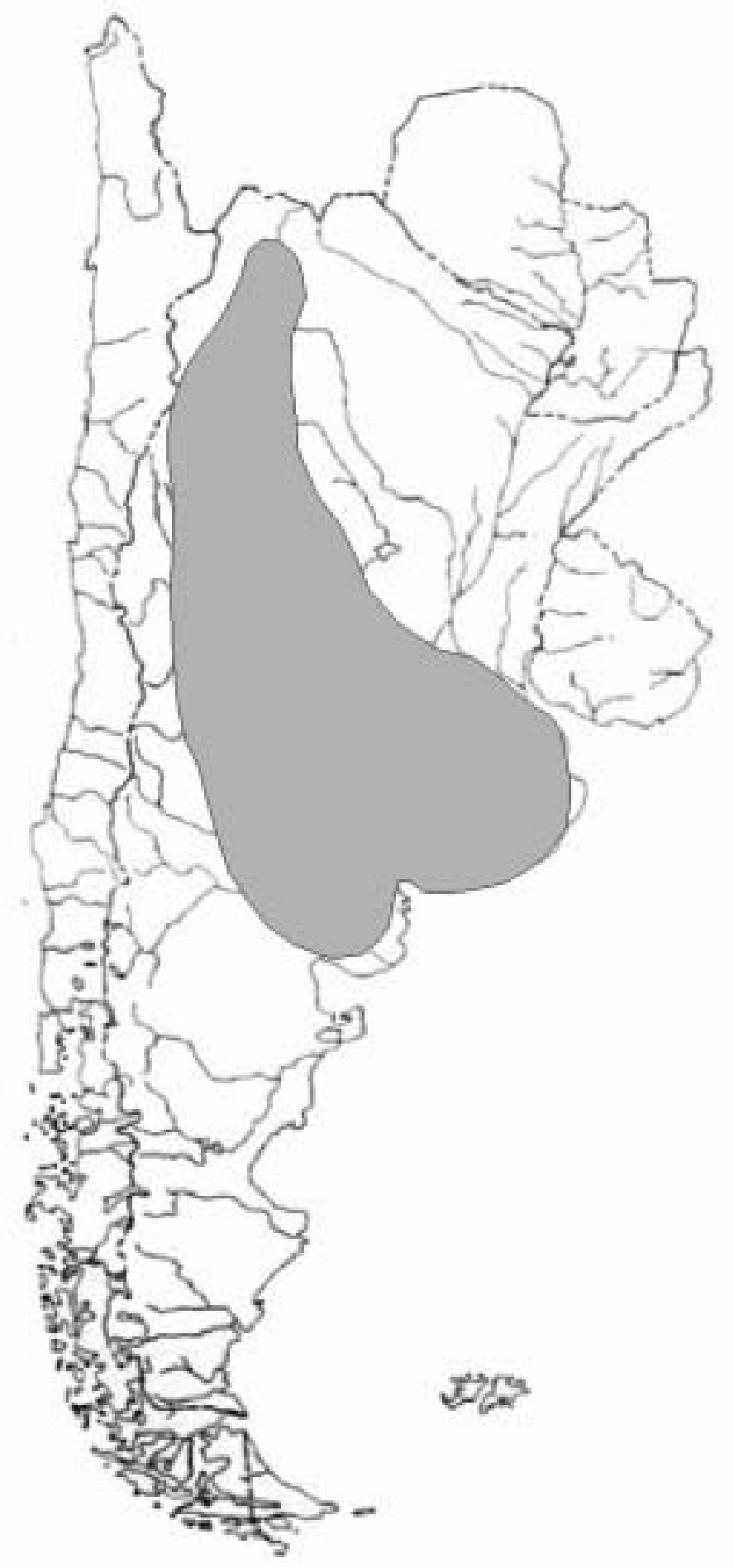

Adaptado de: Redford y Eisenberg (1992) 
Fig. 16. Mapa de distribución de Eligmodontia typus

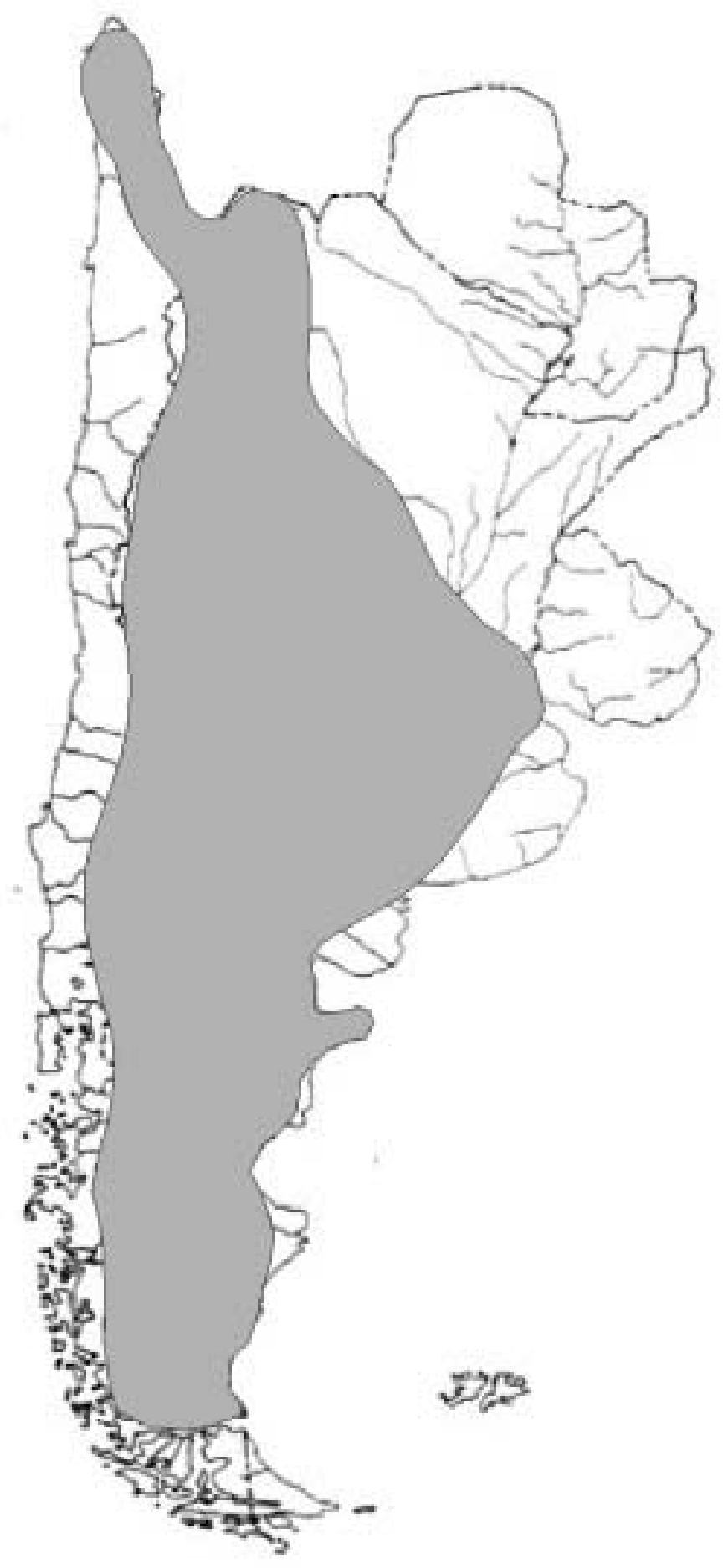

Adaptado de: Redford y Eisenberg (1992) 
Fig. 17. Mapa de distribución de Thylamys pusillus

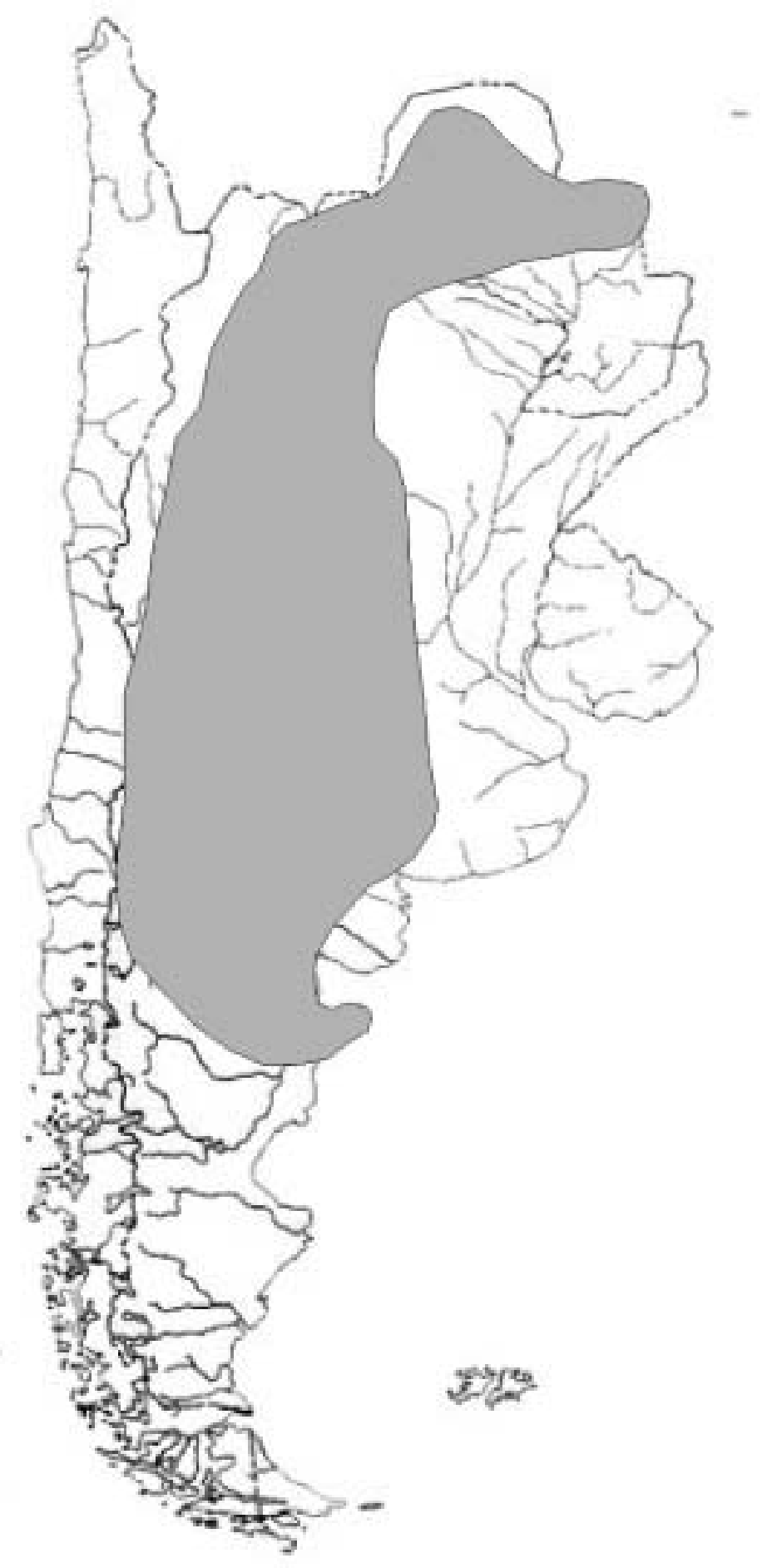

Adaptado de: Redford y Eisenberg (1992) 
2.6. APÉNDICE 1. Clasificación sistemática de los roedores y marsupiales presentes en la Reserva de la Biósfera de Ñacuñán

$\underline{\text { Orden Rodentia }}$

Fam. Caviidae

Subfam. Caviinae

Microcavia australis

Galea musteloides

Subfam. Dolichotinae

Dolichotis patagona

Fam. Octodontidae

Subfam. Octodontinae

Tympanoctomys barrerae

Subfam. Ctenomyinae

Ctenomys eremophilus

Fam. Chinchillidae

Subfam. Lagostominae

Lagostomus maximus

Fam. Muridae

Subfam. Sigmodontinae

Calomys musculinus

Graomys griseoflavus

Eligmodontia typus

Akodon molinae

Orden Didelphimorphia

Fam. Didelphidae

Subfam. Marmosinae

Thylamys pusillus

Subfam. Didelphinae

Didelphis albiventris 
Capitulo 3

\section{ESTRUCTURA Y DINÁMICA DE LA COMUNIDAD}




\section{Capítulo 3. ESTRUCTURA Y DINÁMICA DE LA COMUNIDAD}

\subsection{INTRODUCCIÓN}

Los términos "heterogeneidad" y "complejidad" han sido usados indistintamente para describir aspectos del hábitat. Sin embargo, algunos autores reconocen que la heterogeneidad indica la variación horizontal en la fisonomía del hábitat (August, 1983; Rotenberry y Wiens, 1980; Wiens, 1974), mientras que la complejidad describe el desarrollo del estrato vertical (August, 1983). Tanto una como la otra han sido propuestas como las responsables del incremento de la diversidad de especies, al proveer más nichos por unidad de espacio (Holbrook, 1978; Levins, 1968; Mac Arthur et al., 1962). Es decir, que los hábitats más complejos (o heterogéneos) por lo general poseen mayor diversidad de especies, ya que contienen mayor variedad de microhábitats ocupados por especies con requerimientos diferentes (August, 1983; Holbrook, 1978; Price, 1986; Rosenzweig y Winakur, 1969). Sin embargo, el número de especies que un hábitat puede sostener es limitado, y los ecosistemas desérticos en general poseen baja riqueza de especies (Brown y Kurzius, 1987; Kelt, 1999; Kelt et al. 1996). En los desiertos de América del Norte es común encontrar combinaciones de 2 a 5 especies de pequeños mamíferos en cada sitio de estudio aún cuando el número de posibles combinaciones sea mayor (Brown y Kurzius, 1987). M Closkey (1978) encontró que en los sitios más diversos, las especies presentes fueron más diferentes en cuanto al uso de recursos que las especies de los ensambles de menor diversidad, avalando la hipótesis de May y MacArthur (1972) que predice que la separación de nichos se incrementa con la riqueza de especies. Este uso diferencial o partición de los recursos facilita la coexistencia de las especies dentro de una comunidad (Kotler y Bown, 1988; Shenbrot et al., 1999). La coexistencia estaría acompañada por diferencias en el comportamiento de forrajeo, la morfología y el tamaño corporal de las especies (Kotler, 1989; Scott y Dunstone, 2000), así como por una segregación temporal. Esta segregación puede ser diaria o estacional (permitiendo que coexistan 
especies diurnas y nocturnas o invernales y estivales con dietas y hábitos similares). La segregación estacional puede estar mediada por los cambios ambientales (relacionados a la precipitación y al consecuente aumento de la productividad primaria) o por las disímiles eficiencias de cada especie para evitar depredadores (algunas especies son más eficientes en determinadas épocas y menos eficientes en otras; Kotler y Bown, 1988, Kotler et al., 1994).

Existen dos conceptos diferentes sobre la distribución de las especies en el espacio. Clements (1916) propone que las especies son interdependientes y ocurren juntas repetidamente en comunidades altamente integradas. En contraste, Gleason $(1917,1926)$ propone que las comunidades están compuestas por especies que se distribuyen de acuerdo a sus requerimientos particulares. Este último concepto está avalado por estudios empíricos y es el de mayor aceptación (Brown y Kurzius, 1987; Cole, 1982; Huntley y Birks, 1983; Whittaker, 1956, 1960). De acuerdo a sus requerimientos, las especies pueden considerarse generalistas o especialistas. Las especies de nicho amplio (o generalistas) pueden tolerar un amplio rango de condiciones físicas, utilizar diferentes clases de recursos y sobrevivir en presencia de varios enemigos potenciales. Las especies de nicho estrecho (o especialistas), en cambio, son tolerantes a condiciones abióticas limitadas, utilizan sólo una pequeña parte de los recursos y son altamente sensibles a los competidores, depredadores, parásitos y enfermedades (Brown, 1995).

Dentro de las especies que componen la comunidad de pequeños mamíferos de esta porción del desierto del Monte, Graomys griseoflavus ha sido considerada como una especie de nicho espacial amplio, ya que utiliza gran variedad de hábitats (Gonnet y Ojeda, 1998), encontrándose desde ríos con selvas en galería hasta localidades típicamente xéricas (Gonnet y Ojeda, 1998; Redford y Eisenberg, 1992). Eligmodontia typus si bien se encuentra principalmente en áreas abiertas y disturbadas, también es abundante en ambientes con cobertura de arbustos de Larrea cuneifolia (Gonnet y Ojeda, 1998). Akodon molinae y Calomys musculinus, en cambio, posiblemente son más especialistas en cuanto a sus requerimientos de 
hábitat, ya que siempre se las ha asociado con áreas con alta cobertura de pastos (Gonnet, 1998).

La especie más estudiada en cuanto a su dinámica poblacional a lo largo del tiempo en el área de estudio es A. molinae (Navarro, 1991). Se encontró que las mayores densidades de esta especie ocurren en otoño (14 ind./ha.) y las mínimas en verano (2,5 ind./ha.), siendo las densidades promedio del jarillal superiores a las del algarrobal (7,9 y 3,4 ind./ha. respectivamente).

En los últimos años se ha incrementado el conocimiento de la biología de estas especies con el desarrollo de estudios ecológicos, tróficos, ecofisiológicos y etológicos (Borruel et al., 1998; Campos, 1997; Campos et al., 2001; Díaz y Ojeda, 1999; Giannoni et al., 1996; Gonnet, 1998; Gonnet y Ojeda, 1998; Mares et al., 1997; Ojeda, 1989). Sin embargo es muy poco lo que se conoce sobre la estructura de la comunidad que integran y la dinámica de sus poblaciones en tiempo y espacio.

Sobre la base del reconocimiento de la importancia de la variación espacial y temporal en la composición de biotas como mecanismos que influyen en la organización de la comunidad (Brown y Kurzius, 1987), se plantearon los siguientes objetivos:

- Cuantificar la composición y diversidad de la comunidad de micromamíferos en cada hábitat (jarillal, algarrobal y medanal) y la relación con la heterogeneidad del mismo

- Cuantificar la densidad, biomasa y dominancia de pequeños mamíferos a lo largo del período de estudio.

- Determinar la amplitud de nicho de cada especie

- Estimar la variación en abundancia de cada especie en relación al hábitat 


\subsection{MATERIALES Y MÉTODOS}

Los muestreos de micromamíferos se llevaron a cabo desde junio de 1999 hasta abril de 2001, utilizando el método de captura y recaptura explicado en el capítulo 2 .

Sobre la base de los datos obtenidos a partir de estos muestreos, se realizaron las siguientes estimaciones:

\section{Diversidad}

Se calculó la diversidad de pequeños mamíferos para cada estación del año y para cada grilla dentro de cada hábitat mediante el Índice de Diversidad de Shannon. A fin de estandarizar los datos, se utilizaron sólo las tres primeras noches de muestreo de cada época, considerando agosto de 1999 como "Invierno 1", octubre de 1999 como "Primavera 1", mayo de 2000 como "Otoño 1", noviembre de 2000 como "Primavera 2" y abril de 2001 como "Otoño 2".

Se obtuvo un índice total para cada hábitat sobre la base del número de individuos capturados en 3 de noches de trampeo a lo largo de todo el período de estudio. Los índices obtenidos para cada hábitat fueron comparados estadísticamente (de a pares) utilizando la distribución $t$ (Magurran, 1988; Zar, 1984):

$t=\frac{H_{1}^{\prime}-H_{2}^{\prime}}{\left(\operatorname{Var} \mathrm{H}_{1}^{\prime}+\operatorname{Var} \mathrm{H}_{2}^{\prime}\right)^{1 / 2}}$

donde H`1 es el índice de Diversidad del hábitat 1, y Var H`1 su varianza, calculada como: 
$\operatorname{Var} \mathrm{H}=\frac{\sum p_{i}\left(\ln p_{i}\right)^{2}-\left(\sum p_{i} \ln p_{i}\right)^{2}}{\mathrm{~N}}+\frac{S-1}{2 \mathrm{~N}^{2}}$

donde

$\mathrm{S}=$ número de especies $\mathrm{y}$

$\mathrm{N}=$ número total de individuos

Los grados de libertad fueron calculados de acuerdo a la siguiente ecuación:

g.l. $=\frac{\left(\operatorname{Var} \mathrm{H}_{1}+\operatorname{Var} \mathrm{H}_{2}\right)^{2}}{\left(\operatorname{Var} \mathrm{H}_{1}\right)^{2} / \mathrm{N}_{1}+\left(\operatorname{Var} \mathrm{H}_{2}\right)^{2} / \mathrm{N}_{2}}$

donde $\mathrm{N} 1$ y $\mathrm{N} 2$ son los números de individuos en las muestras 1 y 2 respectivamente.

Debido a que se realizaron tres comparaciones (algarrobal-jarillal, algarrobal-medanal y jarillal-medanal), y el test se realiza con comparaciones de a pares, se utilizó la corrección de Bonferroni para reducir el error tipo I, fijando el nivel de significación en 0,017 (Byrkit, 1987).

La equitatividad de especies para cada hábitat fue calculada con el programa ECOSTAT, con la ecuación E1 $=\log (\mathrm{N} 1) / \log (\mathrm{N} 0)$.

La heterogeneidad del hábitat fue calculada con el índice de diversidad de Shannon tomando las variables de cobertura (en porcentaje) registradas en cada estación de las grillas (ver capitulo 2). Para ello se utilizaron el porcentaje de suelo desnudo, la cobertura de árboles, de arbustos, de subarbustos y de herbáceas.

La diversidad de micromamíferos y la heterogeneidad del hábitat fueron relacionadas mediante una regresión simple, utilizando los valores de los índices de diversidad de Shannon de cada grilla obtenidos anteriormente. 


\section{Densidad y biomasa}

Se obtuvo un valor de densidad de cada especie en cada época utilizando la forma de estandarización a 3 noches, explicada anteriormente. Para ello, se le agregó al área de cada grilla (0,81 ha) un borde de 7,5 m (igual a la mitad de la distancia entre las estaciones de la grilla), incrementándose el tamaño de la misma a 1,025 ha; luego se expresó la densidad como el número de individuos/ha. Las densidades de cada especie obtenidas para cada grilla fueron promediadas para calcular la densidad promedio del hábitat.

Del mismo modo, se calculó la biomasa de cada especie en cada grilla (suma de pesos/ha) en cada época y se estimó la biomasa promedio (en gramos) del hábitat.

Para determinar el hábitat que soporta mayor biomasa total (suma de pesos de todas las especies) se calculó la misma en cada grilla por cada período de muestreo.

\section{Amplitud de nicho}

La amplitud de nicho de cada especie fue expresada con la recíproca del Índice de Simpson $\left(\mathrm{D}=1 / \Sigma p i^{2}\right)$ (Geier y Best, 1980; Magurran, 1988; Simpson, 1949), donde $p i$ es la proporción de cada especie en cada hábitat. Los valores más altos se atribuyen a las especies más tolerantes, es decir, aquellas con mayor plasticidad para ocupar diferentes hábitats.

\section{Variación espacial en abundancia}

Se comparó la cantidad total de individuos entre los tres hábitats, utilizando las capturas totales, estandarizadas por la cantidad de noches de trampeo. Debido a que los datos fueron valores enteros expresados en proporciones (cantidad de individuos/noches-trampa), y este tipo de datos supone una distribución Binomial, 
se analizaron mediante una regresión logística (Modelos Lineales Generalizados, GLM). El mismo análisis fue realizado separadamente por especie a fin de evaluar la selectividad de hábitat de cada una de ellas y por hábitat a fin de determinar si existen especies dominantes en cada uno de ellos. En todos los casos, cuando los errores residuales en los modelos mostraron sobredispersión (es decir, cuando la devianza residual fue mayor que los grados de libertad), los datos fueros reescalados para corregir los sesgos en los tests de hipótesis (Crawley, 1993). Todos los análisis fueron realizados con el programa GENSTAT (versión Demo). 


\subsection{RESULTADOS}

El esfuerzo total de captura fue de 9386 noches-trampa (3703 en el jarillal, 2716 en el algarrobal y 2967 en el medanal).

Se capturaron un total de 280 individuos de E. typus, 200 de G. griseoflavus, 213 de A. molinae, 159 de C. musculinus y 12 de T. pusillus. El peso corporal promedio de los adultos fue de 17,5 g en E. typus, $18 \mathrm{~g}$ en T. pusillus, 22,2 $\mathrm{g}$ en $C$. musculinus, 37,2 g en A. molinae y 55,8 g en G. griseoflavus. El éxito de captura promedio para el jarillal fue de $21,49 \%$, para el algarrobal $16,91 \%$ y para el medanal 12,09\%, registrándose el valor mínimo en julio de 1999 en el algarrobal $(0,68 \%)$ y el máximo en abril del 2001 en el jarillal (47,19\%).

En los casos en que fue necesario estandarizar los datos por el mismo esfuerzo de captura ( 3 primeras noches de trampeo), se redujo el número de individuos a 156 E. typus, 131 G. griseoflavus, 125 A. molinae, 80 C. musculinus y 4 T. pusillus.

\section{Diversidad de pequeños mamíferos y heterogeneidad del hábitat}

Las cinco especies de micromamíferos estuvieron presentes en los tres hábitats, aunque no todas fueron capturadas en todos los períodos de muestreo. Por lo tanto, la riqueza en cada hábitat fue diferente según la época considerada. En general, esta riqueza fue mayor en el jarillal (4-5 especies) y menor en el medanal (1 a 4 especies), mientras que el algarrobal tuvo una riqueza intermedia ( 2 a 5 especies). Las más elevadas riquezas de especies se registraron en el otoño y las más bajas en el invierno (Fig. 1).

El hábitat de mayor diversidad de micromamíferos fue el jarillal $\left(\mathrm{H}^{\prime}=1,4\right)$, al que le siguió el algarrobal $\left(\mathrm{H}^{\prime}=1,3\right)$, y por último el medanal $\left(\mathrm{H}^{\prime}=0,9\right)$. Se encontraron diferencias significativas entre el algarrobal y el medanal $(t=3,5$; g.l. $=133 ; p<0,001), y$ entre el jarillal y el medanal $(t=4,69 ;$ g.l. $=105$; 
$p<0,00001)$, pero no entre jarillal y el algarrobal $(t=1,98$; g.l. $=232, p=0,05)$ utilizando el ajuste de Bonferroni $(p=0,017)$. La equitatividad fue $\mathrm{E}=0,88$ en el jarillal, $\mathrm{E}=0,82$ en el algarrobal y $\mathrm{E}=0,64$ en el medanal.

Dentro de cada hábitat no se encontraron diferencias en los índices de diversidad entre las dos grillas del algarrobal ni entre las dos grillas del medanal, pero sí entre las grillas del jarillal (Tabla 1).

La diversidad fue aumentando a lo largo del período de estudio, principalmente en el algarrobal y en el medanal. En este último hábitat puede observarse que hay mayor diversidad en otoño con respecto a las demás épocas (Fig. 2).

Los hábitats estructuralmente más heterogéneos fueron el algarrobal $\left(\mathrm{H}_{\mathrm{A}}^{\prime}=1,34\right.$ y $\mathrm{H}_{\mathrm{B}}^{\prime}=1,39$ para cada grilla, A y B $)$ y el jarillal $\left(\mathrm{H}_{\mathrm{A}}^{\prime}=1,32\right.$ y $\left.\mathrm{H}_{\mathrm{B}}^{\prime}=1,22\right)$, mientras que el medanal representó al hábitat menos heterogéneo $\left(\mathrm{H}_{\mathrm{A}}^{\prime}=1,11\right.$ y $\left.\mathrm{H}_{\mathrm{B}}^{\prime}=1,04\right)$. La heterogeneidad del hábitat y la diversidad de especies es menor en el medanal respecto a los otros hábitats, observándose una tendencia al aumento de la diversidad a medida que aumenta la heterogeneidad del hábitat, siendo significativa la regresión entre los índices $\left(\mathrm{R}_{\text {adj. }}^{2}=0,72 ; p=0,02 ; \mathrm{n}=6\right.$; Fig. $3)$.

\section{Variación temporal en densidad y biomasa}

Densidad: Las mayores densidades se registraron en ambos otoños (2000 y 2001) y en la primavera del 2000 (Primavera 2; Fig. 4). En el algarrobal, G. griseoflavus se mantuvo con densidades ligeramente mayores que el resto de las especies, alcanzando los 13,32 ind./ha en el Otoño 2. En el Otoño 1 y la Primavera 2, los valores de densidad de A. molinae fueron similares a los de G. griseoflavus $(6,19$ ind./ha). En el jarillal las fluctuaciones en la densidad de todas las especies fueron más evidentes, sin poder reconocerse una especie dominante a lo largo de todo el período de muestreo. La densidad máxima en este hábitat corresponde a A. molinae (16,18 ind./ha) en el Otoño 1 . En el medanal se ve claramente que E. typus fue la 
especie dominante en todo el período de estudio, aunque la densidad máxima en este hábitat ( 8,56 ind./ha en el Otoño 1$)$ no superó la máxima densidad registrada en el jarillal para esta especie (12,85 ind./ha en el Otoño 2$)$.

Debido a que las mayores densidades totales en ambos otoños y en la primavera del 2000 pueden responder al aporte de crías y juveniles, se compararon estas clases de edades (ver capítulo 4) entre las distintas épocas del año. Para ello se usó regresión logística (MLG), ya que la proporción "juveniles/total de individuos capturados" o "crías/ total de individuos capturados" se distribuye en forma binomial. Se encontró que la proporción de juveniles fue mayor en el otoño del 2000 y en el otoño del $2001(p=0,012)$, pero la proporción de crías no fue significativa $(p>0,05)$.

Biomasa: la biomasa de cada hábitat también mostró fluctuaciones estacionales, siguiendo un patrón similar al de la densidad (Fig. 5). Tanto en el algarrobal como en el jarillal el aporte principal de biomasa corresponde a las especies de mayor tamaño, G. griseoflavus y A. molinae, mientras que en el medanal el mayor aporte corresponde a la especie más abundante, E. typus.

La biomasa total de cada grilla (sumando todas las especies) también mostró fluctuaciones a lo largo del período de estudio, siendo las grillas del jarillal y las del medanal las que soportan mayor y menor biomasa total, respectivamente. Las grillas del algarrobal en general tuvieron menor biomasa total que las del jarillal, excepto en la última fecha de muestreo (Otoño 2), donde la grilla 1 superó en biomasa a todo el resto (Fig. 6).

\section{Amplitud de nicho}

La especie con mayor índice de amplitud de nicho fue E. typus $(\mathrm{D}=2,68)$, seguida por G. griseoflavus $(\mathrm{D}=2,26)$, C. musculinus $(\mathrm{D}=2,10) \mathrm{y}$, por último, $A$. molinae $(\mathrm{D}=1,93)$. No pudo determinarse la amplitud de nicho de $T$. pusillus debido al bajo número de individuos capturados en 3 noches de trampeo $(n=4)$. 


\section{Variación espacial}

En un análisis global, la abundancia total de pequeños mamíferos no mostró diferencias significativas entre los tres hábitats $(p=0,07)$. Las comparaciones particulares, en cambio, revelan que en el jarillal la abundancia es mayor que en el medanal $(p=0,02)$.

Al comparar la abundancia de cada especie entre los tres hábitats, se encontró que A. molinae y $C$. musculinus fueron más abundantes en el jarillal y el algarrobal, mientras que G. griseoflavus lo fue en el algarrobal. E. typus fue más abundante en el medanal respecto al algarrobal, pero las diferencias en las abundancias entre el medanal y el jarillal sólo fueron marginalmente significativas ( $p=0,049$; Tabla 2; Fig. 7).

Cuando se comparó la abundancia de las distintas especies dentro de cada hábitat, se encontró que en el medanal, E. typus fue la especie significativamente más abundante ( $p<0,001$ en todos los casos), considerándose la especie dominante en este hábitat. No se encontraron diferencias significativas en las abundancias de las distintas especies en el jarillal $(p=0,43)$ ni en el algarrobal $(p=0,08)$, por lo que no puede considerarse a ninguna especie como dominante en estos hábitats. Sin embargo, la comparación particular de G. griseoflavus y C. musculinus en el algarrobal demuestra que el primero es más abundante que el segundo $(p=0,02)$ (Tabla 3; Fig. 7). 


\subsection{DISCUSIÓN}

Muchos autores han encontrado que a mayor heterogeneidad del hábitat, corresponde mayor diversidad de especies, debido al mayor número de microhábitats disponibles (Levins, 1968; Mac Arthur et al., 1962). En esta porción del desierto del Monte se ha encontrado una alta asociación entre estas dos variables. A pesar de que el algarrobal, debido al aporte de cobertura de árboles, resultó el hábitat más heterogéneo pero no el de mayor diversidad de pequeños mamíferos, la relación heterogeneidad-diversidad es más clara al comparar el jarillal y el algarrobal respecto al medanal, donde se ha encontrado menor heterogeneidad del hábitat, así como menor diversidad de especies. Una situación similar se ha observado en el desierto de Negev, donde los tipos de hábitat fácilmente distinguibles fisonómicamente son los arenosos y los rocosos, mientras que la distinción entre otros tipos de hábitat es menos pronunciada. Los médanos, por sus características ambientales particulares, son percibidos por los roedores como diferentes del resto (Shenbrot et al., 1999).

Si bien la riqueza y composición de pequeños mamíferos en este estudio fue similar en todos los hábitats, la abundancia, dominancia y biomasa fueron diferentes entre ellos, especialmente al comparar el medanal con los restantes hábitats. En general, en los ecosistemas desérticos coexisten sólo unas pocas especies en cada sitio. En los desiertos de América del Norte, el $80 \%$ de los sitios son ocupados por combinaciones de dos a cinco especies de mamíferos de menos de $100 \mathrm{~g}$ (Brown y Kurzius, 1987). Los resultados aquí obtenidos se ajustan al patrón observado por estos autores, ya que cuatro especies de pequeños mamíferos (cinco incluyendo a $T$. pusillus), coexisten en cada hábitat durante los picos de mayor densidad poblacional, mientras que una o dos especies fueron capturadas en épocas de baja densidad. Brown y Kurzius (1987) observaron que en los sitios donde la combinación de especies es la misma, existen marcadas diferencias en las abundancias relativas de las especies existentes. En este trabajo, donde los tres 
hábitats poseen la misma composición de especies, se encontró que E. typus es la especie dominante en el medanal, mientras que en el algarrobal y en el jarillal no hay dominancia de ninguna especie en particular, es decir, que las diferencias en las abundancias relativas de las especies pueden observarse sólo al comparar el medanal con los demás hábitats. E. typus es capaz de ocupar distintos tipos de hábitats (es la especie con mayor índice de amplitud de nicho) siendo su abundancia total mayor en el medanal, aunque las diferencias con el jarillal fueron marginalmente significativas $(\mathrm{p}=0,049)$. En los análisis estacionales se registró la máxima densidad para esta especie en este último hábitat (12,85 ind./ha en el Otoño 2). El resto de las especies, en cambio, no son frecuentes en el medanal, registrándose sus mayores abundancias en hábitats más cerrados. Así, G. griseoflavus usa más frecuentemente el algarrobal, mientras que $A$. molinae y $C$. musculinus se encuentran en igual abundancia en el jarillal y en el algarrobal. Estas diferencias en abundancias entre hábitats podrían estar relacionadas tanto a las características morfológicas de las especies estudiadas como a la disponibilidad de refugios y alimento. Los atributos ecomorfológicos de E. typus (miembros posteriores elongados, presencia de almohadillas plantares con pelo, locomoción a saltos y escape en zig-zag frente a potenciales depredadores; Mares, 1975a, Mares, 1975b; Redford y Eisenberg, 1992; Straccia y De Santis, 2000; Taraborelli et al., 2003) le otorgarían a esta especie mayor eficiencia para evitar depredadores respecto a las restantes. Este comportamiento, así como la coloración clara que no ofrece contraste con el sustrato, le permitiría a E. typus ocupar hábitats con baja cobertura vegetal y suelos arenosos, lo que llevaría a que en el medanal sea la especie dominante. Un estudio realizado sobre disturbios por fuego en la Reserva, indicó que la única especie presente luego de un año después de ocurrido el incendio fue E. typus, relacionándose su presencia a una disminución en la complejidad vegetal (Ojeda, 1989). El resto de las especies serían más dependientes de la cobertura vegetal, especialmente $A$. molinae. Esta especie es característica de los pastizales pampeanos y la Reserva de Ñacunán constituye el límite occidental de su distribución. Los hábitats más heterogéneos (con mayor cobertura) podrían ofrecer mayor cantidad de microhábitats que pueden ser usados como refugios para 
la construcción de nidos y protección ante depredadores, así como mayor disponibilidad de alimento al albergar mayor diversidad de especies animales (insectos) y vegetales (hojas, semillas). Los hábitats más heterogéneos (jarillal y algarrobal), por lo tanto, serían los más adecuados para muchas especies de micromamíferos y explicaría la mayor abundancia de especies que se registra en ellos. G. griseoflavus está considerada como una especie capaz de ocupar tanto hábitats xéricos, como campos cultivados, áreas arenosas y rocosas (Redford y Eisenberg 1992). Gonnet y Ojeda (1998) observaron que en el pedemonte andino esta especie utiliza mayor variedad de hábitats que otras especies presentes en el área. En este trabajo también se ha demostrado una gran amplitud de su nicho, pero su abundancia fue significativamente mayor en el algarrobal, donde predomina el estrato arbóreo. Su capacidad de trepado (Mares 1977a), su uso del estrato arbóreo (Bender y Tabeni com. pers.), su comportamiento agresivo y su dieta compuesta principalmente por hojas de algarrobo (Campos 1997, Campos et al. 2001) sugieren que esta especie podría coexistir con las demás (principalmente A. molinae y $C$. musculinus) gracias a un uso diferencial del estrato vertical dentro del hábitat. El jarillal, donde predominan los estratos arbustivo y herbáceo, y donde hay baja proporción de perchas para aves, ofrecería un sitio seguro para los pequeños mamíferos. A. molinae y C. musculinus no poseen características morfológicas que le permitan explotar otro tipo de microhábitats.

Thylamys pusillus es una especie insectívora de hábitos semiarborícolas. Probablemente el tipo de cebo utilizado y/o la ubicación de las trampas fueron la causa del bajo número de capturas registrado para esta especie, impidiendo sacar conclusiones sobre sus asociaciones de hábitat, amplitud de nicho y dinámica poblacional.

La variación temporal en comunidades de roedores ha sido demostrada en otros desiertos (Brown y Heske, 1990; Ernest et al., 2000; Whitford, 1976). En este trabajo se registraron variaciones anuales tanto en diversidad como en biomasa. Lo mismo ocurrió con la densidad de todas las especies, algunas de las cuales no han sido capturadas en ciertos períodos de muestreo. Los otoños (comienzo de la 
estación seca) y la primavera 2 (comienzo de la estación húmeda) fueron los períodos de mayores densidades poblacionales. Navarro (1991) encontró que $A$. molinae es más abundante en otoño, alcanzando los 14 ind./ha en el jarillal. Estos resultados son similares a los aquí encontrados, donde la máxima densidad registrada de esta especie fue de 16,18 ind./ha en mayo del 2000 en el jarillal. La alta abundancia de pequeños mamíferos en otoño (abril-mayo) podría explicarse por reclutamiento de juveniles nacidos en los meses con mayor disponibilidad de alimento (brotes nuevos ricos en proteínas, semillas de gramíneas, frutos e insectos). En la primavera, con el comienzo de las lluvias, las plantas inician su fase vegetativa debido al sistema radical poco profundo que caracteriza a las especies desérticas (Dalmasso, 1994; Guevara et al., 1997; Rossi, 1994). La producción de frutos de C. atamisquea, C. microphylla y L. tenuespinosum es importante en los meses de verano (cuando las precipitaciones son más abundantes) y están disponibles hasta marzo-abril (Rossi, 1994), coincidentemente con los picos poblacionales de las especies de pequeños mamíferos. En esta época, además, se ha registrado una mayor cobertura de subarbustos y arbustos, así como mayor altura de herbáceas y densidad de follaje (ver capítulo 5). Estas características del hábitat también podrían explicar la mayor densidad de pequeños mamíferos encontrada en esta época.

En resumen, las comunidades de roedores en el Monte demuestran un gran dinamismo, tanto en términos espaciales como temporales. El hábitat más estable en cuanto a la composición y abundancia de pequeños mamíferos es el medanal, dominado por E. typus a lo largo de todo el año. En los hábitats estructuralmente más heterogéneos no es posible encontrar especies dominantes debido a que las abundancias relativas varían entre las distintas épocas del año. De todos modos, a pesar de la variación temporal y espacial, se destaca la fuerte asociación de E. typus con ambientes abiertos (recordando las especies bipedales norteamericanas) y la relación del resto de las especies con hábitats cerrados, con mayor cobertura vegetal (igual que los roedores cuadrúpedos del norte del continente). Esto sugiere que las variables inherentes a cada hábitat (cobertura de árboles, de arbustos, de hierbas, 
porcentaje de suelo desnudo, etc.) son determinantes en la distribución de las especies y la estructuración de las comunidades de estos roedores desérticos. 


\subsection{CONCLUSIONES}

Sobre la base de los resultados obtenidos en este capítulo, se destacan las siguientes conclusiones:

- Los hábitats más heterogéneos (algarrobal y jarillal) poseen mayor diversidad de especies de pequeños mamíferos.

- La riqueza de especies fue similar en los tres hábitats.

- Existe variación temporal en diversidad, densidad y biomasa, siendo el otoño de 2000, el otoño de 2001 y la primavera de 2000 los períodos en que los valores de estos parámetros fueron más altos.

- La especie con mayor amplitud de nicho es E. typus, seguida por G. griseoflavus, A. molinae y C. musculinus.

- Desde el punto de vista de las especies, se encontró que C. musculinus y $A$. molinae son más abundantes en el jarillal y el algarrobal, mientras que $G$. griseoflavus es más abundante en el algarrobal y E. typus lo es en el medanal y en el jarillal.

- Desde el punto de vista del hábitat, no se observaron especies dominantes en el jarillal y en el algarrobal, pero sí en el medanal, siendo característica la presencia de E. typus en este hábitat. 


\subsection{TABLAS y FIGURAS}

Tabla 1. Diversidad de micromamíferos en cada grilla de cada hábitat de la Reserva de la Biósfera de Ñacuñán y comparación entre grillas

\begin{tabular}{|lcc|ccc|}
\hline \multirow{2}{*}{ Habitat } & \multicolumn{2}{|c|}{ Índice de Shannon } & \multicolumn{3}{|c|}{ Comparación entre grillas } \\
\cline { 2 - 6 } & Grilla A & Grilla B & $t$ & g.l. & $p$ \\
\hline Algarrobal & 1.23 & 1.34 & 1.27 & 139 & 0.2 \\
Jarillal & 1.42 & 1.32 & 2.14 & 228 & 0.033 \\
Medanal & 0.98 & 0.69 & 1.4 & 92 & 0.16 \\
\hline
\end{tabular}


Tabla 2. Probabilidades al comparar las diferencias de abundancias de cada especie de micromamífero entre los tres hábitats de la Reserva de la Biósfera de Ñacuñán

a) Akodon molinae

\begin{tabular}{|l|c|c|c|}
\hline & Algarrobal & Jarillal & Medanal \\
\hline Algarrobal & - & & \\
\hline Jarillal & 0,41 & - & \\
\hline Medanal & $\mathbf{0 , 0 3}$ & $\mathbf{0 , 0 1}$ & - \\
\hline
\end{tabular}

b) Calomys musculinus

\begin{tabular}{|l|c|c|c|}
\hline & Algarrobal & Jarillal & Medanal \\
\hline Algarrobal & - & & \\
\hline Jarillal & 0,09 & - & \\
\hline Medanal & 0,41 & $\mathbf{0 , 0 2}$ & - \\
\hline
\end{tabular}

c) Graomys griseoflavus

\begin{tabular}{|l|c|c|c|}
\hline & Algarrobal & Jarillal & Medanal \\
\hline Algarrobal & - & & \\
\hline Jarillal & $\mathbf{0 , 0 4}$ & - & \\
\hline Medanal & $\mathbf{0 , 0 0 1}$ & $\mathbf{0 , 0 4}$ & - \\
\hline
\end{tabular}

d) Eligmodontia typus

\begin{tabular}{|l|c|c|c|}
\hline & Algarrobal & Jarillal & Medanal \\
\hline Algarrobal & - & & \\
\hline Jarillal & 0,48 & - & \\
\hline Medanal & $\mathbf{0 , 0 2}$ & $\mathbf{0 , 0 4 9}$ & - \\
\hline
\end{tabular}


Tabla 3. Probabilidades al comparar las diferencias de abundancias entre las especies de micromamíferos en a) algarrobal, b) jarillal y c) medanal de la Reserva de la Biósfera de Ñacuñán.

a) Algarrobal

\begin{tabular}{|l|c|c|c|}
\hline & C. musculinus & A. molinae & E. typus \\
\hline C. musculinus & - & & \\
\hline A. molinae & 0,11 & - & \\
\hline E. typus & 0,41 & 0,39 & - \\
\hline G. griseoflavus & $\mathbf{0 , 0 2}$ & 0.39 & 0,10 \\
\hline
\end{tabular}

b) Jarillal

\begin{tabular}{|l|c|c|c|}
\hline & C. musculinus & A. molinae & E. typus \\
\hline C. musculinus & - & & \\
\hline A. molinae & 0,416 & - & \\
\hline E. typus & 0,838 & 0,313 & - \\
\hline G. griseoflavus & 0,416 & 0,117 & 0,538 \\
\hline
\end{tabular}

c) Medanal

\begin{tabular}{|l|c|c|c|}
\hline & C. musculinus & A. molinae & E. typus \\
\hline C. musculinus & - & & \\
\hline A. molinae & 0,33 & - & \\
\hline E. typus & $<\mathbf{0 , 0 0 1}$ & $<\mathbf{0 . 0 0 1}$ & - \\
\hline G. griseoflavus & 0,65 & 0,60 & $<\mathbf{0 , 0 0 1}$ \\
\hline
\end{tabular}


Fig.1. Riqueza de especies de micromamíferos encontrada en cada hábitat de la Reserva de la Biósfera de Ñacuñán a lo largo del período de estudio (junio de 1999 - abril de 2001)

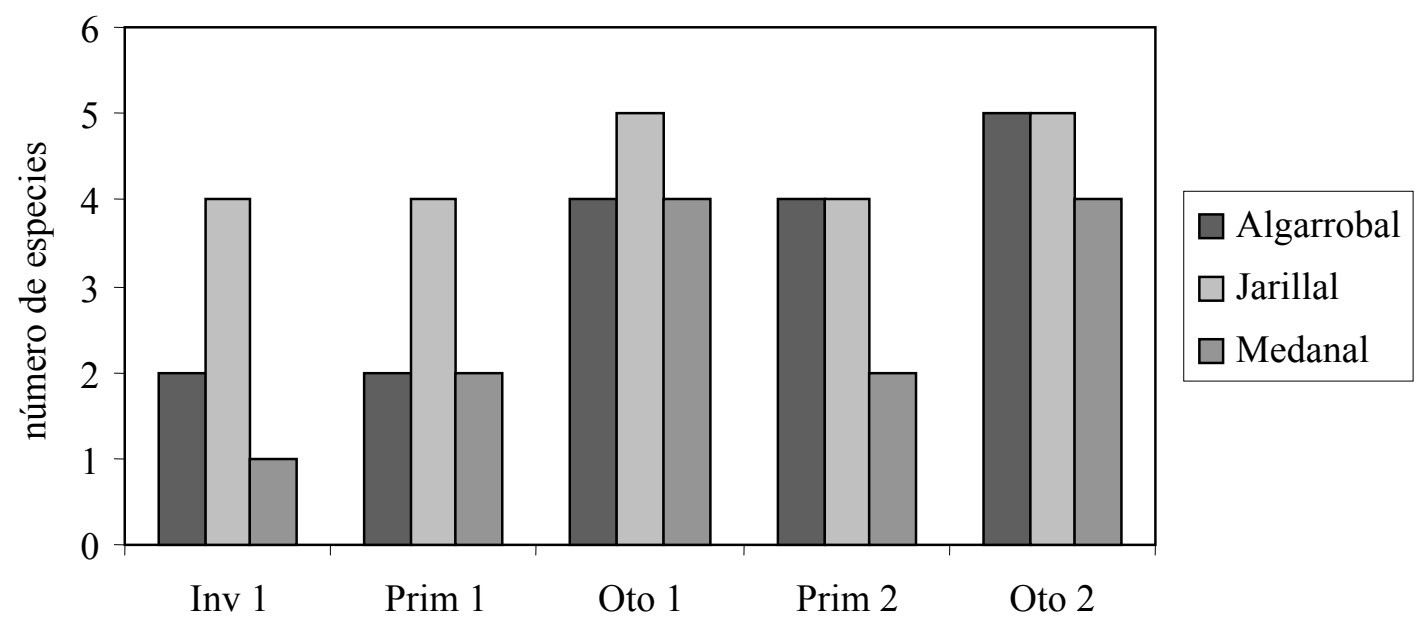


Fig. 2. Diversidad de micromamíferos en cada grilla a lo largo del periodo de estudio (junio de 1999 - abril de 2001) en la Reserva de la Biósfera de Ñacuñán

A: Algarrobal; J: Jarillal; M: Medanal

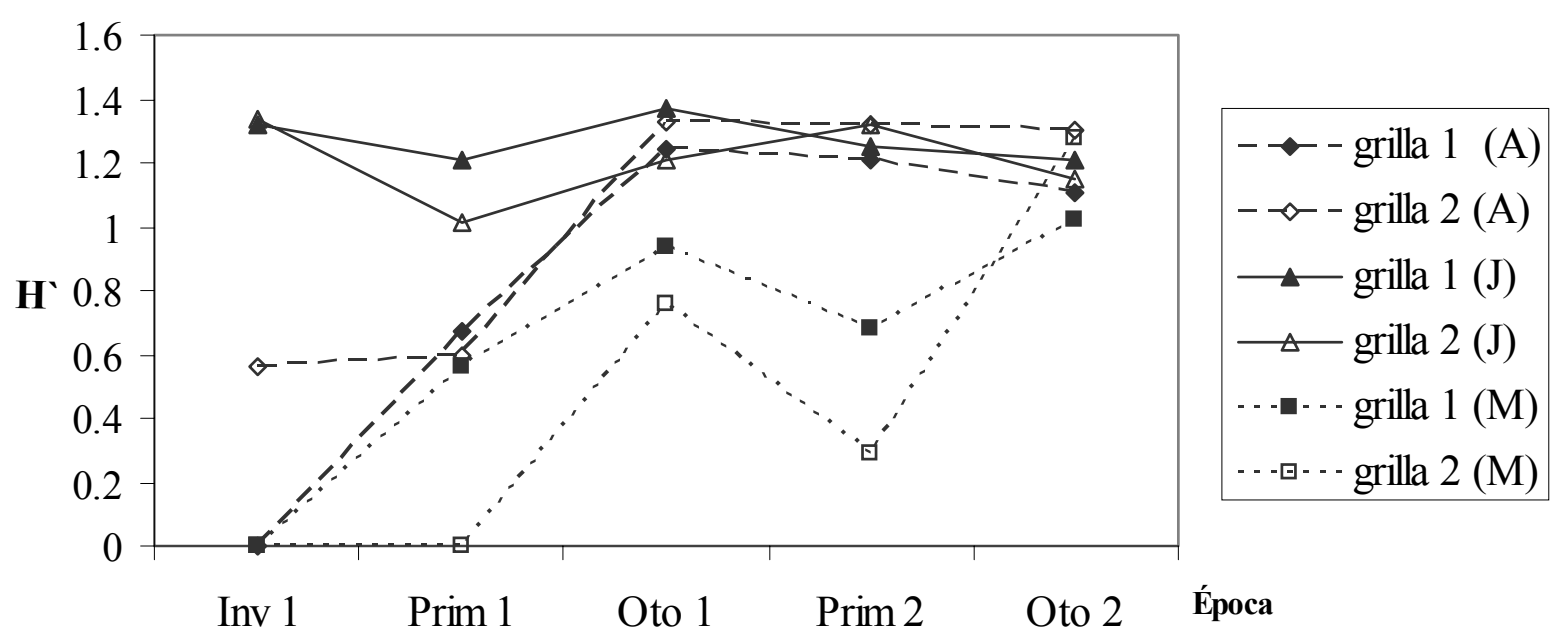


Fig. 3. Diversidad de especies de micromamíferos en relación a la heterogeneidad del hábitat en la Reserva de la Biósfera de Ñacuñán

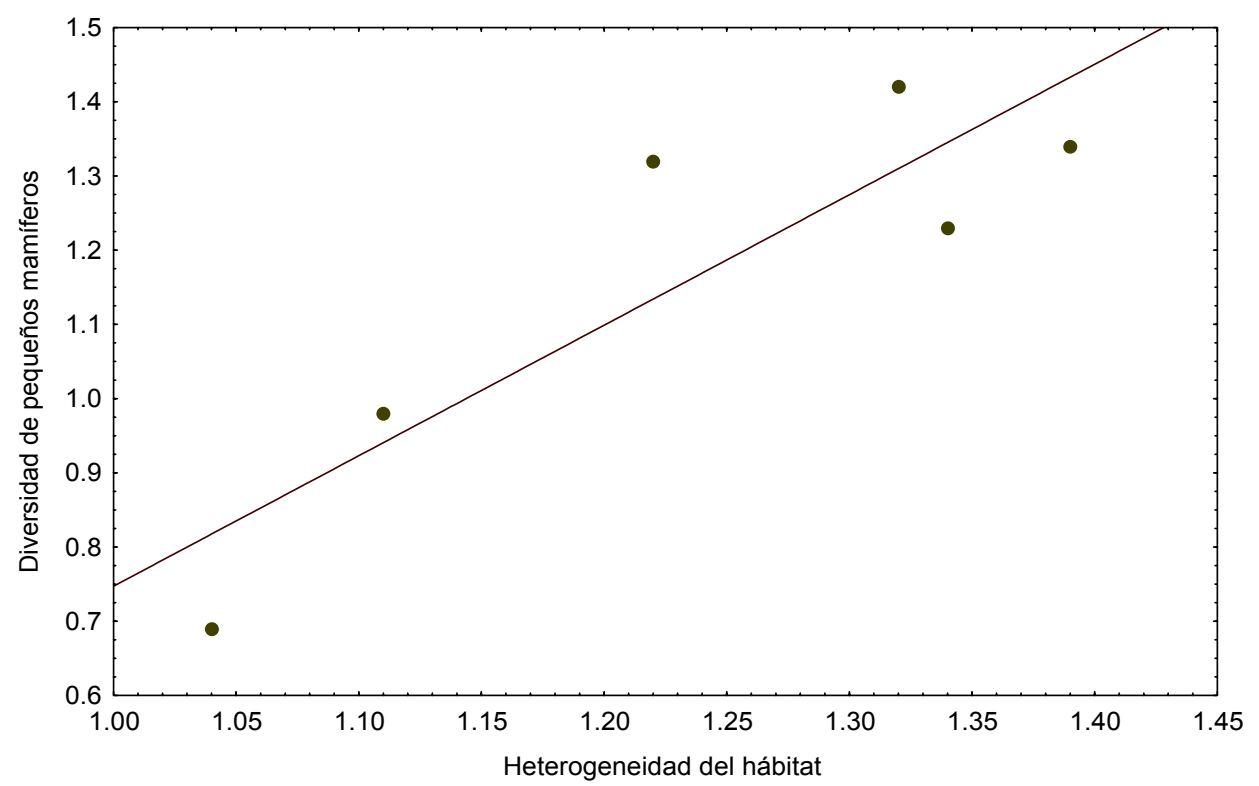


Fig 4. Densidad (ind./ha) de cada especie de micromamífero a lo largo del período de estudio (junio de 1999 - abril de 2001)

a) Algarrobal; b) Jarillal; c) Medanal

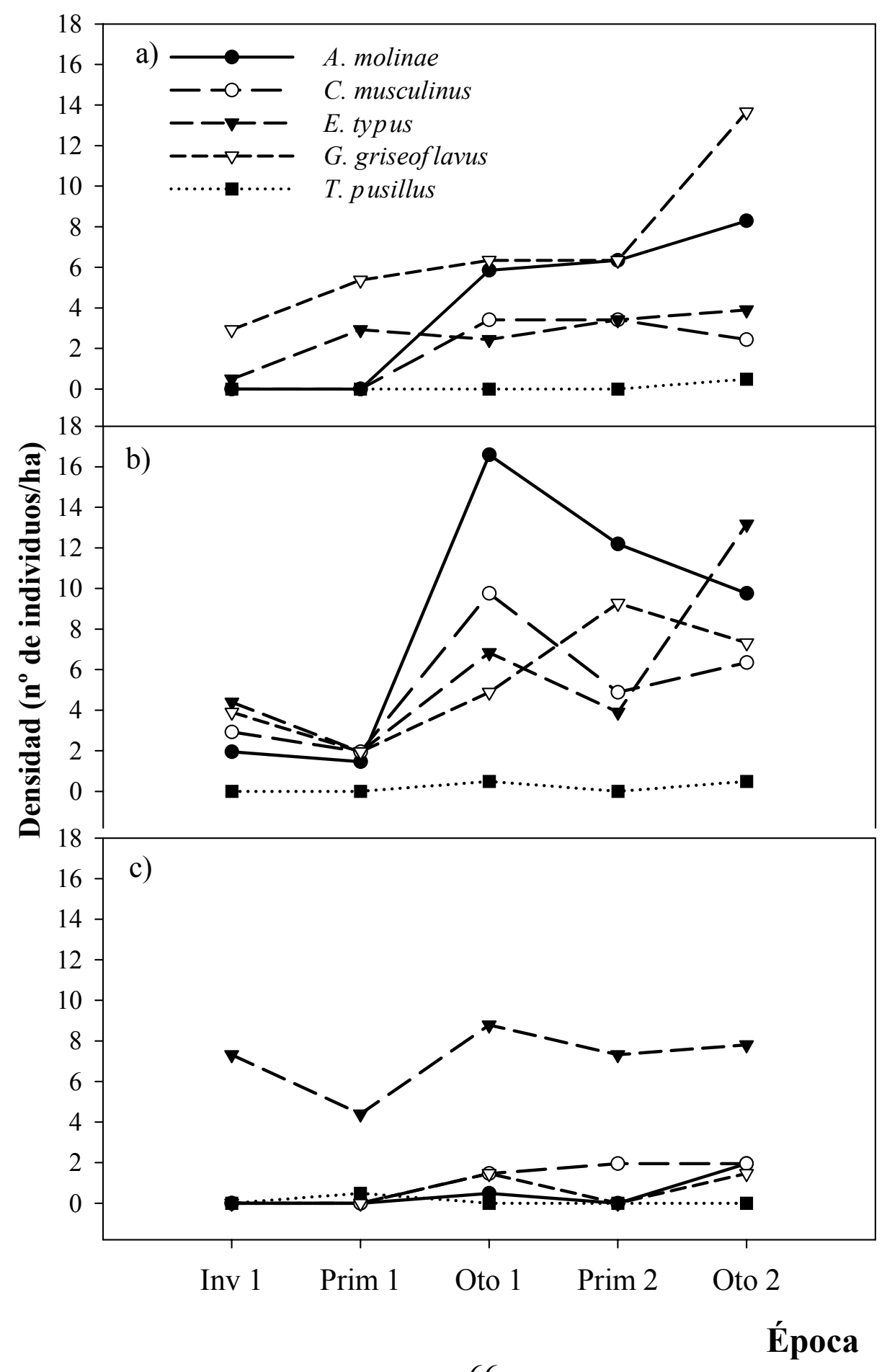


Fig. 5. Biomasa de cada especie de micromamífero em cada hábitat de la Reserva de la Biósfera de Ñacunán a lo largo del período de estudio (junio de 1999 - abril de 2001).

a) Algarrobal; b) Jarillal; c) Medanal

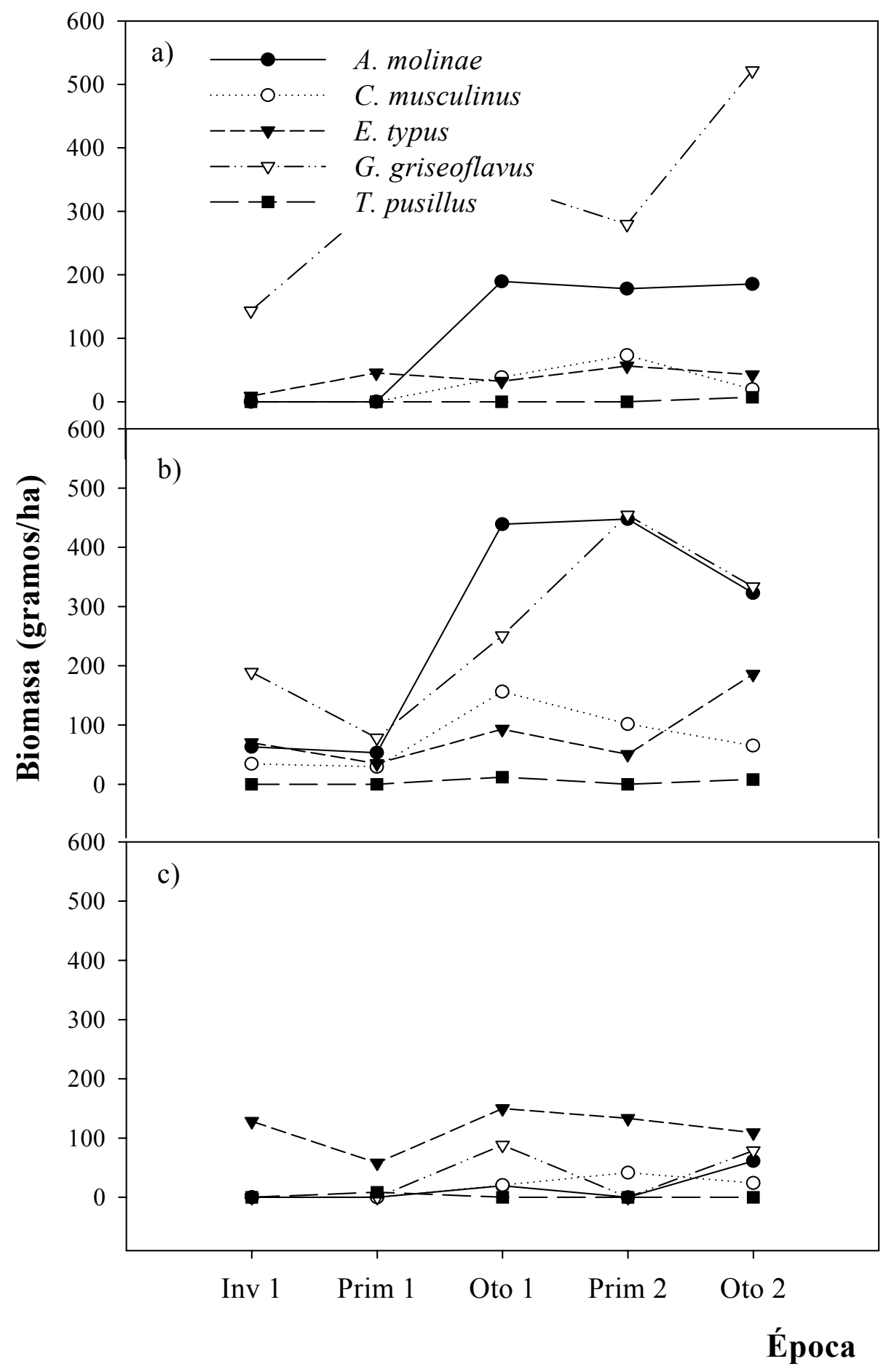


Fig. 6. Biomasa total de micromamíferos en cada grilla a lo largo del período de muestreo (junio de 1999 - abril de 2001)

A: Algarrobal; J: Jarillal, M: Medanal.

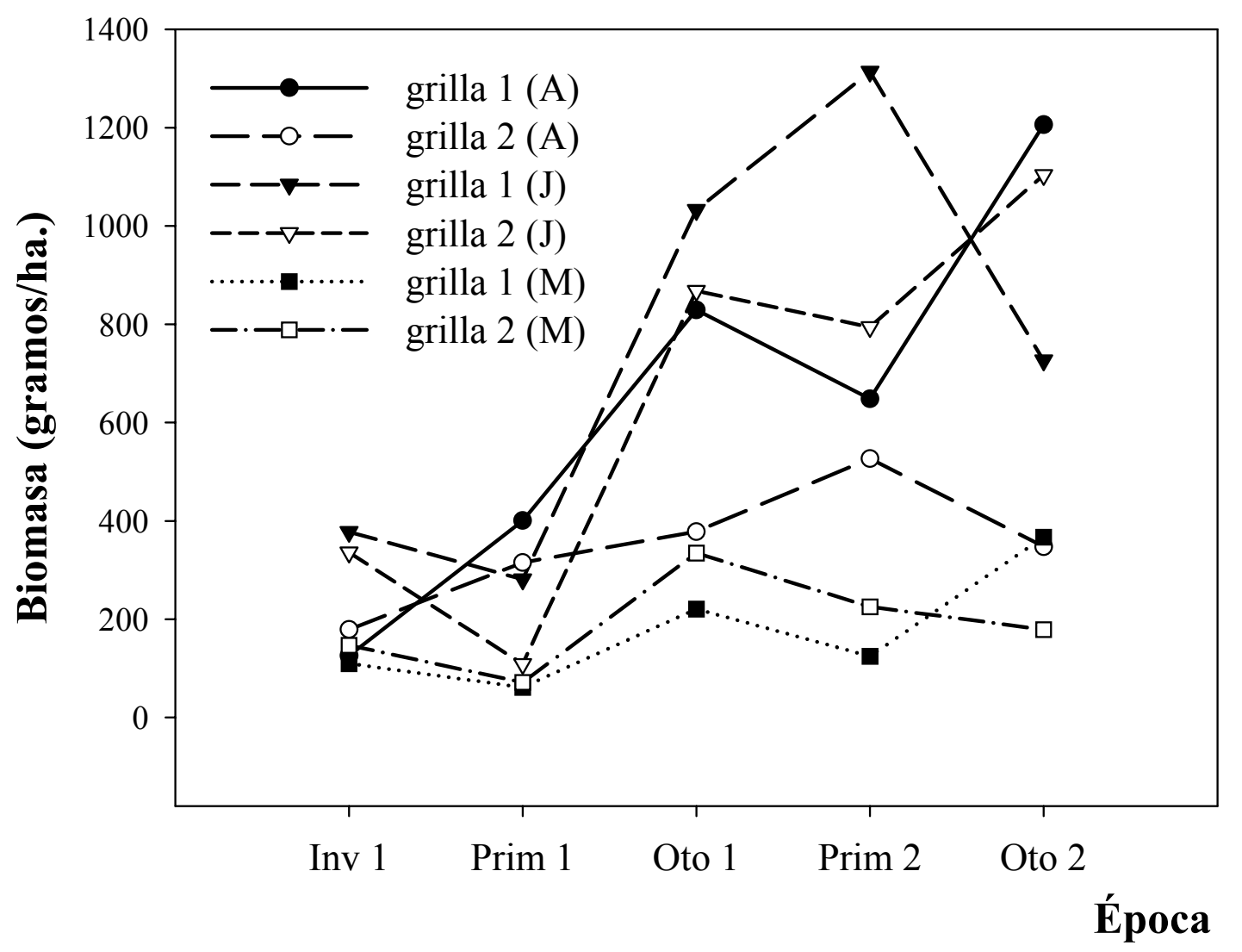


Fig. 7. Abundancia relativa de las especies de micromamíferos en cada hábitat de la Reserva de la Biósfera de Ñacuñán

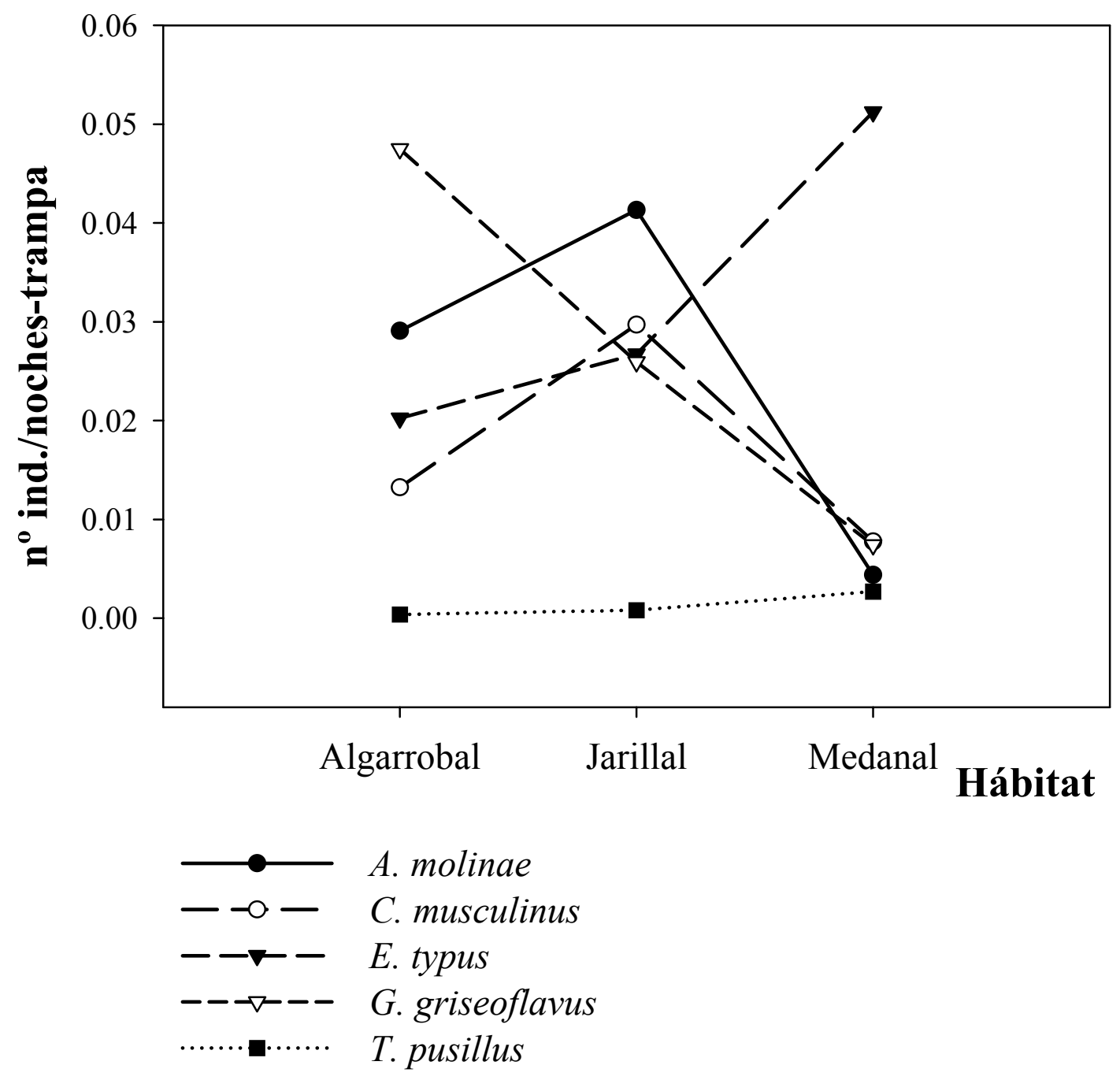


Capítulo 4

\section{ESTRUCTURA Y DINÁMICA DE LAS POBLACIONES DE MÚRIDOS}




\section{Capítulo 4. ESTRUCTURA Y DINÁMICA DE LAS POBLACIONES DE MÚRIDOS}

\subsection{INTRODUCCIÓN}

Como mostré anteriormente (capítulo 3), la comunidad de pequeños mamíferos del desierto del Monte difiere, en términos de abundancia relativa de las especies componentes, entre los distintos hábitats estudiados. Es decir, que la heterogeneidad que caracteriza a los sistemas desérticos se ve reflejada en las distintas poblaciones animales. De acuerdo a la teoría de selección de hábitat de Fretwell y Lucas (1970), las especies pueden distinguir entre hábitats de distintas calidades (Sutherland, 1996), estableciéndose en aquellos donde maximizan su éxito reproductivo (o fitness). La sóla presencia de una población en un hábitat, sin embargo, no necesariamente implica que sea el más adecuado para esa especie (Pulliam, 2000; Van Horne, 1983; Winker et al., 1995). Cuando existen movimientos de dispersión, es posible que hábitats subóptimos en un momento dado sustenten una mayor densidad de individuos que los hábitats óptimos, debido a la migración desde éstos (Bissonette y Broekhuizen, 1995). Por lo tanto, la densidad poblacional no es un indicador adecuado de calidad de hábitat (Loeb, 1999; Pulliam, 1988; Van Horne, 1983). Teniendo en cuenta que la ocupación de los hábitats dentro de la reserva difiere entre las distintas especies, aún cuando la composición de la comunidad es la misma, se podría esperar una diferencia en los atributos de cada población (estructura de edades, características reproductivas, proporción de sexos, supervivencia) al ser comparados entre los distintos hábitats. Las diferencias en la supervivencia y tasas reproductivas de animales en áreas con distintas características podría reflejar diferencias en la calidad de hábitat (Loeb 1999). En los hábitats donde las especies maximizan su fitness se esperaría una mayor proporción de hembras reproductivas así como mayor supervivencia (Diffendorfer, 1998). 
Con el fin de conocer cómo se comporta cada población que integra la comunidad de pequeños mamíferos del desierto del Monte en los distintos hábitats estudiados, se plantearon los siguientes objetivos:

- Conocer la estructura de edades de cada especie en cada hábitat

- Comparar la proporción de individuos reproductivamente activos entre los hábitats

- Conocer la relación de sexos dentro de cada hábitat y en especial durante la época reproductiva

- Conocer la supervivencia de las especies en cada hábitat 


\subsection{MATERIALES Y MÉTODOS}

\section{Metodología general}

Los datos utilizados para estimar los parámetros poblacionales de cada especie, provienen de la captura, marcado y recaptura de los individuos, metodología descripta en el capítulo 2. Para los análisis fueron incluidas la totalidad de las capturas de todas las especies, es decir, que los datos provienen de las 9386 noches-trampa.

\section{Estructura de edades}

Sobre el total de individuos capturados de cada especie por cada hábitat, se calculó la proporción de crías, juveniles y adultos. Las categorías de edades se establecieron sobre la base de los pesos y signos reproductivos. Se consideraron individuos de edad adulta a aquellos que presentaron signos reproductivos (hembras preñadas, machos con testículos escrotales) y a los individuos carentes de estas características pero de igual o mayor peso que éstos. La diferenciación entre crías y juveniles estuvo basada en el peso del individuo, cuya distinción fue realizada de manera subjetiva, debido a que no hay datos de ello en la bibliografía.

La siguiente tabla muestra los pesos de cada clase de edad para las distintas especies (en gramos):

\begin{tabular}{|l|l|l|l|l|}
\hline & E. typus & C. musculinus & A. molinae & G. griseoflavus \\
\hline cría & $1-8$ & $1-8$ & $1-14$ & $1-15.5$ \\
\hline juvenil & $9-14$ & $9-14$ & $15-29$ & $16-38$ \\
\hline adulto & $>15$ & $>15$ & $>30$ & $>39$ \\
\hline
\end{tabular}

Para determinar si existen diferencias entre las distintas clases de edad en cada hábitat, se realizó un test $G$. 
Luego se compararon las frecuencias de juveniles y adultos de cada especie dentro de cada hábitat usando la prueba binomial. Para un tamaño de muestra grande ( $>25)$, se utilizó la corrección de continuidad (Siegel, 1991).

\section{Reproducción}

A fin de determinar si hay diferencias en la cantidad de individuos reproductivos (R) y no reproductivos (NR) entre los tres hábitats, se compararon las frecuencias observadas de los individuos pertenecientes a cada una de estas categorías mediante un test $G$. Se denominó "reproductivos" a las hembras preñadas o con vagina abierta y a los machos con testículos escrotales o semi-escrotales y "no reproductivos" a aquellos individuos carentes de estas características.

Para establecer la época reproductiva de cada especie se analizó la proporción de individuos adultos en estado reproductivo y no reproductivo en cada época del año, mediante regresión logística (MLG).

\section{Relación de sexos}

La relación de sexos fue determinada en primer término a nivel general (cantidad de individuos adultos machos y hembras en cada hábitat). Luego esta relación fue comparada sólo durante la época reproductiva. En ambos casos se utilizó la prueba binomial, con la corrección de continuidad cuando N > 25 (Siegel, 1991)

\section{Medidas de persistencia}

La persistencia o supervivencia de los individuos en cada hábitat se estimó sobre la base del número de individuos "residentes" (encontrados en 2 o más campañas de muestreo) y al "tiempo de residencia" (cantidad de tiempo transcurrido entre la primera y la última captura) (Loeb, 1999). Debido a la desigualdad entre los días transcurridos entre diferentes campañas de muestreo, el tiempo de residencia de 
cada individuo en cada hábitat fue asignado a categorías determinadas de modo subjetivo. Se reconocieron 10 categorías: 1) 15 a 30 días, 2) 31 a 60 días, 3) 60 a 100 días, 4) 101 a 150 días, 5) 151 a 200 días, 6) 201 a 250 días, 7) 251 a 300 días, 8) 300 a 400 días, 9) 401 a 500 días y 10) más de 500 días. 


\subsection{RESULTADOS}

\section{Estructura de edades}

Se ha encontrado una baja proporción de crías de todas las especies. En el algarrobal se destacó C. musculinus por el alto porcentaje de esta clase de edad, llegando a conformar el 20\% del total de individuos capturados (Fig.1).

La comparación entre las distintas clases de edad sólo pudo realizarse entre juveniles y adultos, debido a que la baja frecuencia de las crías (en muchos casos el valor fue 0) no permitió la realización del test $G$. Comparando la cantidad de juveniles y adultos entre los tres hábitats sólo fue significativamente diferente para E. typus $(G=19 ;$ g.l. $=2 ; p<0,001)$. La figura 1 muestra que en el medanal hay mayor proporción de adultos, mientras que en el jarillal hay mayor proporción de juveniles de esta especie.

Dentro de cada hábitat, la cantidad de adultos fue significativamente mayor que la de juveniles de A. molinae en el jarillal ( $p<0,001 ; \mathrm{n}=142$ ), de E. typus en el algarrobal $(p=0,03 ; \mathrm{n}=53)$ y en el medanal $(p<0,001 ; \mathrm{n}=141)$ y de $G$. griseoflavus en los tres hábitats ( $p<0,001$ en todos los casos; $\mathrm{n}=119$ en algarrobal, $\mathrm{n}=96$ en jarillal, $\mathrm{n}=21$ en medanal). En cambio, la cantidad de juveniles de $C$. musculinus fue mayor que la de adultos en el jarillal $(p=0,04 ; \mathrm{n}=96)$.

\section{Reproducción}

La cantidad de individuos adultos en estado reproductivo y en estado no reproductivo no difirió entre hábitats para $A$. molinae $(G=3,58$; g.l. $=2 ; p=0,17)$, C. musculinus $(G=3,56$; g.1. $=2 ; p=0,17)$ ni $G$. griseoflavus $(G=2,65$; g.l. $=2$; $p=0,26)$. E. typus, en cambio, mostró diferencias significativas entre individuos $\mathrm{R}$ y NR entre hábitats $(G=10$; g.l. $=2 ; p=0,007)$. La figura 2 demuestra que en el medanal hay más cantidad de individuos adultos de esta especie en estado reproductivo con respecto a los demás hábitats. 
Al analizar separadamente los sexos, no se encontraron diferencias significativas entre los individuos machos R y NR de $A$. molinae $(G=1,49 ;$ g.1. $=2$; $p=0,47)$, E. typus $(G=1,18 ;$ g.l. $=2 ; p=0,55)$ ni de G. griseoflavus $(G=3,27$; g.l. $=2 ; p=0,19)$. Esta comparación no pudo realizarse para $C$. musculinus debido a la ausencia de individuos machos reproductivos en el medanal. Al comparar las hembras adultas R y NR sólo se encontraron diferencias significativas para E. typus $(G=13,14$; g.l. $=2 ; p=0,001)$. En la figura 3 puede observarse que la mayor cantidad de hembras $\mathrm{R}$ de esta especie pertenecen al medanal.

Los individuos en estado reproductivo de C. musculinus se encontraron principalmente en otoño ( $p=0,015)$, mientras que A. molinae y G. griseoflavus poseen más individuos reproductores en primavera respecto a las otras épocas ( $p<$ 0,001 en ambos casos). E. typus posee más individuos reproductivos en primavera y verano ( $p<0,001$; Fig. 4$)$.

\section{Relación de sexos}

En ningún caso se encontró un número de hembras significativamente mayor que el de machos al comparar las frecuencias totales de adultos en cada hábitat. En cambio, se encontró mayor cantidad de machos de E. typus y G. griseoflavus en el jarillal y en el medanal (Tabla 1).

Durante la época reproductiva, no hubo diferencias significativas entre machos y hembras adultos en ningún hábitat para ninguna especie. Sólo $A$. molinae mostró diferencias marginalmente significativas en el jarillal, con una relación hembra-macho 2:1 $(p=0,05 ; \mathrm{n}=30)$.

\section{Persistencia}

En general, la proporción de individuos "residentes" es baja en todos los hábitats. De los individuos residentes de A. molinae ( $\mathrm{n}=24)$, el 35,5\% permaneció de 151 a 200 días (categoría 5) en las grillas del jarillal y el 20,83\% en la misma 
categoría en el algarrobal. Los individuos que más tiempo permanecieron en el campo, tanto en el jarillal como en el algarrobal, lo hicieron aproximadamente durante 345 días (Fig. 5a). De un total de 6 individuos residentes de C. musculinus, dos permanecieron por 190 días en el algarrobal, mientras que el máximo tiempo de permanencia fue registrado en un individuo en el jarillal por un término de aproximadamente 255 días (Fig. 5b). El mayor número de individuos residentes de E. typus pertenecieron al medanal $(56,52 \%)$. Nunca se encontraron individuos de esta especie por término mayor a 200 días, siendo estos registros máximos provenientes también del medanal (Fig. 5c). G. griseoflavus fue la especie con mayor número de individuos residentes encontrados $(\mathrm{n}=31)$, la mayoría provenientes del jarillal y algarrobal; en este último hábitat, un individuo permaneció por 510 días aproximadamente (Fig. 5d). 


\subsection{DISCUSIÓN}

Los resultados revelan que las poblaciones de las especies de múridos muestran diferencias en alguno de los parámetros estudiados (estructura de edades, individuos reproductivos, proporción de sexos, supervivencia) cuando éstos son comparados entre los tres hábitats característicos de la reserva. La especie que mostró mayor diferencia en estos parámetros fue E. typus, mientras que $C$. musculinus sólo presentó diferencias en la proporción de crías, siendo éstas más abundantes en el algarrobal. La cantidad de adultos de E. typus fue mayor en el medanal. En este hábitat, además, presentó mayor proporción de individuos reproductivos (especialmente hembras), así como mayor tiempo de permanencia y mayor número de individuos residentes. A. molinae presentó más adultos que juveniles en el jarillal y una relación de sexos donde la cantidad de hembras duplica la cantidad de machos durante la época reproductiva en este mismo hábitat. Los parámetros de supervivencia indicarían que, para esta especie, tanto el tiempo de permanencia como el número de residentes es mayor en el algarrobal y en el jarillal respecto al medanal. La proporción de adultos de G. griseoflavus fue mayor que la de juveniles en los tres hábitats, pero la supervivencia fue mayor en el algarrobal y en el jarillal, sin encontrarse diferencias en cuanto a la proporción de individuos reproductivos ni de sexos.

Las tasas de reproducción y superviviencia de las especies varían en respuesta a las condiciones ambientales, reflejando la calidad del hábitat (Van Horne, 1983). La mayor proporción de individuos en estado reproductivo en un hábitat podría indicar que es el más favorable para la especie en consideración (Loeb, 1999; Ritchie, 1997). Lo mismo ocurre con el porcentaje de crías; un alto número de ellas indicaría una mayor tasa de reproducción en ese hábitat. Por otro lado, en los mejores hábitats, suele ocurrir una mayor tasa de adultos que de juveniles. Dado que los juveniles son considerados subdominantes en comparación con los adultos, se podría esperar que un hábitat favorable se identifique por una 
alta frecuencia de adultos, mientras que altas frecuencias de juveniles se podrían asociar a un hábitat desfavorable, por ser estos individuos expulsados de los mejores hábitats por competencia intraespecífica (Van Horne, 1982).

La relación entre sexos (de adultos) y el tiempo de permanencia de los individuos dentro del hábitat también serían buenos indicadores de calidad de hábitat (Lidicker, 1995; Loeb, 1999). En general, en los mejores hábitats, la relación de sexos favorece a las hembras durante la época reproductiva (Lidicker, 1995). Del mismo modo, la supervivencia también sería mayor (Diffendorfer, 1998; Doncaster et al., 1997; Loeb, 1999).

En los últimos años, ha habido un incremento de trabajos donde se intenta estimar, sobre la base de los parámetros estudiados, la calidad de hábitat para distintas especies. Así, surgió la teoría de "fuente-sumidero" (Pulliam y Danielson, 1991). Según la definición de hábitats "fuente" y "sumidero", en los hábitats más favorables (fuente) las tasas de natalidad exceden las tasas de mortalidad, mientras que en los hábitats "sumidero" las tasas de mortalidad exceden las tasas de natalidad (Pulliam y Danielson, 1991; Ritchie, 1997). Muchas veces es difícil distinguir nacimiento de inmigración, y muerte de emigración. Algunos autores (Lidicker, 1995) consideran que el hábitat fuente es aquel donde la tasa de emigración excede la tasa de inmigración y el hábitat sumidero es aquel donde la tasa de inmigración excede a la tasa de emigración. Para salvar este inconveniente otros autores estiman la tasa de desaparición, sin distinguir si se trata de muerte o emigración (Kreuzer y Huntly, 2003). Esta teoría asume que en los sumideros, las poblaciones no son viables en ausencia de inmigración. En oposición, Diffendorfer (1998) desarrolló la teoría de "dispersión balanceada", donde se asume que un número igual de individuos se mueve entre los distintos hábitats. Esta teoría invalida la existencia de los hábitats sumidero (Diffendorfer, 1998). Sin embargo, en sistemas reales embebidos en un paisaje, las poblaciones podrían describirse por una combinación de ambos modelos (Diffendorfer, 1998).

Cuando no se tienen datos de movimientos de las especies, no es fácil poder ajustar los datos a alguno de estos modelos. Además, cuando las densidades 
poblaciones son bajas, como es el caso de estudio, es difícil pensar que los individuos migran de un hábitat fuente a uno sumidero por haber un exceso de individuos en el primero.

Sin embargo, con los resultados obtenidos hasta aquí, se podría estimar cuál es el hábitat más apropiado para las especies de pequeños mamíferos. Si bien no todos los parámetros arrojaron diferencias significativas en todas las especies, se ve bastante clara una diferenciación entre E. typus y el resto de las especies. Mientras A. molinae y G. griseoflavus mostraron mayor supervivencia en el jarillal y en el algarrobal, E. typus lo hizo en el medanal. El resto de los parámetros también indicarían que este último hábitat es el de mejor calidad para E. typus. El mayor porcentaje de crías de C. musculinus en el algarrobal, indicaría que es el hábitat donde se reproduce esta especie, es decir, el de mejor calidad. Sin embargo, la supervivencia es mayor en el jarillal. Ambos hábitats serían los más adecuados para la especie, al ser comparados con el medanal.

Los resultados obtenidos sugieren que los hábitats donde ocurren las mayores abundancias poblacionales (ver capítulo 3) son percibidos por las especies como los hábitats de mejor calidad. 


\subsection{CONCLUSIONES}

Las principales conclusiones obtenidas a partir del estudio de la estructura poblacional de cada especie son las siguientes:

- La mayor proporción de individuos reproductivos, de hembras reproductivas, de individuos adultos, así como el mayor número de individuos residentes y el mayor tiempo de residencia de E. typus se encontró en el medanal. Esto indicaría que este hábitat es el de mejor calidad para esta especie.

- La mayor proporción de hembras de A. molinae durante la época reproductiva se ha encontrado en el jarillal. En este hábitat también se ha encontrado mayor proporción de adultos que de juveniles, así como mayor número de individuos residentes. El mayor tiempo de residencia fue registrado tanto en el jarillal como en el algarrobal. Estos hábitats, especialmente el jarillal, serían los más favorables para esta especie.

- La mayor cantidad de crías y de individuos residentes de C. musculinus en algarrobal indicarían que este hábitat sería el más favorable para esta especie. Sin embargo, el mayor tiempo de residencia se encontró en el jarillal.

- El mayor número de residentes de G. griseoflavus proviene del algarrobal y del jarillal, observándose el mayor tiempo de residencia en el algarrobal. Sobre la base estos parámetros de supervivencia, estos hábitats serían los más favorables para $G$. griseoflavus. 


\subsection{TABLAS y FIGURAS}

Tabla 1. Frecuencias de ocurrencia de cada sexo y probabilidad de rechazar la $\mathrm{H}_{0}$ de que la relación de sexos es $1: 1{ }^{*}$

\begin{tabular}{|l|l|c|c|c|c|}
\hline \multicolumn{2}{|l}{} & $\mathrm{n}$ hembras & $\mathrm{n}$ machos & $\mathrm{z}$ & $\mathrm{p}$ \\
\hline A. molinae & Algarrobal & 16 & 23 & -0.96077 & 0.17 \\
\cline { 2 - 6 } & Jarillal & 49 & 46 & -0.2052 & 0.42 \\
\cline { 2 - 6 } & Medanal & 1 & 6 & & 0.06 \\
\hline C. musculinus & Algarrobal & 9 & 5 & & 0.21 \\
\cline { 2 - 6 } & Jarillal & 17 & 22 & -0.64051 & 0.26 \\
\cline { 2 - 6 } & Medanal & 3 & 8 & & 0.11 \\
\hline E. typus & Algarrobal & 16 & 18 & -0.1715 & 0.43 \\
\cline { 2 - 6 } & Jarillal & 16 & 28 & -1.65831 & $\mathbf{0 . 0 4 9}$ \\
\cline { 2 - 6 } & Medanal & 41 & 64 & -2.14698 & $\mathbf{0 . 0 1}$ \\
\hline G. griseoflavus & Algarrobal & 47 & 49 & -0.10206 & 0.46 \\
\cline { 2 - 6 } & Jarillal & 32 & 51 & -1.97576 & $\mathbf{0 . 0 2}$ \\
\cline { 2 - 6 } & Medanal & 4 & 13 & & $\mathbf{0 . 0 2}$ \\
\hline
\end{tabular}

* El valor de z de la prueba Binomial fue calculado por medio de la corrección de continuidad para muestras de $\mathrm{N}>25$. 
Fig. 1. Proporción de edades de las especies de micromamíferos en cada hábitat de la Reserva de la Biósfera de Ñacuñán

a) A. molinae; b) C. musculinus; c) E. typus; d) G. griseoflavus

a) A. molinae

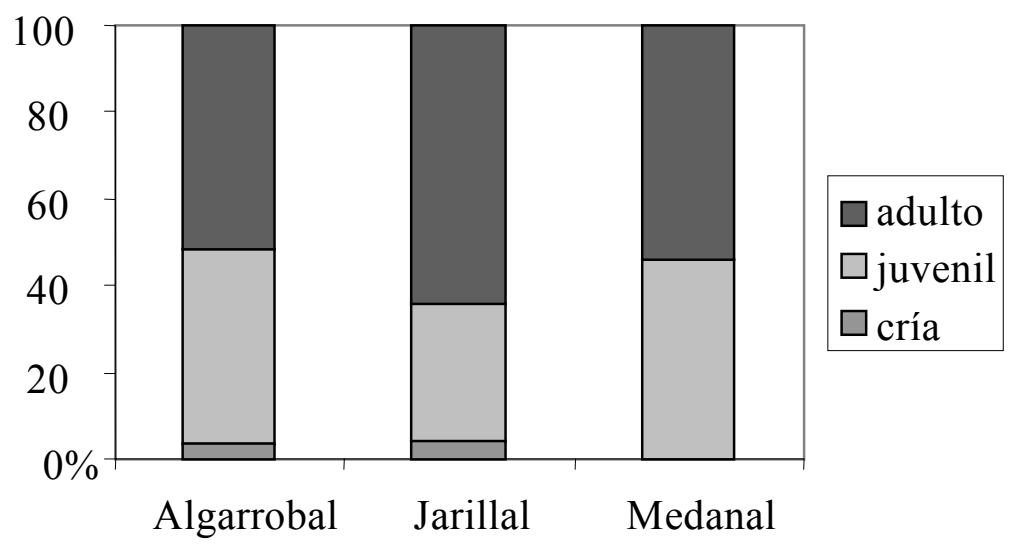

b) C. musculinus

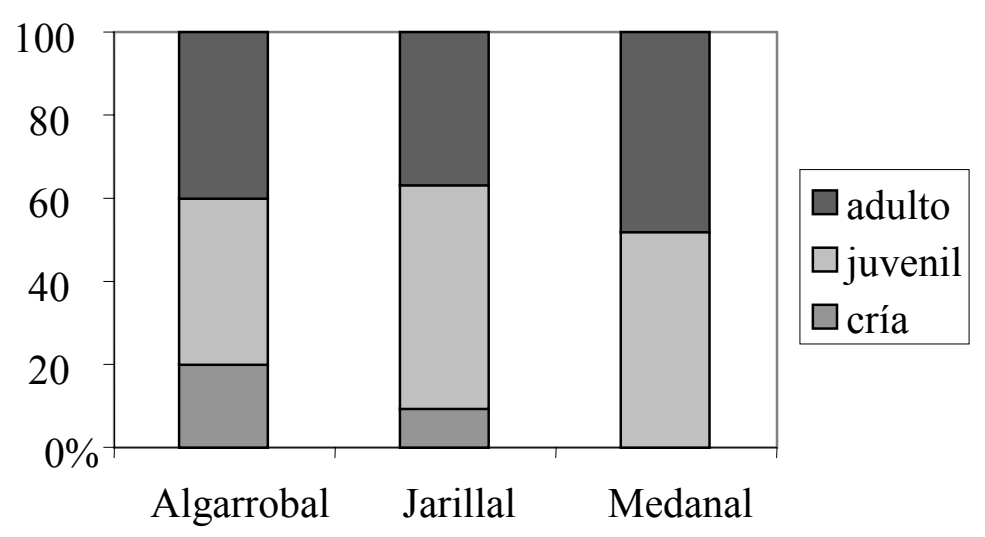


c) E.typus

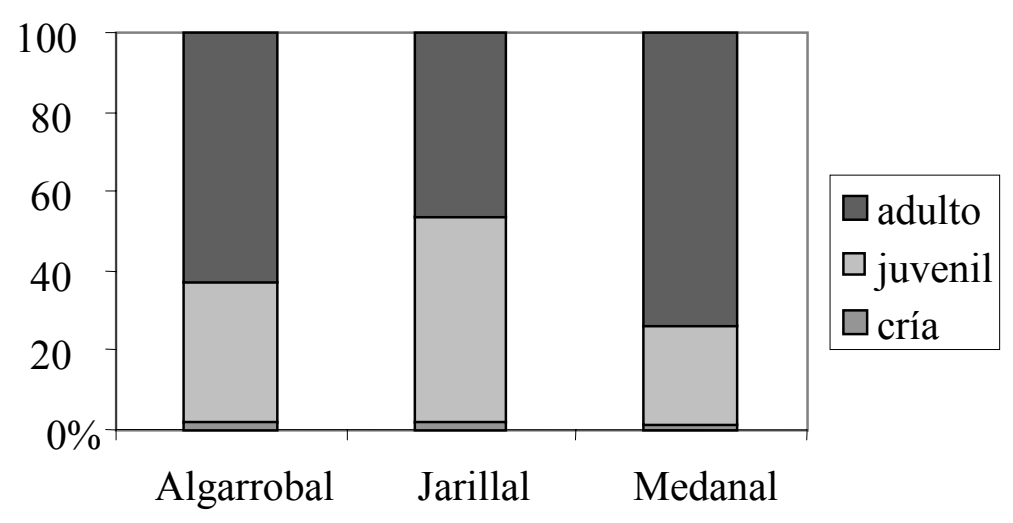

d) G. griseoflavus

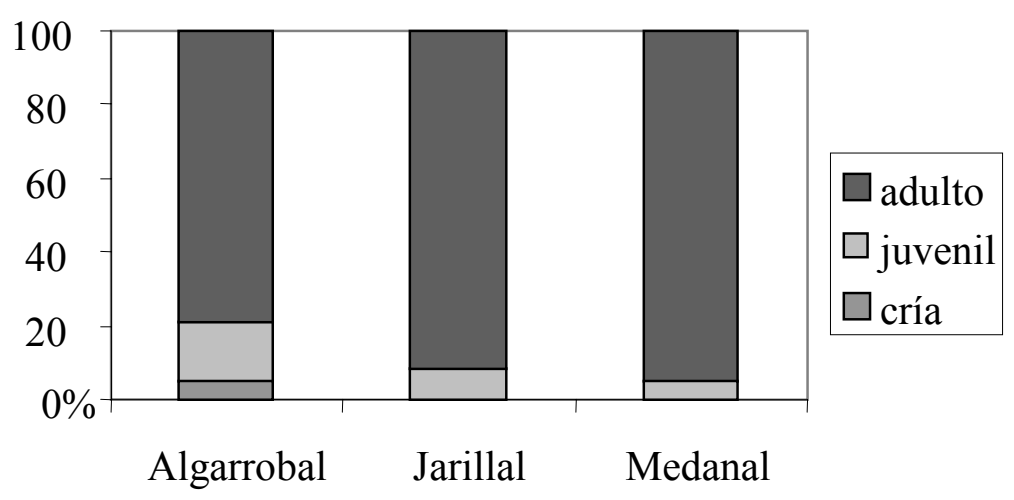


Fig. 2. Comparación de individuos reproductivos (R) y no reproductivos (NR) de $E$. typus entre los tres hábitats de la Reserva de la Biósfera de Ñacuñán

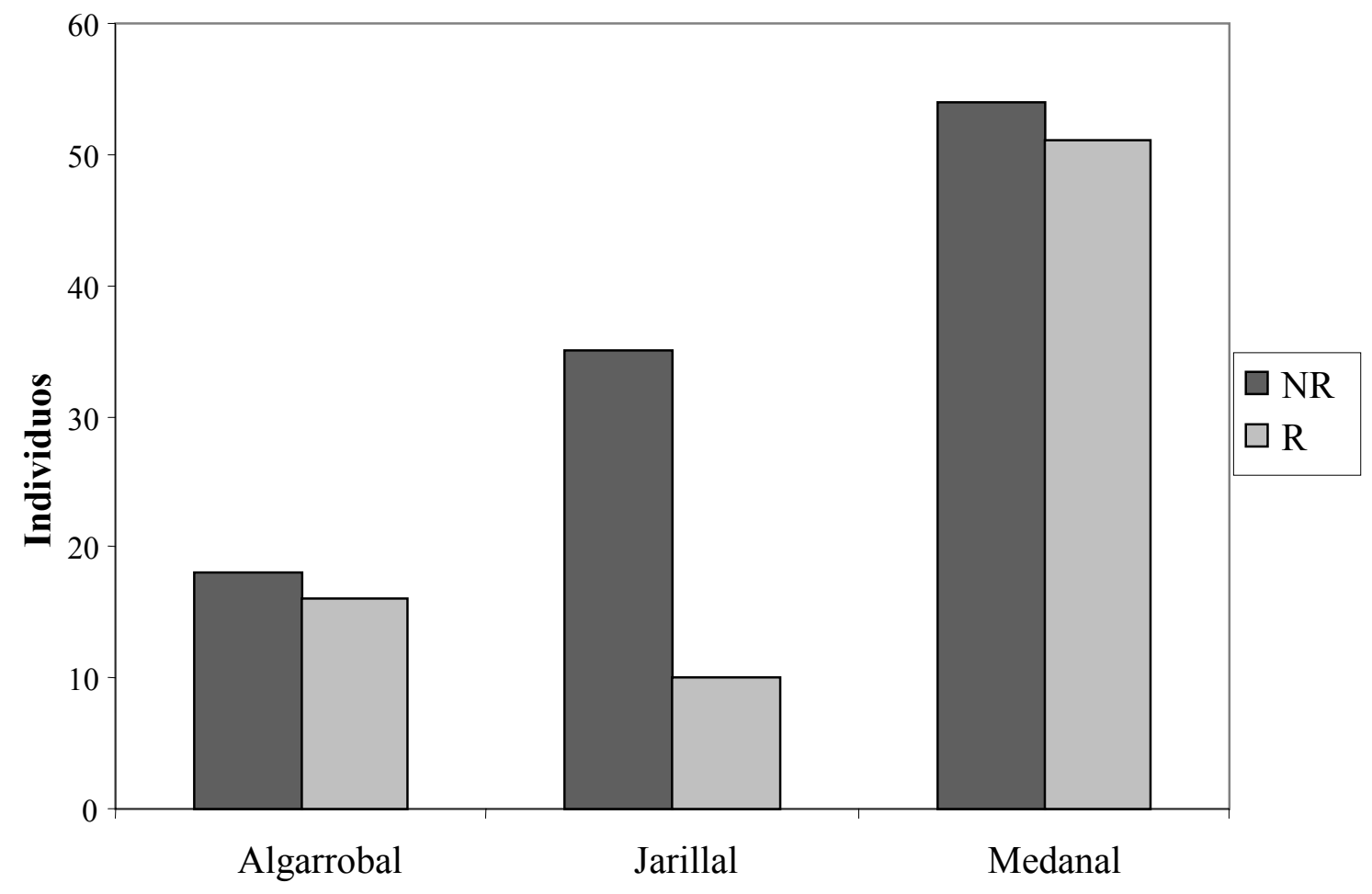


Fig. 3. Comparación de las hembras adultas en estado reproductivo (R) y no reproductivo (NR) de E. typus entre los tres hábitats de la Reserva de la Biósfera de Ñacuñán

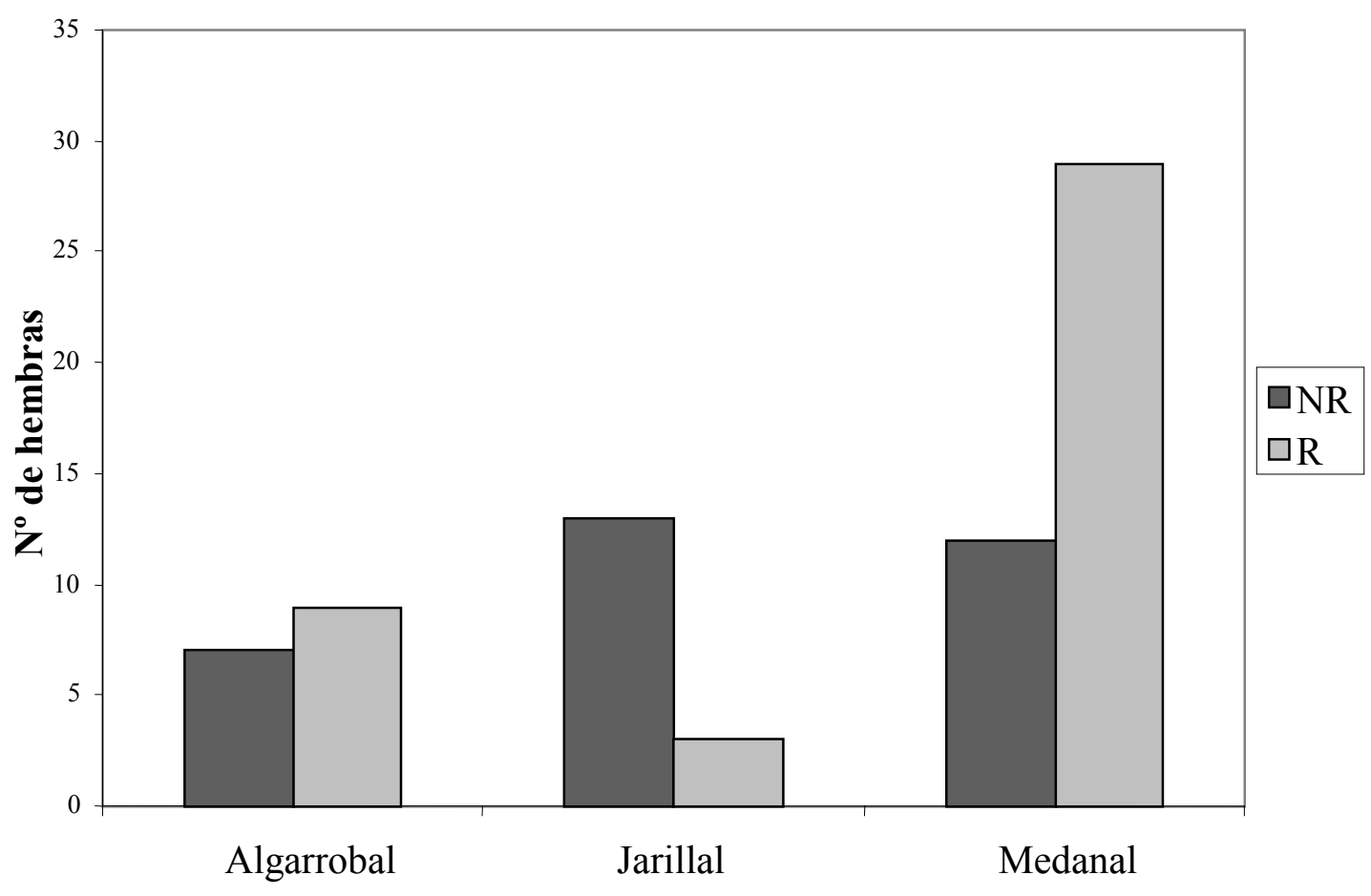


Fig. 4. Proporción de individuos reproductivos ( R ) y no reproductivos ( NR ) en cada hábitat de la Reserva de la Biósfera de Ñacuñán en las distintas épocas del año a) A. molinae

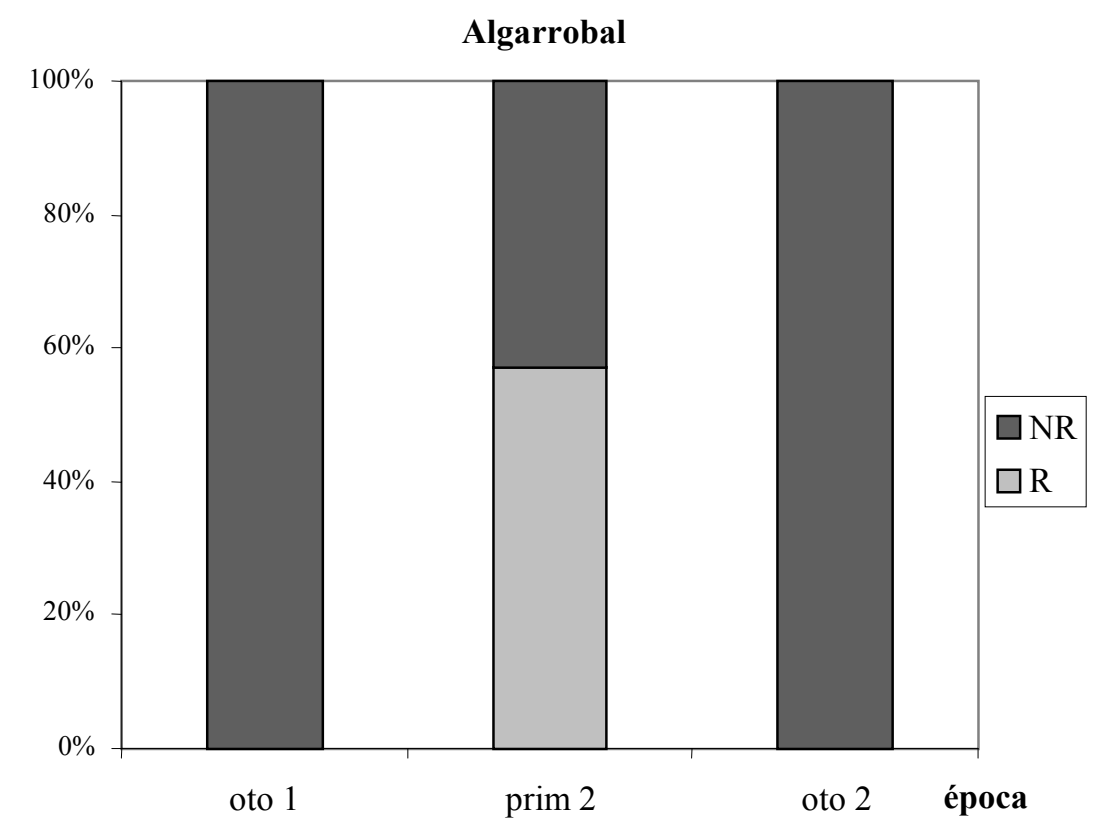

Jarillal

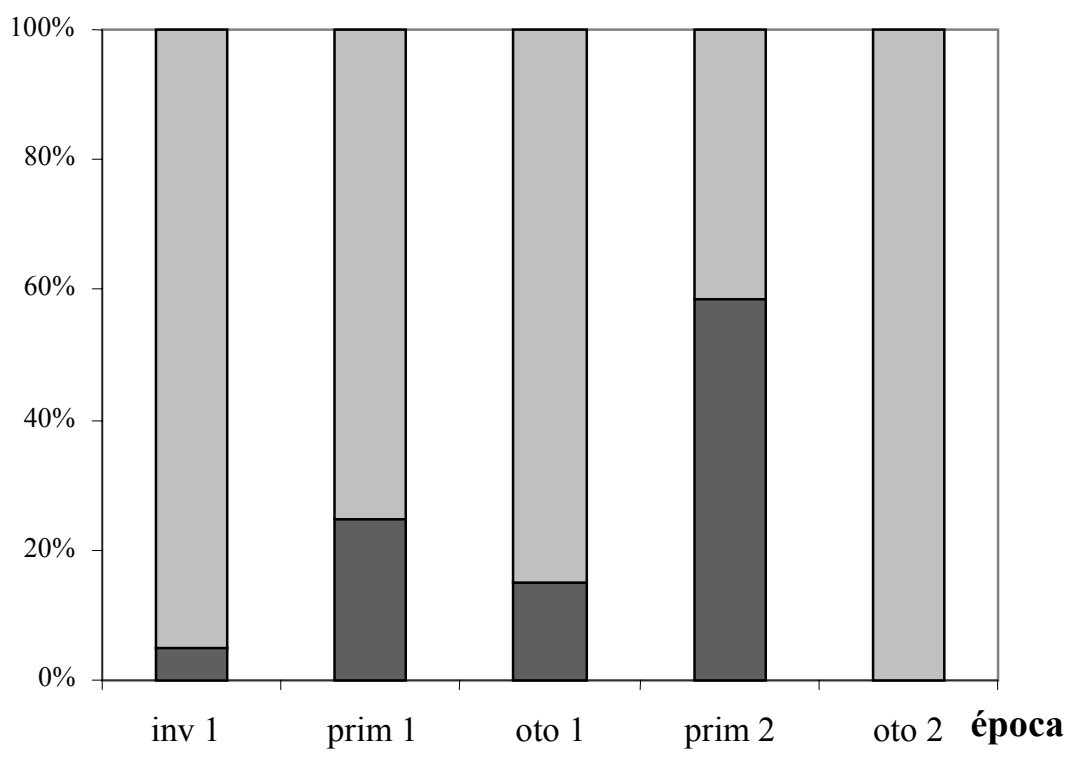


b) C.musculinus

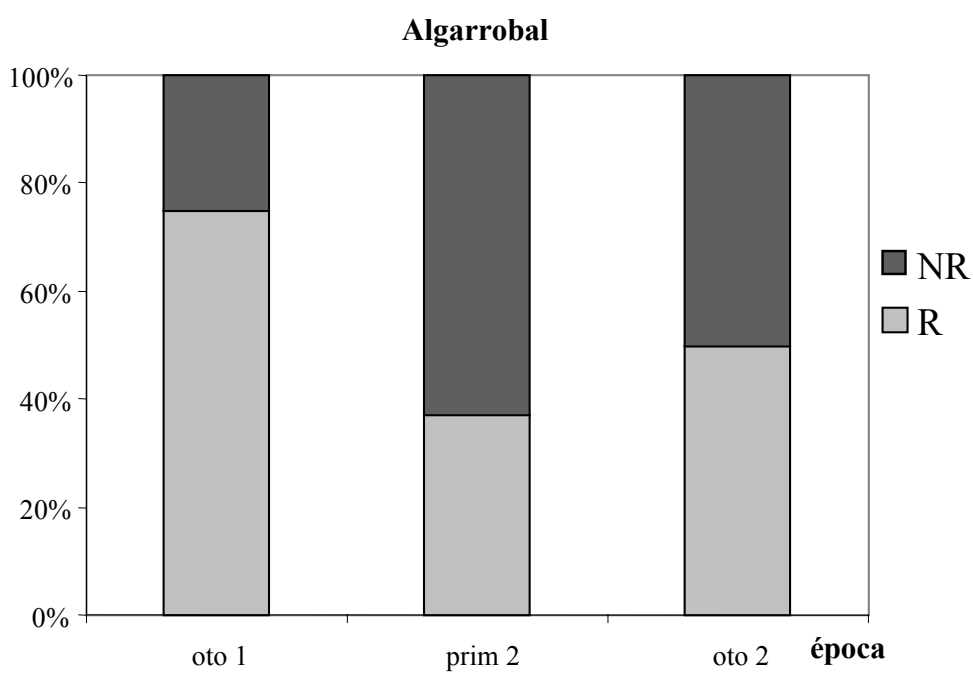

Jarillal

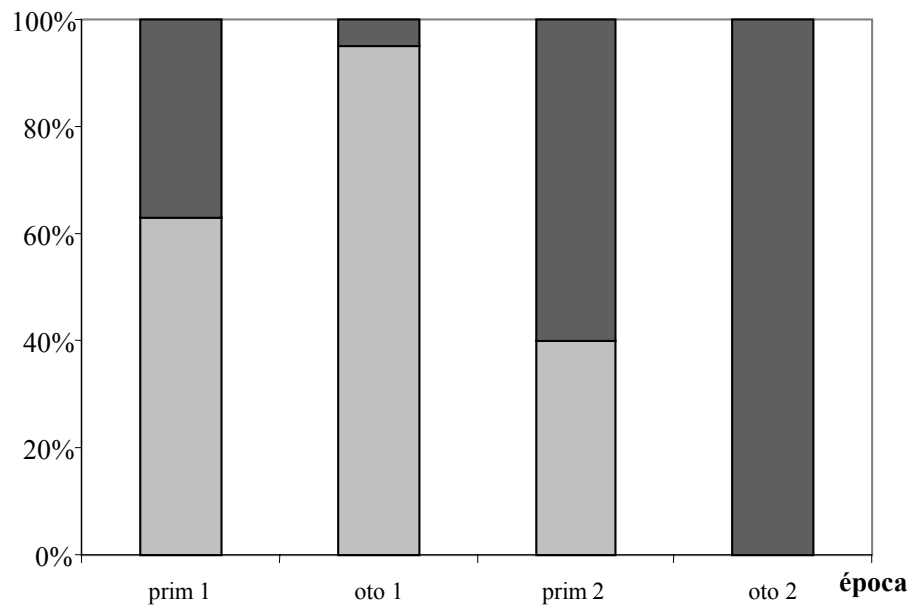

Medanal

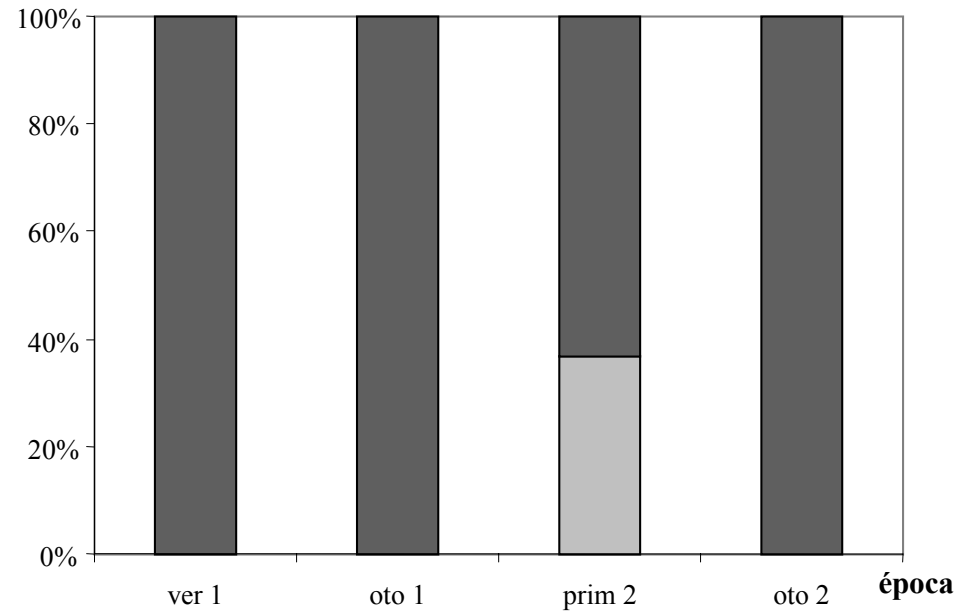


c) E. typus
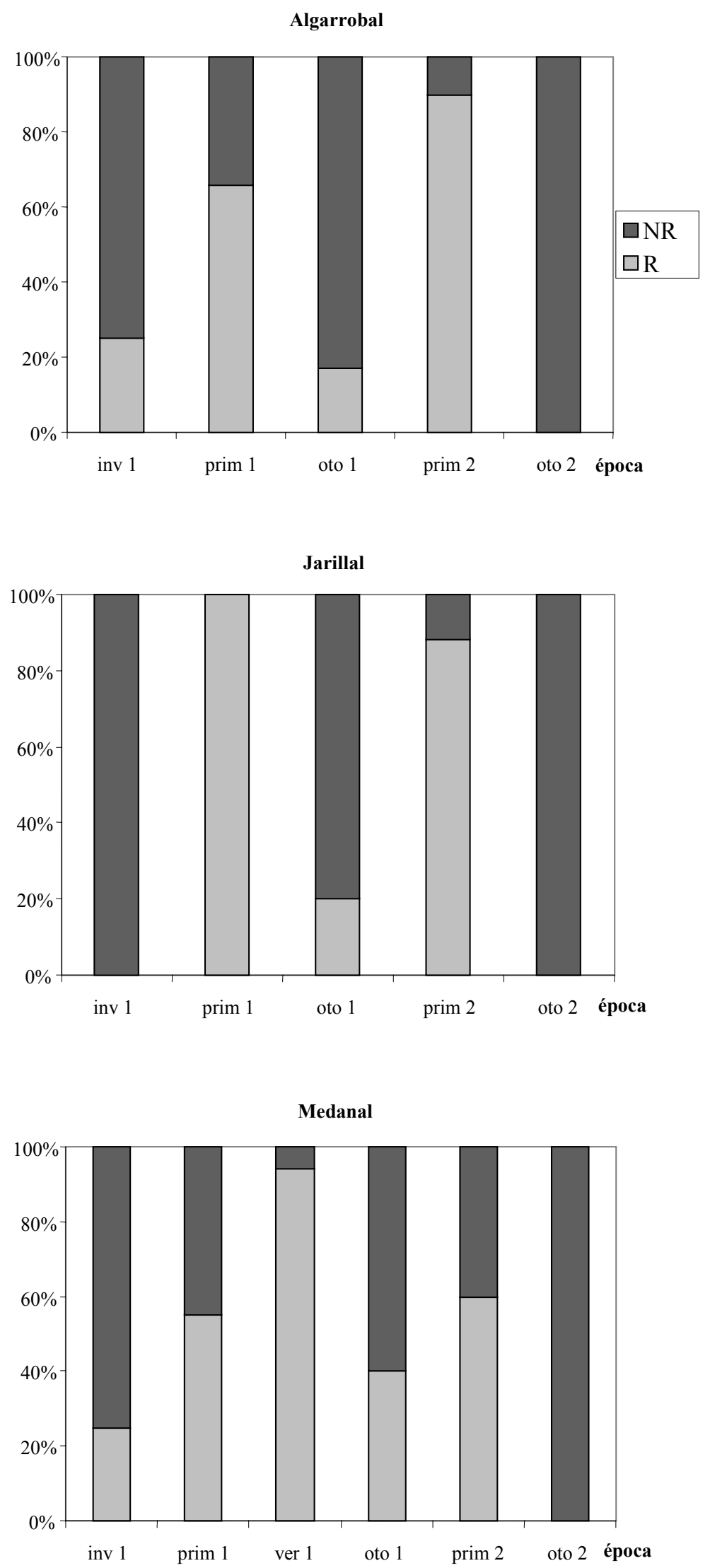
d) G. griseoflavus
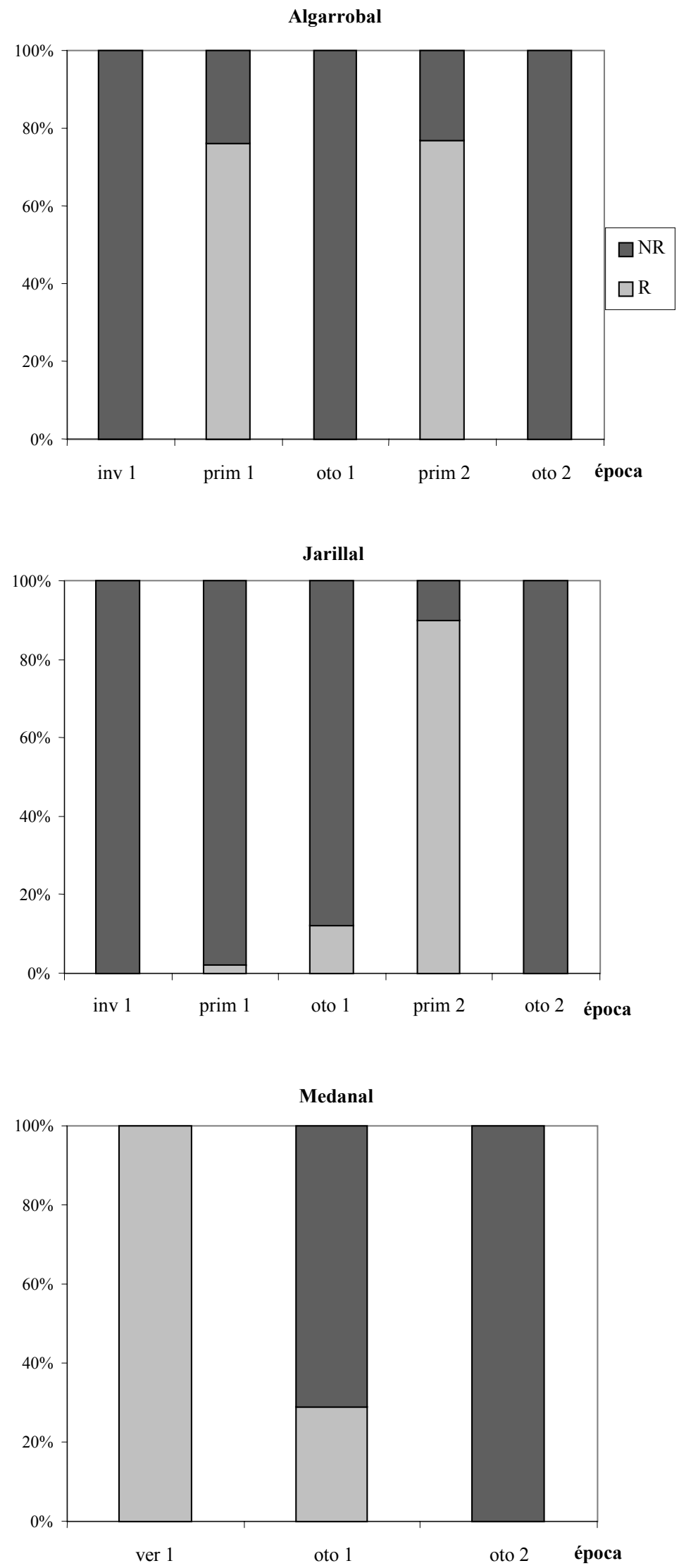
Fig. 5. Tiempo de permanencia de cada especie de micromamífero en los distintos hábitats de la Reserva de la Biósfera de Ñacuñán

Categorías: 1: 15 a 30 días; 2: 31 a 60 días; 3: 60 a 100 días; 4: 101 a 150 días; 5: 151 a 200 días; 6: 201 a 250 días; 7: 251 a 300 días; 8: 300 a 400 días; 9: 401 a 500 días y 10: más de 500 días

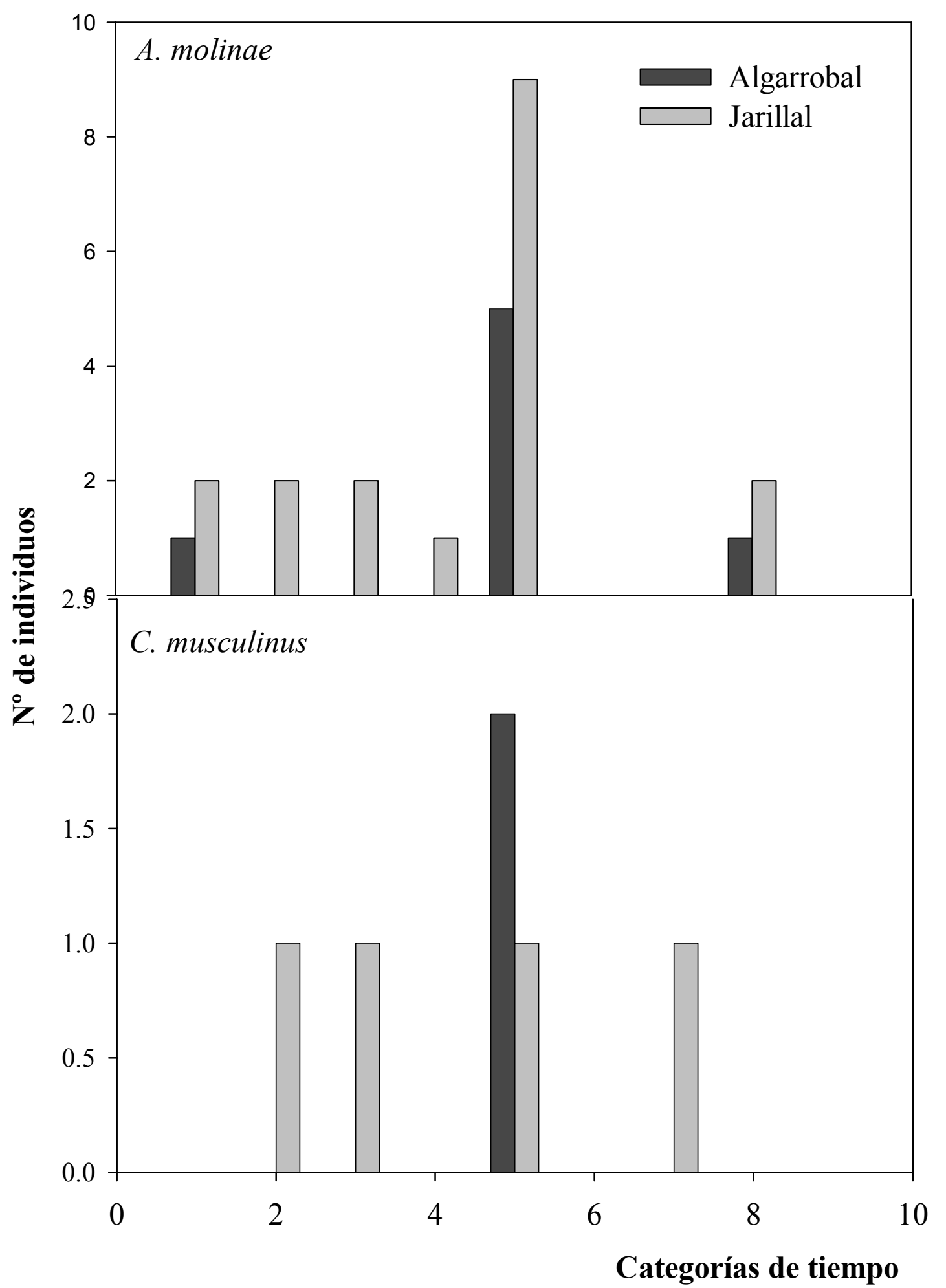


Fig 5. (Continuación)

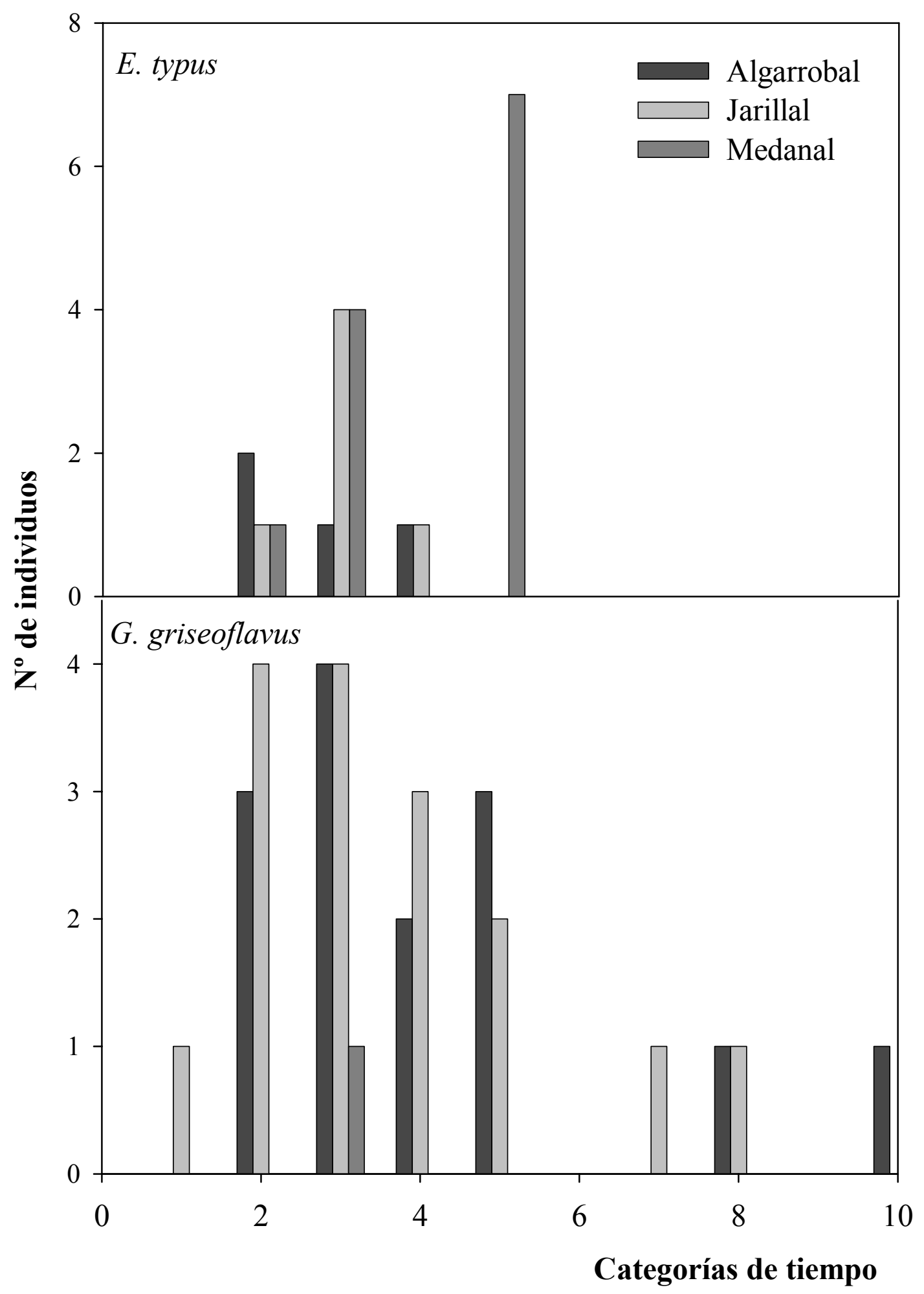


Capítulo 5

\section{SELECCIÓN DE HÁBITAT A DISTINTAS ESCALAS ESPACIALES}




\section{Capítulo 5. SELECCIÓN DE HÁBITAT A DISTINTAS ESCALAS} ESPACIALES

\subsection{INTRODUCCIÓN}

La coexistencia de especies relacionadas filogenética y ecológicamente puede ser el resultado de interacciones entre las poblaciones tales como competencia, depredación e incluso parasitismo. La competencia y el riesgo de depredación pueden resultar en una segregación de recursos, principalmente el hábitat y el alimento (Kotler, 1989; Kotler et al., 1994; Schoener, 1974; Stokes, 1995), los dos ejes del nicho de mayor importancia en mamíferos no carnívoros (Kalcounis-Rüppell y Millar, 2002; Schoener, 1974). La superposición de nichos está relacionada con la diversidad de especies presente en el área (May y MacArthur, 1972; M'Closkey, 1978; Pianka, 1972). M'Closkey (1978) menciona que en roedores de desierto, donde la diversidad es baja, la separación de nichos está positivamente correlacionada con la diversidad (siendo el tamaño de las semillas y las diferencias en el hábitat los responsables de esta separación). Brown (1975), contrariamente, observó que la diversidad de especies está acompañada de una mayor superposición de nichos. Estas diferencias en los resultados pueden atribuirse a diferencias en el diseño experimental, así como a diferencias en la diversidad estructural de los desiertos estudiados por ambos autores (M'Closkey, 1978). En las comunidades donde opera la segregación del espacio, es probable que cada especie seleccione un microhábitat particular.

Como fue explicado en el Capítulo 1, la selección de hábitat (es decir, la elección de un tipo de lugar donde vivir; Partridge, 1978) es un proceso jerárquico que involucra una serie de decisiones comportamentales innatas y aprendidas realizadas por un animal acerca del hábitat que usará a distintas escalas del ambiente (Hutto, 1985). Es decir, esta selección puede ocurrir tanto a nivel de macrohábitat como de microhábitat (Kotler y Brown, 1988). La importancia de la escala de medida a la que se aborda una investigación ha sido demostrada por varios 
autores, ya que puede influir en los resultados obtenidos y en su interpretación (Wiens, 1981, 1983, 1989). Por ejemplo, Morris (1987) encontró que el macrohábitat es un buen predictor de la densidad de roedores en zonas templadas, mientras que el microhábitat no lo es. Por otro lado, los factores ambientales que determinan la distribución local de la mayoría de los roedores de los desiertos de Asia pueden ser fácilmente identificados, mientras que los intentos de analizar las relaciones de las especies con el ambiente en las especies desérticas norteamericanas ha fracasado, siendo las correlaciones entre ambas variables muy bajas o inexistentes (Shenbrot et al., 1999). Consecuentemente, los análisis de uso de hábitat demuestran las condiciones que son evitadas pero no las que son preferidas. Esto indica que las especies de América del Norte perciben el ambiente como de grano fino, respondiendo a cambios sutiles en cada factor separado dentro de cada unidad de paisaje. En contraste, las especies asiáticas lo hacen de modo de grano grueso, respondiendo a cambios de factores complejos entre las unidades de paisaje (Shenbrot et al., 1999). Descubrir la escala a la cual los animales perciben su entorno es esencial para el entendimiento de la estructura de la comunidad (Cramer y Willig, 2002).

La vegetación es una variable importante que influye en la distribución de los roedores, ya que ofrece protección ante los depredadores y alimento debido a la mayor concentración de semillas que hay bajo los arbustos. Sin embargo, esto resulta cierto para los roedores granívoros de América del Norte, pero no para los sudamericanos que son omnívoros con tendencias no sólo hacia la granivoría sino también hacia la insectivoría o herbivoría.

Como se ha demostrado anteriormente, la abundancia de pequeños mamíferos es diferente en cada uno de los hábitats estudiados en esta porción del desierto del Monte, indicando que existe selección a esta escala. Sin embargo, aún no han sido consideradas las variables ambientales que determinan esta selección, ni se ha cuantificado la selección a nivel de microhábitat. Por lo tanto, los objetivos de este capítulo son: 
- Cuantificar las variables que caracterizan cada tipo de hábitat estudiado

- Determinar si ocurre selección de hábitat en los pequeños mamíferos y a qué nivel se produce la misma (macrohábitat - microhábitat)

a) Identificar las variables de microhábitat que determinan la selección.

b) Calcular el grado de selectividad al microhábitat de cada especie. 


\subsection{MATERIALES Y MÉTODOS}

\section{Caracterización del hábitat}

De acuerdo a la definición de hábitat como cualquier porción de la superficie de la Tierra donde una especie es capaz de colonizar y vivir (temporaria o permanentemente) con una densidad mayor que cero (Fretwell, 1972), se consideraron al "algarrobal", al "jarillal" y al "medanal", los tres macrohábitats de la Reserva, elegidos para estudiar la selección de los mismos por parte de los pequeños mamíferos. En cada uno de ellos se trazaron dos grillas de $7 \times 7$ estaciones de muestreo, donde se colocaron las trampas de captura viva para los roedores (ver capítulo 2).

Siguiendo el sistema de "Muestreo centralizado" de Mueller-Dombois y Ellenberg (1974), se registraron las variables de microhábitat en parcelas de $4 \mathrm{~m}^{2}$ circundantes a cada estación de trampeo. Las variables de microhábitat medidas fueron: cobertura de arbustos, cobertura de subarbustos, cobertura de herbáceas, cobertura de árboles, cobertura de mantillo, porcentaje de suelo desnudo, altura de herbáceas y altura del estrato más bajo. Cada una de estas variables fue medida independientemente de las demás.

Debido a que la vegetación puede variar estacionalmente, las variables de microhábitat fueron registradas en dos épocas del año: estación húmeda (noviembre de 1999) y estación seca (mayo de 2000). Para determinar si existen diferencias en la cobertura entre las dos épocas, se realizó un test de Mann-Whitney. Luego, se realizó un Análisis de Componentes Principales (PCA) para examinar cuáles son las variables más predictivas para describir la estructura de cada hábitat. Todos los porcentajes fueron previamente transformados (Arcoseno $\sqrt{ } p$; Zar, 1984). 


\section{Asociación de las especies de roedores con las variables ambientales}

Se realizó un Análisis de Correspondencia (CA) general (incluyendo los datos de los tres hábitats) entre cada especie de roedor y las variables de microhábitat (adjudicadas a distintas categorías) a fin de visualizar las asociaciones entre ellos. Luego se realizó el mismo análisis para cada hábitat por separado para visualizar las asociaciones con la vegetación dentro de cada uno de ellos.

La selección de hábitat fue analizada para cada especie separadamente utilizando regresión logística múltiple y $\chi^{2}$ como medida de ajuste. Cuando los errores residuales mostraron sobredispersión (es decir, cuando la devianza fue mayor que los grados de libertad), los datos fueron reescalados para corregir los sesgos en los test de hipótesis (Crawley, 1993), usando el test $F$ en lugar de $\chi^{2}$. Se incluyeron los datos de las estaciones de trampeo usadas y no usadas en cada fecha de muestreo, utilizando como variable dependiente la proporción del número de individuos capturados en cada estación de trampeo y el número total de noches de trampeo para esa estación.

Cada uno de estos datos tuvo su correspondiente dato de vegetación (variables de microhábitat medidas) para la realización de la regresión logística. Como primer paso, se incluyeron el "hábitat" y la "época" como factores con el objeto de extraer sus efectos y dejar la variabilidad que pueda ser explicada por las variables de microhábitat. Luego, se incluyeron todas las variables de microhábitat utilizando la opción de selección de "a pasos hacia delante", usando un valor de $P>$ 0,25 (siguiendo a Ellis et al., 1997) como límite para rechazar las variables no seleccionadas por las especies de roedores.

En un segundo análisis se realizó la regresión logística separadamente para cada hábitat, utilizando sólo las variables de microhábitat, con el propósito de determinar los mejores predictores de la presencia de cada especie en cada hábitat. 
Para obtener resultados confiables, se estableció que serían analizadas aquellas especies que presentaran un mínimo de 20 capturas. Debido al bajo número de capturas de A. molinae en el medanal, no se pudo predecir la selección de microhábitat de esta especie en este hábitat.

\section{Indices de selectividad}

A fin de determinar cuán selectivas son las especies, se calculó un índice de selectividad para cada una de ellas. El mismo permite identificar especies indicadoras de sitios (Dufrêne y Legendre, 1997). En un paso previo al cálculo del índice se obtuvieron grupos de sitios (microhábitats) en base a los datos de coberturas (de mantillo, arbustos, subarbustos, herbáceas, porcentaje de suelo desnudo y, en el caso del algarrobal, la cobertura de árboles). Para ello se realizó un análisis de clusters (UPGMA, Unweighted pairgroup method using arithmetic averages), utilizando el coeficiente de correlación de Pearson. Debido a que los datos están expresados en porcentajes, fueron previamente transformados (Arcoseno $\checkmark p$; Zar, 1984). Se obtuvieron grupos de microhábitats con características similares para cada grilla de cada hábitat y época. Una vez obtenidos estos grupos, se calcularon los índices de selectividad de acuerdo a la fórmula:

$\mathrm{VI}_{i j}=\mathrm{A}_{i j} \times \mathrm{B}_{i j} \times 100$

donde:

$\mathrm{A}_{i j}=$ Nindividuos $_{i j} /$ Nindividuos $_{i}$

$\mathrm{B}_{i j}=\mathrm{N}_{\text {microhábitats }} / \mathrm{N}$ microhábitats $\mathrm{N}_{j}$

VI es el valor indicador de la especie $i$ en el grupo $j$. $\mathrm{A}_{i j}$ es una medida de especificidad, Nindividuos ${ }_{i j}$ es el número promedio de individuos de la especie $i$ entre los microhábitats del grupo $j, \mathrm{y} \operatorname{Nindividuos}_{i}$ es la suma de los números 
promedios de individuos de la especie $i$ entre todos los grupos ${ }^{1}$. B es una medida de fidelidad, $\mathrm{N}$ microhábitats ${ }_{i j}$ es el número de microhábitats en el grupo $j$ donde la especie $i$ está presente, y $\mathrm{N}$ microhábitats $\mathrm{s}_{j}$ es el número total de microhábitats en el grupo $j$.

El valor es máximo (100\%) cuando los individuos de la especie $i$ estuvieron presentes en un solo grupo y en todos los microhábitats pertenecientes a ese grupo.

Una vez identificadas las parcelas (microhábitats) que conformaron cada grupo, se compararon las variables de cobertura entre los distintos grupos. Esto permitió caracterizar cada grupo de acuerdo al tipo de vegetación. Para ello se realizaron ANOVAs de una vía con test a posteriori de Tukey con cada una de las variables. Con el propósito de visualizar las características generales de cada grupo (teniendo en cuenta todas las variables), se conformaron siete "tipos" diferentes de acuerdo a la mayor o menor cobertura de cada variable (ver resultados).

\footnotetext{
${ }^{1}$ La utilización del promedio y no de la suma elimina cualquier efecto de la desigualdad en el número de microhábitats presentes en cada grupo y las diferencias en abundancias entre microhábitats pertenecientes al mismo grupo
} 


\subsection{RESULTADOS}

\section{Caracterización de cada hábitat}

La mayoría de las variables de hábitat mostraron diferencias significativas entre la época húmeda y la época seca, principalmente en el algarrobal y en el jarillal. La cobertura de mantillo y la altura de herbáceas difirieron de acuerdo a la época en los tres hábitats, mientras que la cobertura de herbáceas y de árboles en el algarrobal fue similar en ambos períodos. La mayor parte de las variables demostraron que tanto la cobertura como las alturas fueron mayores en la estación seca (Tabla 1).

Los resultados del PCA revelaron que el eje 1 (PC1) explicó el 72\% de la variabilidad. Este eje fue definido principalmente por la cobertura de arbustos, de mantillo, la distancia al arbusto más próximo y por el porcentaje de suelo desnudo (los autovectores se indican en la tabla 2). El eje 2 (PC2) permitió describir el 28\% de la variabilidad y fue definido por la cobertura de árboles y de herbáceas. El medanal estuvo asociado con alto porcentaje de suelo desnudo y mayor distancia entre la estación de muestreo y el arbusto más próximo (Fig. 1), mientras que el jarillal estuvo asociado con alta cobertura de arbustos, mantillo y herbáceas. El algarrobal estuvo asociado con alta cobertura de árboles, de subarbustos y densidad de follaje.

\section{Selección de macrohábitat}

El factor hábitat resultó altamente significativo $(p<0,001)$ en todas las especies de pequeños roedores, explicando la mayor porción de la devianza total. Esta selección fue más evidente en A. molinae y G. griseoflavus, explicando este factor el $12,81 \%$ y el $9,2 \%$ de la devianza total, respectivamente (Tabla 3). El número de capturas de A. molinae y de C. musculinus fue mayor en el jarillal y más 
bajo en el medanal ${ }^{2}$. Luego de seleccionar el hábitat, A. molinae eligió principalmente alta cobertura de mantillo, de herbáceas y de subarbustos, mientras que C. musculinus seleccionó alta cobertura de herbáceas, mantillo y árboles (Tabla 3). La laucha colilarga baya E. typus, en cambio, fue capturada en mayor proporción en el medanal, seleccionando baja cobertura de arbustos y árboles, alta cobertura de subarbustos y mayor altura del estrato arbustivo más bajo (Tabla 3). Las capturas de G. griseoflavus fueron mayores en el algarrobal y menores en el medanal. Esta especie mostró preferencia por una alta cobertura de subarbustos, árboles y arbustos, y una baja cobertura de herbáceas (Tabla 3).

El análisis de correspondencia (CA) general, muestra gráficamente estas tendencias. Hay una separación clara entre E. typus y el resto de las especies, asociándose aquella a menor cobertura de arbustos y árboles. Sin embargo, en este análisis A. molinae y C. musculinus se relacionan no sólo a mayor cobertura de mantillo y herbáceas sino también de arbustos, en tanto que G. griseoflavus a una cobertura intermedia de subarbustos (Fig. 2).

La época resultó un factor significativo para C. musculinus y G. griseoflavus, siendo el número de capturas de C. musculinus más alto en la época húmeda, y el de G. griseoflavus en la época seca. La interacción "hábitat*época" fue significativa para A. molinae y E. typus (Tabla 3).

\section{Selección de microhábitat}

En los análisis de correspondencia por hábitat no pueden distinguirse claramente las variables de microhábitats asociadas a cada especie de roedor, sugiriendo que no existe una fuerte selección a este nivel (Fig. 3 a 5). Sólo es posible encontrar una asociación entre E. typus y alto porcentaje de suelo desnudo y baja densidad de follaje en el medanal (Fig. 5), así como una asociación de $C$.

\footnotetext{
${ }^{2}$ Cabe aclarar que, si bien los resultados son similares a los encontrados en el capítulo 2, los análisis realizados fueron ligeramente diferentes. En este capítulo se tuvo en cuenta el número de capturas (es decir, nuevas capturas y recapturas), mientras que en el capítulo 2 se consideraron las abundancias (esto es, sin tener en cuenta las recapturas)
} 
musculinus con alta cobertura de mantillo y arbustos y baja cobertura de subarbustos en el jarillal (Fig. 4).

El análisis de regresión logística indicó que si bien las especies son selectivas, las variables de microhábitat explican muy poco de la devianza total, ya que ninguna de ellas superó el 6\%. Todo indica que la selección de microhábitat es más débil que la selección a nivel de macrohábitat

La cobertura de mantillo aparece como la variable principal seleccionada por A. molinae, ya que fue incluida en el modelo logístico tanto en el jarillal como en el algarrobal. Otras variables elegidas por esta especie fueron la alta cobertura de árboles y el bajo porcentaje de suelo desnudo (Tabla 4). Se encontró una relación inversa altamente significativa entre el porcentaje de suelo desnudo y las capturas de C. musculinus en el jarillal, pero con el resto de las variables no hubo consistencia entre los tres hábitats estudiados (Tabla 5). Los microhábitats seleccionados por E. typus se caracterizaron por la baja cobertura de árboles y arbustos en el medanal, baja cobertura de arbustos y alta cobertura de subarbustos de baja estatura en el jarillal, y alta cobertura de herbáceas y baja altura de las mismas y arbustos altos en el algarrobal (Tabla 6). G. griseoflavus seleccionó microhábitats con alta cobertura de mantillo, subarbustos, árboles y arbustos en el algarrobal, y con alta cobertura de subarbustos en el jarillal (Tabla 7).

\section{Grado de Selectividad}

El análisis de clusters permitió establecer en todos los casos tres grupos de parcelas (microhábitats) para cada grilla, excepto en la grilla 2 del algarrobal, donde en la estación húmeda se reconocieron 5 grupos, y en la grilla 2 del medanal, donde se reconocieron sólo dos grupos en la época seca. La cantidad de sitios o microhábitats que conformaron cada grupo fue variable $(\overline{\mathrm{x}}: 11,19 \pm 3,4)$. En general los valores de los índices de selectividad fueron bajos para todas las especies (Tabla 8). El promedio de los valores máximos encontrados en cada grupo fue de $23,59 \%$. 
En base a la cobertura de la vegetación de los microhábitats que conforman cada grupo, se podrían reconocer los siguientes tipos de microhábitats:

- tipo "A": alta cobertura de arbustos, alta cobertura de herbáceas, alto porcentaje de mantillo

- tipo "B": alta cobertura de arbustos, baja cobertura de herbáceas

- tipo "C": baja cobertura de arbustos, alta cobertura de herbáceas

- tipo "D": alta cobertura de arbustos, alta cobertura de subarbustos

- tipo "E": alta cobertura de arbustos, baja cobertura de subarbustos

- tipo "F": baja cobertura de arbustos, alta cobertura de subarbustos

- tipo "G": alto porcentaje de suelo desnudo; baja cobertura de arbustos, baja cobertura de herbáceas, bajo porcentaje de mantillo.

La tabla 8 muestra el tipo de microhábitat correspondiente a cada grupo obtenido en el análisis de clusters.

Se encontró que la mayor proporción $(33,33 \%)$ de los grupos seleccionados por A. molinae corresponden al tipo "A". C. musculinus seleccionó mayormente los grupos del tipo "C" (25\%) y "A" (25\%), mientras que en E. typus, la mayor proporción de los grupos (58,33\%) fueron del tipo "G", y el 33\% de los grupos seleccionados por G. griseoflavus correspondieron al tipo "C".

El mayor valor de índice para A. molinae $(40,68)$ y para G. griseoflavus $(55,74)$ correspondió a los tipos B y E (alta cobertura de arbustos y baja cobertura de subarbustos y herbáceas). El mayor valor para C. musculinus $(32,67)$ correspondió al tipo C (baja cobertura de arbustos y alta cobertura de herbáceas), mientras que para E. typus el mayor valor (50) correspondió al tipo G (alto porcentaje de suelo desnudo). 


\subsection{DISCUSIÓN}

La heterogeneidad que caracteriza a los sistemas desérticos se ve claramente reflejada en la porción central del desierto del Monte. Las diferencias en la vegetación dentro de la Reserva no sólo permiten diferenciar distintas comunidades vegetales o "hábitats", sino que es variable de acuerdo a la época del año. Una característica de las especies de plantas de desiertos es la rápida respuesta frente a las condiciones ambientales, principalmente las precipitaciones (Noy/Meir, 1979/80). Tanto Lycium tenuispinosum como L. chilensis, los principales componentes de la variable "subarbustos", son sensibles a las lluvias débiles debido a su sistema radical superficial, las que determinan el inicio de su período reproductivo (Dalmasso, 1994). La mayor cobertura de subarbustos registrada en mayo respecto a noviembre probablemente se debe al aumento de cobertura durante toda la estación húmeda, perdurando hasta iniciado el otoño. La mayor cobertura de mantillo en esta época puede atribuirse al aporte de materia seca proveniente de estos subarbustos o de los arbustos (ver capítulo 6). A pesar de estas diferencias en cuanto a la vegetación, la época no resultó un factor significativo para A. molinae y E. typus, aunque sí su interacción con el hábitat. Los resultados obtenidos en el capítulo 3 indicaron que la abundancia de estos roedores fluctúa a lo largo del año, siendo los meses de otoño los de mayor abundancia.

La cuantificación de las variables de hábitat permitió caracterizar al jarillal como el de mayor cobertura de arbustos y herbáceas, al algarrobal como el de mayor cobertura de árboles y al medanal como el hábitat más abierto, con baja cobertura vegetal y alto porcentaje de suelo desnudo. Las especies de micromamíferos son capaces de distinguir entre estos tipos de hábitat. En todas las especies, es el macrohábitat el principal factor que determina la selección por parte de los roedores múridos, mientras que las variables de microhábitat explican muy poco de la variabilidad total de los datos (ninguna variable explica por sí misma más del $6,14 \%$ de la devianza total). La falta de consistencia entre las variables seleccionadas a ambos niveles (macro y microhábitat) y entre las distintas 
comunidades vegetales (jarillal, algarrobal y medanal) en todas las especies, estaría indicando que la selección responde a la jerarquía señalada por Hutto (1985). Es decir, una vez seleccionado el macrohábitat, los sitios que cada individuo ocupará dentro del mismo serán elegidos de acuerdo a variables diferentes a aquellas que han sido importantes en la primera elección. Sin embargo, es posible encontrar un cierto patrón, que relaciona a E. typus con sitios más abiertos, con baja cobertura de árboles y arbustos, $\mathrm{y}$ al resto de las especies con mayor cobertura vegetal (especialmente de herbáceas para A. molinae y C. musculinus, y de árboles y subarbustos para G. griseoflavus).

La selección a nivel de macrohábitat es más fuerte en $A$. molinae y $G$. griseoflavus que en el resto de las especies. E. typus aparece como la especie menos selectiva a nivel de macrohábitat (es decir, que el hábitat explica un menor porcentaje de la devianza de los datos que en las demás especies). Este resultado es esperable de acuerdo al alto índice de amplitud de nicho obtenido en el capítulo 3 para esta especie. Considerando que el comportamiento de forrajeo podría determinar la selección de hábitat (Kotler et al, 1994, Rosenzweig, 1981), el hecho de que E. typus sea la especie más omnívora del ensamble, podría explicar el menor grado de selectividad encontrado respecto a las otras especies. A. molinae, en cambio, posee el menor índice de amplitud de nicho y su dieta es más estrecha, con tendencias hacia la insectivoría (Campos et al., 2001), lo que llevaría a esta especie a ser más selectiva tanto a nivel de macro como de microhábitat. La alta asociación del mantillo con las capturas de esta especie (17,64\% del total de la variabilidad) no está muy clara. Una posible explicación podría ser que el mantillo reduciría el contraste de color oscuro de la especie con el substrato, además de proveerle mayor proporción de semillas e insectos que el suelo desnudo sin mantillo, disminuyendo los costos energéticos en la búsqueda del alimento. En los desiertos, la productividad primaria es principalmente de semillas y materia vegetal seca (mantillo) que se acumula en el hábitat debido a que la baja humedad limita la descomposición microbiana. Por lo tanto, los organismos macrodetritívoros (termitas, escarabajos, isópodos) y los depredadores de semillas (hormigas) 
conforman un primer nivel trófico que soporta a su vez una rica fauna de artrópodos depredadores y reptiles. El tercer nivel en esta red está dada por las aves y los mamíferos, que se alimentan tanto del primer como del segundo nivel (Ayal y Merkl, 1994; Crawford, 1986; Parmenter y MacMahon, 1988; Polis y Yamashita, 1991).

La selectividad de hábitat de G. griseoflavus hacia el algarrobal y la asociación con la cobertura de árboles también podría explicarse por el comportamiento de forrajeo. Esta es la especie más folívora del ensamble, incluyendo en su dieta gran proporción de hojas de algarrobo (Campos, 1997; Campos et al., 2001). Además, su capacidad de trepado le otorgaría ventajas en la eficiencia de forrajeo en este hábitat.

Calomys musculinus, mostró selectividad hacia el jarillal. Este hábitat se caracterizó por la presencia de alta cobertura de herbáceas, variable que lo distingue de los otros dos hábitats. Las herbáceas le proporcionarían cobertura (refugio) además de proveerle alimento, ya que esta especie consume alto porcentaje de semillas de gramíneas (Campos, 1997). Los resultados obtenidos para $C$. musculinus son comparables a los reportados por Busch et al. (2000), quienes encontraron que esta especie muestra selección a nivel de macrohábitat en agroecosistemas, pero las asociaciones a variables de hábitat cambian de acuerdo a la escala considerada, demostrando que la especie percibe la heterogeneidad del hábitat. Estos autores atribuyen las mayores abundancias en los bordes respecto a los campos cultivados, a la mayor protección de los nidos superficiales que ofrece el primer hábitat.

La baja selectividad a nivel de microhábitat se vio también reflejada al evaluar las especies indicadoras de sitios. Ninguna de las especies mostró un alto índice de selectividad hacia algún grupo de microhábitats. Sin embargo, se observó un porcentaje relativamente alto $(58,33 \%)$ de asociación entre E. typus y los sitios con alto porcentaje de suelo desnudo y baja cobertura de arbustos, herbáceas y mantillo. Excepto para G. griseoflavus, en general, los sitios asociados con cada especie son semejantes a los microhábitats seleccionados en el análisis de regresión 
logística. Mientras que G. griseoflavus fue muy selectivo a nivel de macrohábitat, la inconsistencia en los resultados a partir de distintos análisis a nivel de microhábitat, refleja la falta de una fuerte selectividad a este último nivel.

En resumen, las cuatro especies de roedores estudiadas muestran que la selectividad del hábitat depende de la escala (siendo más importante a nivel de macrohábitat que de microhábitat). 


\subsection{CONCLUSIONES}

Las principales conclusiones obtenidas en este capítulo se pueden resumir de la siguiente manera:

- Los hábitats seleccionados a priori sobre la base de comunidades vegetales, difieren entre sí en cuanto a que el jarillal posee mayor cobertura de arbustos y herbáceas, el algarrobal mayor cobertura de árboles y el medanal baja cobertura vegetal, alto porcentaje de suelo desnudo y mayor distancia entre los arbustos.

- Existe selección de hábitat, siendo más acentuada a nivel de macrohábitat que de microhábitat

- No hay consistencia absoluta entre las variables seleccionadas a nivel de macrohábitat y aquellas seleccionadas a nivel de microhábitat, pero en general se relaciona a $E$. typus con sitios más abiertos, con baja cobertura de árboles y arbustos, y al resto de las especies con mayor cobertura vegetal (especialmente de herbáceas para A. molinae y C. musculinus, y de árboles y subarbustos para $G$. griseoflavus).

- En general, el grado de selectividad fue bajo para todas las especies, sin haberse podido identificar claramente especies indicadoras de sitios. 


\subsection{TABLAS y FIGURAS}

Tabla 1. Diferencias en cada variable de la vegetación entre la estación seca y la estación húmeda en la Reserva de la Biósfera de Naacuñán (test de Mann-Whitney, $*=p<0,05 ; * *=p<0,01 ; * * *=p<0,001 ;$ n.s. $=$ no significativo, $p>0,05$ )

\begin{tabular}{|lccc|}
\hline & Jarillal & Algarrobal & Medanal \\
\hline Suelo desnudo & $>\operatorname{seca}(* * *)$ & $>\operatorname{seca}(* *)$ & n.s. \\
Cob. árboles & n.s & n.s. & n.s. \\
Cob. arbustos & $>\operatorname{seca}(*)$ & $>\operatorname{seca}(*)$ & n.s. \\
Cob. subarbustos & $>\operatorname{seca}(*)$ & $>\operatorname{seca}(* * *)$ & n.s. \\
Cob. herbáceas & n.s & n.s. & n.s. \\
Cob. mantillo & $>\operatorname{seca}(* * *)$ & $>\operatorname{seca}(* * *)$ & $>$ seca $(* * *)$ \\
Densidad de follaje & $>\operatorname{seca}(* * *)$ & $>\operatorname{seca}(* * *)$ & n.s. \\
Altura de herbáceas & $>\operatorname{seca}(* * *)$ & $>\operatorname{seca}(* * *)$ & $>$ húmeda $(* * *)$ \\
\hline
\end{tabular}


Tabla 2. Autovectores para el primer (PC1) y segundo (PC2) ejes obtenidos en el análisis de componentes principales (PCA).

\begin{tabular}{|lrc|}
\hline \multicolumn{1}{|c}{ Variables } & PC1 & PC2 \\
\hline Suelo desnudo & $-0,38$ & 0,18 \\
Cobertura de árboles & $-0,09$ & 0,61 \\
Cobertura de arbustos & 0,39 & 0,05 \\
Cobertura de subarbustos & 0,35 & 0,29 \\
Cobertura de herbáceas & 0,24 & $-0,5$ \\
Cobertura de mantillo & 0,37 & $-0,23$ \\
Densidad de follaje & 0,31 & 0,38 \\
Distancia al arbusto próximo & $-0,39$ & 0,02 \\
\hline
\end{tabular}


Tabla 3. Modelos logísticos de selección de macrohábitat

Los signos $(+)$ indican asociación positiva entre las variables y las capturas, mientras que los signos (-) indican relación negativa

Para la construcción del modelo fueron incluidas todas las variables de microhábitat $\operatorname{con} p<0,25$

\begin{tabular}{|c|c|c|c|c|}
\hline & Modelo logístico & asociación & $\mathbf{p}$ & $\begin{array}{c}\text { Devianza explicada } \\
(\%)\end{array}$ \\
\hline \multirow[t]{6}{*}{ A. molinae } & hábitat & & $<0.001$ & 12.81 \\
\hline & época & & $>0.05$ & - \\
\hline & hábitat*época & & $<0.001$ & 0.77 \\
\hline & mantillo & $(+)$ & $<0.001$ & 3.68 \\
\hline & cobertura de herbáceas & $(+)$ & 0.12 & 0.15 \\
\hline & cobertura de subarbustos & $(+)$ & 0.09 & 0.23 \\
\hline \multirow[t]{6}{*}{ C. musculinus } & hábitat & & $<0.001$ & 4.48 \\
\hline & época & & $<0.001$ & 4.30 \\
\hline & hábitat*época & & $>0.05$ & - \\
\hline & cobertura de herbáceas & $(+)$ & $<0.01$ & 1.23 \\
\hline & mantillo & $(+)$ & 0.14 & 0.27 \\
\hline & cobertura de árboles & $(+)$ & 0.22 & 0.19 \\
\hline \multirow[t]{7}{*}{ G. griseoflavus } & hábitat & & $<0.001$ & 9.20 \\
\hline & época & & $<0.001$ & 0.80 \\
\hline & hábitat*época & & $>0.05$ & - \\
\hline & cobertura de subarbustos & $(+)$ & $<0.001$ & 0.64 \\
\hline & cobertura de árboles & $(+)$ & 0.08 & 0.16 \\
\hline & cobertura de arbustos & $(+)$ & 0.06 & 0.21 \\
\hline & cobertura de herbáceas & $(-)$ & 0.20 & 0.11 \\
\hline \multirow[t]{7}{*}{ E. typus } & hábitat & & $<0.001$ & 5.50 \\
\hline & época & & $>0.05$ & - \\
\hline & hábitat*época & & 0.01 & 0.58 \\
\hline & cobertura de arbustos & $(-)$ & 0.02 & 0.35 \\
\hline & cobertura de árboles & $(-)$ & 0.03 & 0.29 \\
\hline & estrato bajo & $(+)$ & 0.19 & 0.12 \\
\hline & cobertura de subarbustos & $(+)$ & 0.21 & 0.12 \\
\hline
\end{tabular}


Tabla 4. Selección de microhábitat por A. molinae

Los signos $(+)$ indican asociación positiva entre las variables y las capturas, mientras que los signos (-) indican relación negativa

Para la construcción del modelo fueron incluidas todas las variables de microhábitat $\operatorname{con} p<0,25$

\begin{tabular}{|llccc|}
\hline Hábitat & Modelo logístico & asociación & $\mathbf{p}$ & $\begin{array}{c}\text { Devianza explicada } \\
\text { Jarillal }\end{array}$ \\
& mantillo & $(+)$ & $<0.001$ & 5.84 \\
& suelo desnudo & $(-)$ & 0.13 & 0.32 \\
& total & & & 6.16 \\
Algarrobal & mantillo & & \\
& cobertura de árboles & $(+)$ & $<0.001$ & 4.73 \\
& total & $(+)$ & 0.20 & 0.51 \\
& & & 5.24 \\
\hline
\end{tabular}

Tabla 5. Selección de microhábitat por C. musculinus

Los signos $(+)$ indican asociación positiva entre las variables y las capturas, mientras que los signos (-) indican relación negativa

Para la construcción del modelo fueron incluidas todas las variables de microhábitat con $p<0,25$

\begin{tabular}{|llccc|}
\hline Hábitat & Modelo logístico & asociación & p & $\begin{array}{c}\text { Devianza explicada } \\
\text { (\%) }\end{array}$ \\
\hline Jarillal & suelo desnudo & $(-)$ & $<0.001$ & 5.93 \\
& altura de herbáceas & $(-)$ & 0.03 & 1.03 \\
& estrato bajo & $(+)$ & 0.09 & 0.65 \\
& total & & & 7.61 \\
Algarrobal & estrato bajo & & \\
& mantillo & $(-)$ & 0.10 & 1.59 \\
& total & $(+)$ & 0.09 & 1.64 \\
& & & & 3.23 \\
Medanal & cobertura de árboles & $(+)$ & 0.01 & 4.35 \\
& suelo desnudo & $(+)$ & 0.02 & 3.82 \\
& altura de herbáceas & $(+)$ & 0.02 & 3.69 \\
& total & & & 11.86 \\
\hline
\end{tabular}


Tabla 6. Selección de microhábitat por E. typus

Los signos $(+)$ indican asociación positiva entre las variables y las capturas, mientras que los signos (-) indican relación negativa

Para la construcción del modelo fueron incluidas todas las variables de microhábitat con $p<0,25$

\begin{tabular}{|c|c|c|c|c|}
\hline Hábitat & Modelo logístico & asociación & $\mathbf{p}$ & $\begin{array}{c}\text { Devianza explicada } \\
(\%)\end{array}$ \\
\hline \multirow[t]{5}{*}{ Jarillal } & cobertura de arbustos & $(-)$ & 0.01 & 1.44 \\
\hline & altura de herbáceas & $(+)$ & 0.01 & 1.29 \\
\hline & estrato bajo & $(-)$ & 0.09 & 0.55 \\
\hline & cobertura de subarbustos & $(+)$ & 0.23 & 0.26 \\
\hline & total & & & 3.54 \\
\hline \multirow[t]{4}{*}{ Algarrobal } & estrato bajo & $(+)$ & $<0.001$ & 3.43 \\
\hline & altura de herbáceas & $(-)$ & 0.04 & 1.16 \\
\hline & cobertura de herbáceas & $(+)$ & 0.13 & 0.61 \\
\hline & total & & & 5.20 \\
\hline \multirow[t]{3}{*}{ Medanal } & cobertura de árboles & $(-)$ & 0.14 & 0.38 \\
\hline & cobertura de arbustos & $(-)$ & 0.14 & 0.36 \\
\hline & total & & & 0.74 \\
\hline
\end{tabular}


Tabla 7. Selección de microhábitat por G. griseoflavus

Los signos $(+)$ indican asociación positiva entre las variables y las capturas, mientras que los signos (-) indican relación negativa

Para la construcción del modelo fueron incluidas todas las variables de microhábitat $\operatorname{con} p<0,25$

\begin{tabular}{|llccc|}
\hline Hábitat & Modelo logístico & asociación & $\mathbf{p}$ & $\begin{array}{c}\text { Devianza explicada } \\
\text { Jarillal }\end{array}$ \\
& cobertura de subarbustos & \\
& total & $(+)$ & 0.02 & 0.67 \\
Algarrobal & mantillo & & & 0.67 \\
& altura de herbáceas & $(+)$ & $<0.001$ & 1.99 \\
& cobertura de subarbustos & $(+)$ & 0.01 & 1.03 \\
& cobertura de árboles & $(+)$ & 0.05 & 0.64 \\
& cobertura de arbustos & $(+)$ & 0.24 & 0.30 \\
& estrato bajo & $(-)$ & 0.19 & 0.23 \\
& cobertura de herbáceas & $(-)$ & 0.22 & 0.28 \\
& total & & & 0.25 \\
& & & & 4.72 \\
Medanal & suelo desnudo & $(+)$ & 0.17 & 0.80 \\
& total & & & 0.80 \\
\hline
\end{tabular}


Tabla 8. Índices de selectividad obtenidos para cada especie de múrido. En negrita se resaltan los máximos valores de cada especie para cada grilla y las características de la vegetación que corresponde a cada grupo de microhábitats está identificado como "tipo de microhábitat" (ver texto).

\begin{tabular}{|c|c|c|c|c|c|c|c|c|}
\hline Hábitat & Época & grilla & Grupo & A. molinae & C. musculinus & E. typus & G. griseoflavus & $\begin{array}{l}\text { tipo de } \\
\text { microhábitat }\end{array}$ \\
\hline \multirow[t]{14}{*}{ algarrobal } & \multirow[t]{8}{*}{ húmeda } & \multirow[t]{3}{*}{1} & 1 & 18.18 & 17.14 & 0 & 24.5 & $\mathrm{C}$ \\
\hline & & & 2 & 12.37 & 0 & 9.77 & 13.89 & $\mathrm{~A}$ \\
\hline & & & 3 & 2.56 & 0.71 & 13.75 & 11.7 & $\mathrm{G}$ \\
\hline & & \multirow{5}{*}{2} & 1 & 0.6 & 0.78 & 1.26 & 13.09 & $\mathrm{G}$ \\
\hline & & & 2 & 1.16 & 1.5 & 0.81 & 19 & $\mathrm{C}$ \\
\hline & & & 3 & 0.48 & 5.09 & 8.3 & 5 & A y E \\
\hline & & & 4 & 22.71 & 11.71 & 0 & 6 & $\mathrm{~A}$ \\
\hline & & & 5 & 4.17 & 2.78 & 21.5 & 3.64 & $F$ \\
\hline & \multirow[t]{6}{*}{ seca } & \multirow[t]{3}{*}{1} & 1 & 30.36 & 2.86 & 6.67 & 41 & $\mathrm{C}$ \\
\hline & & & 2 & 30.75 & 17.86 & 0 & 33.25 & $\mathrm{~A}$ \\
\hline & & & 3 & 9.18 & 0 & 26.8 & 12 & $\mathrm{G}$ \\
\hline & & \multirow[t]{3}{*}{2} & 1 & 5.25 & 3.25 & 2.12 & 5.61 & $\mathrm{G}$ \\
\hline & & & 2 & 10.5 & 8.12 & 18.75 & 3.75 & A y D \\
\hline & & & 3 & 40.68 & 29.17 & 13.33 & 55.74 & B y E \\
\hline \multirow[t]{12}{*}{ jarillal } & \multirow[t]{6}{*}{ húmeda } & \multirow[t]{3}{*}{1} & 1 & 15.81 & 2.94 & 0.84 & 31.82 & $\mathrm{~B}$ \\
\hline & & & 2 & 15.15 & 16.04 & $\mathbf{1 7 . 5}$ & 20.83 & $\mathrm{G}$ \\
\hline & & & 3 & 22.5 & 13.5 & 4.17 & 36 & $\mathrm{~A}$ \\
\hline & & \multirow[t]{3}{*}{2} & 1 & 11 & 15.55 & 0.38 & 11.67 & A \\
\hline & & & 2 & 40 & 32.67 & 0 & 23 & $\mathrm{C}$ \\
\hline & & & 3 & 0 & 2 & 25 & 5.18 & $G$ \\
\hline & \multirow[t]{6}{*}{ seca } & \multirow[t]{3}{*}{1} & 1 & 25.66 & 21.18 & 17.87 & 13.59 & $\mathrm{~A}$ \\
\hline & & & 2 & 21.66 & 22.2 & 10.8 & 25.57 & A y E \\
\hline & & & 3 & 15.27 & 31.09 & 39.09 & 2.73 & $\mathrm{~F}$ \\
\hline & & \multirow[t]{3}{*}{2} & 1 & 35.47 & 27.53 & 0.84 & 16.2 & $\mathrm{~A}$ \\
\hline & & & 2 & 16.67 & 3.33 & 8.33 & 35.25 & B y E \\
\hline & & & 3 & 36.9 & 5 & 25.69 & 13.5 & $\mathrm{G}$ \\
\hline \multirow[t]{11}{*}{ medanal } & \multirow[t]{6}{*}{ húmeda } & \multirow[t]{3}{*}{1} & 1 & 0 & 15.69 & 14.23 & 0 & $\mathrm{C}$ \\
\hline & & & 2 & 8 & 1.75 & 3.33 & 18.94 & $\mathrm{G}$ \\
\hline & & & 3 & 0 & 0.81 & 10.61 & 1.94 & $\mathrm{~A}$ \\
\hline & & \multirow[t]{3}{*}{2} & 1 & 8 & 0 & 19.38 & 14.08 & $\mathrm{G}$ \\
\hline & & & 2 & 0 & 14 & 13 & 0 & $\mathrm{C}$ \\
\hline & & & 3 & 0 & 0 & 19.1 & 7.84 & $\mathrm{~A}$ \\
\hline & \multirow[t]{5}{*}{ seca } & \multirow[t]{3}{*}{1} & 1 & 8.95 & 1.51 & 22.12 & 10.26 & $\mathrm{~A}$ \\
\hline & & & 2 & 2.33 & 3.62 & 20 & 9.26 & $G$ \\
\hline & & & 3 & 9.32 & 14 & 16 & 0 & $\mathrm{~F}$ \\
\hline & & \multirow[t]{2}{*}{2} & 1 & 0 & 19.5 & 50 & 3 & $G$ \\
\hline & & & 2 & 9 & 1.93 & 31.9 & 17.45 & B \\
\hline
\end{tabular}


Fig. 1. Análisis de componentes principales mostrando los tres tipos de hábitat y las variables asociadas.

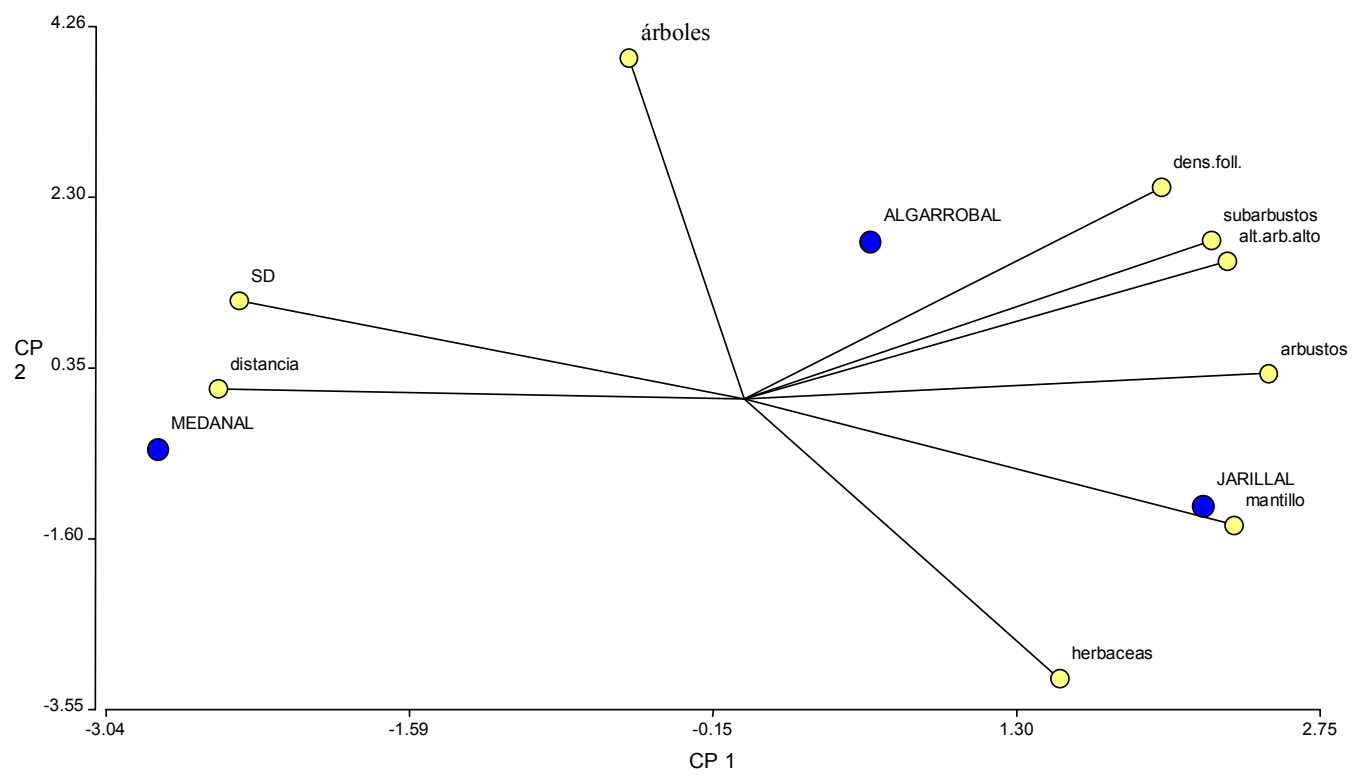


Fig. 2. Análisis de Correspondencia general. Muestra la asociación de las especies de múridos con la vegetación al graficar juntos los tres hábitats de la Reserva de la Biósfera de Ñacuñán

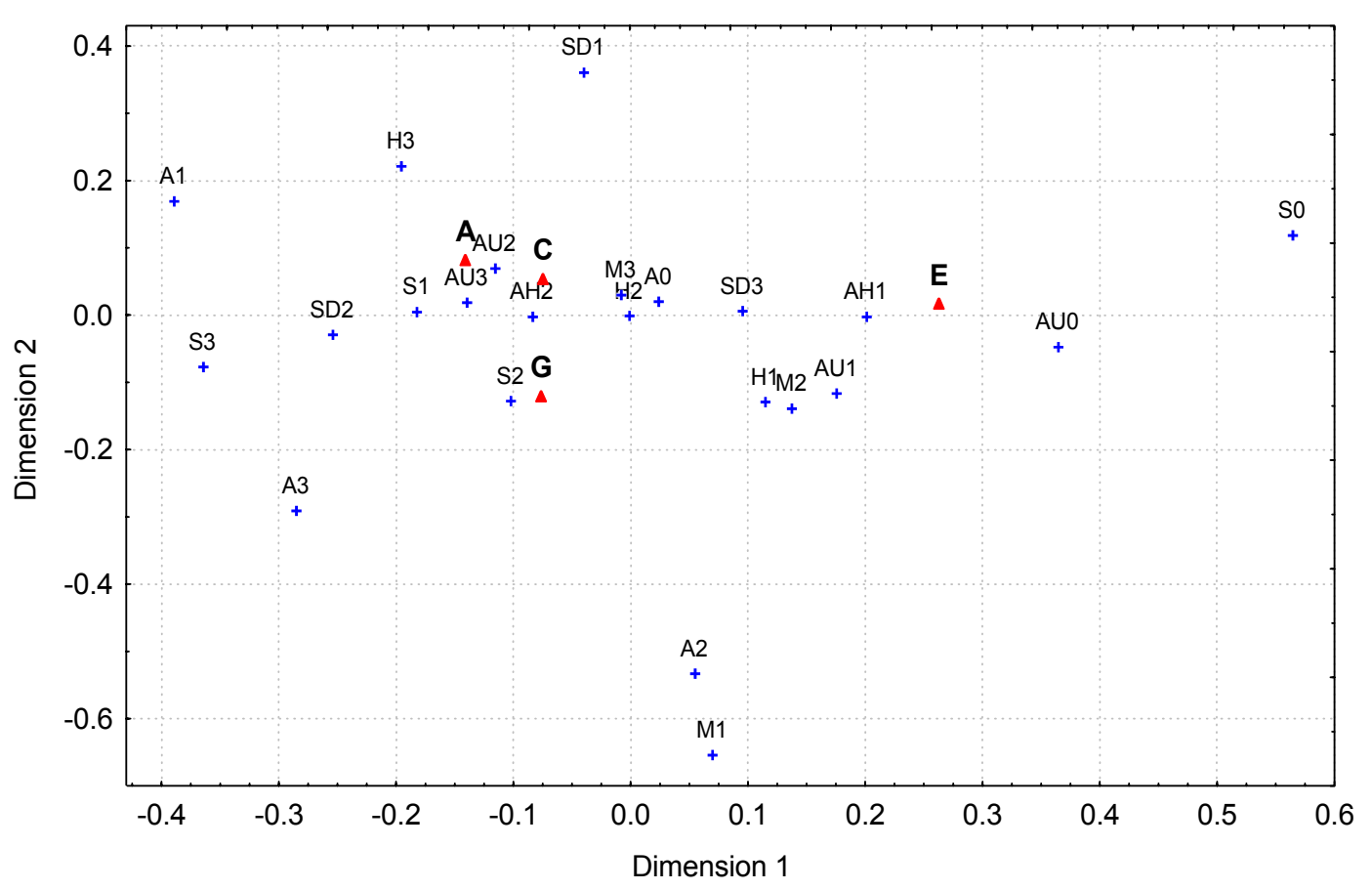

Referencias
A: Akodon molinae
C: Calomys musculinus
E: Eligmodontia typus
G: Graomys griseoflavus
SD: suelo desnudo

A: cobertura de árboles

AU: cobertura de arbustos

S: cobertura de subarbustos

$\mathrm{H}$ : cobertura de herbáceas

AH: altura de herbáceas

M: cobertura de mantillo

0 a 3 representa las categorías de menor a mayor cobertura o altura. 
Fig. 3. Análisis de Correspondencia que muestra la asociación de las variables de microhábitat con las especies de múridos en el algarrobal de la Reserva de la Biósfera de Ñacuñán

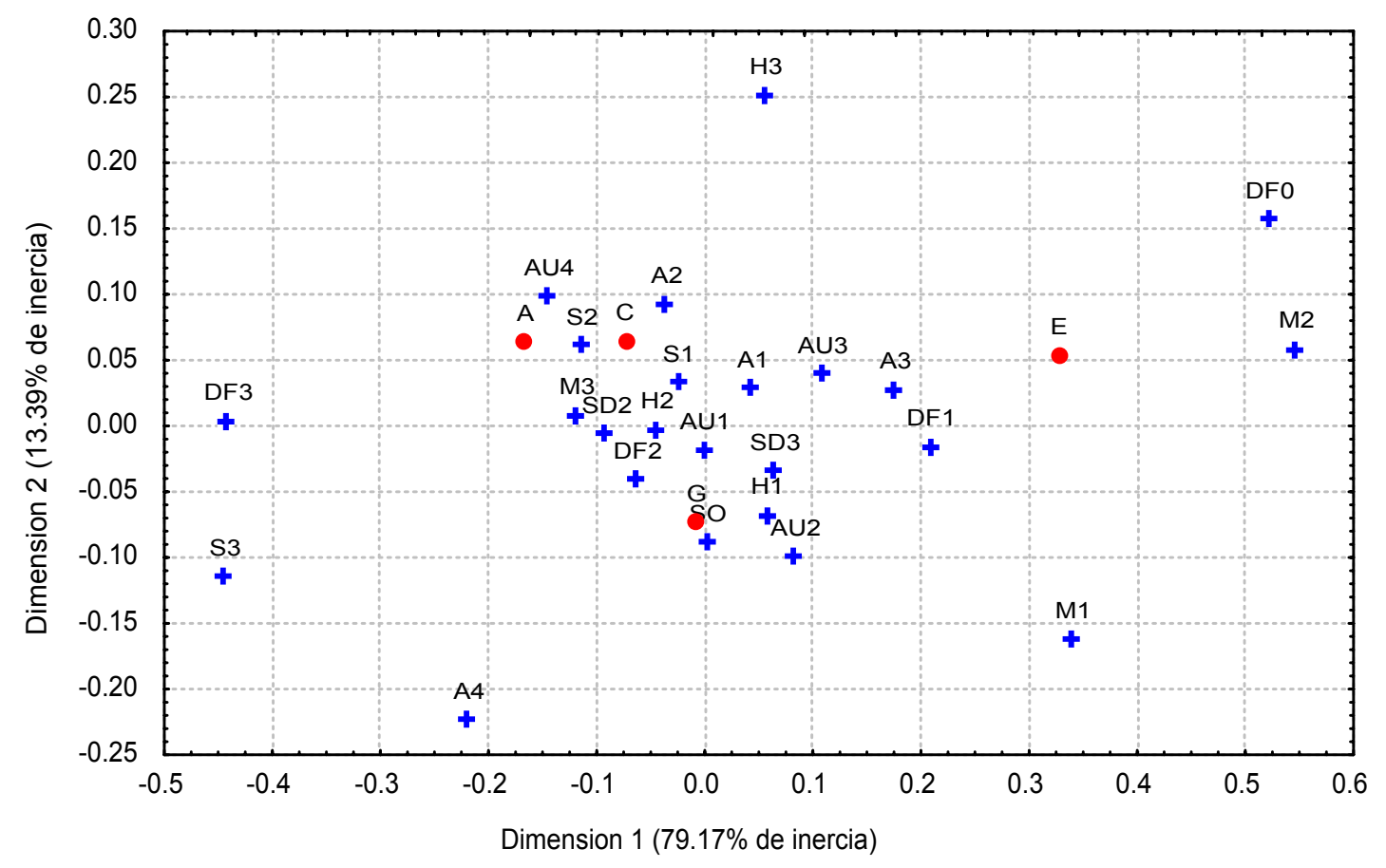

$\underline{\text { Referencias }}$
A: Akodon molinae
C: Calomys musculinus
E: Eligmodontia typus
G: Graomys griseoflavus
SD: suelo desnudo

A: cob. de árboles

AU: cob. arbustos

S: cob. subarbustos

$\mathrm{H}$ : cob herbáceas

AH: altura de herbáceas

M: cob. de mantillo

DF: densidad de follaje

0 a 3 representa las categorías de menor a mayor cobertura o altura. 
Fig. 4. Análisis de Correspondencia que muestra la asociación de las variables de microhábitat con las especies de múridos en el jarillal de la Reserva de la Biósfera de Ñacuñán

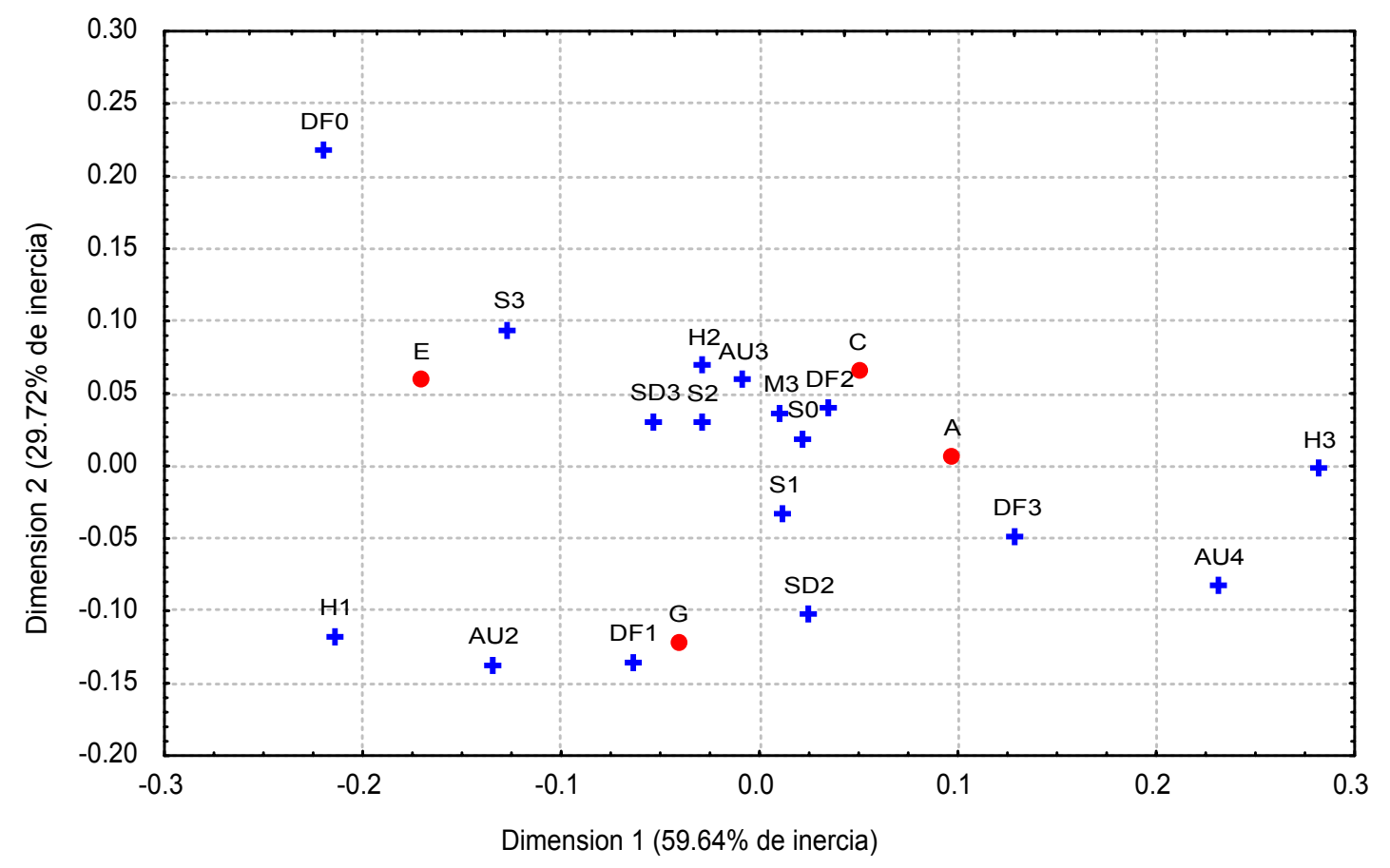

$\underline{\text { Referencias }}$
A: Akodon molinae
C: Calomys musculinus
E: Eligmodontia typus
G: Graomys griseoflavus
SD: suelo desnudo

A: cob. de árboles

AU: cob. arbustos

S: cob. subarbustos

$\mathrm{H}$ : cob herbáceas

AH: altura de herbáceas

M: cob. de mantillo

DF: densidad de follaje

0 a 3 representa las categorías de menor a mayor cobertura o altura. 
Fig. 5 Análisis de Correspondencia que muestra la asociación de las variables de microhábitat con las especies de múridos en el medanal de la Reserva de la Biósfera de Ñacunán

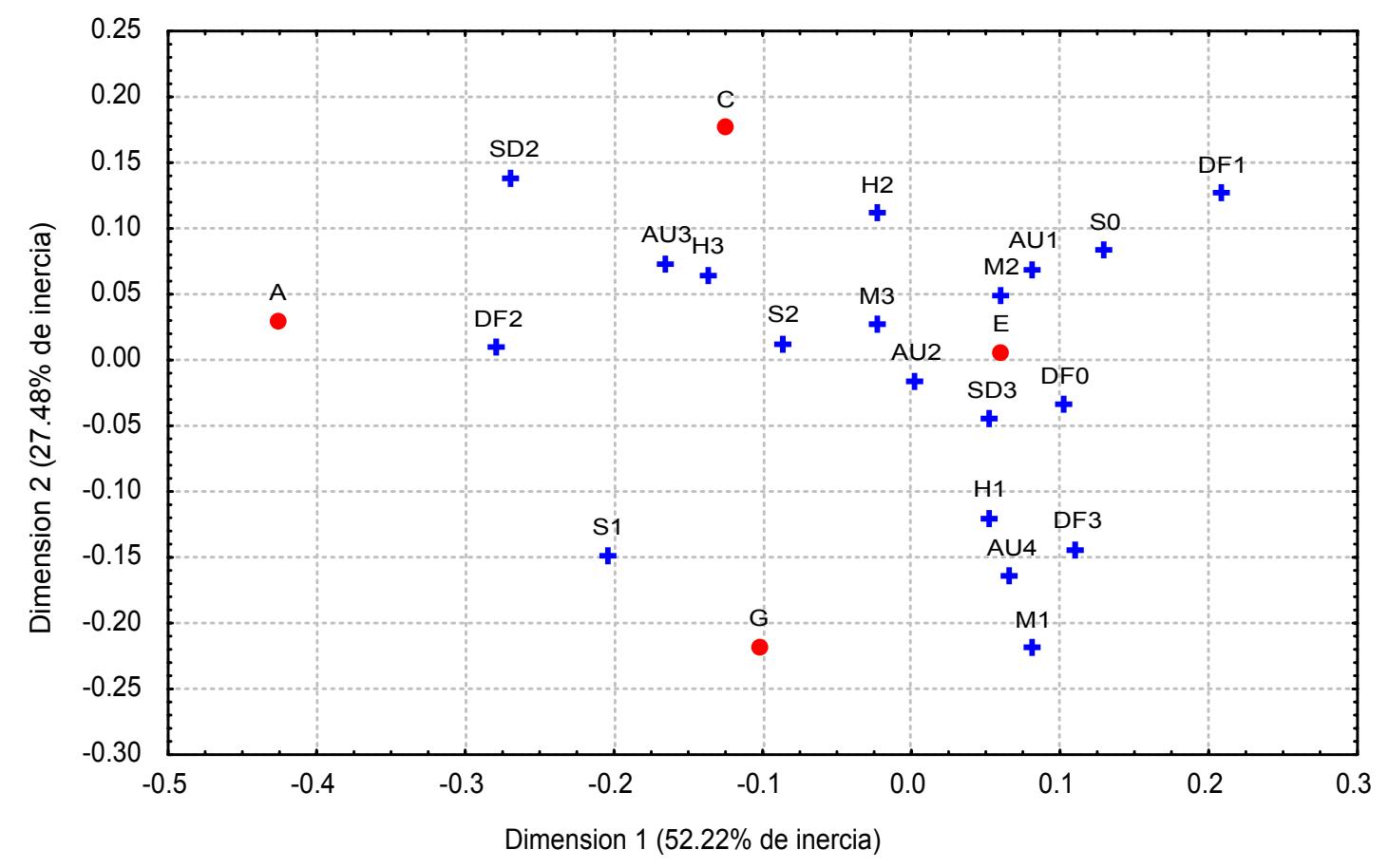

$\underline{\text { Referencias }}$
A: Akodon molinae
C: Calomys musculinus
E: Eligmodontia typus
G: Graomys griseoflavus
SD: suelo desnudo

A: cob. de árboles

AU: cob. arbustos

S: cob. subarbustos

H: cob herbáceas

AH: altura de herbáceas

M: cob. de mantillo

DF: densidad de follaje

0 a 3 representa las categorías de menor a mayor cobertura o altura. 
Capítulo 6

ESTIMACIÓN DE USO Y SELECCIÓN DE MICROHÁBITAT MEDIANTE LA TÉCNICA DE POLVOS LUMINOSOS 


\section{Capítulo 6. ESTIMACIÓN DE USO Y SELECCIÓN DE MICROHÁBITAT MEDIANTE LA TÉCNICA DE POLVOS LUMINOSOS}

\subsection{INTRODUCCIÓN}

Como ha sido explicado en el capítulo 1, los términos uso y selección son frecuentemente mal usados en la literatura. Para evitar confusiones, es necesario aclarar que en este capítulo el uso de microhábitat se referirá a la asociación de las características del microhábitat con cada especie, mientras que la selección se referirá al uso de este recurso comparándolo con lo disponible en el ambiente.

En el capítulo 4 se ha analizado la selección de macro y microhábitat a partir de un método tradicional, el trampeo. Sin embargo, este tipo de muestreo es una medida indirecta de los movimientos de los roedores y es poco lo que se conoce del efecto de trampas con cebo sobre el comportamiento de los animales (Lemen y Freeman, 1985).

En los últimos años se han implementado métodos diferentes para este tipo de estudios como la telemetría y la utilización de polvos fluorescentes. Esta última técnica fue desarrollada por Duplantier et al. (1984) y consiste en la aplicación de polvo sobre el pelaje del animal. Es de fácil administración, económica y no ejerce efectos patológicos sobre los individuos (Stapp et al, 1994). Como el rastro dejado por los animales se debe principalmente al roce del pelaje con las herbáceas o gramíneas, la alta cobertura de herbáceas en esta porción del Desierto del Monte permite el uso de esta técnica.

La importancia de este método reside en que es posible observar y cuantificar el camino exacto recorrido por el animal, visualizar el uso de distintos estratos en el ambiente y descubrir sus cuevas. Ha sido utilizado también en estudios de interacciones con otros individuos (Dickman, 1988), de dispersión de roedores (Citadino y Kravetz, 2000; Duplantier et al., 1984) y en experimentos de remoción de semillas (Longland y Clements, 1995). 
Existen variantes en el empleo de polvos fluorescentes para estudiar el uso de microhábitat. Bestelmeyer y Stevenson (1998) han colocado el pigmento dentro de cápsulas, las cuales son sujetadas a la base de la cola de los individuos y el polvo es esparcido a través de orificios. Jones y Longland (1999) han ofrecido platos con semillas cubriendo todo con polvo fluorescente. El polvo se adhiere a las patas del animal cuando éste cosecha las semillas y luego es posible seguir su rastro.

En el desierto del Monte, el uso de polvos fluorescentes permite obtener datos precisos de los movimientos de especies difíciles de estudiar por medio de trampeos (debido a sus bajas capturas), como es el caso de Thylamys pusillus. Además, aporta información acerca de los movimientos verticales de las especies dentro del ambiente (sobre gramíneas, subarbustos, arbustos o árboles), que no fue posible determinar con la técnica tradicional, ya que las trampas fueron colocadas siempre sobre el suelo.

Utilizando polvos luminosos como una técnica complementaria en el estudio de uso y selección de microhábitat por los pequeños mamíferos del desierto, se plantearon los siguientes objetivos:

- Estimar el uso o selección de microhábitat por las especies de micromamíferos

- Comparar los resultados obtenidos con aquellos inferidos a través del trampeo 


\subsection{MATERIALES Y MÉTODOS}

\section{Uso de microhábitat}

Las campañas realizadas para la toma de datos se realizaron en noviembre de 2000, marzo de 2001, octubre de 2001 y mayo de 2002. Se colocaron trampas de captura viva en transectas paralelas a la Picada "La Torre.", a la Picada "La Fadina" y en los médanos (área de "30 palos") de la Reserva de la Biósfera de Ñacunán. Las trampas eran colocadas y cebadas con avena al atardecer y revisadas luego de 3 o 4 horas (10-11 PM) ${ }^{1}$. Para no interferir en el comportamiento de los animales y para evitar que los individuos elegidos para el experimento volvieran a caer en las trampas, previamente se liberaban los individuos no elegidos y se cerraban todas las trampas vacías. Luego los animales capturados eran pesados, sexados y colocados en bolsas transparentes conteniendo polvo luminoso. Los colores utilizados fueron rojo (BioQuip, \#1162R) y azul (BioQuip, \#1162B; Fig. 1). Una vez que los individuos se encontraban totalmente cubiertos de polvo se liberaban en el sitio exacto de captura y se abandonaba el lugar rápidamente. Al día siguiente, con la luz del día se volvía al lugar y se marcaba con banderines el recorrido de polvo dejado por el animal (Fig. 2). Luego, se registraba la presencia de suelo desnudo o mantillo, de árboles, arbustos, subarbustos o herbáceas que tocaban una varilla cada $15 \mathrm{~cm}$ a lo largo del recorrido usando el método de punto interceptado (Krebs, 1999).

En el algarrobal y en el jarillal se calculó la distancia mínima recorrida por cada individuo multiplicando la cantidad de puntos registrados x $15 \mathrm{~cm}$. En el medanal, donde los registros son más discontinuos se midió la distancia total recorrida con cinta métrica. Los puntos más alejados a lo largo y a lo ancho del recorrido fueron usados para calcular el área mínima recorrida.

\footnotetext{
${ }^{1}$ Sólo en una ocasión (primer día de muestreo) las trampas fueron revisadas a la mañana siguiente y los individuos de E. typus capturados fueron mantenidos durante el día hasta su liberación con polvo fluorescente al atardecer. Se volvió al lugar de noche para observar el recorrido con luz ultravioleta.
} 


\section{Disponibilidad}

La disponibilidad fue medida solamente en las últimas campañas (octubre de 2001 y mayo de 2002). Para ello, se realizó una transecta al azar de $50 \mathrm{~m}$ cercana al sitio donde fue registrado el uso de microhábitat para cada individuo coloreado con polvo luminoso. Siguiendo el mismo método del punto interceptado, se registró la vegetación que tocaba la varilla cada $15 \mathrm{~cm}$ a lo largo de la transecta. Debido a que los datos de E. typus y A. molinae provienen de las primeras campañas, no fue posible estimar selección de microhábitat, sino solamente uso.

\section{Análisis estadísticos}

Los datos fueron adjudicados a distintas categorías de cobertura: 1) "mantillo" (sólo cobertura de mantillo), 2) "suelo desnudo" (sólo suelo desnudo), 3) "herbácea" (cobertura de herbáceas sin cobertura de arbustos ni subarbustos), 4) "arbustiva" (cobertura de arbustos o árboles, sin cobertura de subarbustos), 5) "subarbustiva" (cobertura de subarbustos sin cobertura de arbustos ni árboles) y 6) "compleja" (cobertura de herbáceas más cobertura de arbustos (o árboles) y subarbustos). Las categorías 3 a 6 pueden contener mantillo o suelo desnudo.

Se usaron Modelos Lineales Generalizados (regresión logística) para comparar la vegetación usada por los individuos y las transectas al azar. Cada individuo y su correspondiente transecta al azar fue considerada una unidad de muestreo. Este análisis es similar a una tabla de contingencia pero se puede trabajar con proporciones (Everitt, 1992); es decir, que las frecuencias observadas en cada categoría se analizaron como proporciones respecto al número total de observaciones (toques). Esta proporción fue la variable respuesta. Para estimar si una categoría de cobertura tuvo un mayor menor uso por el individuo, se tuvo en cuenta la interacción entre las dos variables categóricas (categoría de cobertura y transecta al azar o rastro del individuo). En los casos donde no hay datos de disponibilidad, las frecuencias de cada categoría usada 
fueron comparadas entre sí para estimar la categoría proporcionalmente más usada. En estos casos y cuando los registros del recorrido fueron lo suficientemente continuos, también se midieron las distancias recorridas bajo cobertura de arbustos, bajo cobertura de subarbustos o herbáceas y sin ningún tipo de cobertura y fueron comparadas mediante el test de Kruskall Wallis con comparaciones a posteriori de Dunn. 


\subsection{RESULTADOS}

Se analizaron 5 individuos de E. typus (totalizando 943 registros de uso de microhábitat), 2 de A. molinae (427 registros), 8 de C. musculinus (3581 registros) y 3 de $T$. pusillus (651 registros). Debido a la agresividad de G. griseoflavus no fue posible emplear la técnica de polvos luminosos para esta especie. La tabla 1 muestra los datos de los individuos (peso, sexo, hábitat del cual provienen, fecha de captura) y las áreas y distancias mínimas recorridas en cada individuo. En la tabla 2 se resumen las distancias y áreas promedio para cada especie.

\section{Uso de microhábitat por Eligmodontia typus (Fig. 3)}

Esta especie utilizó en mayor proporción los microhábitats con cobertura arbustiva $(p<0,001)$. El individuo proveniente del algarrobal, luego de la cobertura de arbustos usó la cobertura de subarbustos y el suelo desnudo, mientras que los individuos del medanal utilizaron en segunda instancia la cobertura de herbáceas, la de subarbustos y el suelo desnudo.

En el medanal, se pudieron comparar las distancias recorridas de E. typus bajo cobertura de arbustos, bajo cobertura de herbáceas o subarbustos y sin ningún tipo de cobertura agrupando los datos de 3 de los 4 individuos, ya que los provenientes del otro individuo eran muy fragmentados. Se encontró que recorren mayores distancias bajo la cobertura de arbustos (Promedio y Desvío estándar: 1,27 $\pm 1,42$ metros) respecto a otro tipo de cobertura $(0,65 \pm 0,59$ metros $)$, y de estos tipos de cobertura respecto a microhábitats sin cobertura $(0,34 \pm 0,23$ metros; $\mathrm{H}: 33,99 ; p<0,0001)$.

En el algarrobal, en cambio, no se encontraron diferencias significativas entre las distancias recorridas bajo estos tres tipos de cobertura $(\mathrm{H}: 2,27 ; p=0,32)$. El individuo proveniente de este hábitat recorrió distancias promedio de 1,31 $\pm 1,67$ metros bajo arbustos, $1,46 \pm 1,6$ metros sin cobertura de arbustos y $0,56 \pm 0,39$ metros sin ningún tipo de cobertura. 


\section{Uso de microhábitat por Akodon molinae (Fig. 4)}

Los datos provenientes de ambos individuos, indican que esta especie utiliza en mayor proporción la cobertura de arbustos respecto a las otras categorías de cobertura $(p<0,017)$. Analizando cada individuo separadamente, se encontró el mismo resultado, con la diferencia de que el individuo del jarillal utilizó también la cobertura de herbáceas y la cobertura más compleja, mientras que el individuo del algarrobal utilizó, además de la cobertura arbustiva, la cobertura de subarbustos, la herbácea y el suelo desnudo.

Se pudo observar que $A$. molinae en su trayectoria no realiza grandes distancias sin cobertura de arbustos. Sumando los datos de ambos individuos estudiados se encontró que, en promedio, recorren bajo arbustos distancias de 3,05 metros (Desvío estándar: 3,22), sin cobertura de arbustos pero con cobertura de subarbustos o de herbáceas $1,13 \pm 1,05$ metros, y sin ningún tipo de cobertura $0,42 \pm 0,41$ metros. Se encontraron diferencias significativas entre las distancias recorridas bajo arbustos respecto a las recorridas sin ningún tipo de cobertura (H: 8,39; $p=0,01$; Test de Dunn: $p<0,05)$.

\section{Segregación de microhábitat}

Debido a que dentro de una misma área en el algarrobal fueron capturados individuos de E. typus y A. molinae en la misma fecha de muestreo, se compararon las dos especies con regresión logística para saber si hacen uso diferencial del microhábitat bajo las mismas condiciones. Se encontraron diferencias significativas $(p<0,001)$ entre ambas especies, utilizando A. molinae más cobertura de herbáceas que E. typus. Esta última especie utilizó más porcentaje de suelo desnudo y mantillo que A. molinae (Fig. 5). 


\section{Selección de microhábitat por Calomys musculinus (Fig. 6)}

En el jarillal: Los dos individuos de esta especie provenientes del jarillal en mayo de 2002, no muestran diferencias significativas en su recorrido con la disponibilidad de micrositios del ambiente cuando son analizados juntos $(p=0,85)$. Sin embargo, al comparar particularmente cada individuo con las transectas al azar, se encontró que en ambos casos seleccionaron los microhábitats más “complejos” $(p<0,001)$.

Uno de los individuos evitó el suelo desnudo $(p=0,041)$ y la cobertura arbustiva ( $\sin$ cobertura de subarbustos) $(p=0,033)$ pero prefirió la cobertura de subarbustos $(p=0,008)$, mientras que el otro individuo evitó la cobertura herbácea $(p<0,001)$. Además, se registró el uso del estrato vertical, ya que se encontraron rastros de polvo fluorescente sobre gramíneas y subarbustos hasta los $0,5 \mathrm{~m}$ de altura.

En otra fecha de muestreo (octubre de 2001), los individuos capturados provenientes de este mismo hábitat, seleccionaron la cobertura compleja $(p<0,001)$, pero evitaron la cobertura donde solo había arbustos $(p<0,001)$.

En el medanal: Cuando se analizaron los 3 individuos de C. musculinus provenientes del medanal, se encontraron diferencias significativas entre el uso y la disponibilidad en el ambiente $(p=0,008)$, seleccionando aquellos microhábitats donde era mayor la cobertura de arbustos.

En el algarrobal: Al analizar los dos individuos del algarrobal, no se encontraron diferencias significativas respecto al azar $(p=0,9)$. Sin embargo, las comparaciones individuales resultaron significativas $(p<0,001)$ y ambos individuos seleccionaron el suelo desnudo. Uno de los individuos además evitó la cobertura de subarbustos, mientras que el otro seleccionó también la cobertura arbustiva y evitó la cobertura herbácea. 


\section{Selección de microhábitat por Thylamys pusillus (Fig. 7)}

En el algarrobal: No se encontraron diferencias significativas al comparar los dos individuos del algarrobal respecto a lo disponible en el ambiente $(p=0,099)$, pero la utilización del microhábitat de uno de los individuos fue significativamente diferente a lo disponible, seleccionando el suelo desnudo $(p<0,001)$ y evitando la cobertura de subarbustos $(p<0,001)$ y la cobertura más compleja $(p=0,002)$. En este hábitat fue posible determinar el uso del estrato vertical, ya que uno de los individuos dejó rastros sobre algarrobo, llaullín y atamisque, llegando en este último hasta 1,9 m de altura, mientras que en el otro individuo hubo registros sobre llaullín hasta $0,5 \mathrm{~m}$ de altura.

En el medanal: El individuo proveniente del medanal seleccionó la cobertura de mantillo $(p=0,046)$ y la cobertura herbácea $(p=0,005)$ y evitó la cobertura arbustiva $(p=0,002)$. 


\subsection{DISCUSIÓN}

Los resultados obtenidos por este método no sólo aportan nueva información, sino que ayudan a comprender los resultados obtenidos a través de trampeos. En el capítulo 4 se encontró que a nivel de microhábitat, A. molinae seleccionaba el mantillo tanto en el algarrobal como en el jarillal. Al analizar los datos provenientes del experimento con polvos fluorescentes, se quiso averiguar si el mantillo por sí mismo es un atributo de la vegetación que esta especie selecciona. Por tal motivo, se dejó una categoría donde sólo había uso de mantillo, sin cobertura de otro tipo (arbustiva, herbácea o subarbustiva). Se encontró que esta categoría fue la menos usada por los dos individuos sometidos al experimento, mientras que la cobertura de arbustos resultó la categoría más usada. De todos los registros con cobertura de arbustos, el 90,53\% también contenían mantillo y sólo el 9,47\% no lo contenían, existiendo una estrecha relación entre estas dos variables. La correlación entre la cobertura de arbustos y el mantillo en las transectas al azar es altamente significativa $\left(\mathrm{r}^{2}=0,98 ; \mathrm{t}=16,55\right.$; $p<0,0001)$. Por lo tanto, es más razonable sugerir que A. molinae utiliza los microhábitats con alta cobertura de arbustos (los que a su vez contienen alto porcentaje de mantillo), que atribuir la selección del mantillo como la variable más importante. El mayor uso de la cobertura arbustiva, así como las cortas distancias que recorren cuando no existe cobertura, indicaría que la cobertura vegetal es importante para disminuir el riesgo de depredación. Por consiguiente, resulta curioso que la cobertura de arbustos no haya sido una variable importante cuando se analizó la selección de hábitat y microhábitat en el capítulo 5. Probablemente esto se deba al tipo de metodología y análisis estadísticos empleados. La alta cobertura de arbustos que caracteriza al jarillal puede haber llevado a una homogeneidad de esta variable entre los distintos microhábitats, y al analizar las estaciones de trampeo con capturas y sin capturas de esta especie no se detectó la selección.

Cuando fue analizada la selección de microhábitat en C. musculinus a través de trampeos (capítulo 5), no pudo encontrarse un fuerte patrón de selección ni ninguna 
variable altamente significativa que permitiera predecir la presencia de esta especie. Con los resultados obtenidos en este estudio tampoco se pudo encontrar un patrón de selección, ya que la misma difirió de acuerdo al hábitat. En el jarillal esta especie prefirió los microhábitats más complejos (con herbáceas, arbustos y subarbustos), pero en el medanal seleccionó la cobertura de arbustos y en el algarrobal el suelo desnudo. Por otro lado, estas variables elegidas en cada hábitat tampoco corresponden a las seleccionadas cuando se analizaron en base a los trampeos (ver capítulo 5, tabla 5), indicando que C. musculinus no es una especie fuertemente selectiva a nivel de microhábitat. También resulta curioso el hecho de que esta especie, considerada asociada a alta cobertura de pastos por otros autores (Gonnet y Ojeda, 1998) evita, según las observaciones realizadas en este trabajo, la cobertura de herbáceas tanto en el jarillal como en el algarrobal. Sin embargo, el bajo número de individuos sometidos al experimento, no permiten arrojar conclusiones contundentes respecto a la selección de microhábitat por esta especie.

El uso de microhábitats con cobertura de arbustos por E. typus también resultó sorprendente. Tanto en el jarillal como en el medanal, los datos de trampeo indicaban que esta especie evitaba los microhábitats con cobertura arbustiva. Debido a que mediante el método tradicional no se puede saber cómo son los movimientos entre dos sitios de captura, el método de polvos luminosos permitió obtener información importante a este respecto, indicando que esta especie se mueve bajo la protección que le ofrecen los arbustos.

Si bien no ha sido cuantificada la tortuosidad de las rutas realizadas por los animales, fue posible observar, al menos para las especies de múridos, que cuando se desplazaban bajo arbustos, sus recorridos eran más tortuosos, pasando más de una vez por el mismo sitio, y rodeando en círculo el tronco de las jarillas; mientras que cuando los desplazamientos se realizaban entre arbustos, éstos eran hechos en línea recta. Además, las distancias de desplazamientos sin cobertura fueron menores a aquellas bajo cobertura. Esto podría estar indicando que el riesgo de depredación influye en el comportamiento de forrajeo. Bajo cobertura, los animales se sentirían más seguros y se moverían libremente en busca de alimento, mientras que en ausencia de la misma los 
animales tratarían de moverse lo más rápido posible para alejarse de esta zona de peligro (Stapp y Van Horne, 1997). Esta observación, resulta de importancia sobre todo para E. typus, especie que en general se ha asociado con microhábitats abiertos. El mayor uso de la cobertura de arbustos especialmente en el medanal y los movimientos rectilíneos de poca longitud en ausencia de cobertura, indicarían que si bien esta especie puede explotar hábitats abiertos, sus movimientos se restringen a los parches donde encuentran protección. De todas maneras, sería necesario aumentar el número de observaciones para llegar a un patrón de uso del espacio por esta especie.

Un estudio de oferta de semillas en el medanal indicó que los individuos (probablemente de E. typus) prefirieron consumir las semillas ofrecidas bajo arbustos que las ofrecidas en ausencia de cobertura (Taraborelli, 2001), indicando que el riesgo de depredación juega un papel importante en el comportamiento de forrajeo de los roedores del desierto del Monte. Sin embargo, ningún estudio ha determinado el tiempo que los individuos permanecen bajo arbustos o sin cobertura, por lo que la comparación de las distancias recorridas entre distintos tipos de cobertura y la tortuosidad de los movimientos debería estar acompañada de observaciones del tiempo expedido en cada situación para poder afirmar que los individuos restringen sus movimientos a la protección de los arbustos.

A pesar de que E. typus es hábil trepadora (Orofino, com. pers.) no se han obtenido registros que indiquen la utilización del estrato vertical. Sin embargo, resultó interesante el hallazgo de polvo fluorescente dejado por un individuo de C. musculinus (en el $13,72 \%$ de su recorrido) por encima del nivel del suelo, llegando hasta los 50 $\mathrm{cm}$. de altura, sobre gramíneas, llaullín (Lycium sp.) o tomillo (Acantholippia seriphioides). Asimismo, el hallazgo de rastros de polvo dejado por T. pusillus sobre algarrobo, llaullín y atamisque (donde alcanzó 1,9 metros), aporta datos certeros de la utilización vertical del hábitat por esta especie y confirma su capacidad de trepado.

A pesar de estas observaciones, los resultados sobre selección de microhábitat en $T$. pusillus indicaron que esta especie, a diferencia de los múridos, prefiere áreas más abiertas, alejándose de las coberturas complejas y arbustivas y seleccionando 
microhábitats donde sólo hay suelo desnudo o mantillo. Probablemente utilizan los arbustos para trepar, pero no permanecen en el suelo bajo su cobertura. Nuevamente, faltarían datos del tiempo transcurrido arriba de los arbustos y en áreas abiertas para poder concluir la preferencia de esta especie por distintos microhábitats.

La selección diferencial del hábitat podría ser un mecanismo que permita la coexistencia de las especies (Kotler et al., 1994). El uso del estrato vertical por $T$. pusillus y la diferencia en el uso del microhábitat entre A. molinae y E. typus en el algarrobal podrían indicar que en esta porción del desierto del Monte están actuando los mecanismos que permiten la coexistencia, tal como ocurre en otros desiertos del mundo.

A su vez, la selección de hábitat podría estar mediada por el comportamiento de forrajeo. En varias ocasiones se ha observado que los animales pasaban por las estaciones de trampeo donde las trampas permanecían cerradas. Esta conducta podría estar indicando que las trampas con cebo, aún cerradas, afectan el comportamiento de forrajeo, modificando la búsqueda normal de alimento. Para eliminar este ruido, sería adecuado retirar las trampas antes de liberar los individuos y evitar que sean atraídos por ellas.

Los resultados obtenidos en este estudio son los primeros datos que se tienen sobre los movimientos de pequeños mamíferos del desierto del Monte, especialmente de T. pusillus. Aunque la cantidad de individuos utilizados para la aplicación de esta técnica no ha sido muy alta, especialmente de A. molinae y $T$. pusillus, es posible tener una aproximación acerca del uso de microhábitat de las especies de pequeños mamíferos del Monte. Por otro lado, se ha comprobado que a pesar de que en el medanal es un poco más dificultosa la utilización de polvos fluorescentes, es posible realizar estos estudios. Los rastros dejados en la arena son visibles, aún en ausencia de gramíneas. Sólo se necesita paciencia y un máximo de dos personas en el lugar, ya que se debe tener especial cuidado de no pisar sobre ellos. 


\section{Implicancias metodológicas}

Algunos autores (e.g. Stapp, 1997), capturan los animales a la noche, los revisan a la mañana y los mantienen todo el día fuera de su entorno, hasta la liberación al atardecer. Debido a que esto puede desorientar y modificar el comportamiento del animal, en este estudio se prefirió la liberación de los mismos al poco tiempo de ser capturados, tal como se describe en el trabajo de Lemen y Freeman (1985).

En la mayoría de los trabajos que emplearon la técnica de polvos fluorescentes (Barnum et al., 1992; Bestelmeyer y Stevenson, 1998; Cittadino y Kravetz, 2000; Desy et al., 1989; Lemen y Freeman, 1985; Stapp, 1997), se usaron polvos de la misma marca (Radiant, Richmond, CA) y luego luz ultravioleta para seguir el rastro fluorescente dejado por el animal a la noche siguiente de la liberación. Los polvos luminosos utilizados en este trabajo (BioQuip, Gardena, CA) son muy fáciles de visualizar durante el día, e incluso pueden seguirse por más tiempo cuando se ven con luz natural que con luz UV, lo que facilita el trabajo de campo, ahorra tiempo debido a que no es necesario esperar hasta la noche próxima para encontrar el rastro y ahorra dinero en linternas y pilas. La recaptura de animales sometidos al experimento (con rastros de polvos sobre la piel) revela que no afecta la salud de los mismos. En un caso, un mismo individuo fue seguido durante dos noches consecutivas, aplicándole en cada noche un color distinto.

Respecto a los colores utilizados, resultó más efectivo el color rojo (\# 1162R) que el azul (\# 1162B). Este último puede confundirse con algunos reflejos propios de las herbáceas y se pierde de vista más rápidamente.

También se probó la técnica desarrollada por Bestelmeyer y Stevenson (1998) que consiste en la sujeción de una cápsula de gelatina porosa rellena con polvo fluorescente a la base de la cola del animal (Fig. 8). Sin embargo, no resultó adecuada debido a que el animal (un individuo de G. griseoflavus) rápidamente se quitó y destruyó la cápsula, sin dejar rastro de sus movimientos. 
La desventaja de la utilización de polvos es que su duración es efímera (aunque resiste lluvias débiles) y sólo es observable durante unos pocos metros. La técnica de captura y recaptura, en cambio, permite el estudio del movimiento de los individuos durante un período prolongado de tiempo (semanas, meses). A pesar de esto, no puede determinarse qué ocurre entre capturas sucesivas y esta metodología puede sesgar los resultados. Un ejemplo de ello pudo observarse en uno de los individuos de E. typus. Este individuo había sido capturado durante el período de trampeo durante cuatro noches consecutivas en la misma trampa del medanal antes de administrarle polvo luminoso. Con los datos de trampeo no se hubiese obtenido la distancia recorrida, en cambio, con polvo fluorescente en una sola noche pudo observarse que recorrió $130 \mathrm{~m}$ y regresó al punto de partida. El microhábitat de esa estación de trampeo contenía 75\% de suelo desnudo, $50 \%$ de cobertura de arbustos y 55\% de herbáceas. La interpretación que se podría haber hecho es que ese individuo usaba microhábitats abiertos, pero los datos obtenidos a partir del recorrido realizado por el animal, indicaron que el $74 \%$ de los registros estuvieron bajo cobertura de arbustos. Es decir, que los datos provenientes de los trampeos pueden resultar muy útiles para estimar estructura de la comunidad, densidad de cada especie, área de acción, etc., pero para el estudio de selección de microhábitat son más precisos los datos obtenidos a partir de la técnica de polvos luminosos. 


\section{5. CONCLUSIONES}

En base a la utilización de polvos luminosos como técnica alternativa en el estudio de uso y selección de microhábitat, se obtuvieron los siguientes resultados:

- Eligmodontia typus usó en mayor proporción los microhábitats con cobertura de arbustos. En el medanal, las distancias que recorrían bajo la cobertura arbustiva eran mayores a las recorridas en ausencia de cobertura. En el algarrobal no hubo diferencias entre las distancias recorridas bajo cobertura o sin ella.

- Akodon molinae usó principalmente los microhábitats con mayor cobertura de arbustos, aunque también utilizó la cobertura de herbáceas y la cobertura más compleja (arbustos, subarbustos y herbáceas). Las distancias recorridas bajo la cobertura de arbustos son mayores a las recorridas fuera de ellas.

- Se encontró una segregación de microhábitat entre individuos de E. typus y $A$. molinae en el algarrobal, utilizando E. typus más porcentaje de suelo desnudo y mantillo y A. molinae mayor cobertura de herbáceas.

- No se encontró un claro patrón de selección de microhábitat en C. musculinus. En el jarillal esta especie prefirió los microhábitats más complejos (con herbáceas, arbustos y subarbustos), en el medanal seleccionó la cobertura de arbustos y en el algarrobal el suelo desnudo. Se observó la utilización del estrato vertical por esta especie, alcanzando los $50 \mathrm{~cm}$ de altura.

- T. pusillus seleccionó las áreas más abiertas, aunque se encontraron registros sobre árboles y arbustos, alcanzando 1,9 $\mathrm{m}$ de altura.

- En general, los resultados obtenidos a partir de la técnica de polvos luminosos no se corresponden con los obtenidos a partir de trampeos. 


\subsection{TABLAS y FIGURAS}

Tabla 1. Datos de los individuos utilizados para el experimento con polvos luminosos

\begin{tabular}{|c|c|c|c|c|c|c|c|}
\hline Especie & $\begin{array}{l}\text { Fecha de } \\
\text { muestreo }\end{array}$ & Hábitat & Sexo & $\begin{array}{l}\text { Color del } \\
\text { polvo }\end{array}$ & $\begin{array}{l}\text { Peso } \\
\text { (gs) }\end{array}$ & $\begin{array}{l}\text { Distancia } \\
\text { recorrida }\end{array}$ & Área \\
\hline \multirow[t]{5}{*}{ E. typus } & \multirow[t]{4}{*}{ Nov. 2000} & \multirow[t]{4}{*}{ medanal } & \multirow[t]{4}{*}{ macho } & rojo & & $\begin{array}{l}75,5 \\
\end{array}$ & 700 \\
\hline & & & & azul & 13 & 29,5 & 150 \\
\hline & & & & \begin{tabular}{|l|} 
azul \\
\end{tabular} & 19 & 72 & 375 \\
\hline & & & & rojo & 21 & 130 & 1102,5 \\
\hline & Marzo 2001 & algarrobal & macho & rojo & & 33 & 177,6 \\
\hline \multirow[t]{2}{*}{ A. molinae } & \multirow[t]{2}{*}{ Marzo 2001} & jarillal & hembra & rojo & & 43,95 & 129,8 \\
\hline & & algarrobal & hembra & azul & & 20,55 & 52,8 \\
\hline \multirow[t]{8}{*}{ C. musculinus } & \multirow[t]{2}{*}{ Oct. 2001} & \multirow[t]{2}{*}{ algarrobal } & $?$ & rojo & & 133,8 & 1397 \\
\hline & & & hembra & azul & 22 & 67,8 & 114,75 \\
\hline & Oct. 2001 & \multirow{3}{*}{ jarillal } & \multirow[t]{3}{*}{ macho } & rojo y azul & 27,5 & $92,2-65,8$ & $407-348$ \\
\hline & \multirow[t]{2}{*}{ Mayo 2002} & & & rojo & 12 & 107,1 & 200 \\
\hline & & & & rojo & 12 & 48,15 & 306 \\
\hline & \multirow[t]{3}{*}{ Mayo 2002} & \multirow[t]{3}{*}{ medanal } & macho & rojo & 13 & 38,55 & 135 \\
\hline & & & hembra & azul & 12 & 44,85 & 153 \\
\hline & & & hembra & azul & 14 & 28,8 & 72 \\
\hline \multirow[t]{3}{*}{ T. pusillus } & \multirow[t]{3}{*}{ Mayo 2002} & jarillal & macho & rojo & 24 & 15 & 206 \\
\hline & & algarrobal & macho & rojo & 15 & 74,1 & 518 \\
\hline & & medanal & macho & rojo & 18 & 8,55 & 22,5 \\
\hline
\end{tabular}


Tabla 2. Distancias mínimas recorridas en una noche por cada especie, áreas promedio y desvíos estándar.

\begin{tabular}{|lcc|}
\hline Especie & Dist. promedio $(\mathrm{m})$ & Área promedio $\left(\mathrm{m}^{2}\right)$ \\
\hline E. typus & $68 \pm 40,69$ & $501,02 \pm 401,58$ \\
A. molinae & $32,25 \pm 16,55$ & $91,3 \pm 54,45$ \\
C. musculinus & $69,7 \pm 34,92$ & $348,08 \pm 409,5$ \\
T. pusillus & $32,55 \pm 36,13$ & $248,83 \pm 250,5$ \\
\hline
\end{tabular}


Fig. 1. Individuos coloreados con polvos luminosos

a) Individuo de E. typus con polvo azul

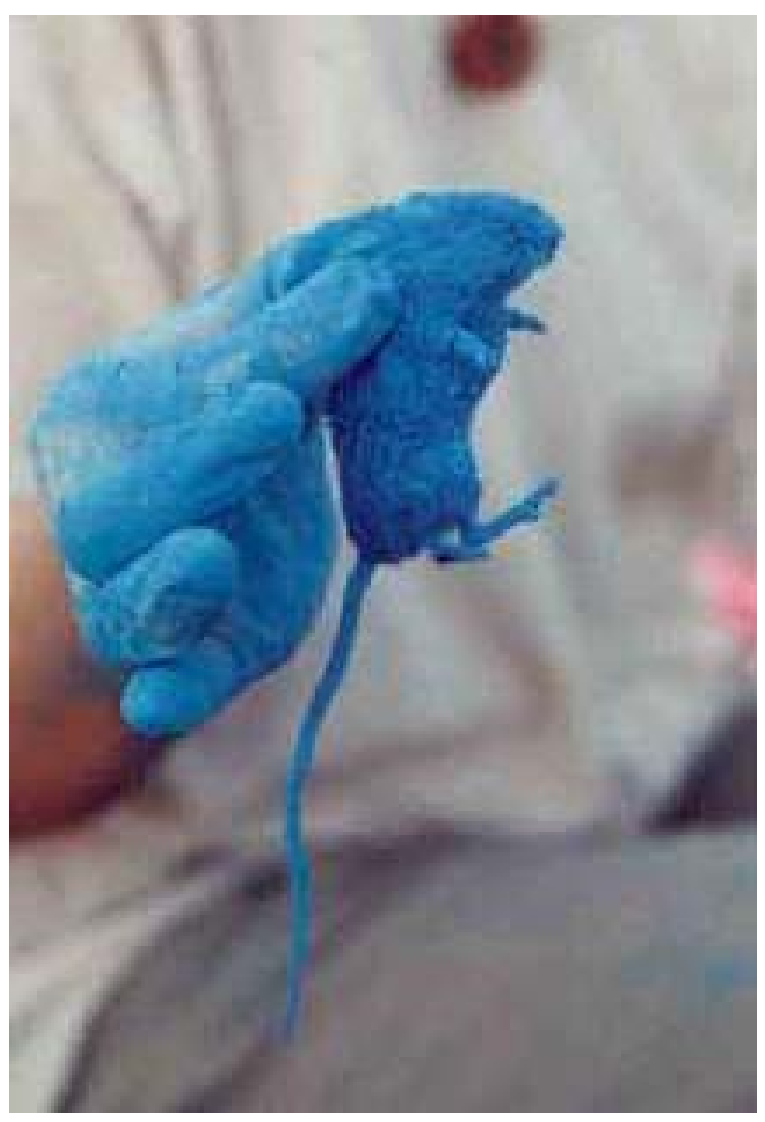

b) Individuo de $A$. molinae con polvo rojo

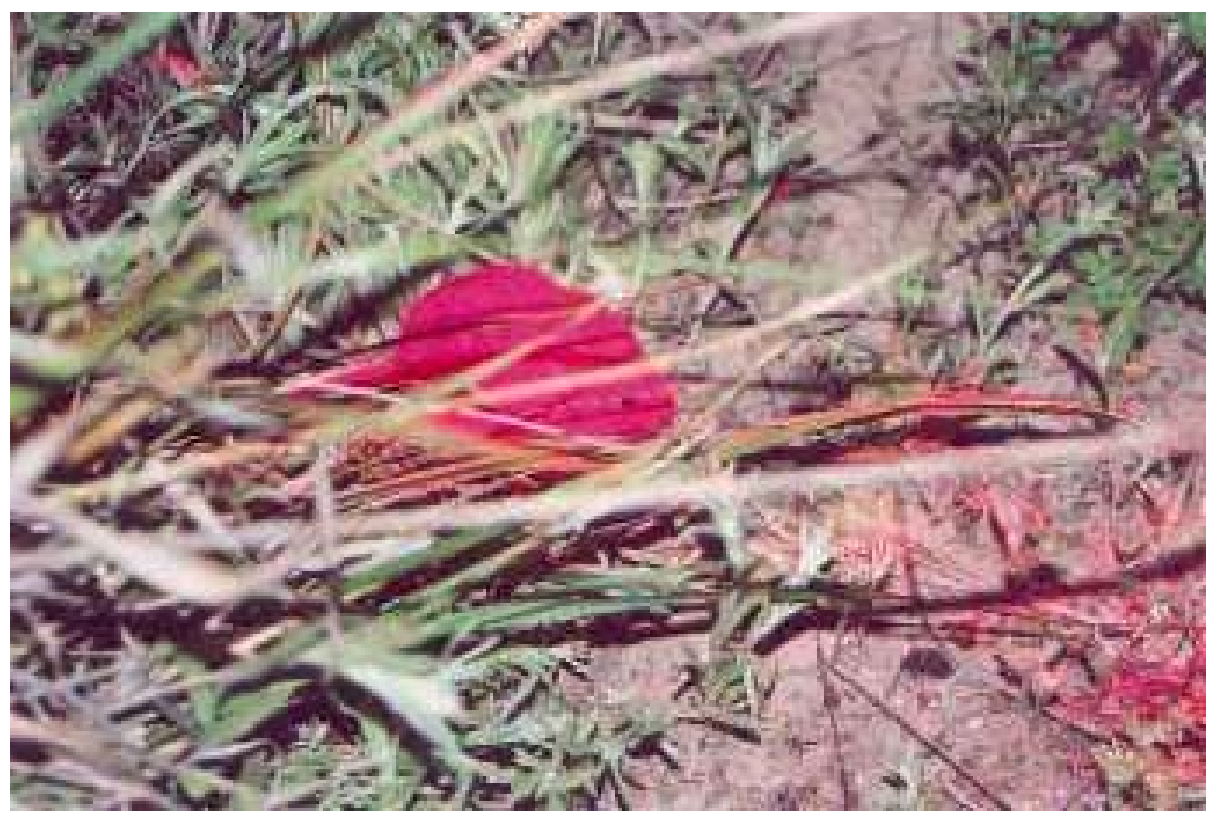


Fig. 2. Recorrido dejado por un individuo de Eligmodontia typus en el medanal de la Reserva de la Biósfera de Nacuñán

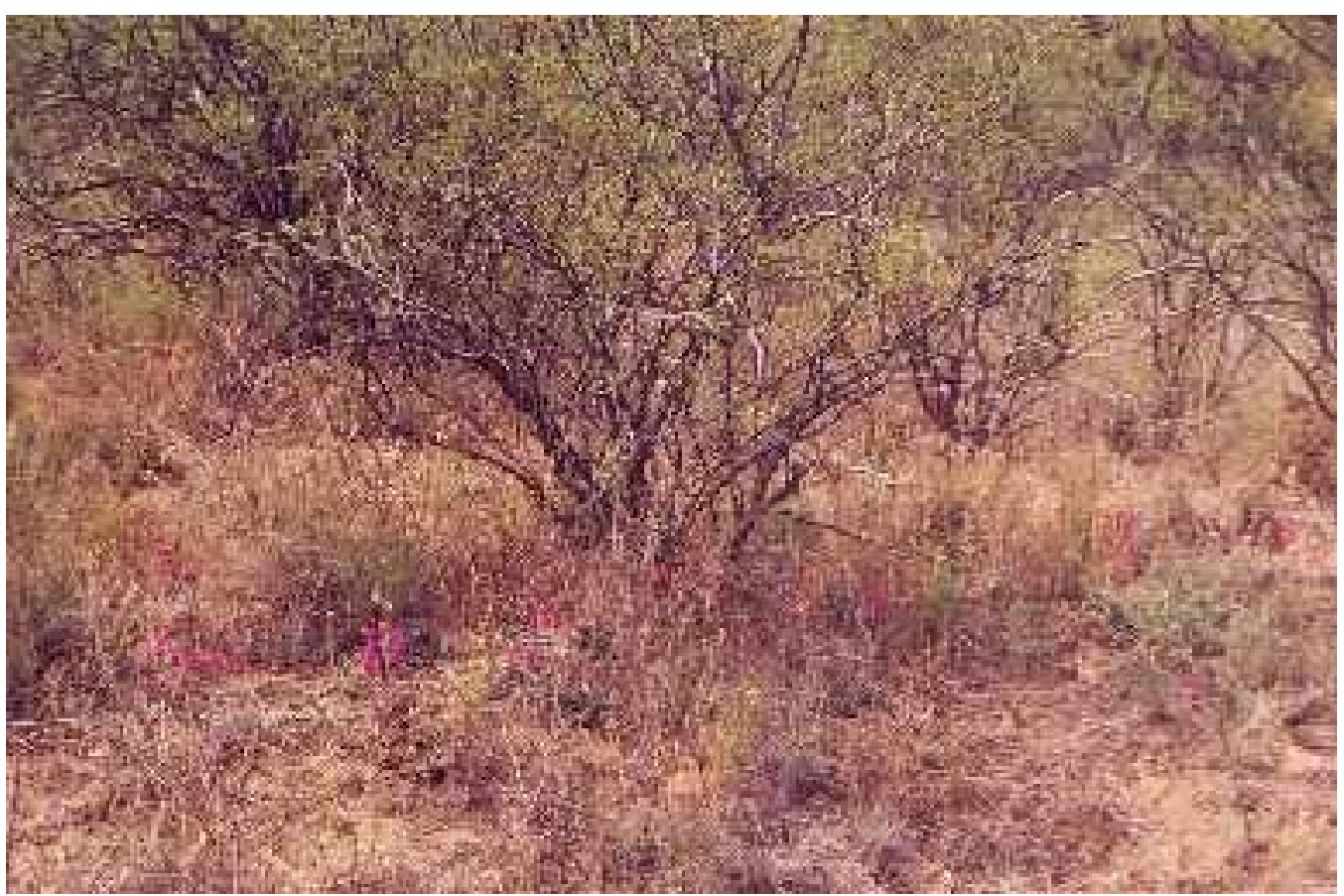


Fig. 3. Uso de microhábitat por E. typus en la Reserva de la Biósfera de Ñacuñán SD: suelo desnudo; M: cobertura de mantillo solamente; H: cobertura de herbáceas; $\mathbf{S}$ : cobertura subarbustiva; $\mathbf{A}$ : cobertura arbustiva; $\mathbf{C}$ : cobertura compleja Las letras diferentes (a, b, c y d) indican diferencias significativas entre las distintas categorías

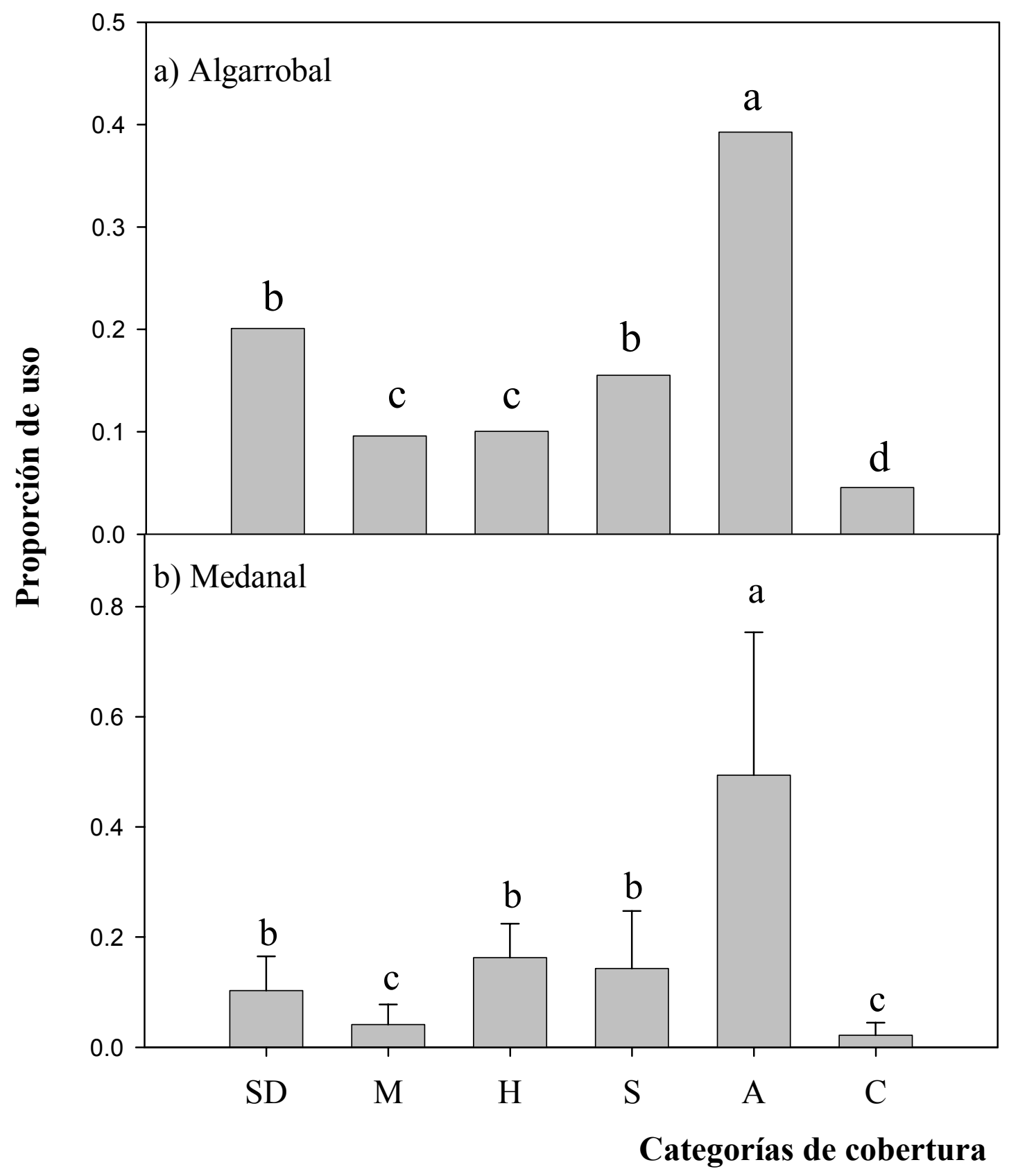


Fig. 4. Uso de microhábitat por A. molinae en la Reserva de la Biósfera de Ñacuñán SD: suelo desnudo; M: cobertura de mantillo solamente; H: cobertura de herbáceas; $\mathbf{S}$ : cobertura subarbustiva; $\mathbf{A}$ : cobertura arbustiva; $\mathbf{C}$ : cobertura compleja Las letras diferentes $(\mathrm{a}, \mathrm{b}, \mathrm{c}$ y d) indican diferencias significativas entre las distintas categorías

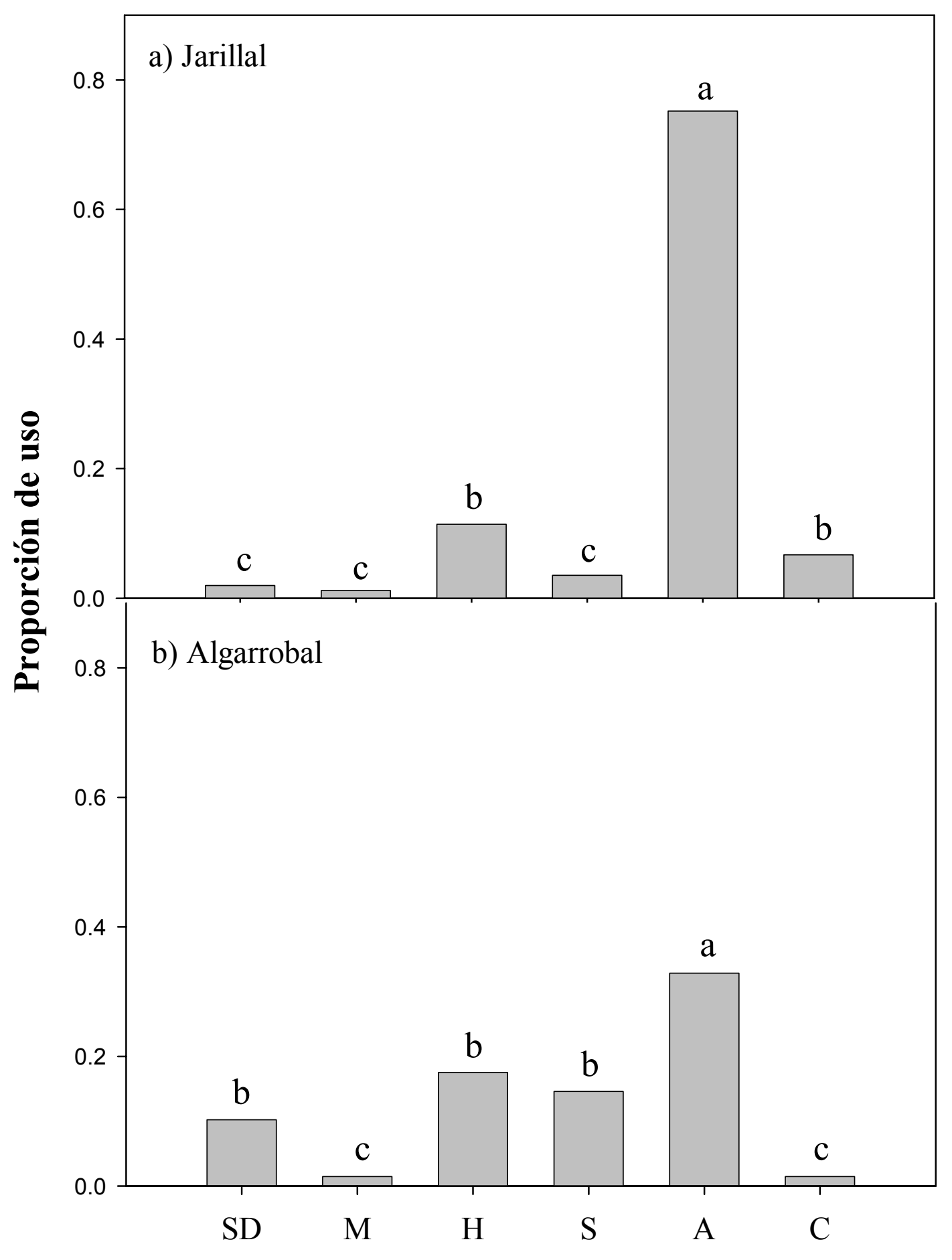

\section{Categoría}


Fig. 5. Segregación de microhábitat por Akodon molinae y Eligmodontia typus en la Reserva de la Biósfera de Nacuñán

Las categorías con asteriscos indican que son usadas de manera significativamente diferente por las dos especies

SD: suelo desnudo; M: cobertura de mantillo solamente; $\mathbf{H}$ : cobertura de herbáceas; $\mathbf{S}$ : cobertura subarbustiva; $\mathbf{A}$ : cobertura arbustiva; $\mathbf{C}$ : cobertura compleja

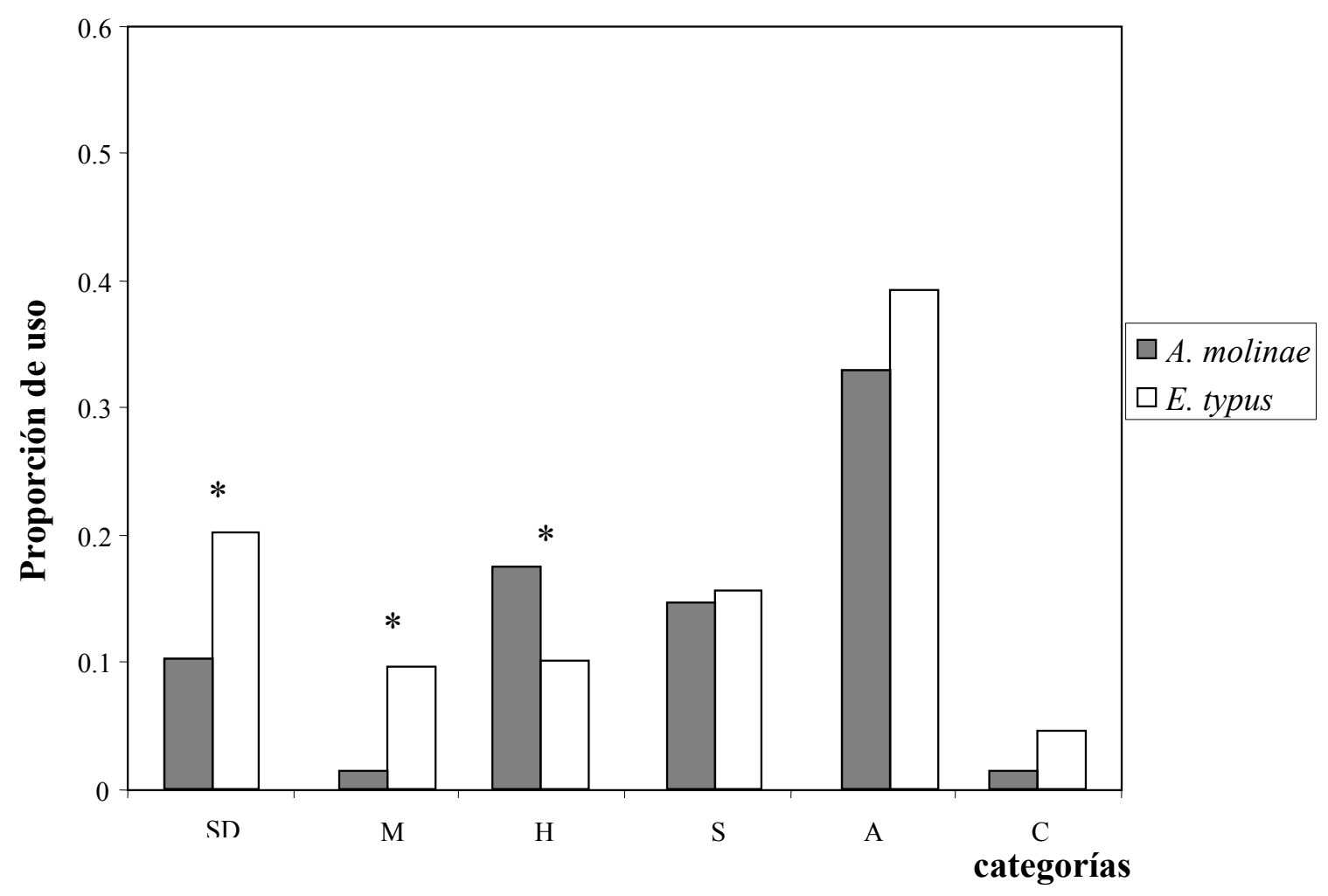


Fig. 6. Selección de microhábitat por C. musculinus

SD: suelo desnudo; $\mathbf{M}$ : cobertura de mantillo solamente; $\mathbf{H}$ : cobertura de herbáceas; $\mathbf{S}$ : cobertura subarbustiva; $\mathbf{A}$ : cobertura arbustiva; $\mathbf{C}$ : cobertura compleja Los asteriscos indican diferencias significativas entre el uso por los individuos y la disponibilidad en el ambiente

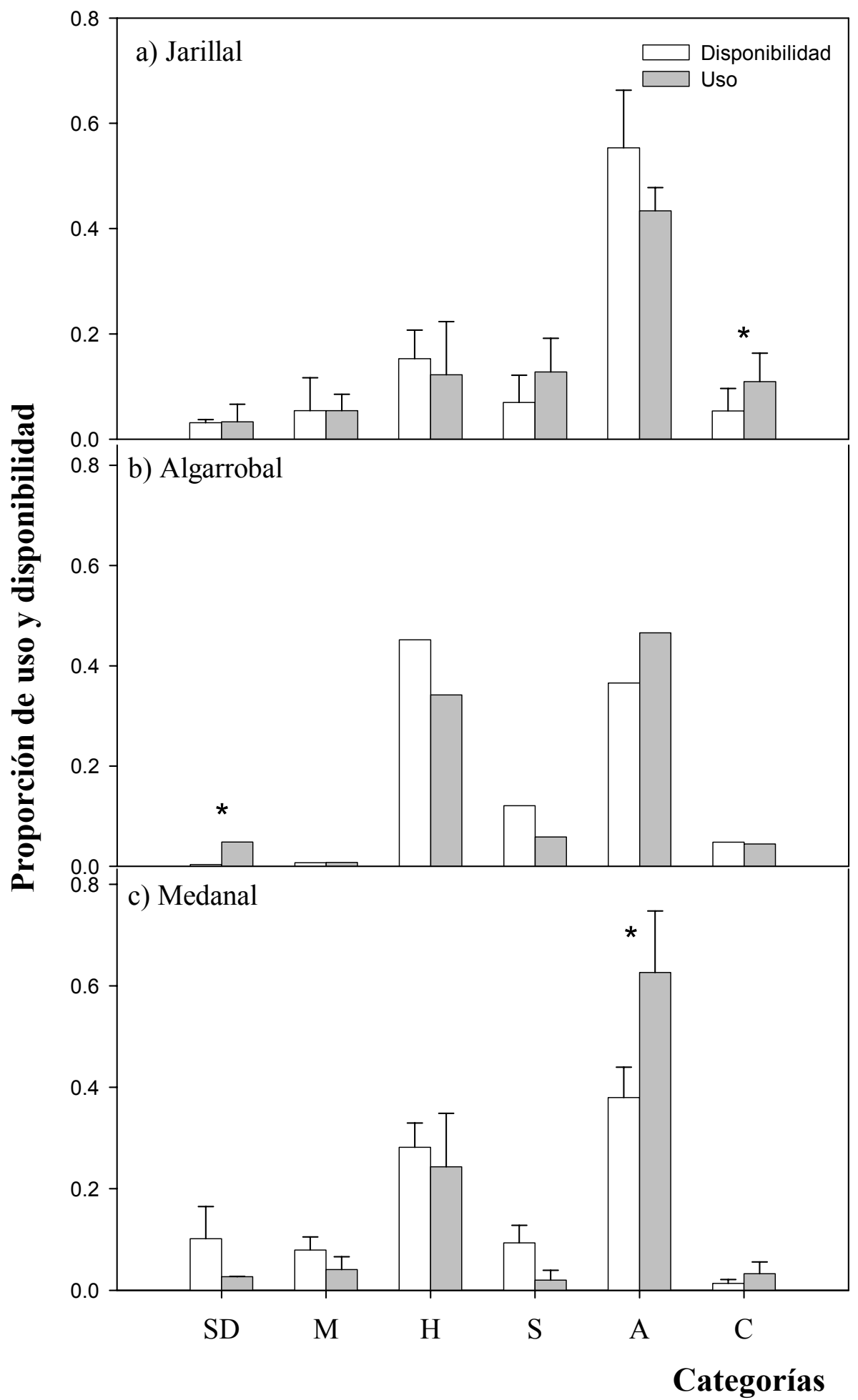


Fig. 7.Selección de microhábitat por T. pusillus

SD: suelo desnudo; $\mathbf{M}$ : cobertura de mantillo solamente; $\mathbf{H}$ : cobertura de herbáceas; $\mathbf{S}$ : cobertura subarbustiva; $\mathbf{A}$ : cobertura arbustiva; $\mathbf{C}$ : cobertura compleja Los asteriscos indican diferencias significativas entre el uso por los individuos y la disponibilidad en el ambiente

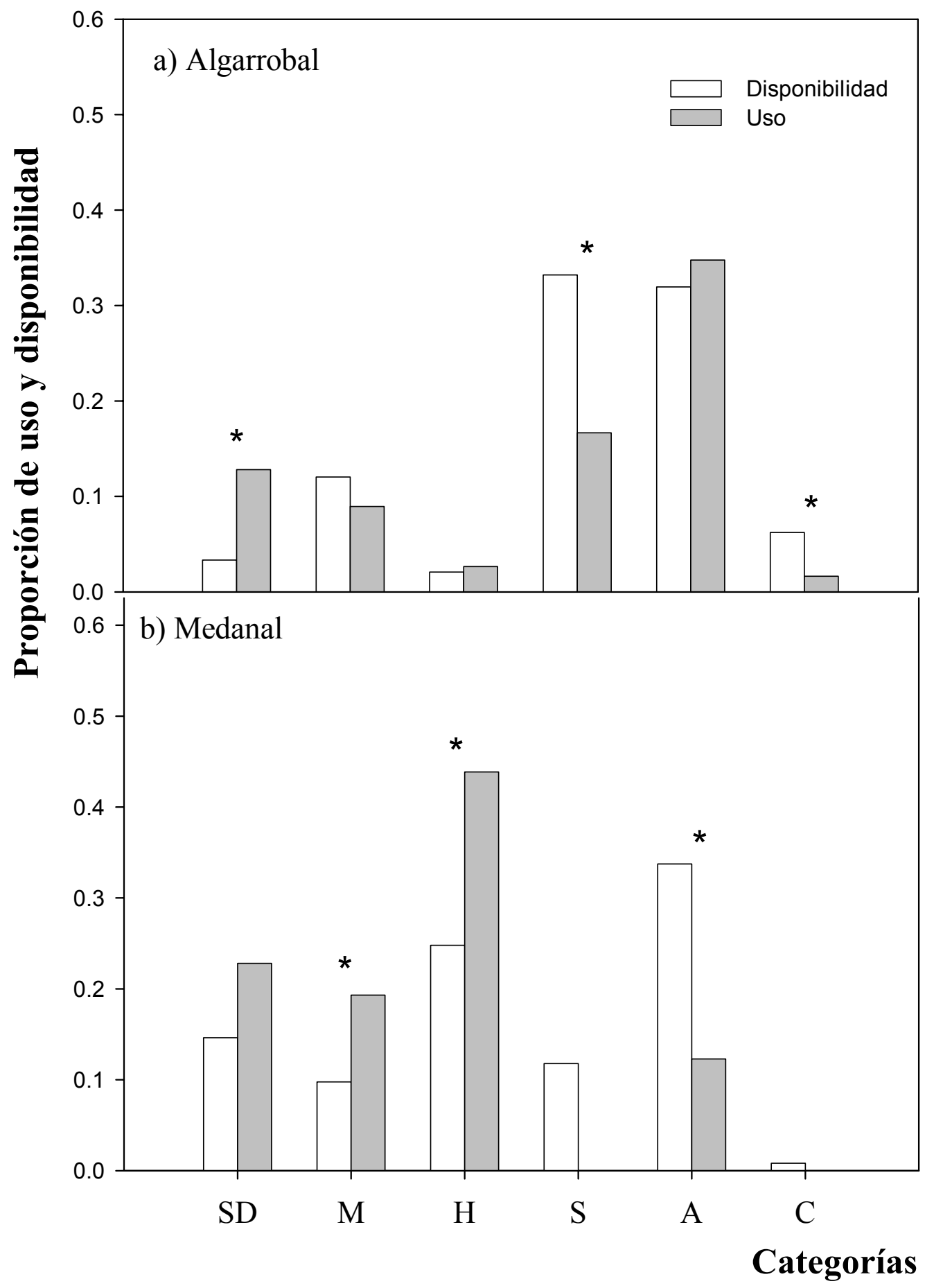


Fig. 8. Técnica de Bestelmeyer y Stevenson (1998) aplicada a un individuo de Graomys griseoflavus

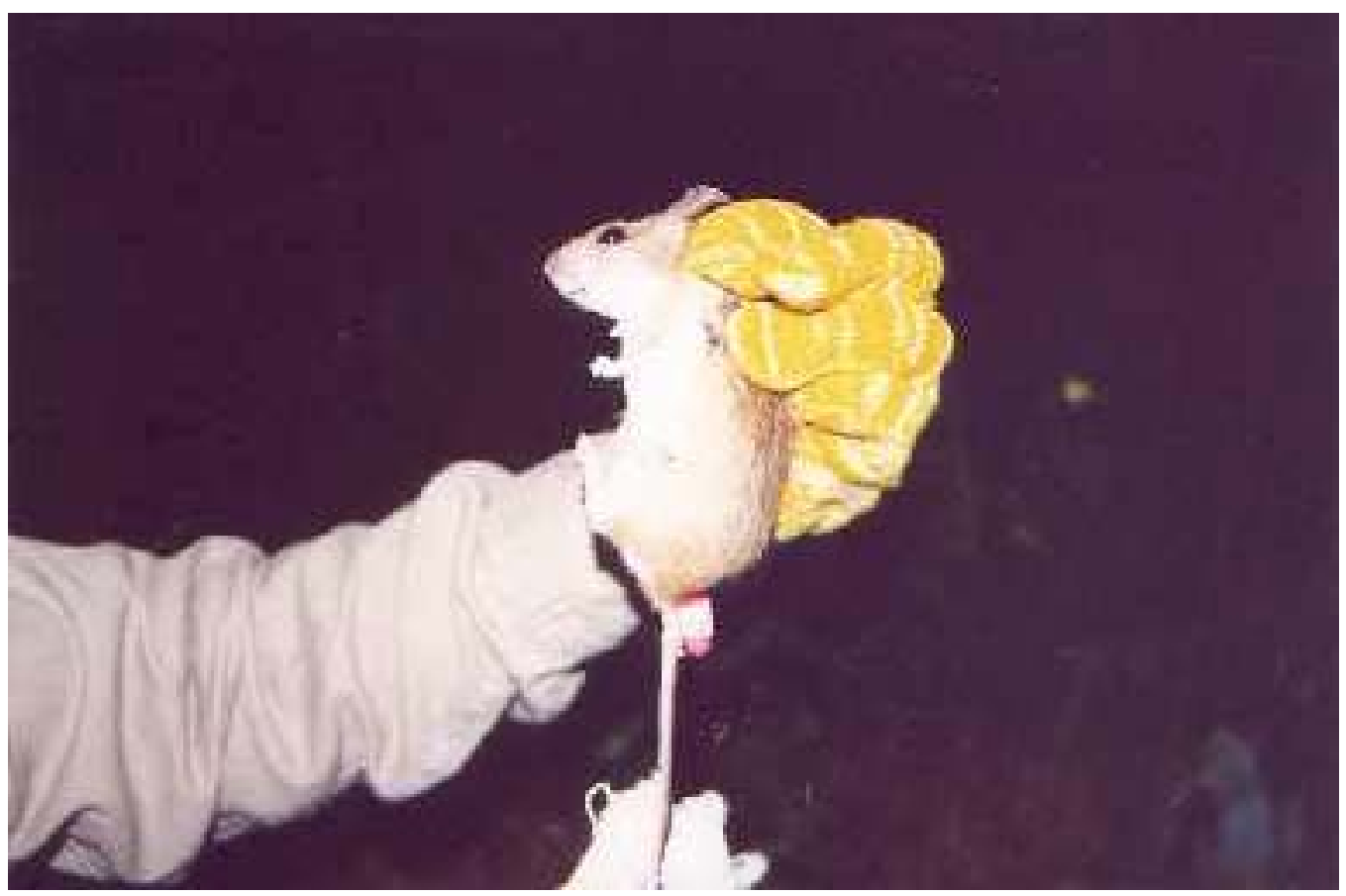


Capítulo 7

ÁREA DE ACCIÓN DE LAS CUATRO
ESPECIES DE MÚRIDOS 


\section{Capítulo 7. ÁREA DE ACCIÓN DE LAS CUATRO ESPECIES DE MÚRIDOS}

\subsection{INTRODUCCIÓN}

El área de acción ("home range") de un mamífero está definida como aquella donde el animal desarrolla sus actividades diarias normales tales como forrajeo, apareamiento y cuidado de las crías incluyendo conductas de exploración y de contacto (Burt, 1943). El territorio, por otro lado, es un área defendida por el animal a través de esquemas innatos de conducta intraespecífica y, generalmente, de menor tamaño que el área de acción (Howard, 1920; Noble, 1939).

La forma en que los individuos de una población utilizan el espacio refleja la manera en que éstos interactúan entre sí y con el ambiente (Heinemann et al, 1995). El tamaño del área de acción puede estar afectado por la calidad del hábitat, la distribución y abundancia del alimento, la densidad poblacional, el sexo, la edad, el tamaño corporal, la condición social y la actividad reproductiva (Gentile et al., 1997; Heinemann et al., 1995; Maza et al., 1973; Mazurkiewicz, 1971; Pires et al., 1999; Priotto y Steinmann, 1999; Ribble y Stanley, 1998; Webster y Brooks 1981; Wolff 1985). El tamaño suele ser mayor cuando el alimento es escaso y se encuentra disperso, ya que el animal tiene que explorar un área mayor en la búsqueda del mismo. En muchas especies (jerbos, por ejemplo), existe una relación positiva entre tamaño corporal y área de acción (Shenbrot et al., 1999). Las especies de mayor tamaño requieren más energía para mantener su metabolismo (Kotler et al., 1994), por lo que necesitan recorrer áreas más extensas. Sin embargo, en las ratas canguro no existe relación entre tamaño corporal y área de acción (Shenbrot et al., 1999). Por otro lado, a altas densidades poblacionales, los individuos responden restringiendo su área de acción o aumentando la superposición espacial con individuos de la misma o de otras especies (Gentile et al., 1997; Ribble y Stanley, 1998). Las especies más agresivas (o "dominantes") tienden a excluir a las especies 
subordinadas, resultando en una baja superposición espacial para las primeras y una alta superposición en las segundas (O`Farrell, 1980).

Ostfeld (1990), propone que las hembras son intrasexualmente territoriales ya sea para proteger los recursos alimenticios o alternativamente para prevenir el infanticidio (Wolff, 1993). Por otra parte, las áreas de los machos suelen ser mayores para permitir el acceso a varias hembras (Gentile et al., 1997; Ribble y Stanley, 1998) y asegurar la descendencia.

El sistema de apareamiento de una población puede ser inferido a partir del estudio de los patrones de movimiento de ambos sexos (Gaulin y Fitzerald, 1986, 1988). Heinemann et al. (1995) describen tres hipótesis alternativas de estrategias reproductivas de pequeños mamíferos utilizadas por una población sobre la base del dimorfismo sexual, el tamaño del área de actividad de machos y hembras y la superposición del área de un individuo con la de sus congéneres:

1) Monogamia: las poblaciones tendrían escaso dimorfismo sexual, tamaño similar de las áreas de actividad de machos y hembras, superposición total del área de cada individuo con la de un individuo del otro sexo. Territorialidad en ambos sexos.

2) Poliginia: machos de mayor tamaño corporal con áreas de actividad mayores que las de las hembras, sin superposición intrasexual y abarcando las áreas de varias hembras en forma exclusiva. Las hembras podrían o no ser territoriales.

3) Promiscuidad: no existiría un marcado dimorfismo sexual. Las áreas de actividad de los machos, también mayores que las de las hembras, se superpondrían entre sí, y ambos sexos presentarían superposiciones intersexuales múltiples. Aquí también las hembras podrían o no ser territoriales.

El conocimiento de la organización social y espacial de los roedores del Monte es escaso. Los mayores aportes provienen de Contreras y Rosi (1980c 1981), especialmente para C. musculinus cordovensis. Sus estudios revelaron que el área de acción de esta especie es de $366,07 \mathrm{~m}^{2}$ al tiempo que existe alta superposición de las áreas de acción y carencia de espacios exclusivos (excepto en las áreas de los 
machos supuestamente dominantes, donde hay un bajo grado de superposición). A pesar de esta interpenetrabilidad de las áreas de acción, los autores afirman que la especie demuestra una organización espacial de tipo territorial (Contreras y Rosi, 1980c, 1981), tal como la encontrada para C. musculinus murillus por Kravetz (1978).

El comportamiento territorial también fue observado para algunas especies del género Akodon (Contreras y Rosi, 1981), lo que ha llevado a generalizar este comportamiento como característico de los akodontinos (Gentile et al., 1997).

Para el resto de las especies no hay información, salvo que está reportado un diámetro del home range para E. typus de $31 \mathrm{~m}$ (Redford y Eisenberg, 1992). Debido a esta escasa información, se plantearon los siguientes objetivos:

- Conocer las áreas de acción de las especies de roedores del Monte central.

- Evaluar si existen diferencias en el área de acción entre machos y hembras de cada especie

- Establecer si las diferencias en la estructura del hábitat (abierto/cerrado) influye en el tamaño del área de acción de los individuos

- Evaluar la influencia de la densidad poblacional sobre la superposición espacial interespecífica.

- Estimar la superposición espacial entre sexos en individuos de la misma especie 


\subsection{MATERIALES Y MÉTODOS}

\section{Área de acción}

El área de acción fue calculada a partir de las capturas y recapturas de los individuos en las 6 grillas de muestreo establecidas en el área de estudio. Para ello se utilizó el Método del Mínimo Polígono Convexo (Jenrich y Turner, 1969; Stickel, 1954) con inclusión de borde. Este método consiste en unir los puntos de capturas de cada individuo de manera de obtener un polígono convexo (es decir, las líneas unen los puntos más alejados entre sí) y agregarle un borde igual a la mitad de la distancia entre las estaciones de trampeo (7,5 m en este caso).

El número de capturas necesarias para calcular el área de acción en cada especie fue establecido sobre la base de la estabilización de una curva al graficar el número de capturas y el área obtenida (Pires et al, 1999). Así, para E. typus $(\mathrm{n}=72)$, A. molinae $(\mathrm{n}=69)$ y C. musculinus $(\mathrm{n}=24)$ con tres capturas es suficiente, en cambio para G. griseoflavus $(\mathrm{n}=59)$ son necesarias al menos 5 .

Para calcular las áreas de acción de cada especie en un período de muestreo (una sesión de trampeo), se incluyeron en los análisis 72 individuos de E. typus, 24 de C. musculinus, 69 de A. molinae y 12 de G. griseoflavus. Las áreas calculadas fueron comparadas entre especies, entre sexos y entre hábitats. Debido a que en algunos individuos no pudo determinarse el sexo, las comparaciones de las áreas entre sexos fue realizada sólo con los individuos que han sido sexualmente determinados, por lo que la cantidad de individuos utilizada en los análisis fue en algunos casos menor al número total.

Debido a la naturaleza de los datos se debió utilizar para ello estadística no paramétrica, siendo el test U de Mann Whitney el empleado para las comparaciones de dos o más conjuntos de datos, y el test de Kruskal Wallis el empleado para más de dos comparaciones. La relación entre el peso y el área de acción de cada especie y del total de los individuos fue establecida con una regresión lineal simple. 
También se calcularon las áreas de acción en aquellos individuos que fueron recapturados en más de una sesión de trampeo, es decir, estas áreas incluyen los movimientos de los individuos en un mes o más ("períodos largos"). Para calcular estas áreas se utilizaron 20 individuos de E. typus, 5 de C. musculinus, 20 de $A$. molinae y 20 de G. griseoflavus.

Sólo las áreas correspondientes a períodos cortos (una sesión) de muestreo fueron utilizadas para las comparaciones entre especies, entre sexos y entre hábitats.

Con el objeto de investigar potenciales interacciones interespecíficas en las tres comunidades estudiadas, se calculó un índice de superposición espacial en cada período de trampeo. Se consideró más apropiado calcular la superposición de los sitios de captura o microhábitats que la superposición de áreas, debido a que no pudieron calcularse las áreas de acción de todos los individuos de la población por no obtener 3 o más capturas de cada uno. Las crías fueron excluidas de los cálculos.

Siguiendo a O'Farrell (1980), quien llama "loci" a los sitios de captura se utilizó la siguiente ecuación:

$$
\mathrm{IS}_{\mathrm{i}}=\frac{\mathrm{M}_{\mathrm{i}} \cap \mathrm{M}_{\mathrm{i}}}{\mathrm{M}_{\mathrm{iTot}}}
$$

donde $\mathrm{M}_{\mathrm{i}} \cap \mathrm{M}_{\mathrm{j}}$ es el número de sitios de captura (microhábitats) que la especie $i$ comparte con individuos de la especies $j$; y $\mathrm{M}_{\mathrm{iTot}}$ es el número total de sitios de captura para la especie $i$.

La ecuación 1 calcula la superposición de $j$ sobre $i$, mientras que la ecuación

$$
\mathrm{IS}_{\mathrm{j}}=\frac{\mathrm{M}_{\mathrm{i}} \cap \mathrm{M}_{\mathrm{j}}}{\mathrm{M}_{\mathrm{jTot}}}
$$

calcula la superposición de $i$ sobre $j$.

Un índice de superposición multiplicado por 100 expresa el valor en porcentaje. 
El mismo índice fue adaptado para evaluar la superposición espacial entre sexos dentro de una misma especie y entre individuos del mismo sexo. Estas estimaciones fueron realizadas sólo para los adultos en la época reproductiva. 


\subsection{RESULTADOS}

\section{Diferencias entre sexos}

No se encontraron diferencias significativas entre las áreas de acción de machos y hembras de G. griseoflavus $(\mathrm{U}=16, p=1)$, E. typus $(\mathrm{U}=543, p=0,67)$ ni C. musculinus ( $\mathrm{U}=41,5, p=0,36)$. Sin embargo, se encontró que los machos de A. molinae tienen un área de acción mayor que las hembras de esa especie $(\mathrm{U}=232,5, p=0,01)($ Tabla 1$)$.

\section{Diferencias entre especies}

Para comparar las áreas de las distintas especies entre sí, fueron agrupados los datos de machos y hembras excepto para $A$. molinae, que se analizaron separadamente. El análisis de la varianza no paramétrico (Kruskal Wallis) demostró que las áreas de las distintas especies no difieren entre sí (K-W=8,42, $p=0,08)$. Tampoco se encontraron diferencias significativas al repetir el análisis agrupando los datos de ambos sexos de A. molinae (K-W = 4,54, $p=0,21$; Tabla 1).

El tamaño del área promedio de cada especie para una sesión de trampeo (períodos cortos) y varias sesiones (períodos largos) se informan en la Tabla 2.

\section{Diferencias entre hábitats}

Cuando se compararon las áreas de acción de cada especie entre los distintos hábitats, no se encontraron diferencias significativas en C. musculinus $(\mathrm{K}-\mathrm{W}=0,34$; $p=0,84)$ ni en E. typus (K-W =3,14, $p=0,21)$. Al agrupar los datos de ambientes cerrados (jarillal y algarrobal) y compararlos con ambientes abiertos (medanal) tampoco se encontraron diferencias significativas $(\mathrm{U}=33,5 ; p=0,64$ en $C$. musculinus; $\mathrm{U}=517, p=0,14$ en E. typus). La comparación en G. griseoflavus sólo 
pudo realizarse entre el jarillal y el algarrobal debido a la ausencia de datos en el medanal, sin encontrarse diferencias en las áreas entre estos dos hábitats $(U=15,5$, $p=0,75)$. Cuando fueron comparadas las áreas de acción de $A$. molinae, en cambio, se encontraron diferencias significativas entre el algarrobal y el jarillal $(\mathrm{U}=304$; $p=0,027)$, siendo de mayor tamaño las áreas en el algarrobal.

\section{Relación entre peso y área de acción}

No se encontró una relación entre el peso y el área de acción al realizar la regresión entre los pesos promedios y las áreas promedio de cada especie $\left(\mathrm{R}^{2}=0,78 ; p=0,07 ; \mathrm{n}=4\right)$. Al realizar la regresión con el total de los individuos, se encontró que la asociación entre ambas variables es muy débil $\left(R^{2}=0,051\right.$; $p=0,0017 ; \mathrm{n}=170)$.

Dentro de cada especie tampoco se encontró una relación entre estas variables para E. typus, A. molinae y C. musculinus $\left(\mathrm{R}^{2}=0,036, p=0,27, \mathrm{n}=68\right.$; $\mathrm{R}^{2}=-0,015, p=0,85, \mathrm{n}=66 ; \mathrm{R}^{2}=0,054, p=0,14, \mathrm{n}=24$, respectivamente). En cambio, se encontró que el área de acción de G. griseoflavus aumenta al aumentar el peso de los individuos $\left(\mathrm{R}^{2}=0,28 ; p=0,045 ; \mathrm{n}=12\right)$.

\section{Superposición espacial interespecífica}

En los meses de mayor densidad poblacional (abril, mayo), la superposición interespecífica es mayor que en los meses de menor densidad poblacional (Fig. 1). Mientras que en el jarillal y en el algarrobal en los meses de mayor densidad los índices de superposición fueron altos (alcanzando el 92\% y 88\% respectivamente), en el medanal los índices fueron más bajos, fluctuando entre 0 y $67 \%$ (Fig. 1). En este hábitat no pudo calcularse un índice de superposición interespecífica en los meses de agosto y octubre de 1999 debido a que la única especie capturada fue $E$. typus. La figura 2 ejemplifica la superposición de las áreas de acción de las especies en época de alta y baja densidad poblacional. 


\section{Superposición espacial intraespecífica}

Los valores de superposición intersexual (machos sobre hembras) en la época reproductiva no superan el $26 \%$ de superposición, siendo este valor registrado para G. griseoflavus, mientras que la menor se registró para A. molinae. (Tabla 3; Fig. 3).

La superposición espacial intrasexual también fue baja en todas las especies, aunque los valores de la superposición entre hembras resultaron ligeramente menores a la superposición entre machos (Tabla 3 ). 


\subsection{DISCUSIÓN}

Las áreas de acción no difirieron entre las distintas especies de múridos que coexisten en el Desierto del Monte. Este hecho, sumado a la baja o ausente relación entre el peso de los individuos y el área de acción utilizada, indicaría que el tamaño de la especie no influye en el tamaño del área. Resultados similares fueron encontrados por O' Farrell (1978) al comparar las áreas de las distintas especies de heterómidos de Nevada.

$\mathrm{El}$ área promedio para C. musculinus fue más del doble de la encontrada por Contreras y Rosi (1980c). Esta diferencia probablemente se deba al bajo número de individuos utilizado por estos autores, subestimando el área de acción promedio.

En la única especie donde se encontraron diferencias en el tamaño del área de acción entre sexos fue en $A$. molinae, siendo mayores las de machos respecto a las hembras. Este resultado es similar al encontrado para otras especies del género, como A. cursor (Gentile et al., 1997), A. olivaceus (Fulk, 1975) у A. azarae (Bonaventura et al., 1992). También fue observada esta relación en especies de Peromyscus (P. truei y P. boylii) en Norteamérica. (Ribble y Stanley, 1998).

La superposición espacial interespecífica fue mayor en las épocas de alta densidad. En las especies más agresivas, se espera encontrar un índice de superposición espacial más bajo respecto al resto. Según Redford y Eisenberg (1992), los individuos de G. griseoflavus son fuertes y agresivos. Sin embargo, los gráficos de superposición no indican que la superposición de microhábitats de $G$. griseoflavus sea menor que la superposición en las restantes especies. Además, ninguna de ellas presentó signos de agresión (por ejemplo, orejas lastimadas) en el momento de la captura. Quizás las bajas densidades poblacionales en esta porción del desierto del Monte permita que las especies puedan coexistir sin que operen los mecanismos de competencia dirigidos por comportamientos agonísticos. 
La superposición espacial intraespecifica fue baja en todas las especies, tanto entre individuos de igual o de distinto sexo. Esto podría estar indicando que las especies estudiadas son territoriales, tal como fue reportado para otras especies de Akodon y para C. musculinus (Contreras y Rosi, 1980c,1981; Gentile et al., 1997). Sin embargo, la territorialidad no es un atributo que caracterice a una especie, pudiendo variar en distintas poblaciones de acuerdo al hábitat, así como al factor limitante (sexo opuesto, alimento), por lo que la superposición intraespecífica no puede ser tomada aisladamente como un indicador de territorialidad (Giannoni, com. pers.).

Resulta dificultoso inferir el sistema de apareamiento a partir de los resultados obtenidos, ya que ninguna de las especies se ajusta totalmente a ninguno de los tipos descriptos por Heinemann et al. (1995). La falta de dimorfismo sexual en $A$. molinae (test $t$ entre pesos de machos y hembras: $t=0,90$ g.l. $=109, p=$ 0,37), el mayor tamaño del área de acción de los machos y la mayor superposición entre las áreas de éstos, sugiere que esta especie presenta un sistema de apareamiento promiscuo. La relativamente alta superposición intersexual de $G$. griseoflavus en las estaciones de muestreo indicaría que esta especie presenta el mismo tipo de apareamiento que $A$. molinae. Para el resto de las especies los datos son insuficientes para realizar inferencias de este tipo, aunque Laconi y CastroVazquez (1999) sugieren que C. musculinus también es una especie promiscua.

El bajo número de individuos residentes (es decir, de individuos capturados en más de una campaña de muestreo, ver capítulo 4), sugiere que los individuos poseen gran movilidad. Este resultado no coincidiría con las observaciones de Contreras y Rosi (1980c) quienes proponen que C. musculinus tiene una alta fidelidad al hábitat, ya que sus áreas de acción no experimentan modificaciones al sufrir perturbaciones en el hábitat, tales como inundaciones. Sin embargo, estos autores reconocen un alto grado de actividad ambulatoria, similar a la encontrada para C. musculinus murillus por Kravetz (1978).

Por último, el tamaño de las áreas reportadas en este capítulo son mayores a las descriptas en el capítulo anterior, con el uso de polvos luminosos. Estas 
diferencias seguramente son causadas por diferencias en el tipo de muestreo, ya que las áreas obtenidas con aquella metodología provienen de los movimientos de los individuos en una noche, mientras que los resultados de este capítulo provienen de datos de al menos tres noches de captura y las áreas calculadas tienen incluido el borde de 7,5 metros. 


\subsection{CONCLUSIONES}

Las principales conclusiones obtenidas en este capítulo son las siguientes:

- Los tamaños de las áreas de acción son similares en todas las especies de múridos.

- Las áreas de los machos de A. molinae son mayores a las de las hembras, no existen diferencias significativas entre las áreas de machos y hembras en el resto de las especies.

- En general, no hay diferencia en el tamaño de las áreas de acción en distintos tipos de hábitat

- La superposición espacial interespecífica es mayor en los meses de alta densidad poblacional y muy baja en los meses de baja densidad. 


\begin{tabular}{|c|c|c|c|c|c|c|c|}
\hline & \multirow{2}{*}{ 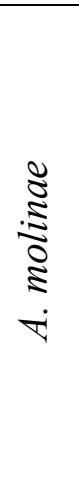 } & 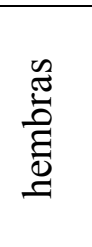 & $\stackrel{m}{n}$ & 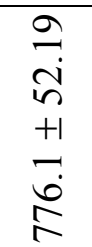 & $\begin{array}{l}\vec{\infty} \\
\stackrel{N}{N}\end{array}$ & in & 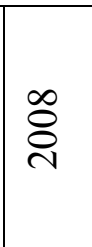 \\
\hline & & $\begin{array}{l}\text { : } \\
\text { : } \\
\stackrel{\Xi}{\Xi}\end{array}$ & $\tilde{\sim}$ & $\begin{array}{l}\stackrel{+}{\ddot{g}} \\
\stackrel{y}{+} \\
+1 \\
\infty \\
\stackrel{\infty}{\Xi}\end{array}$ & $\begin{array}{l}\tilde{n} \\
\tilde{n}\end{array}$ & $\stackrel{8}{7}$ & 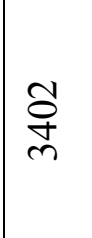 \\
\hline & 芯 & 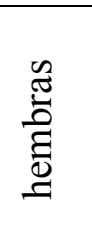 & 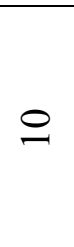 & 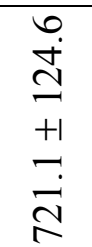 & $\hat{6}$ & $\ddot{\varkappa}$ & $\hat{8}$ \\
\hline & $\begin{array}{l}\underset{\Xi}{\Xi} \\
ن\end{array}$ & 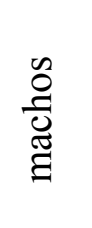 & $=$ & $\begin{array}{l}n \\
n \\
n \\
m \\
+1 \\
\infty \\
\infty \\
0\end{array}$ & 응 & 号 & $\overline{\bar{\sigma}}$ \\
\hline $\begin{array}{l}0 \\
0 \\
0 \\
0 \\
\tilde{J} \\
0 \\
0 \\
0\end{array}$ & $\mathfrak{\Xi}$ & 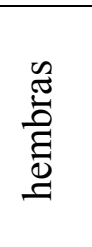 & ষ্ల & $\begin{array}{l}\infty \\
\stackrel{\infty}{+} \\
\stackrel{+}{+} \\
+1 \\
\infty \\
\infty \\
\infty \\
\infty\end{array}$ & $\begin{array}{l}0 \\
\infty \\
\stackrel{\infty}{+}\end{array}$ & $\stackrel{\sim}{\tilde{N}}$ & $\stackrel{+}{\sigma}$ \\
\hline 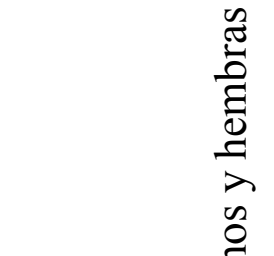 & $\begin{array}{l}\vec{Z} \\
\text { xi }\end{array}$ & 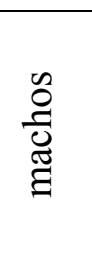 & ఉా & 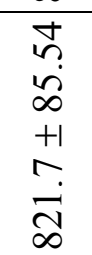 & $\stackrel{\circ}{\stackrel{R}{R}}$ & $\ddot{\sim}$ & $\stackrel{\infty}{\stackrel{2}{2}}$ \\
\hline 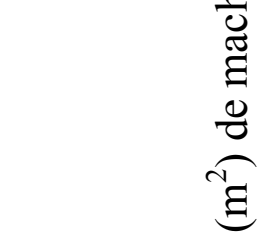 & $\begin{array}{l}\frac{3}{3} \\
\text { है }\end{array}$ & 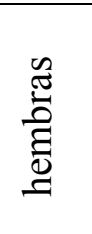 & $\nabla$ & $\begin{array}{l}\hat{0} \\
\dot{0} \\
+1 \\
+1 \\
\hat{\theta}\end{array}$ & $\stackrel{n}{\infty}$ & $\frac{n}{6}$ & $\stackrel{\widetilde{\sigma}}{\varrho}$ \\
\hline 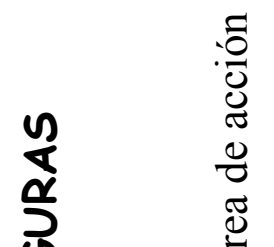 & 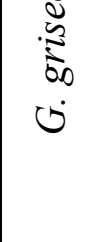 & $\begin{array}{l}\text { 0 } \\
\frac{0}{\tilde{J}} \\
\tilde{\Xi}\end{array}$ & $\infty$ & $\begin{array}{l}a \\
\infty \\
\infty \\
\infty \\
+1 \\
0 \\
0 \\
0 \\
0\end{array}$ & $\begin{array}{l}n \\
n \\
\alpha\end{array}$ & $\stackrel{\circ}{r}$ & $\begin{array}{l}n \\
m \\
m\end{array}$ \\
\hline 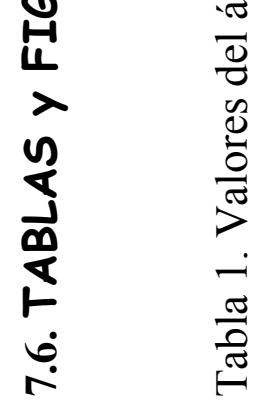 & & & Z & 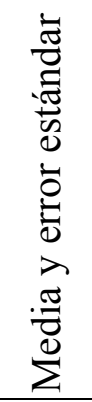 & 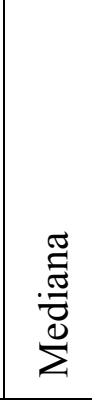 & 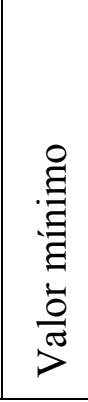 & 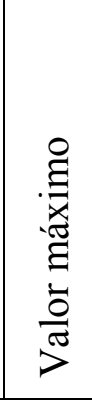 \\
\hline
\end{tabular}




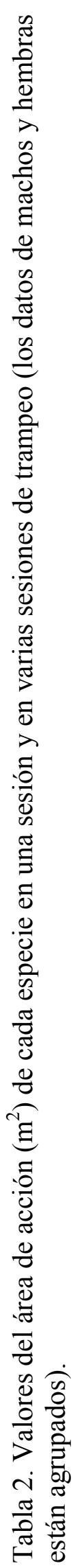

\begin{tabular}{|c|c|c|c|c|c|c|}
\hline \multirow{2}{*}{ 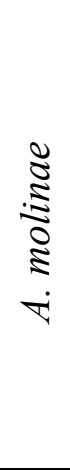 } & 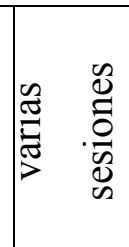 & 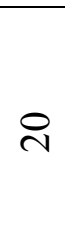 & 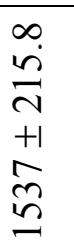 & $\stackrel{゚}{\stackrel{2}{=}}$ & $\begin{array}{r}\stackrel{y}{m} \\
\dot{m}\end{array}$ & 总 \\
\hline & 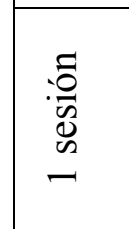 & bे & $\begin{array}{l}0 \\
n \\
\infty \\
\infty \\
+1 \\
+1 \\
\Delta \\
\sigma\end{array}$ & छे & $\stackrel{8}{7}$ & 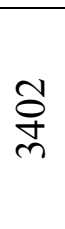 \\
\hline \multirow{2}{*}{ 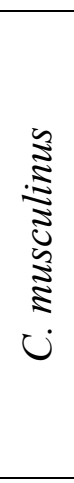 } & 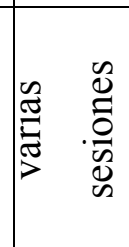 & in & 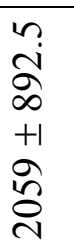 & $\hat{n}$ & $\begin{array}{l}n \\
\tilde{n} \\
a\end{array}$ & $\begin{array}{l}\infty \\
n \\
n \\
n\end{array}$ \\
\hline & 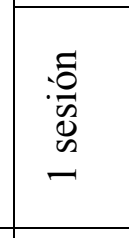 & 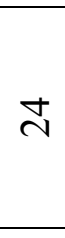 & $\begin{array}{l}\stackrel{n}{i} \\
\underset{I}{+1} \\
\Xi \\
\sigma\end{array}$ & $\begin{array}{l}\underset{0}{0} \\
\stackrel{\infty}{+}\end{array}$ & $\stackrel{\varkappa}{\wedge}$ & $\vec{b}$ \\
\hline \multirow{2}{*}{ 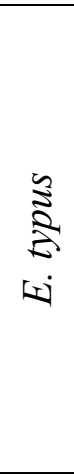 } & 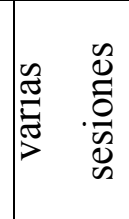 & $\stackrel{\sim}{ }$ & $\begin{array}{l}\hat{n} \\
+1 \\
\tilde{n} \\
\tilde{n}\end{array}$ & 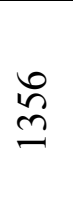 & i̊ & 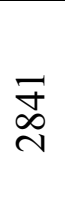 \\
\hline & 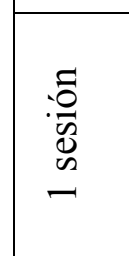 & $\mathbb{N}$ & 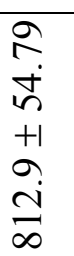 & 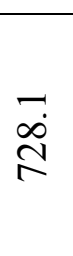 & $\stackrel{\sim}{\tilde{N}}$ & よ̆ \\
\hline \multirow{3}{*}{ 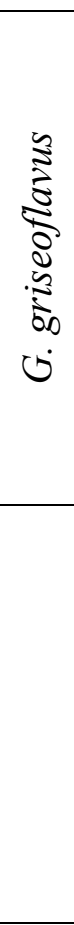 } & 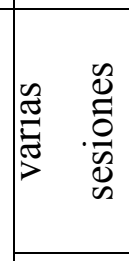 & $\stackrel{\wedge}{ }$ & 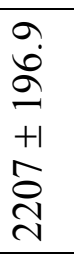 & 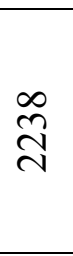 & $\vec{\infty}$ & $\stackrel{0}{0}$ \\
\hline & 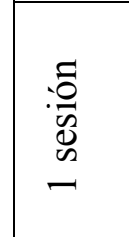 & $\simeq$ & 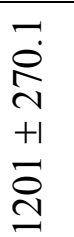 & $\begin{array}{l}n \\
\tilde{n} \\
\hat{n}\end{array}$ & $\stackrel{8}{\not}$ & $\begin{array}{l}n \\
m \\
m\end{array}$ \\
\hline & & $z$ & 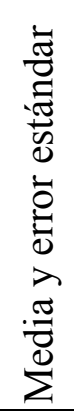 & 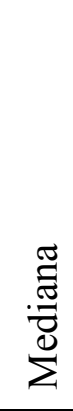 & 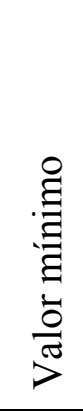 & 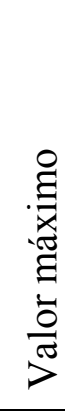 \\
\hline
\end{tabular}


Tabla 3. Índices de superposición espacial intraespecífica (Promedio y error estándar) de cada especie de múrido de la Reserva de la Biósfera de Ñacuñán

\begin{tabular}{|l|c|c|c|c|}
\hline & A. molinae & C. musculinus & E. typus & G. griseoflavus \\
\hline machos sobre hembras & $0,13 \pm 0,09$ & $0,19 \pm 0,10$ & $0,22 \pm 0,11$ & $0,26 \pm 0,11$ \\
\hline entre hembras & $0,07 \pm 0,04$ & 0 & $0,10 \pm 0,04$ & $0,10 \pm 0,07$ \\
\hline entre machos & $0,16 \pm 0,13$ & $0,07 \pm 0,05$ & $0,31 \pm 0,09$ & $0,13 \pm 0,08$ \\
\hline
\end{tabular}


Fig. 1. Índices de superposición interespecífica (cada especie sobre las demás)

AG: agosto; OC: octubre; NO: noviembre; MA: mayo; AB: abril

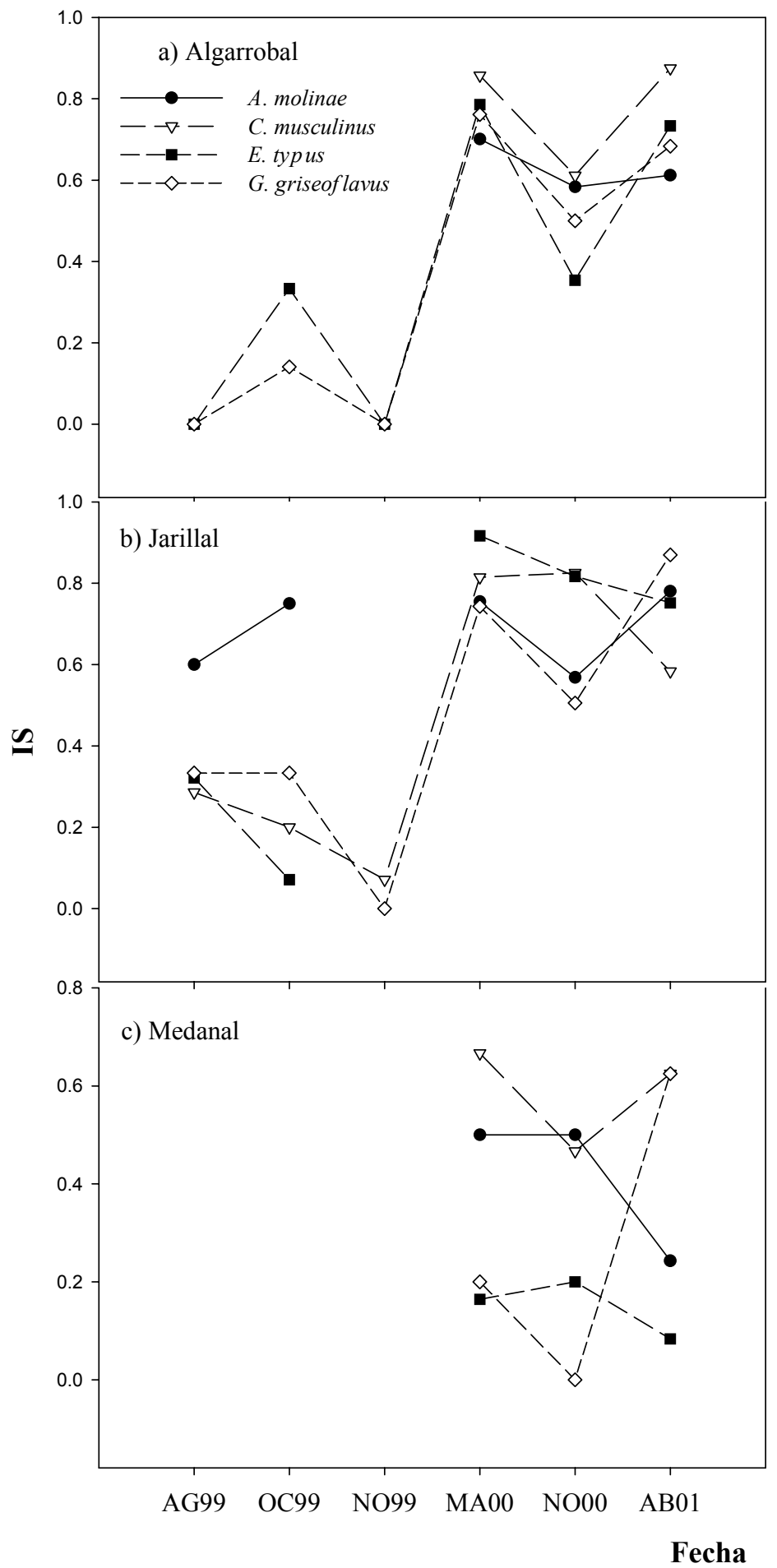


Fig. 2. Áreas de acción de las cuatro especies de múridos en la grilla 1 del jarillal en épocas de distinta densidad poblacional

a) Alta densidad (mayo de 2000)

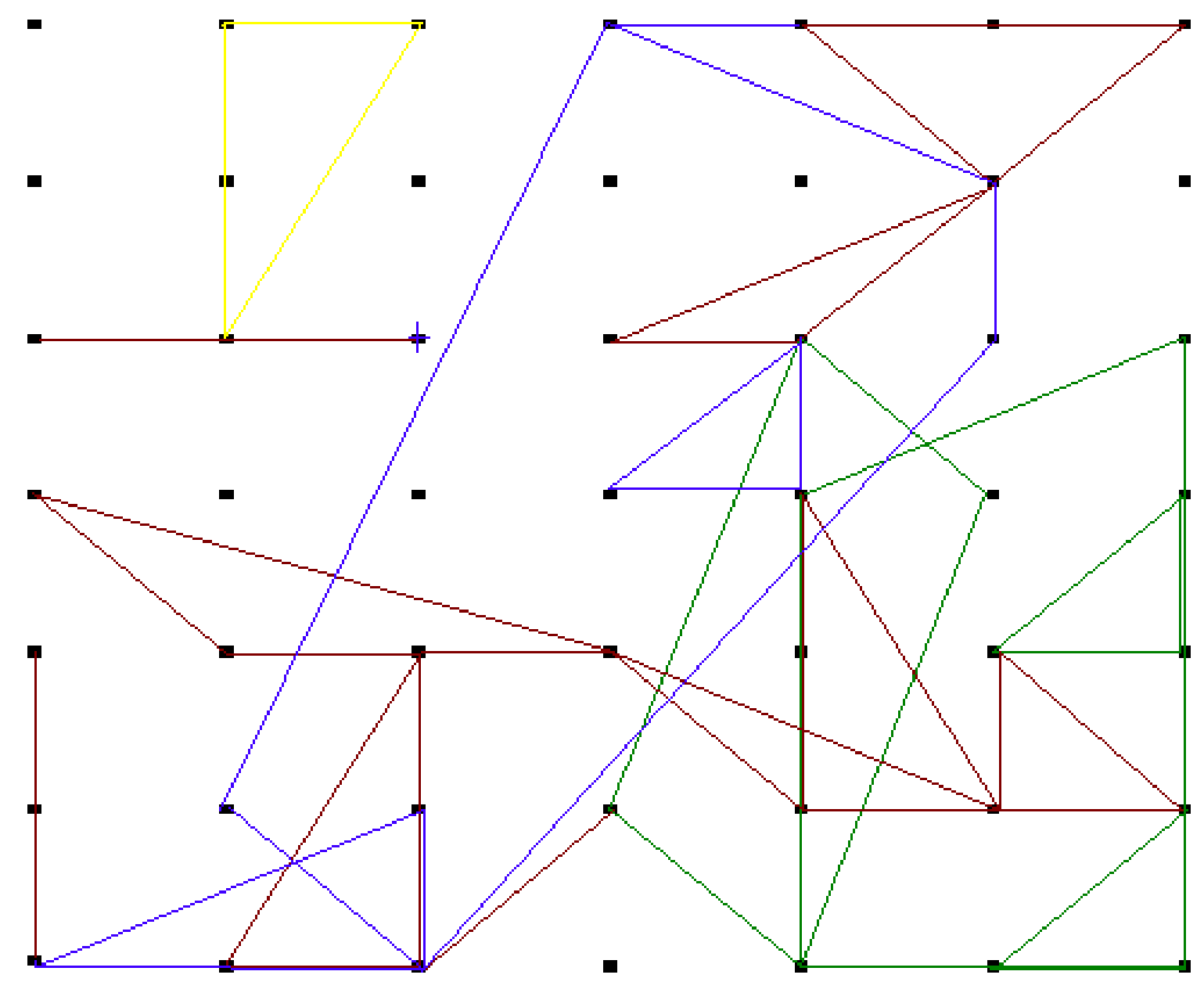
- A. molinae
- G. griseoflavus
- C. musculinus
E. typus 
b) Baja densidad (agosto de 1999)

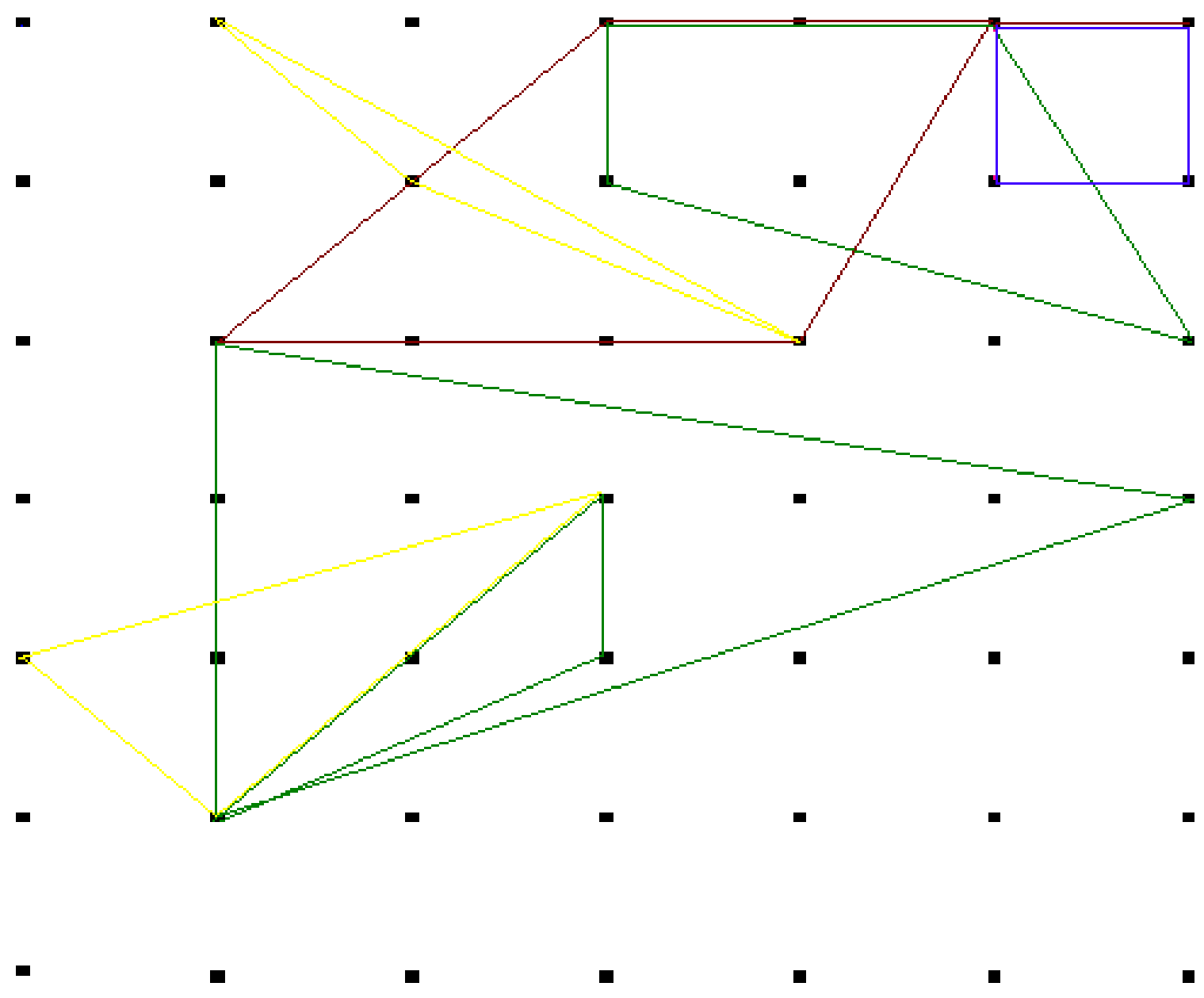

- A. molinae

- G. griseoflavus

C. musculinus

E. typus 
Fig. 3. Mapas de distribución de los individuos de Graomys griseoflavus y de Akodon molinae en la grilla 1 del algarrobal durante la época reproductiva (noviembre de 2000). Los círculos azules indican estaciones de trampeo ocupadas sólo por machos, los círculos rojos indican estaciones de trampeo ocupadas sólo por hembras, y los círculos verdes estaciones de trampeo ocupadas por ambos sexos.

a) G. griseoflavus

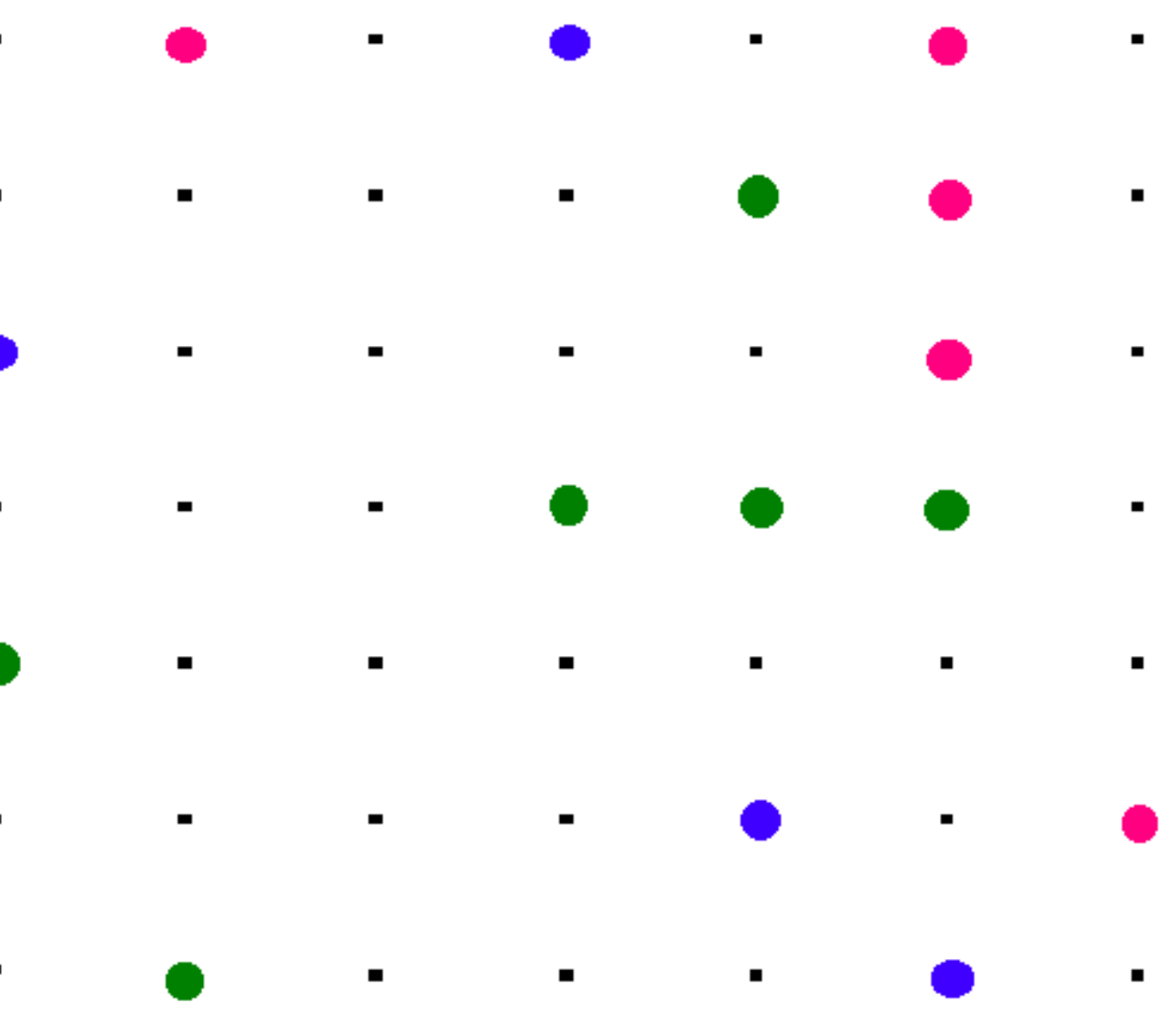


b) A. molinae

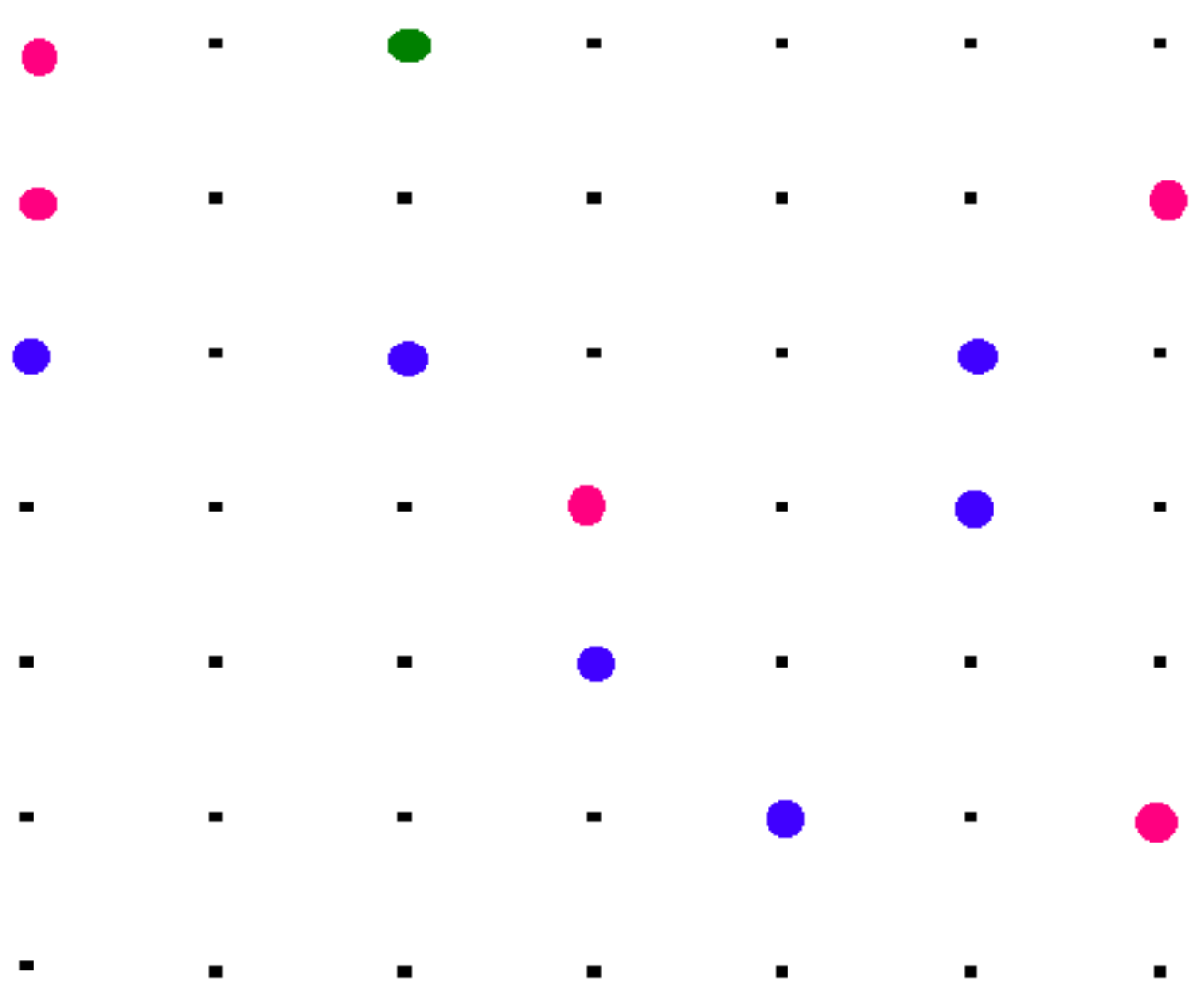


Capitulo 8

CONCLUSIONES Y DISCUSIÓN GENERAL 


\section{Capítulo 8. CONCLUSIONES Y DISCUSIÓN GENERAL}

Hasta hace algunos años, los roedores múridos sudamericanos no se consideraban "adaptados" a la vida de desierto, debido a que no compartían características morfológicas y fisiológicas similares a las de los roedores norteamericanos que habitan las zonas áridas; esto es, bipedalismo, dieta granívora, independencia de agua libre. El poco tiempo de colonización transcurrido desde el Gran Intercambio Biótico Americano a través del istmo de Panamá en el Plioceno medio (4 Ma), evento que se suponía época de ingreso de los Sigmodontidae, ha sido el argumento seguido para explicar esa supuesta falta de adaptación (Mares, 1975a). Sin embargo, nuevas evidencias provenientes del registro fósil y de estudios moleculares indican que el arribo de los sigmodontinos a Sudamérica se produjo antes de la formación del istmo de Panamá, siendo los registros fósiles más antiguos de una antigüedad de 5.5 a $6 \mathrm{Ma}$ (Verzi, com. pers.).

Por otro lado, estudios recientes sobre la morfología y funcionamiento renal (Díaz, 2001) ponen de manifiesto que estos roedores son capaces de aprovechar el agua disponible gracias a mecanismos de concentración de la orina, llegando a tener índices renales superiores a los de los heterómidos norteamericanos. A pesar de ello, no se puede decir que las especies que habitan el desierto del Monte son especies estrictamente desérticas, ya que su distribución es más amplia y pueden ocupar otros tipos de hábitats.

Las diferencias morfológicas y etológicas entre las especies que conforman una comunidad pueden favorecer la coexistencia de las mismas. En desiertos, las especies que ocupan un mismo tipo de hábitat en general se diferencian en tamaño corporal o morfología (Brown y Zeng, 1989). Por ejemplo, en la región de Badia (Jordán), cuando dos o más especies de la misma familia coexisten, hay una tendencia a tener tamaño corporal diferente o adaptaciones a un tipo particular de hábitat (Scott y Dunstone, 2000). En el desierto de Sudán, la diferenciación dietaria 
permitiría la coexistencia en dos especies de roedores de tamaño corporal y preferencias de microhábitats similares (Happold, 1975). La segregación de recursos (alimento, espacio, tiempo) es un mecanismo importante que opera en las comunidades para disminuir la competencia interespecífica.

En la porción central del desierto del Monte, ha sido estudiada la selección de alimentos por las especies de micromamíferos, encontrándose una separación ecológica de las especies basada en la dieta (Campos, 1997). En este estudio se ha abordado la selección de recursos desde el punto de vista espacial. Los resultados obtenidos indican que las especies de pequeños mamíferos son capaces de distinguir entre distintos tipos de hábitat y efectuar una selección a este nivel.

Eligmodontia typus aparece como la especie representativa del medanal, el hábitat más abierto, con mayor porcentaje de suelo desnudo y baja cobertura arbustiva. Sus densidades permanecen siempre por encima de las densidades de las demás especies, y en algunas épocas es la única especie presente en este hábitat. El resto de las especies, en cambio, son más abundantes en los hábitats más cerrados, con mayor porcentaje de herbáceas, arbustos y árboles. A. molinae y C. musculinus mostraron selección hacia el jarillal, mientras que G. griseoflavus fue más selectiva hacia el algarrobal. Es importante destacar, sin embargo, que la abundancia total de E. typus prácticamente no difiere entre el medanal y el jarillal (es decir, las diferencias en el uso de estos hábitats fueron marginalmente significativas) y que las mayores densidades se registraron en este último hábitat. Shenbrot et al. (1999) sugieren que la especialización al tipo de hábitat por las especies es muy similar en diferentes desiertos. La presencia de arena en muchos desiertos da lugar a la presencia de especies psammófilas (adaptadas a sustratos arenosos). Los médanos del desierto de Chihuahua están habitados principalmente por Dipodomys ordii y Chaetodipus penicillatus (Fam. Heteromyidae), pero estas especies ocupan también otros tipos de ambientes. Eligmodontia typus, con sus largas patas traseras y bullas timpánicas infladas, sus escapes a saltos frente a depredadores, su pequeño tamaño, y la presencia de callos con pelo en sus patas traseras, es capaz de explotar las áreas abiertas y el suelo arenoso (Redford y Eisenberg, 1992; Taraborelli et al., 2003). 
Estas características le dan a la especie ventajas para evadir depredadores y aumentan su eficiencia para explotar el medanal. Al no competir con otras especies, percibe a este hábitat como el adecuado para la reproducción. Esto está sustentado por la mayor cantidad de individuos reproductivos y la mayor proporción de individuos adultos encontrados en el medanal respecto a otros hábitats, así como a la mayor cantidad de hembras durante la época reproductiva y el mayor número de individuos residentes. El resto de las especies encuentran al jarillal y al algarrobal como los hábitats de mejor calidad. Se pudo inferir que el jarillal es el de mejor calidad para A. molinae, debido a que en este hábitat hay mayor proporción de hembras adultas que de machos durante la época reproductiva, mayor proporción de individuos adultos que de jóvenes, mayor número de individuos residentes y mayor tiempo de permanencia de los individuos en las grillas. Para G. griseoflavus y $C$. musculinus, en cambio, fue difícil determinar cuál de estos dos hábitats es el de mejor calidad debido a que sólo unos pocos parámetros medidos resultaron significativos.

La selección a nivel de microhábitat, por otro lado, no opera de un modo tan evidente como la selección a nivel de macrohábitat. Los resultados obtenidos a partir de los trampeos indican que las variables seleccionadas por cada especie son diferentes a distintas escalas y aún entre los distintos hábitats. Similarmente, estudios realizados en el desierto de Negev (Israel) (Brown et al., 1992) han demostrado que Gerbillus allenbyi (Fam. Muridae, Subfam. Gerbillinae) selecciona los microhábitats cerrados para forrajear, pero que los costos de forrajeo varían mucho más a escala de hábitat que de microhábitat. No obstante, en general se mantiene la preferencia de E. typus por microhábitats más abiertos y la selección de las demás especies por microhábitats con mayor cobertura vegetal. Esta selección por microhábitats cerrados parece ser una característica compartida por las especies cuadrúpedas y nocturnas tanto en todos los desiertos de Norteamérica como en los de Asia y África, y relacionado principalmente al riesgo de depredación. Si bien hasta el momento se relaciona a E. typus con los hábitats y microhábitats abiertos, no puede obviarse el hecho de que con la metodología de polvos luminosos se 
encontró que esta especie utiliza en mayor proporción los microhábitats con cobertura arbustiva. En el medanal, los individuos de esta especie recorren mayores distancias bajo la cobertura de arbustos que en ausencia de cobertura. No obstante, el bajo número de individuos analizados con esta técnica, impide asegurar que la especie selecciona activamente los microhábitats con mayor cobertura vegetal. De las cuatro especies de múridos, A. molinae aparece como la especie más selectiva, ocupando los microhábitats con alto porcentaje de mantillo, lo que estaría relacionado a una mayor cobertura arbustiva. Estos resultados se corresponderían con los observados previamente por otros autores (Contreras y Rosi, 1980c; Gonnet y Ojeda, 1998; Ojeda, 1989).

La competencia es considerada uno de los factores más importantes que operan en las comunidades de roedores de desiertos norteamericanos, mientras que juega un papel menor en Asia (Shenbrot et al., 1999). El tipo de estudio realizado en esta tesis no permitió identificar relaciones de competencia, ya que para ello es necesario abordar experimentos de remoción de especies. Sin embargo, el hallazgo de indicios de segregación de microhábitat por A. molinae y E. typus, sumado al uso del estrato vertical por algunas especies (C. musculinus, T. pusillus) y observaciones previas de G. griseoflavus sobre algarrobos (Bender y Tabeni, com. pers.; Mares, $1977 a$ ), permite inferir que existe una partición de microhábitats en esta comunidad de pequeños mamíferos. La partición de microhábitats, a su vez, podría reflejar la existencia de competencia interespecífica. Es interesante aclarar que esta segregación de microhábitats ha sido posible identificarla sólo con el uso de polvos luminosos, método que refleja fielmente los movimientos de los individuos en el espacio.

La segregación (o, contrariamente, la superposición) de microhábitats puede estar influenciada por la diversidad de especies presente en el área (Brown, 1975; May y MacArthur, 1972; MCloskey, 1978; Pianka, 1972), así como por la densidad poblacional. A altas densidades poblacionales, los individuos pueden restringir su área de acción o aumentar la superposición espacial con individuos de la misma o de otras especies (Gentile et al., 1997; Ribble y Stanley, 1998). En este 
ensamble de pequeños mamíferos, la superposición interespecífica es mayor en los meses de más elevada densidad poblacional (abril, mayo) que en los meses de menor densidad poblacional. Por otro lado, las áreas de acción de las diferentes especies no son diferentes entre sí, lo que indicaría que el tamaño del área no está relacionado con el tamaño de la especie. Resultados similares fueron encontrados en otros desiertos (O`Farrell, 1978). Tampoco se encontraron diferencias en las áreas de ambos sexos, excepto para $A$. molinae, donde las áreas de los machos son mayores que las áreas de las hembras, tal como lo observado para Akodon cursor (Gentile et al., 1997), A. olivaceus (Fulk, 1975) y A. azarae (Bonaventura et al., 1992).

Otro mecanismo de coexistencia de especies es la segregación temporal. Algunas especies son más eficientes en forrajear en determinadas épocas que en otras y mientras aumenta el tamaño poblacional de una especie, puede disminuir el de otra. Esta eficiencia está dada principalmente por la capacidad de evitar depredadores. En esta porción del desierto del Monte, sin embargo, todas las especies son más abundantes a mediados del otoño. Quizás la segregación temporal entre las especies esté dada por una segregación diaria y no estacional, siendo algunas especies más activas durante las primeras horas de la noche y otras durante las últimas horas. El patrón de actividad de pequeños mamíferos ha sido estudiado por varios autores, encontrando que hay especies bicrepusculares como Akodon olivaceus, Oryzomys longicaudatus (Iriarte et al., 1989), Zygodontomys microtinus, Sigmodon alstoni y Marmosa robinsoni (Vivas et al., 1986) y especies con patrón unimodal de actividad como Akodon cursor, Oryzomys russatus (Bittencourt et al., 1999), Calomys tener y Thylamys velutinus (Vieira y Baummgarten, 1995). Si bien el ritmo de actividad no ha sido estudiado en este trabajo, la mayor proporción de individuos capturados durante el día o el atardecer (encontrados en el momento en que se cebaban las trampas), corresponden a $A$. molinae $(52,63 \%)$ y el menor porcentaje corresponde a E. typus $(5,26 \%)$. Teniendo en cuenta que las especies de múridos del desierto se caracterizan por sus hábitos nocturnos, estos datos anecdóticos sobre la diferencia en las capturas de distintas especies antes de la 
noche, podría indicar la posibilidad de que las especies tengan diferentes ritmos de actividad y de que exista una segregación temporal diaria.

La mayor abundancia de las especies en determinadas épocas (otoño) podría relacionarse con la productividad del ambiente. Las precipitaciones determinarían una mayor productividad primaria debido a la rápida respuesta de las plantas a la disponibilidad de agua. Esto a su vez influiría en la respuesta de los pequeños mamíferos, los cuales se alimentan de hojas, frutos y semillas (Jaksic, 2001; Whitford, 1976). Las respuestas de los mamíferos a las lluvias pueden ser inmediatas o con retraso de hasta 6 meses o un año (Jaksic et al., 1993; Jaksic et al., 1996; Jaksic, 2001; Meserve et al., 1995). En este estudio sólo se ha encontrado una relación entre las precipitaciones y la abundancia de los roedores en casos puntuales, como al correlacionar las precipitaciones acumuladas entre 30 y 60 días antes de las fechas de muestreo con la abundancia de C. musculinus $(\mathrm{r}=0.81$; $p=0.01)$ у E. typus $(\mathrm{r}=0.85 ; p=0.007)$ en el jarillal, de G. griseoflavus $(\mathrm{r}=0.91$; $p=0.01)$ en el algarrobal y de G. griseoflavus $(\mathrm{r}=0.87 ; p=0.02)$ en el medanal. La corta duración del estudio quizás no sea suficiente para encontrar una fuerte relación entre ambas variables.

En conclusión, la comunidad de pequeños mamíferos del desierto del Monte central fluctúa espacial y temporalmente. El hábitat es un factor importante que actúa en la distribución de los organismos y en la estructura de la comunidad. La cobertura vegetal proporciona refugio para todas las especies de múridos y disminuye el riesgo de depredación. Esto conlleva a una mayor diversidad y riqueza de especies de micromamíferos en el algarrobal y en el jarillal respecto al medanal. E. typus es una especie que se distingue del resto ya que es capaz de ocupar el medanal durante todo el año y reproducirse en este hábitat. Sus características morfológicas (que recuerdan a las especies norteamericanas que habitan áreas abiertas) le otorgan ventajas frente a las demás especies para ocupar este ambiente de baja cobertura vegetal y suelo arenoso. Sin embargo, existe una contrariedad en los resultados obtenidos para esta especie. Por un lado, la mayor abundancia y la reproducción en el medanal sugieren que este es el hábitat óptimo. Por otro lado, se 
encontró que esta especie es la de mayor amplitud de nicho del ensamble, y los análisis de selección de hábitat con trampeos no mostraron una fuerte selección a nivel de macrohábitat. Además, los análisis de microhábitat a partir del uso de polvos luminosos indicarían que E. typus se mueve bajo la cobertura que ofrecen los arbustos y subarbustos más que en microhábitats abiertos. Estudios más precisos serían interesantes para comprender estas contradicciones y profundizar en el comportamiento y ecología de esta especie.

La información aportada por este estudio contribuye a la integración del conocimiento de la ecología de especies de pequeños mamíferos que habitan las zonas áridas. El conocimiento de la distribución espacial de las especies y sus requerimientos de hábitat son elementales para entender el funcionamiento del ecosistema y aporta las herramientas básicas necesarias para el desarrollo de planes de manejo y la conservación de la biodiversidad. 
Capítulo 9

\section{BIBLIOGRAFÍA}




\section{Capítulo 9. BIBLIOGRAFÍA}

Abraham, E. (2001). Geomorfología y suelos. En: Claver, S. y S. Roig-Junent, (Eds.), El desierto del Monte: La Reserva de Biosfera de Ñacuñán, pp. 1924. Mendoza: IADIZA-MAB-UNESCO. 226 pp.

August, P.V. (1983). The role of habitat complexity and heterogeneity in structuring tropical mammal communities. Ecology, 64: 1495-1507.

Ayal, Y. y O. Merkl (1994). Spatial and temporal disribution of tenebrionid species in the Negev Highlands, Israel. Journal of Arid Environments, 27: 337-361

Barnum, S.A., Manville, C.J., Tester, J.R. y W.J. Carmen (1992). Path selection by Peromyscus leucopus in the presence and absence of vegetative cover. Journal of Mammalogy, 73(4): 797-801.

Bestelmeyer, B.T. y M.T. Stevenson (1998). Documenting risk-avoidance in desert rodents using a new technique. The Southwestern Naturalist, 43(3): 397-402.

Bissonette, J.A. y S. Broekhuizen (1995). Martes populations as indicators of habitat spatial patterns: the need for a multiscale approach En: W.Z. Lidicker Jr.(Ed). Landscape approaches in mammalian ecology and conservation, pp. 95-121 University of Minnesota Press, Minneapolis. 215 pp.

Bittencourt, E.B., Conde, V.C.F., Rocha, C.F.D. y H.G. Bergallo (1999). Activity patterns of small mammals in an Atlantic forest area of southeastern Brazil. Ciência e Cultura, 51: 126-132.

Bonaventura, S.M., Kravetz, F.O. y O.V. Suarez (1992). The relationship between food availability, space use and territorility in Akodon azarae (Rodentia, Cricetidae). Mammalia, 56(3): 407-416. 
Borruel, N., Campos, C.M., Giannoni, S.M y C.E. Borghi (1998). Effect of herbivorous rodents (cavies and tuco-tucos) on a shrub community in the Monte desert, Argentina. Journal of Arid Environments, 39: 33-37.

Brown, J.H. (1975). Geographical ecology of desert rodents. En: Cody, M.L. y J.M. Diamond (Ed.), Ecology and Evolution of Communities, pp 315-41. Belknap Press, Cambridge. $560 \mathrm{pp}$

Brown, J.H. (1995). Macroecology. The University of Chicago Press. 269 pp

Brown, J.H. y E.J. Heske (1990). Temporal changes in a Chihuahuan desert rodent community, Oikos, 59: 290-302.

Brown, J.H. y M.A. Kurzius (1987). Composition of desert rodent faunas: combinations of coexisting species. Annales Zoologici Fennici, 24: 227-237.

Brown, J.H. y Z. Zeng (1989). Comparative population ecology of eleven species of rodents in the Chihuahuan desert. Ecology, 70: 1507-1525.

Brown, J.S., Arel, Y., Abramsky, Z. y B. Kotler (1992). Patch use by gerbils (Gerbillus allenbyi) in sandy and rocky habitats. Journal of Mammalogy, 73(4): 821-829.

Burt, W.H. (1943). Territoriality and home range concepts as applied to mammals. Journal of Mammalogy, 24: 346-352.

Busch, M., Alvarez, M.R., Cittadino, E.A y F.O. Kravetz (1997). Habitat selection and interespecific competition in rodents in pampean agroecosystems. Mammalia, 61: 167-184.

Busch, M., Kravetz, F.O., Percich, R.E y G.A. Zuleta (1984). Propuestas para un control ecológico de la Fiebre Hemorrágica Argentina a través del manejo del hábitat. Medicina (Buenos Aires) 44: 34-40. 
Busch, M., Miño, M.H., Dadon, J.R. y K. Hodara (2000). Habitat selection by Calomys musculinus (Muridae, Sigmodontinae) in crop areas of the pampean region, Argentina Ecología Austral, 10: 15-26.

Byrkit, D. (1987). Statistics today: a comprehensive introduction. California: Menlo Park: Benjamin-Cummings Publishing Company.

Cabrera, A. y A. Willink (1980). Biogeografía de América Latina. Serie de Biología. Monografías nro 13. Washington, DC: Organización de Estados Americanos. 117 pp.

Campos, C.M. (1997). Utilización de recursos alimentarios por mamíferos medianos y pequeños del Desierto del Monte. Tesis de Doctorado en Ciencias Biológicas. Facultad de Ciencias. Exactas, Físicas y Naturales, U.N.C.

Campos, C.M., Ojeda, R.A., Monge, S. y M. Dacar (2001). Utilization of food resources by small and medium-sized mammals in the Monte desert biome, Argentina. Austral Ecology, 26: 142-149.

Cittadino, E.A. y F.O. Kravetz (2000). Fluorescent piments: a method for the study of dispersal in small rodents. Mastozoología Neotropical, 7(1): 15-21.

Clements, F.E. (1916). Plant succession: an analysis of the development of vegetation. Carnegie Institute Publ., Washington, D.C. 242 pp.

Cole, K.L. (1982). Late Quaternary zonation of vegetation in the eastern rand Canyon. Science, 217: 1142-1145.

Contreras, J.R. (1968). Akodon molinae una nueva especie de ratón de campo del sur de la provincia de Buenos Aires. Zool. Platense 1(2): 9-12.

Contreras. J.R. y M.I. Rosi (1980a). El ratón de campo Calomys musculinus cordovensis (Thomas) en la provincia de Mendoza. 1. Consideraciones taxonómicas. Historia Natural. 1(5): 17-28. 
Contreras. J.R. y M.I. Rosi (1980b). Acerca de la presencia en la provincia de Mendoza del ratón de campo Akodon molinae Contreras (1968 (Rodentia: Cricetidae) Historia. Natural, 1(26): 181-84.

Contreras, J.R. y M.I. Rosi (1980c). Comportamiento territorial y fidelidad al hábitat en una población de roedores del centro de la provincia de Mendoza. Ecología Argentina, 5: 17-29.

Contreras, J.R. y M.I. Rosi (1981). Investigaciones sociobiológicas acerca de roedores silvestres de Mendoza. Serie Científica, 12-17.

Cramer, M.J. y M.R. Willig (2002). Habitat heterogeneity, habitat associations, and rodent species diversity in a sand-shinnery-oak landscape. Journal of Mammalogy, 83(3): 743-753.

Crawford, C.S. (1986). The role of invertebrates in desert ecosystems. En: Whitford, W.G. (Ed.), Pattern and process in desert ecosystems, pp. 73-91. University of New Mexico Press, Abuquerque New Mexico. 139 pp.

Crawley, M.J. (1993). GLIM for Ecologists. Oxford, UK: Blackwell Scientific Publications. 379 pp

Crespo, J.A., Sabattini, M.S., Piantanida, M.J. y G. de Villafañe (1970). Estudios ecológicos sobre roedores silvestres, observaciones sobre densidad, reproducción y estructura de comunidades de roedores silvestres en el sur de Córdoba. Buenos Aires: Ministerio de Bienestar Social.

Daciuk, J. (1974). Notas faunísticas y bioecológicas de Península Valdés y Patagonia. 12. Mamíferos colectados y observados en la Península Valdés y zona litoral de los Golfos San José y Nuevo (provincia de Chubut, república Argentina). Physis, sec. C, 33(86): 23-39.

Dalmasso, A.D. (1994). Fenología de cinco gramíneas nativas de interés forrajero Pappophorum caespitosum ${ }_{2}$ Trichloris crinita ${ }_{2}$ Setaria leucopila, Digitartia californica, y Diplachne dubia. Multequina, 3: 9-34. 
Desy, E.A., Batzli, G.O. y L. Jike (1989). Comparison of vole movements assessed by live trapping and radiotracking. Journal of Mammalogy, 70(3): 652-656.

Díaz, G.B. (2001). Ecofisiología de pequeños mamíferos de las tierras áridas de Argentina: adaptaciones renales. Tesis doctoral, Programa de posgrado en Biología de la Universidad Nacional de Cuyo, 174 pp.

Díaz, G.B. y R.A. Ojeda (1999). Kidney structure and allometry of Argentine desert rodents. Journal of Arid Environments, 41: 453-461.

Díaz, G.B. y R.A. Ojeda (2000). Libro rojo de mamíferos amenazados de la Argentina. SAREM, $106 \mathrm{pp}$.

Dickman, C. (1988). Detection of physical contact interactions among free-living mammals. Journal of Mammalogy, 69(4): 865-868.

Diffendorfer J. E. (1998). Testing models of source-sink dynamics and balanced dispersal. Oikos 81, 417-433.

Doncaster, C.P., Clobert, J., Doligez, B., Gustafsson, L. y E. Danchin (1997). Balanced dispersal between spatially varying local populations: an alternative to the source-sink model. American Naturalist, 150: 425-445.

Dufrêne, M. y P. Legendre (1997). Species assemblages and indicators species: the need for a flexible asymmetrical approach. Ecological Monographs, 67: 345366.

Duplantier, J.M., Cassaing, J., Orsini, P. y H. Croset (1984). Utilisation de poudres fluorescentes pour l'analyse des déplacements des petits rongeurs dans la nature. Mammalia, 48(2) : 293-298.

Ellis, B.A., Mills, J.N., Childs, J.E., Muzzini, M.C., McKee, K.T., Enria, D.A y G.E. Glass (1997). Structure and floristic of habitats associated with five rodent species in an agroecosystem in Central Argentina. Journal of Zoology (London), 243: 437-460. 
Ernest, S.K.M., Brown, J.H. y R. Parmenter (2000). Rodents, plants, and precipitation: spatial and temporal dynamics of consumers and resources. Oikos, 88: 470-482.

Everitt, B.S. (1992). The Analysis of Contingency Tables (2nd Edn). New York: Chapman \& Hall. 164 pp.

Flores, D.A., Díaz, M.M. y R.M. Barquez (2000). Mouse opossums (Didelphimorphia, Didelphidae) of northwestern Argentina: Systematics and distribution. Zeitschrift für Säugetierkunde, 65: 1-19.

Fretwell, S. y H. Lucas (1970). On territorial behavior and other factors influencing habitat distribution in birds. I. Theoretical development. Acta Biotheoretica 19: 16-36.

Fretwell, S.D. (1972). Theory of habitat distribution. En: Populations in a seasonal environment, pp 79-114. Princeton University Press.

Fulk, G.W. (1975). Population ecology of rodents in the smiarid shrublands of Chile. Occas. Pap. Mus. Texas Tech. Univ., 33: 1-40.

Galliari, C., Pardiñas, U. y F. Goin (1996). Lista comentada de los mamíferos argentinos. Mastozoología Neotropical, 3(1): 39-61.

Gaulin, J.C. y R.W. Fitzerald (1986). Sex differences in spatial ability: an evolutionary hipothesis and test. American Naturalist, 127: 74-88.

Gaulin, J.C. y R.W. Fitzerald (1988). Home range size as a predictor of mating systems in Microtus. Journal of Mammalogy, 69(2): 311-319.

Geier A.R. y L.B. Best (1980) Habitat selection by small mammals of riparian communities: evaluating effects of habitat alterations. Journal of Wildlife. Management,. 44: 16-24. 
Gentile, R., D’Andrea, P.S. y R. Cerqueira (1997). Home ranges of Philander frenata y Akodon cursor in a brazilian restinga (Coastal shrubland). Mastozoología Neotropical, 4(2): 105-112.

Giannoni, S.M., Borghi, C.E. y R.A. Ojeda (2000). Feeding behaviour of Tympanoctomys barrerae, a rodent specialized in consuming Atriplex leaves. Journal of Arid Environments, 46: 117-121.

Giannoni, S.M., Borghi, C.E. y V.G. Roig (1996). The burrowing behavior of Ctenomys eremophilus (Ctenomyidae, Rodentia) in relation with substrata hardness. Mastozoología Neotropical, 3: 5-12.

Gleason, H.A. (1917). The structure and development of the plant asociation. Bull. Torrey Botanical Club, 44: 463-481.

Gleason, H.A. (1926). The individualistic concept of plant asociation. Bull. Torrey Botanical Club, 53: 7-26.

Gonnet, J.M. (1998). Influencia del pastoreo sobre poblaciones de aves y mamíferos herbívoros en la región de la Reserva de la Biósfera 'Ñacuñán', Mendoza, Argentina. Tesis Doctoral en Ciencias Biológicas, Universidad Nacional de Córdoba. 166 pp.

Gonnet, J.M. y R.A. Ojeda (1998). Habitat use by small mammals in the arid Andean foothills of the Monte Desert of Mendoza, Argentina. Journal of Arid Environments, 38: 349-357.

Guevara, J.C., Cavagnaro, J.B., Estevez, O.R., Le Houérou, H.N. y C.R. Stasi (1997). Productivity, management, and development problems in the arid rangelands of the central Mendoza plains (Argentina). Journal of Arid Environments, 35: 575-600.

Gyldenstolpe, N. (1932). A manual of Neotropical Sigmodont rodents. Kungliga Svenska Vetenskapsakademiens Handlingar. 11(3): 1-164 
Happold, D.C.D (1975). The ecology of rodents in the northern Sudan. En: Prakash, I. y G. Ghosh (Eds), Rodents in Desert Environments, pp. 15-46. The Hague: W. Junk.

Heinemann, K.M., Guthmann, N., Lozada, M. y J.A. Monjeau (1995). Area de actividad de Abrothrix xanthorhinus (Muridae, Sigmodontinae) e implicancias para su estrategia reproductiva Mastozoologia Neotropical, 2(1): 23-30.

Holbrook, S.J. (1978). Habitat relationships and coexistence of four sympatric species of Peromyscus in Northwestern New Mexico. Journal of Mammalogy, 59: 18-26.

Howard, H.E. (1920). Territory in bird life. Murray, London., 308 pp.

Huntley, B. y H.J.B. Birks (1983). An atlas of past and present pollen maps for Europe: 0-13000 years ago. Cambridge University Press, Cambridge.

Hutto, R.L. (1985). Habitat selection by nonbreeding migratory land birds En: Cody, M.L. (Ed.). Habitat selection in birds, pp 455-476. Academic Press, Orlando, Fla. 558 pp

Iriarte, J.A., Contreras, L.C. y F.M. Jaksic (1989). A long-term study of a smallmammal assemblage in the central Chilean matorral. Journal of Mammalogy, 70: 79-87.

Jaksic, F.M. (2001). Ecological effects of El Niño in terrestrial ecosystems of western South America. Ecography, 24: 241-250.

Jaksic, F.M., Feisinger, P. y J.E. Jiménez (1993). A long-term study on the dynamics of guild structure among predatory vertebrates at a semi-arid neotropical site. Oikos, 67: 87-96.

Jaksic, F.M., Feisinger, P. y J.E. Jiménez (1996). Ecological redundancy and longterm dynamics of vertebrate predators in semiarid Chile. Conservation biology, 10: 252-262. 
Jenrich, R.J. y F.B. Turner (1969). Measurement of Non-circular Home Range. Journal of Theoretical Biology, 22: 227-237.

Jones, A.L. y W.S. Longland (1999). Effects of cattle grazing on salt desert rodent communities. American Midland Naturalist, 141: 1-11.

Kalcounis-Rüppell, M.C. y J.S. Millar (2002). Partitioning of space, food, and time by syntopic Peromyscus boylii and P. californicus. Journal of Mammalogy, 83: 614-625.

Kelt, D.A. (1999). On the relative importance of history and ecology in structuring communities of desert small animals. Ecography, 22: 123-137.

Kelt, D.A., Brown, J.H., Heske, E.J., Marquet, P.A., Morton, S.R., Reid, J.R.W, Rogovin, K.A. y G. Shenbrot (1996). Community structure of desert small mammals: comparisons across four continents. Ecology, 73: 746-761.

Kotler, B.P. (1989). Temporal variation in the structure of a desert rodent community. En:. Morris, D.W,. Abramsky, Z., Fox, B.J. y M.R. Willig (Eds.), Patterns in the structure of mammalian communities, pp. 127-139. Texas: Texas Technical University Press. 266 pp.

Kotler, B. y J. Brown (1988). Environmental heterogeneity and the coexistence of desert rodents. Annual Review of Ecology and Systematics., 19: 281-307.

Kotler, B.P., Brown, J.S. y W.A. Mitchell (1994). The role of predation in shaping the behavior, morphology and community organisation of desert rodents. Australian Journal of Zoology, 42: 449-466.

Kravetz, F.O. (1978). Ecología de las comunidades de roedores involucrados en la Fiebre Hemorrágica Argentina. Tesis Doctoral, Universidad Nacional de Buenos Aires.

Kravetz, F.O. y J.J. Polop (1983). Comunidades de roedores en agroecosistemas del Departamento de Río Cuarto, Córdoba. Ecosur, 10: 1-18. 
Krebs, C.J. (1999). Ecological Methodology (2da. Ed.). Menlo Park, CA: Benjamin/Cummings. 620 pp.

Kreuzer, M.P. y N.J. Huntly (2003) Habitat-specific demography: evidence for source-sink population structure in a mammal, the pika. Oecologia, 134: 343-349.

Laconi, M.R. y A. Castro-Vázquez (1999). Nest building and parental behaviour in two species of Calomys (Muridae, Sigmodontinae): A laboratory study. Mammalia, 63(1): 11-20.

Lemen C.A. y P.W. Freeman (1985). Tracking mammals with fluorescent pigments: a new technique. Journal of Mammalogy, 66(1): 134-136.

Levins, R. (1968). Evolution in changing environments. Princeton University Press, Princeton, New Jersey, USA. 120 pp

Lidicker, W.Z. (1995). The landscape concept: Something old, something new. En: W.Z. Lidicker Jr (Ed.), Landscape approaches in Mammalian ecology and conservation. $215 \mathrm{pp}$.

Litvaitis, J., Titus, K. y E. Anderson (1994). Measuring vertebrate use of terrestrial habitats and foods. En: Bookhout, T.A (Ed.). Research and management techniques for wildlife and habitats. pp. 254-274. The wildlife society, Bethesda Maryland. 740 pp.

Loeb, S. (1999). Responses of small mammals to coarse woody debris in a Southeastern pine forest. Journal of Mammalogy, 80(2): 460-471.

Longland, W.S. y C. Clements (1995). Use of fluorescent pigments in studies of seed caching by rodents. Journal of Mammalogy, 76: 1260-1266.

M'Closkey, R.T. (1978). Niche separation and assembly in four species of Sonoran desert rodents. The American Naturalist, 112: 683-694. 
Mac Arthur, R.H., Mac Arthur, J.W. y J. Preer (1962). On bird species diversity. II. Prediction of bird census from habitat measurenments. American Naturalist, 96: $167-174$.

Magurran, A.E. (1988). Ecological Diversity and Its Measurement. Princeton, New Jersey: Princeton University Press. 179 pp.

Manly, B.F.J., McDonald, L.L. y D. Thomas (1993). Resource selection by animals: Statistical design analysis for field studies. Chapman \& Hall, London, 177 pp.

Mares, M.A. (1973). Climates, Mammalian communities and desert rodent adaptations: An investigation into evolutionary convergence. Ph.d. diss., University of Texas at Austin.

Mares, M.A. (1975a). South American Mammal Zoogeography: Evidence from Convergent Evolution in Desert Rodents. Proceedings National Academy.of Sciences, 72: 1702-1706.

Mares, M.A. (1975b). Observations of Argentine Desert Rodent Ecology, with emphasis on water relations of Eligmodontia typus. En: Prakash, I.y P.K. Ghosh (Eds.), Rodents in desert environments (Vol. 28), pp. 155-173. The Hague: Dr.W.Junk b.v. Publishers. 624 pp.

Mares, M.A. (1977a). Water balance and other ecological observations on three species of Phyllotis in northwestern Argentina. Journal of Mammalogy, 58: 514-20.

Mares, M.A. (1977b). Water economy and salt balance in a South American desert rodent, Eligmodontia typus. Comparative Biochemestry and Physiology. 56(A): 325-32.

Mares, M.A., Blair, W.F., Enders, F.A., Greegor, D., Hulse, A.C., Hunt, J.H., Otte, D., Sage, R.D. y C.S. Tomoff (1977). The strategies and community patterns of desert animals. En: Orians, G.H. y O.T. Solbrig (Eds.), Convergent 
Evolution in Warm Deserts, pp. 107-163. US/IBP synthesis series; 3. Dowden, Hutchinson \& Ross.

Mares, M.A., Ojeda, R.A., Borghi, C.E., Giannoni, S.M., Díaz, G.B. y Braun, J (1997). How desert rodents overcome halophytic plant defenses. BioScience, 47: 699-704.

Mares, M.A., Ojeda, R.A. y M.P. Kosco (1981). Observations on the distribution and ecology of the mammals of Salta Province, Argentina, Annals of Carnegie Museum, 50(6): 151-206.

Massoia, E., Fornes, A., Wainberg, R.L. y T.G. Fronza (1968). Nuevos aportes al conocimiento de las especies bonaerenses del género Calomys (Rodentia, Cricetidae). Rev. Invest. Agropecuarias, INTA (Buenos Aires), ser. 1, Biol. Prod. Anim. 5(4): 63-92.

May, R.M. y R.H. MacArthur (1972). Niche overlap as a function of environmental variability. Proceedings of the National Academy of Science, . 69: 1109-1113.

Maza, B.G., French, N.R. y A.P. Aschwanden (1973). Home range dynamics in a population of Heteromyid Rodents. Journal of Mammalogy, 54: 405-425.

Mazurkiewicz, M. (1971). Shape, size and distribution of home ranges of Clethrionomys glareolus (Schreber, 1780). Acta Theriologica, 16: 23-60.

Meserve, P.L., Yunger, J.A., Gutiérrez, J.R., Contreras, L.C., Milstead, W.B., Lang, B.K., Cramer, K.L., Herrera, S., Lagos, V.O., Silva, S.I., Tabilo, E.L., Torrealba, M.A. y F.M. Jaksic (1995). Heterogeneous responses of small mammals to an El Niño Southern Oscillation event in northcentral semiarid Chile and the importance of ecological scale. Journal of Mammalogy, 76: 580-595.

Mills, J.N., Ellis, B.A., McKee, K.T., Maiztegui, J.I. y J.E. Childs (1991). Habitat associations and relative densities of rodent populations in cultivated areas of central Argentina. Journal of Mammalogy, 72: 470-479. 
Mills, J.N., Ellis, B.A., McKee, K.T., Maiztegui, J.I. y J.E. Childs (1992). Reproductive characteristics of roedent assemblages in cultivated regions of central Argentina. Journal of Mammalogy, 73: 515-526.

Morello, J. (1958). La Provincia fitogeográfica del Monte. Universidad Nacional de Tucumán e Instituto Miguel Lillo, Opera Lilloana, 11: 155 pp.

Morris, D.W. (1987). Ecological scale and habitat use. Ecology, 68(2): 362-369

Mueller-Dombois, D. y H. Ellenberg (1974). Aims and methods of vegetation ecology. John Wiley y Sons. New York, 547 pp.

Navarro, M.C. (1991). Ecología de Akodon molinae en el Monte Argentino. Tesis de licenciatura, Universidad Nacional de Tucumán, Tucumán, Argentina.

Noble, G.K. (1939). The role of dominance in the social life of birds. The Auk, 56: 263-273.

Noy-Meir, I. (1974). Desert ecosystems: higher trophic levels. Annual Review of Ecology and Systematics, 195-214.

Noy-Meir, I. (1979/80). Structure and function of desert ecosystems. Israel Journal of Botany, 28: 1-19.

O`Farrell, M.J. (1978). Home range dynamics in a sagebrush community. Journal of Mammalogy, 59(4): 657-668.

O`Farrell, M.J. (1980). Spatial relationships of rodents in a sagebrush community. Journal of Mammalogy, 61(4): 589-605.

Ojeda, R.A. (1989). Small mammal responses to the fire in the Monte Desert, Argentina. Journal of Mammalogy, 70: 416-420.

Ojeda, R.A., Borghi, C.E., Díaz, G.B., Giannoni, S.M., Mares, M.A. y J.K. Braun (1999). Evolutionary convergence of the highly adapted desert rodent Tympanoctomys barrerae (Octodontidae). Journal of Arid Environments, 41: 443-452. 
Ojeda, R.A., Campos, C.M., Gonnet, J.M., Borghi, C.E. y V. Roig (1998). The MaB Reserve of Nacunanan, Argentina: its role in understanding the Monte Desert biome. Journal of Arid Environments, 39: 299-313.

Orians, G. y J. Wittenberger (1991). Spatial and temporal scales in habitat selection. American Naturalist, 137 : 29-49.

Ostfeld, R.S. (1990). The ecology of territoriality in small mammals. Trends in Ecology \& Evolution, 5(12): 411-415.

Parmenter, R.R. y J.A. MacMahon (1988). Population limiting factors of arid-land darkling beetles (Coleoptera: Tenebrionida): Predation by rodents. Environmental Entomology, 17:280-286.

Partridge, L. (1978). Habitat selection. En: Krebs Jr y N.B. Davies (Eds), Behavioral ecology and evolutionary approach, pp 351-376. Blackwell, Oxford.

Pianka, E.R. (1972). $r$ and $k$ selection or $b$ and $d$ selection? American Naturalist, 106: 581-588.

Pianka, E.R. (1982). Ecología evolutiva. Omega, Barcelona, 365 pp.

Pires, A.S., Fernandez, F.A.S. y D. de Freitas (1999). Patterns of space use by Micoureus demerarae (Marsupialia: Didelphidae) in a fragment of Atlantic forest in Brazil. Mastozoologia Neotropical. 6(1): 39-45.

Polis, G.A. and T. Yamashita (1991). The ecology and importance of predaceous arthropods in desert communities. En: Polis, G.A. (Ed.), The ecology of desert communities, pp 180-222. The University of Arizona Press, Tuscon.

Polop, J.J., Martinez, R.L. y M.P. Torres (1985). Distribución y abundancia de poblaciones de pequeños roedores en la zona del embalse de Río Tercero, Córdoba. 5(5): 33-44. 
Price, M.V. (1986). Structure of desert rodent communities: a critical review of questions and approaches. American Zoologist, 26: 39-49.

Priotto, J.W. y A.R. Steinmann (1999). Factors affecting home range size and overlap in Akodon azarae (Muridae: Sigmodontinae) in natural pasture of Argentina. Acta Theriologica, 44(1): 37-44.

Pulliam, H.R. (1988). Sources, sinks, and population regulation. The American Naturalist, 132: 652-661.

Pulliam, H.R. (2000). On the relationship between niche and distribution. Ecol lett, 3: 349-361.

Pulliam, H.R. y B.J. Danielson (1991). Sources, sinks, and habitat selection: a landscape perspective on population dynamics. The American Naturalist, 137: 50-66.

Redford, K. y J.F. Eisenberg (1992). Mammals of the Neotropics. The Southern Cone. Chile, Argentina, Uruguay, Paraguay. Vol. 2. The University of Chicago Press. 430 pp.

Ribble, D.O. y S. Stanley (1998). Home ranges and social organization of syntopic Peromyscus boylii and P. Truei. Journal of Mammalogy, 79(3): 932-941.

Ritchie, M.E. (1997). Populations in a landscape context: sources, sinks, and metapopulations. En: Bissonette, J.A (Ed.), Wildlife and landscape ecology: Effects of pattern and scale. Springer-Verlag, New York Inc. 410 pp.

Roig, F.A. (1971). Flora y vegetación de la Reserva Forestal de Nacuñán. Deserta 1: 25-232.

Roig, F.A. y B. Rossi (2001). Flora y vegetación. En: Claver, S. y S. Roig-Junent (Eds.), El desierto del Monte: La Reserva de Biosfera de Ñacuñán, pp. 4170. Mendoza: IADIZA-MAB-UNESCO. 226 pp.

Rosenzweig, M.L. (1981). A theory of habitat selection. Ecology, 62: 327-335. 
Rosenzweig. M.L. y J. Winakur (1969). Population ecology of desert rodent communities: habitats and environmental complexity. Ecology, 50: 558-572.

Rosi, M.I. (1983). Notas sobre la ecología, distribución y sistemática de Graomys griseoflavus griseoflavus (Waterhouse, 1837) (Rodentia, Cricetidae) en la provincia de Mendoza. Historia Natural, 3(17): 161-67.

Rossi, B. (1994). Fenología de especies de gramíneas, arbustos y árboles de la Reserva de Biósfera de Ñacuñán (Mendoza, Argentina). Informe de beca de Iniciación. Facultad de Ciencias Agrarias, UNC. 64 pp.

Rotenberry, J.T y J.A. Wiens (1980). Habitat structure, patchiness, and avian communities in North American steppe vegetation: a multivariate analysis. Ecology, 61: 1228-1250.

Schoener, T.W. (1974). Resource partitioning in ecological communities. Science, 185: 27-39.

Scott, D.M. y N. Dunstone (2000). Environmental determinants of the composition of desert-living rodent communities in the north-east Badia region of Jordan. Journal of Zoology, 251: 481-494.

Shenbrot, G.I., Krasnov, B.R. y K.A. Rogovin. (1999). Spatial ecology of desert rodent communities. SpringerVerlag. 292 pp.

Siegel, S. (1991). Estadística no paramétrica. (Ed. Trillas), 344 pp.

Simpson, E.H. (1949). Measurement of diversity. Nature, 163: 688.

Stapp, P. (1997). Habitat selection by an insectivorous rodent: patterns and mechanisms across multiple scales. Journal of Mammalogy, 78(4): 11281143.

Stapp, P. y B. Van Horne (1997). Response of deer mice (Peromyscus maniculatus) to shrubs in shortgrass praire: linking small-scale movements and the spatial distribution of individuals. Functional Ecology, 11: 644-651. 
Stapp, P., Young, J, VandeWoude, S y B. Van Horne (1994). An evaluation of the pathological effects of fluorescent powder on deer mice (Peromyscus maniculatus). Journal of Mammalogy, 75(3): 704-709.

Stickel, L.F. (1954). A comparison of certain methods of measuring ranges of small mammals. Journal of Mammalogy,35: 1-15.

Stokes, M.K. (1995). Selection of refuge sites by sympatric Microtus ochrogaster and Sigmodon hispidus. Journal of Mammalogy, 76(1): 83-87.

Straccia, P.C. y L.J.M. De Santis (2000). Análisis morfofuncional preliminar de la locomoción de Eligmodontia (Rodentia, Sigmodontinae) de la Argentina. XV Jornadas Argentinas de Mastozoología. 8, 9 y 10 de noviembre de 2000, La Plata, Argentina.

Sutherland, W.J. (1996). From individual behavior to population ecology (Capítulo 1). Oxford University Press 213 pp.

Tanquilevich, R.F. (1971). Los suelos de la Reserva ecológica de Ñacuñán. Deserta 2: 131-206.

Taraborelli, P.A., Corbalán, V. y S. Giannoni (2003). Locomotion and escape modes in rodents of the Monte desert (Argentina). Ethology, 109 (6): 475485.

Taraborelli, P.A. (2001). Efecto de la cobertura vegetal sobre la remoción de semillas por roedores en el desierto del Monte (Mendoza, Argentina). Tesis de Licenciatura en Biología, Facultad de Ciencias Exactas y Naturales, Universidad Nacional de Mar del Plata, 51 pp.

Thompson, S.D. (1982). Microhabitat utilization and foraging behavior of bipedal and quadrupedal Heteromyid rodents. Ecology, 63(5): 1303-1312.

Tognelli, M., Claver, S., Videla, F. y J. Gonnet (2001). Los vertebrados de la Reserva de Nacuñán. En: Claver, S. y S. Roig-Junent (Eds.), El desierto del 
Monte: La Reserva de Biosfera de Ñacuñán, pp. 84-110. Mendoza: IADIZAMAB-UNESCO. 226 pp.

Van Horne, B. (1982). Niches of adult and juvenile deer mice (Peromyscus maniculatus) in seral stages of coniferous forest. Ecology, 63(4): 992-1003.

Van Horne, B. (1983). Density as a misleading indicator of habitat quality. The Journal of Wildlife Management, 47: 893-901.

Vieira, E.M. y L.C. Baumgarten (1995). Daily activity patterns of small mammals in a cerrado area from central Brazil. Journal of tropical Ecology, 11: 255262.

Vivas, A.M., Roca, R., Weir, E., Gil, K. y P. Gutiérrez (1986). Ritmo de actividad nocturna de Zygodontomys microtinus, Sigmodon alstoni y Marmosa robinsoni en Masaguaral, Estado Guarico. Acta Cientifica Venezolana, 37: 456-458.

Webster, A.B. y R.J. Brooks (1981). Social behavior of Microtus pennsylvanicus in relation to seasonal changes in demography. Journal of Mammalogy, 62: 738-751.

Whitford, W.G. (1976). Temporal fluctuations in density and diversity of desert rodent populations. Journal of Mammalogy, 57: 351-369.

Whittaker, R.H. (1956). Vegetation of the Great Smoky Mountains. Ecological Monographs, 22: 1-44.

Whittaker, R.H. (1960). Vegetation of the Siskiyou Mountains, Oregon and California. Ecological Monographs, 30: 279-338.

Wiens, J.A. (1974). Habitat heterogeneity and avian community structure in North American grasslands. American Midland Naturalist, 91: 195-213.

Wiens, J.A. (1981). Scale problems in avian censuring. Studies in Avian Biology,. 6 : 513-521. 
Wiens, J.A. (1983). Avian community ecology: an iconoclastic view. En Brush, A.H. y G.A. Clark, Jr. (Eds.), Perspectives in ornithology, pp 355-403. Cambridge Univ. Press, Cambridge, U.K. 560 pp.

Wiens, J.A. (1989). The ecology of birds community. Vol 2. Cambridge Univ. Press, New York, N.Y. 316 pp.

Winker, K., Rappole, J.H. y M.A. Ramos (1995). Yhe use of movement data as an assay of habitat quality. Oecologia, 101: 211-216.

Wolff, J.O. (1985). The effects of density, food, and interespecific interference on home range size in Peromyscus leucopus and Peromyscus maniculatus. Canadian Journal of Zoology, 63: 2657-2662.

Wolff, J.O. (1993). Why are female small mammals territorial? Oikos, 68(2): 364370.

Zar, J.H. (1984). Biostatistical Analysis (2da. Ed.). New Jersey, NY: Prentice-Hall International. $636 \mathrm{pp}$ 